\title{
When surgery alone won't cut it
}

\author{
Citation for published version (APA):
}

Monpellier, V. M. (2019). When surgery alone won't cut it: physical and psychological influences on weight loss after bariatric surgery. [Doctoral Thesis, Maastricht University]. Maastricht University. https://doi.org/10.26481/dis.20190322vm

Document status and date:

Published: 01/01/2019

DOI:

10.26481/dis.20190322vm

Document Version:

Publisher's PDF, also known as Version of record

\section{Please check the document version of this publication:}

- A submitted manuscript is the version of the article upon submission and before peer-review. There can be important differences between the submitted version and the official published version of record.

People interested in the research are advised to contact the author for the final version of the publication, or visit the DOI to the publisher's website.

- The final author version and the galley proof are versions of the publication after peer review.

- The final published version features the final layout of the paper including the volume, issue and page numbers.

Link to publication

\footnotetext{
General rights rights.

- You may freely distribute the URL identifying the publication in the public portal. please follow below link for the End User Agreement:

www.umlib.nl/taverne-license

Take down policy

If you believe that this document breaches copyright please contact us at:

repository@maastrichtuniversity.nl

providing details and we will investigate your claim
}

Copyright and moral rights for the publications made accessible in the public portal are retained by the authors and/or other copyright owners and it is a condition of accessing publications that users recognise and abide by the legal requirements associated with these

- Users may download and print one copy of any publication from the public portal for the purpose of private study or research.

- You may not further distribute the material or use it for any profit-making activity or commercial gain

If the publication is distributed under the terms of Article $25 \mathrm{fa}$ of the Dutch Copyright Act, indicated by the "Taverne" license above, 




\section{WHEN SURGERY ALONE WON'T CUT IT}

Physical and psychological influences on weight loss after bariatric surgery

Valerie Maureen Monpellier 
ISBN: $\quad 978-94-6332-462-5$

Cover design: Rienk Hoven

Photo: Ilse Hartman

Layout: Klaas Leussink

Print: $\quad$ GVO

(C) copyright V.M. Monpellier, Amsterdam 2019, the Netherlands

All rights are reserved. No part of this book may be reproduced, distributed, stored in a retrieval system, or transmitted in any form or by any means, without prior permission of the author. 


\section{WHEN SURGERY ALONE WON'T CUT IT}

Physical and psychological influences on weight loss after bariatric surgery

\section{PROEFSCHRIFT}

Ter verkrijging van de graad van doctor aan de Universiteit Maastricht, op gezag van de Rector Magnificus, Prof. Dr. Rianne Letschert, volgens het besluit van het College van Decanen, in het openbaar te verdedigen op vrijdag 22 maart 2019 om 10:00 uur

door

Valerie Maureen Monpellier 


\section{Promotor}

Prof. dr. A. T. M. Jansen

\section{Copromotoren}

Dr. E. E. Antoniou

Dr. A. B. Mink van der Molen

\section{Beoordelingscommissie}

Prof. dr. A. J. Roefs (voorzitter)

Prof. dr. N. D. Bouvy

Prof. dr. R. R. J. W. van der Hulst

Prof. dr. E. F. C. van Rossum (Erasmus Medisch Centrum)

Prof. dr. E. J. Hazebroek (Rijnstate Ziekenhuis / Wageningen University)

Printing of this thesis was financially supported by: Nederlanse Obesitas Kliniek, Dutch Society for Plastic Surgery, Dutch Society for Metabolic and Bariatric Surgery and Fit For Me.
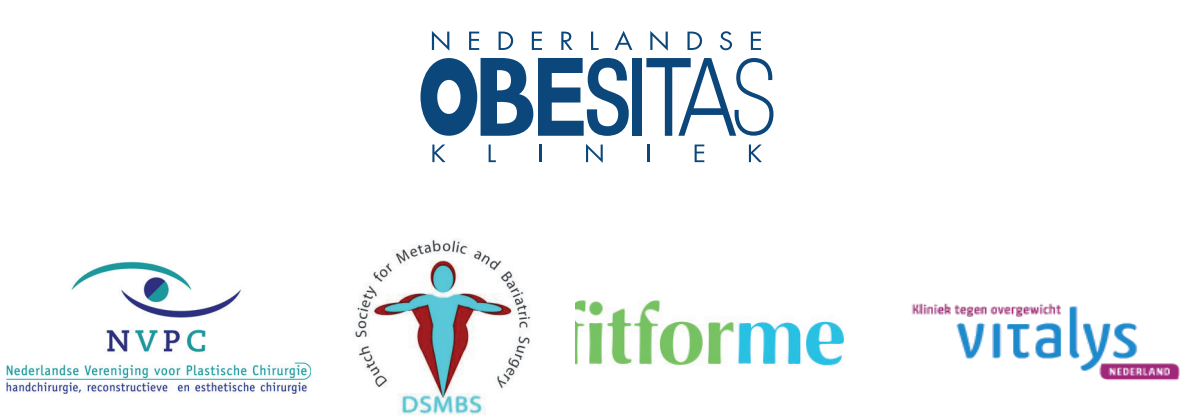
Voor mijn ouders 



\section{CONTENTS}

1. Introduction

\section{Psychological factors and weight change}

2. Influence of psychological factors on weight loss after Roux-and-Y gastric bypass: systematic review and meta-analysis.

3. Weight change after Roux-en-Y gastric bypass, physical activity and eating style: is there a relationship?

4. Improvement of health-related quality of life after Roux-en-Y gastric bypass related to weight loss.

\section{Body image, excess skin and body contouring surgery}

5. Body image dissatisfaction and depression in post-bariatric patients is associated with less weight loss and a desire for body contouring surgery.

6. Body contouring surgery after massive weight loss: excess skin, body satisfaction and qualification for reimbursement in a post-bariatric population.

7. Evaluation and modification of the BAPRAS screening tool for reimbursement of post-bariatric body contouring surgery.

\section{Discussion}

\section{Appendices}

Summary - English

Summary - Dutch

Valorization addendum

Curriculum Vitae

Publications \& presentations

Acknowledgements 

INTRODUCTION 
Bariatric surgery has become a standard part of treatment for morbid obesity. Over 10.000 morbidly obese patients a year are treated with bariatric surgery in the Netherlands nowadays, and it is expected that the number of patients will continue to rise substantially ${ }^{1}$. In general, bariatric surgery is a highly successful treatment resulting in significant weight loss, reduction of comorbidities and improvement of patient well-being ${ }^{2-4}$. Yet, some patients do not achieve sufficient weight loss, while others experience significant weight regain ${ }^{5-7}$. The factors that are thought to influence the successes and failures of bariatric surgery are unknown, since they have only been studied sparsely and results have been ambiguous. It is, for example, unclear how body image and self-reported eating style affect weight loss and its maintenance. We do know, that massive weight loss causes extensive skin surplus. However, there is very little knowledge about the impact of overhanging skin on patients and how this overhanging skin possibly influences their weight course. Some authors argue that the excessive skin surplus results in extensive medical, physical and psychological problems which, in turn, might be related to weight regain in the long-term ${ }^{8-12}$. To improve counselling before and after bariatric surgery it is important to identify which factors are related to outcome on the short as well as on the long term. In this thesis, I will focus on patient related factors and study their relationship with outcome after bariatric surgery.

\section{OBESITY}

Obesity is defined as abnormal or excessive fat accumulation that may impair health ${ }^{13}$. It is classified with the body mass index (BMI) defined by person's weight in kilograms divided by the square of his height in meters: $\left(\mathrm{kg} / \mathrm{m}^{2}\right)^{13}$. In adults a $\mathrm{BMI} \geq 30 \mathrm{~kg} / \mathrm{m}^{2}$ is classified as obesity; a BMI $\geq 35$ $\mathrm{kg} / \mathrm{m}^{2}$ with obesity related comorbidities or a $\mathrm{BMI} \geq 40 \mathrm{~kg} / \mathrm{m}^{2}$ is classified as morbid obesity ${ }^{14}$. Obesity is a major public health issue. The worldwide prevalence has tripled since 1975, resulting in 650 million obese adults in $2016^{13}$. In the Netherlands $14.2 \%$ of the population older then 20 year is obese and $0.9 \%$ suffers from morbid obesity 15. Obesity is associated with several medical conditions: diabetes mellitus, hypertension, sleep apnoea and cardiovascular disease ${ }^{14,16-18}$. Additionally, obese patients have higher rates of cancer, overall diseases and health related mortality ${ }^{19}$. The adverse health effects of obesity have resulted in increased health care use. The burden of healthcare expenditure on morbid obesity already exceeds those of smoking and a higher BMI is related to higher healthcare, medical and pharmaceutical costs ${ }^{20-22}$.

Besides the numerous medical complications, obesity is related to extensive problems of social and psychological well-being ${ }^{19,23-25}$. Obese persons generally have a lower health related quality of life (HRQoL), more negative perceptions of their own body (i.e. a negative body image) and higher rates of psychological problems and 
psychopathology, such as depression, compared to non-obese individuals ${ }^{23-29}$. In obese patients who seek surgical treatment for obesity, HRQoL is lower and a negative body image is more prevalent compared to the population who does not want to undergo surgery ${ }^{28,30,31}$. These problems are partly the reasons why these patients seek treatment. The cause of obesity is assumed to be multifactorial and complex. In general, it is thought to be a result of cultural and environmental changes which induced a continuously high energy intake and little physical activity which leads to a positive energy balance ${ }^{13,14}$. Recent studies however, question whether increased intake and decreased activity are the only reasons for the obesity epidemic. They suggest that other factors like certain pharmaceutical agents, (epi)genetics, stress and sleep debt also contribute to the problem ${ }^{32,33}$. The complexity of the multicausal nature of obesity makes treatment of this chronic disease difficult.

\section{Treatment of obesity}

Treatment of obesity is divided in non-surgical, pharmacological and surgical treatment. The cornerstone for all these types of treatment is lifestyle change, with emphasis on regulation of energy intake and improvement of physical activity ${ }^{14,34,35}$. It is advised to include lifestyle treatment and/or behavioural therapy in the treatment program and to treat patients with a multidisciplinary team ${ }^{14,34,36}$. Pharmacotherapy and bariatric surgery are adjuncts to the lifestyle change and only provided to a selection of patients ${ }^{14,34,37}$.

Non-surgical treatment including lifestyle treatment and/or behavioural therapy seems to be an effective treatment for obesity. Weight loss is around $5 \%$, which can be maintained up to 8 year ${ }^{34,38,39}$. Pharmacological treatment is advised in the patients with a $\mathrm{BMI} \geq 30 \mathrm{~kg} / \mathrm{m}^{2}$ or a $\mathrm{BMI} \geq 27 \mathrm{~kg} / \mathrm{m}^{2}$ with an obesity related disease, like hypertension or diabetes mellitus ${ }^{14,37}$. Several pharmaceutical agents have been developed for treatment of obesity. These medications generally affect appetite and cause weight loss only when the agent is taken and in combination with lifestyle change ${ }^{14,37}$. Mean weight loss with pharmacological treatment ranges between $4.4 \%$ and $14.3 \%$ depending on type of medication and treatment regime ${ }^{40}$. In the Netherlands there is one pharmaceutical agent registered for the management of obesity, however, this is not reimbursed by insurance companies.

Bariatric surgery (which is also called metabolic surgery) includes a variety of surgical procedures in which the gastro-intestinal tract is altered. These procedures are all performed as a treatment for morbid obesity and its comorbid conditions. Before, it was thought that weight loss after bariatric surgery resulted from the combination of a reduced intake and reduced absorption of food/nutrients. However, current research is showing that bariatric surgery causes changes in gut hormones, bile acids and microbiota, which subsequently are assumed to induce changes in appetite and 
energy expenditure and thereby also causes weight loss ${ }^{41}$. Surgery is advised to patients with a $\mathrm{BMI} \geq 40 \mathrm{~kg} / \mathrm{m}^{2}$ or a $\mathrm{BMI} \geq 35 \mathrm{~kg} / \mathrm{m}^{2}$ with comorbid conditions ${ }^{14,37}$. There are several types of bariatric surgery. The most popular types are the Rouxen-Y gastric bypass (RYGB) and gastric sleeve (GS) ${ }^{42}$. With the RYGB a small new stomach, pouch, is first created. Then the small intestine is dissected and connected to this pouch. Subsequently, the distal part of this small intestine is connected to the other portion of the small intestine. As a result, food will bypass the greater part of the stomach, the duodenum and part of jejunum. With the gastric sleeve, a large part of the stomach is removed, resulting in a small, longitudinal stomach.

Compared to life-style intervention programs, bariatric surgery has proven to be a superior treatment for morbid obesity ${ }^{2,43-45}$. In the first and largest controlled trial comparing bariatric surgery with a standard life-style intervention, the SOS-study, weight loss up to 15 years was significantly higher in patients undergoing bariatric surgery (27\% in RYGB patients versus around $3 \%$ in the control group $)^{2}$. In addition, diabetes remission rates were significantly higher $(30.4 \%$ versus $6.5 \%)$ and surgery was associated with reductions in cancer incidence, cardiovascular events and cardiovascular deaths ${ }^{2,46,47}$. These outcomes have since then been replicated by other studies ${ }^{43,48}$. Showing that bariatric surgery is currently the most effective treatment for morbid obesity. Hence, the number of patients undergoing bariatric surgery continues to increase worldwide: 579,517 patients were operated in 2014 compared to 685,874 in $2016^{42,49}$.

\section{BARIATRIC SURGERY}

Whether a patient qualifies for bariatric surgery should be determined after a comprehensive multidisciplinary assessment by a team experienced in bariatric surgery ${ }^{17}$. This team assesses if the patient meets the criteria for bariatric surgery, which have been developed by the International Federation for the Surgery of Obesity and Metabolic Disorders (the IFSO) ${ }^{17,50}$. The IFSO-criteria state that a candidate for bariatric surgery is an adult obese patient with:

- a BMI:

- $\quad \geq 40 \mathrm{~kg} / \mathrm{m}^{2}$, or

- $\quad 35.0-39.9 \mathrm{~kg} / \mathrm{m}^{2}$ with obesity related comorbidities that will be positively influenced by bariatric surgery, like diabetes mellitus, hypertension, cardiorespiratory problems, severe joint disease and obesity-related severe psychological problems (not further specified)

- $\quad$ longstanding obesity (more than 5 years)

- proven failure of nutritional and behavioural therapy 
Since several studies have shown that patients with diabetes mellitus and a BMI between 30.0 and $34.9 \mathrm{~kg} / \mathrm{m}^{2}$ also benefit from surgery, these criteria might change soon ${ }^{51-53}$. In addition, is it advised that pre-operative evaluation also includesassessment of motivation, willingness to life-long follow-up andacceptance of lifestyle modification 17,18. Consequently, the following contra-indications for bariatric surgery should also be assessed at the multidisciplinary screening ${ }^{17,18}$ :

- Absence of identifiable medical management

- Unable to participate in prolonged medical follow-up

- Non-stabilized psychotic disorder, severe depression, personality and eating disorders, unless specifically advised by a psychiatrist experienced in obesity

- Alcohol abuse and/or drug dependencies

- Disease threatening life in short term

- Patients who are unable to care for themselves and have no long-term family or social support

\section{NEDERLANDSE OBESITAS KLINIEK}

The Nederlandse Obesitas Kliniek (NOK, Dutch Obesity Clinic) is the largest clinic for treatment of people with morbid obesity in the Netherlands. The NOK has eight locations throughout the country in which about 6,000 new patients are treated each year. The multidisciplinary teams consist of a physician, dietician, physiotherapist and psychologist. This team performs the screening according to the IFSO criteria, to assess whether apatient qualifies for bariatric surgery. This assessment is then discussed with an internist and bariatric surgeon. When patients are accepted for surgery, they start the treatment program, which is carried out by the multidisciplinary team.

The treatment program consists of group counselling before and after bariatric surgery. Group counselling is focused on long-term behavioural change. Patients are prepared for the changes they will have to make in their habits, eating and physical activity, in order for the surgery to be successful. Moreover, counselling is dedicated to the causes of obesity, for example, developing new copingstrategies and improvement of self-care are also part of the program. Before surgery patients participate in six group sessions led by the multidisciplinary teams, each with a duration of three hours. After surgery patients participate in these group sessions up to 1,5 year after surgery, also with a duration of three hours per session. Then patients have a yearly follow-up with themultidisciplinary team starting 2 years after surgery and ending at 5 years after surgery.

\section{ROUX-EN-Y GASTRIC BYPASS}

In the Netherlands, the RYGB is the most popular type of bariatric surgery: 6,897 
patients underwent a RYGB in $2016{ }^{42}$. The RYGB is performed laparoscopically and patients can be released from the hospital after one night. Figure 1 shows a schematic overview of the RYGB procedure. First, a small gastric pouch is constructed (1).Then the jejunum is transsected (2), pulled up to the gastric pouch and the gastro-jejunostomy is created (3). The length of the alimentary limb is than measured and an entero-enterostomy is performed (4). Thus, resulting in a small stomach, the pouch, from which the food directly enters the jejunum, bypassing the remaining stomach and the initial loop of the small intestine. The procedure is both restrictive, patients can eat less, and malabsorptive, nutrients are not properly absorbed. In addition, the RYGB induces changes in the gut hormones, bile acids, gut microbiota and energy balance. This complex system is probably the main cause for weight loss, however it is not completely understood yet ${ }^{41,54-56}$.

Figure 1: The Roux-en-Y gastric bypass.
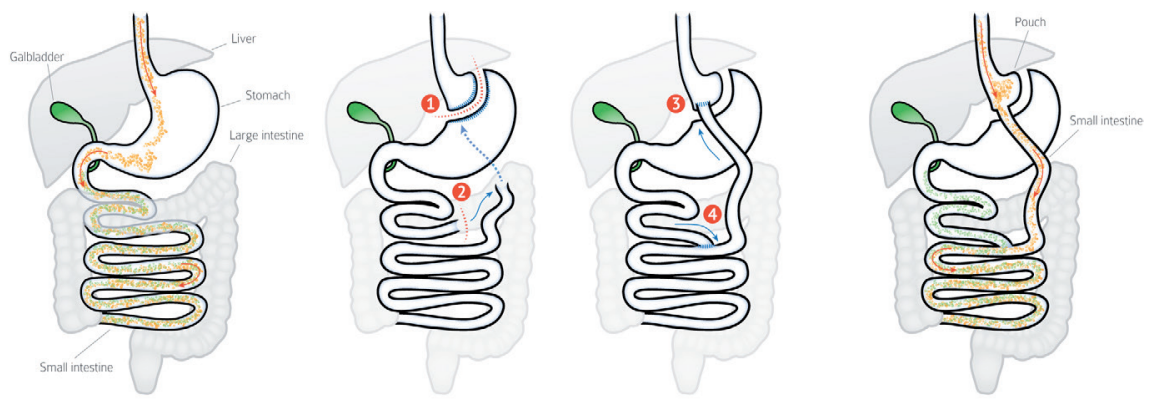

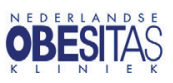

\section{Complications after RYGB}

In the Netherlands short term complication rates are quite low; there is a severe postoperative complication rate of $2.87 \%$ and a mortality rate of approximately $0.05-0.1 \%$

1. Surgical complications on the longer term include ulcer disease $(4.7 \%)$, internal herniation (1-3\%) and post-prandial hyperinsulinemic hypoglycaemia $(0.20-0.36 \%)$ 57,58 . In addition, about one in every 10 patients will have to undergo a cholecystectomy because of the development of cholelithiasis ${ }^{59}$. The most common complications after bariatric surgery are the nutritional deficiencies. These deficiencies can occur in up to $50 \%$ of the population, especially when patients are non-compliant to supplementation regimes ${ }^{60,61}$. The most prevalent deficiencies are of iron, vitamin B12, calcium and vitamin $D^{62-64}$. Another problem is that a large part of the post-bariatric population will develop excess skin, this will be addressed below ${ }^{8-11}$. Thus, in addition to the positive consequences, a RYGB can also have several negative side-effects. 


\section{Weight loss after RYGB}

Weight loss after bariatric surgery was frequently described as percentage excess weight loss (\%EWL), which is calculated with the following formula ${ }^{65}$ :

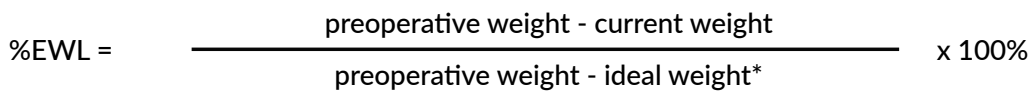

* ideal weight is defined as body weight at BMI: $25 \mathrm{~kg} / \mathrm{m}^{2}$

However, more recently, \%EWL is being replaced by the percentage total weight loss (\%TWL), because \%TWL is less influenced by the preoperative BMI of the patient ${ }^{65-67}$. For the calculation of \% TWL the following formula is used:

$\% \mathrm{TWL}=\frac{\text { preoperative weight }- \text { current weight }}{\text { preoperative weight }} \times 100 \%$

Weight loss after RYGB shows a specific pattern. Patients lose most of their weight in the first 3-6 months, after that the weight loss gradually declines until weight is stabilized around 18 months after surgery ${ }^{2}$. At 18 months after surgery there is a plateau phase ${ }^{2}$. At this point, patients who have undergone a RYGB show a mean EWL of about $60-70 \%$ and mean TWL of about $20-30 \%{ }^{2,3,7,68}$. Like all other bariatric procedures, a RYGB has a significant positive effect on diabetes mellitus, hypertension, cancer incidence and cardiovascular disease ${ }^{2,3,7,68}$. Furthermore, it seems to have a positive influence on patients' well-being ${ }^{69}$. 


\section{Health-related Quality of Life}

Health-related quality of life (HRQoL) was recently defined as a key outcome measure after bariatric surgery by the American Society of Metabolic and Bariatric surgery (ASMBS) ${ }^{65}$. In general, HRQoL improves significantly after bariatric surgery, even up to 10 years postoperatively ${ }^{23,43,69}$. However, there is a great variance in the effect of bariatric surgery on HRQoL ${ }^{65,70}$. This variance seems to be caused by two factors. First, there is no specific questionnaire to assess HRQoL in the bariatric patient and thus numerous questionnaires are used ${ }^{65,70}$. Since all these questionnaires measure different aspects of HRQoL, this is likely to influence outcomes. Second, (improvement of) HRQoL appears to be related to weight loss ${ }^{71-74}$. So, if studies differ in mean weight loss, the effect of bariatric surgery on HRQoL might also be different.

\section{IMPROVING WEIGHT OUTCOME}

Even though bariatric surgery is currently the most effective treatment for morbid obesity, weight outcome varies greatly between patients and the reasons for this are unclear. Unsuccessful weight loss after bariatric surgery is usually defined as an EWL below $50 \%$ or a TWL below $20 \%{ }^{6,7,67}$. There is no uniform definition for weight regain, used definitions range from "any weight regain" to weight regain up to a BMI > 35 $\mathrm{kg} / \mathrm{m}^{275}$. Insufficient weight loss or significant weight regain occurs in $20-30 \%$ of the population, leading to secondary and/or tertiary bariatric procedures in up to $25 \%$ of the patients ${ }^{5-7}$. Weight regain in turn negatively impacts comorbidities and HRQoL 7,69,76. It is essential to identify which factors determine weight outcome after surgery, so that weight loss can be improved and weight regain can be avoided. Most previous research has concentrated on factors that do relate to weight outcome, but cannot (easily) be influenced, such as age, race, presence of co-morbidities, genetics and gastrointestinal hormone levels ${ }^{77-81}$. Surgical factors, like the length of biliary limbs, do not seem to effect long-term weight loss ${ }^{82}$. To further improve weight loss and/or reduce weight regain it seems more logical to focus on factors that can be influenced: patient related factors. This will also allow a shift of focus from the total population to the specific patients that need extra guidance. 


\section{PSYCHOLOGICAL PROBLEMS}

As described briefly before, obesity in general has a negative impact on social and psychological well-being ${ }^{19,23-25}$. The most common psychological problems in obese persons are low self-esteem, depressive symptoms, eating disorders and a negative body image ${ }^{23-29}$. It seems that psychological problems are even more prevalent in the obese population who is seeking surgical treatment ${ }^{28,30,31}$. In daily practice, it is assumed that the best weight loss (maintenance) after bariatric surgery is achieved by patients who have no psychological problems and who are willing to change their physical activity and eating habits after surgery. Therefore, psychological assessment is a standard part of screening for bariatric surgery ${ }^{18,83}$. Nonetheless the scientific evidence for these assumptions is not very strong.

Studies assessing the effect of psychological problems on weight change after bariatric surgery show conflicting results. Depressive symptoms are known to negatively affect body weight in the obese population ${ }^{24,28,29,84}$. But there are only few studies in the bariatric population, that have shown a relationship between depression and worse weight loss results ${ }^{79,85}$. For eating disorders, the effects on weight loss are also inconclusive. Several studies have shown a negative effect of eating disorders on weight loss after bariatric surgery ${ }^{86,87}$. Others conclude that patients with an eating disorder will lose more weight compared to patients without an eating disorder ${ }^{79}$. The effect of a negative body image on weight loss in the bariatric population has only been analysed in two studies. One found that a more negative body image was related to less weight loss ${ }^{88}$. While the other study, using the same questionnaire, found no correlation ${ }^{89}$. Body image is related a range of problems such as avoidance of social situations, low self-esteem and even depression in the obese population $23,24,27,28$. There seems to be sufficient evidence that lack of physical activity and non-compliance to follow-up after surgery have a negative impact on weight outcome after bariatric surgery ${ }^{3,90-93}$.

More and better knowledge of the effect of these psychological and behavioural factors on weight change after surgery is important for a least two reasons. Firstly, because these factors can be influenced by, for example cognitive behavioural therapy, and thereby outcome after bariatric surgery may be improved. Secondly, because some of these factors, like eating disorders, are frequently seen as a contra-indication for bariatric surgery and a common reason for delaying or even refusal of an operation worldwide ${ }^{3}$. This means that these patients do not get a treatment, which can have a significant positive impact on their long-term health, mortality and HRQoL. With a better understanding of the actual influence of these factors on weight change, selection for bariatric surgery and treatment of patients who undergo a bariatric procedure can be improved. 
The aim of the first part of this thesis is to unravel whether physical activity, eating style/disorders, depressive disorders, HRQoL and body image are related to weight change after bariatric surgery.

\section{EXCESS SKIN AFTER BARIATRIC SURGERY}

As stated in the beginning, excess skin is a very important negative consequence of bariatric surgery. Up to $90 \%$ of the population experiences problems with overhanging skin as a consequence of the massive weight loss ${ }^{8-11}$. Excess skin negatively affects patient's wellbeing by causing medical, physical and psychological problems 8-11. Patients describe having trouble finding suitable clothing, limitation in daily activities and sports $8,10,11,98$. Psychological issues are usually related to a negative body image; patients feel ashamed and unattractive ${ }^{11,99,100}$.

Excess skin can only be treated by BCS, a type of surgery in which the excess skin is surgically removed. As expected, BCS generally has a positive effect on the patients' wellbeing. Several studies showed an improvement of HRQoL, even up to 8 years after the body contouring procedure ${ }^{101-105}$. Three small studies have also shown a positive effect of BCS on body image ${ }^{9,105,106}$. Moreover, post-bariatric patients who undergo BCS show better weight loss maintenance ${ }^{107,108}$. This is especially important, since weight loss and (long-term) maintenance is the primary goal of bariatric surgery. Better weight loss maintenance after BCS have might be caused by an improvement of body image, which improves depressive symptoms and thereby weight loss maintenance.

\section{Reimbursement of body contouring surgery}

Despite the positive effects of BCS only a small percentage (18-33\%) of patients seem to undergo one or more body contouring procedures ${ }^{10,11,109,110}$. This is at least partly caused by the fact that BCS is not a standard part of bariatric treatment programs and often not reimbursed by health insurance companies. Patients report that the high costs for BCS are the main reason for not undergoing any procedure ${ }^{10,109}$. This is a worldwide issue ${ }^{10,11} 109,110$.

In the Netherlands there are restrictions for reimbursement of post bariatric body contouring surgical procedures. In order to qualify for reimbursement by health insurance companies in our country patients first have to meet the following qualifications: (a) have to be at least 18 months past bariatric surgery, (b) should have a stable weight for at least 12 months, (c) should have a BMl $<35 \mathrm{~kg} / \mathrm{m}^{2}$. Second, they should have a skin excess grade 3 according to the Pittsburgh Rating Scale (PRS) or an untreatable skin condition caused by the excess skin ${ }^{111,112}$. 
In my opinion the current system has serious drawbacks. The first problem is that the PRS was never created for reimbursement purposes and the evaluation of excess skin by means of visual interpretation of photographs has been proven to be inconsistent and therefore unreliable ${ }^{112-114}$. The second problem is that psychological and physical complaints are not part of the assessment, which seems unfair. Especially because these issues seem to negatively impact patient well-being. The result of the current system is a growing population of patients who have undergone bariatric surgery, but have no access to post-bariatric BCS. Unfortunately, no exact figures are available for the Netherlands.

Several others have described the problem of a large post-bariatric population who don't get reimbursed and neither do have the financial means to pay for BCS themselves ${ }^{109,110,115}$. The British Association of Plastic, Reconstructive and Aesthetic Surgeons (BAPRAS) has now developed a questionnaire to define which post-bariatric patients qualify for referral and reimbursement of BCS ${ }^{116}$. Assessment of weight loss results, medical, physical and psychological complaints of excess skin, and history of the patient are part of this questionnaire.

In the second part of this thesis, I will focus on desire for BCS, body image and excess skin in the post-bariatric population. It is hypothesized that patients who have overhanging skin and desire BCS will have a more negative body image compared to patients who already had BCS. It is also hypothesized that the patients who did not undergo BCS are the patients in whom body image mediates the relationship between weight loss and depressive symptoms. Therefore, patients who did not undergo BCS will be compared with patients who already had BCS and patients who do not want $\mathrm{BCS}$. In each of these groups we will assess the relationship between weight loss, depressive symptoms and body image. Additionally, we will conduct a mediation analysis to assess whether body image mediates the relationship between weight loss and depressive symptoms in the post-bariatric population. In the following study we will compare patients who desire BCS, with patients who don't desire BCS concentrating on demographics, skin surplus and Dutch qualifications for reimbursement of BCS. Perceived reasons why patients have not undergone BCS will be evaluated. In the last chapter a new tool to decide which patients qualify for referral and reimbursement of BCS will be developed and tested. This screening tool will be a modified version of the tool created by the BAPRAS, in which weight loss results, complaints of excess skin, and history of the patient are used to decide which patients qualify for reimbursement. 


\section{Outline of this thesis}

To sum up, bariatric surgery has proven to be a highly effective treatment for one of the most prevalent health issues in this century: morbid obesity. Bariatric surgery generally has a positive outcome, but not in all patients. About $20-30 \%$ of the patients experience insufficient weight loss, or weight regain, and others are seriously affected by overhanging skin. To improve the outcomes after bariatric surgery, it is essential to know which factors influence weight change. Physical and psychological factors that might influence the surgery outcomes are not frequently studied.

The first part of this thesis will focus on the patient related factors as moderators of weight change after surgery. The studies in this part of the thesis are all conducted in patients who have undergone a RYGB without any prior bariatric procedures. This population was chosen because the RYGB is the most popular in the Netherlands and because weight loss can differ between the types of bariatric surgery, especially when patients who undergo secondary or tertiary procedures are included. A systematic review and meta-analysis will discuss the evidence on the role of compliance to follow-up, physical activity, psychopathology, depressive disorders, eating disorders, HRQoL and body image on weight loss after RYGB (chapter 2). Subsequently, we will use the outcome of this systematic review as a base for a prospective data-analysis to study the effect of moderators on weight loss after RYGB in our own population. We will study weight change up to 4 years after RYGB and assess the relationship with eating style and physical activity (chapter 3 ). In chapter $\mathbf{4}$, we will assess the relationship between weight loss and HRQoL using an obesity specific and a generic HRQoL questionnaire.

In the second part of the thesis the emphasis will be on excess skin, BCS and body image. In chapter 5 depressive symptoms, body image and weight loss will be studied in a post-bariatric population, by comparing patients with a desire for BCS with patients who already had BCS and patients without a desire for BCS. The mediating effect of body image on the relationship between weight loss and depressive symptoms will be studied. In chapter 6 differences between these patient groups regarding social economic status, qualification according to Dutch weight criteria, complaints of overhanging skin and satisfaction with body will be analysed. Perceived reasons why patients have not undergone BCS will also be assessed in this chapter. In chapter 7 a new screening tool for reimbursement of BCS will be developed and tested. 


\section{References}

1. Poelemeijer YQM, Liem RSL, Nienhuijs SW. A Dutch Nationwide Bariatric Quality Registry: DATO. Obes Surg. 2018 Jun;28(6):1602-10.

2. Sjostrom L. Review of the key results from the Swedish Obese Subjects (SOS) trial - a prospective controlled intervention study of bariatric surgery. J Intern Med. 2013 Mar;273(3):219-34.

3. Mechanick JI, Youdim A, Jones DB, Garvey WT, Hurley DL, McMahon MM, et al. Clinical practice guidelines for the perioperative nutritional, metabolic, and nonsurgical support of the bariatric surgery patient--2013 update: cosponsored by American Association of Clinical Endocrinologists, The Obesity Society, and American Society for Metabolic \& Bariatric Surgery. Obesity (Silver Spring). 2013 Mar;21 Suppl 1:S1-27.

4. Chang SH, Stoll CR, Song J, Varela JE, Eagon CJ, Colditz GA. The effectiveness and risks of bariatric surgery: an updated systematic review and meta-analysis, 2003-2012. JAMA Surg. 2014 Mar;149(3):275-87.

5. Pinto-Bastos A, Conceicao EM, Machado PPP. Reoperative Bariatric Surgery: a Systematic Review of the Reasons for Surgery, Medical and Weight Loss Outcomes, Relevant Behavioral Factors. Obes Surg. 2017 Aug 8.

6. Rosenthal RJ. Failure of weight loss or weight regain after baratric surgery. Bariatric Times. 2012;9(10).

7. Karmali S, Brar B, Shi X, Sharma AM, de Gara C, Birch DW. Weight recidivism post-bariatric surgery: a systematic review. Obes Surg. 2013 Nov;23(11):1922-33.

8. Kitzinger HB, Abayev S, Pittermann A, Karle B, Bohdjalian A, Langer FB, et al. After massive weight loss: patients' expectations of body contouring surgery. Obes Surg. 2012 Apr;22(4):544-8.

9. Pecori L, Serra Cervetti GG, Marinari GM, Migliori F, Adami GF. Attitudes of morbidly obese patients to weight loss and body image following bariatric surgery and body contouring. Obes Surg. 2007 Jan;17(1):68-73.

10. Klopper E.M., Kroese-Deutman H.C., Berends F.J. Massive weight loss after bariatric surgery and the demand (desire) for body contouring surgery. Eur J Plast Surg. 2014;37(2):103-8.

11. Staalesen T, Fagevik Olsen M, Elander A. Experience of excess skin and desire for body contouring surgery in post-bariatric patients. Obes Surg. 2013 Oct;23(10):1632-44.

12. Coulman KD, MacKichan F, Blazeby JM, Owen-Smith A. Patient experiences of outcomes of bariatric surgery: a systematic review and qualitative synthesis. Obes Rev. 2017 May; 18(5):547-59.

13. WHO, Overweight and Obesity Fact Sheet [Internet].; February 2018 [. Available from: http://www.who.int/mediacentre/factsheets/ fs311/en/.

14. Yumuk V, Tsigos C, Fried M, Schindler K Busetto L, Micic D, et al. European Guidelines for Obesity Management in Adults. Obes Facts. 2015;8(6):402-24

15. Centraal Bureau voor de Statistiek (Statistics Netherlands) [Internet].: CBS; 2018 [updated 04-07-2018; ]. Available from: https://www. cbs.nl/nl-nl/nieuws/2018/27/100-duizend-volwassenen-hebben-morbide-obesitas.

16. Pearson-Stuttard J, Zhou B, Kontis V, Bentham J, Gunter MJ, Ezzati M. Worldwide burden of cancer attributable to diabetes and high body-mass index: a comparative risk assessment. Lancet Diabetes Endocrinol. 2018 Feb;6(2):95-104.
17. Fried M., Yumuk V., Oppert J.M., Scopinaro N., Torres A., Weiner R., et al. Interdisciplinary European guidelines on metabolic and bariatric surgery. Obes Surg. 2014;24(1):42-55.

18. Verdam FJ, de Jonge C, Greve JW. Practice guideline for the treatment of morbid obesity. Ned Tijdschr Geneeskd. 2012;156(23):A4630.

19. Seidell JC, de Beer JJ, Kuijpers T. Guideline 'Diagnosis and treatment of obesity in adults and children'. Ned Tijdschr Geneeskd. 2008 Sep 20;152(38):2071-6.

20. Andreyeva T, Sturm R, Ringel JS. Moderate and severe obesity have large differences in health care costs. Obes Res. 2004 Dec;12(12):1936-43.

21. Sturm R, An R, Maroba J, Patel D. The effects of obesity, smoking, and excessive alcohol intake on healthcare expenditure in a comprehensive medical scheme. S Afr Med J. 2013 Sep 30;103(11):840-4.

22. Kamble PS, Hayden J, Collins J, Harvey RA, Suehs B, Renda A, et al. Association of obesity with healthcare resource utilization and costs in a commercial population. Curr Med Res Opin. 2018 May 10:1-9.

23. Bocchieri LE, Meana M, Fisher BL. Perceived psychosocial outcomes of gastric bypass surgery: a qualitative study. Obes Surg. 2002 Dec;12(6):781-8.

24. Stunkard AJ, Wadden TA. Psychological aspects of severe obesity. Am J Clin Nutr. 1992 Feb;55(2 Suppl):524S-32S.

25. Malik S., Mitchell J.E., Engel S., Crosby R. Wonderlich S. Psychopathology in bariatric surgery candidates: A review of studies using structured diagnostic interviews. Compr Psychiatry. 2014;55(2):248-59.

26. Adami GF, Gandolfo P, Campostano A, Meneghelli A, Ravera G, Scopinaro N. Body image and body weight in obese patients. Int J Eat Disord. 1998 Nov;24(3):299-306.

27. Cargill BR, Clark MM, Pera V, Niaura RS, Abrams DB. Binge eating, body image, depression, and self-efficacy in an obese clinica population. Obes Res. 1999 Jul;7(4):379-86.

28. Friedman KE, Reichmann SK, Costanzo PR, Musante GJ. Body image partially mediates the relationship between obesity and psychological distress. Obes Res. 2002 Jan;10(1):33-41.

29. Wardle J, Waller J, Rapoport L. Body dissatis faction and binge eating in obese women: the role of restraint and depression. Obes Res. 2001 Dec;9(12):778-87.

30. van Nunen AM, Wouters EJ, Vingerhoets AJ, Hox JJ, Geenen R. The health-related quality of life of obese persons seeking or not seeking surgical or non-surgical treatment: a meta-analysis. Obes Surg. 2007 Oct;17(10):1357-66.

31. Karlsson J, Sjöström L, Sullivan M. Swedish obese subjects (SOS)--an intervention study of obesity. Two-year follow-up of health-related quality of life (HRQL) and eating behavior after gastric surgery for severe obesity. International journal of obesity and related metabolic disorders. 1998;22(2):113-26.

32. McAllister EJ, Dhurandhar NV, Keith SW, Aronne LJ, Barger J, Baskin M, et al. Ten putative contributors to the obesity epidemic. Crit Rev Food Sci Nutr. 2009 Nov;49(10):868913.

33. Keith SW, Redden DT, Katzmarzyk PT, Boggiano MM, Hanlon EC, Benca RM, et al. Putative contributors to the secular increase in obesity: exploring the roads less traveled. Int J Obes (Lond). 2006 Nov;30(11):1585-94. 34. Bray GA, Fruhbeck G, Ryan DH, Wilding JP. Management of obesity. Lancet. 2016 May 
$7 ; 387(10031): 1947-56$

Busetto L, Dicker D, Azran C, Batterham RL, Farpour-Lambert N, Fried M, et al. Practical Recommendations of the Obesity Management Task Force of the European Association for the Study of Obesity for the Post-Bariatric Surgery Medical Management. Obes Facts. 2017 Dec 6;10(6):597-632.

36. Dombrowski SU, Knittle K, Avenell A, Araujo-Soares V, Sniehotta FF. Long term maintenance of weight loss with non-surgical interventions in obese adults: systematic review and meta-analyses of randomised controlled trials. BMJ. 2014 May 14;348:g2646.

37. Apovian CM, Aronne LJ, Bessesen DH, McDonnell ME, Murad MH, Pagotto U, et al. Pharmacological management of obesity: an endocrine Society clinical practice guideline. J Clin Endocrinol Metab. 2015 Feb;100(2):342-62.

38. Jacob A, Moullec G, Lavoie KL, Laurin C, Cowan T, Tisshaw C, et al. Impact of cognitive-behavioral interventions on weight loss and psychological outcomes: A meta-analysis. Health Psychol. 2018 May;37(5):417-32.

39. Look AHEAD Research Group. Eight-year weight losses with an intensive lifestyle intervention: the look AHEAD study. Obesity (Silver Spring). 2014 Jan;22(1):5-13.

40. Nuffer W, Trujillo JM, Megyeri J. A Comparison of New Pharmacological Agents for the Treatment of Obesity. Ann Pharmacother. 2016 May;50(5):376-88

41. Madsbad S, Dirksen C, Holst JJ. Mechanisms of changes in glucose metabolism and bodyweight after bariatric surgery. Lancet Diabetes Endocrinol. 2014 Feb;2(2):152-64.

42. Angrisani L, Santonicola A, lovino P, Vitiello A, Higa K, Himpens J, et al. IFSO Worldwide Survey 2016: Primary, Endoluminal, and Revisional Procedures. Obes Surg. 2018 Aug 18.

43. Gloy VL, Briel M, Bhatt DL, Kashyap SR Schauer PR, Mingrone G, et al. Bariatric surgery versus non-surgical treatment for obesity: a systematic review and meta-analysis of randomised controlled trials. BMJ. 2013 Oct 22;347:f5934.

44. Colquitt JL, Pickett K, Loveman E, Frampton GK. Surgery for weight loss in adults. Cochrane Database Syst Rev. 2014 Aug 8;(8):CD003641. doi(8):CD003641.

45. Reges O, Greenland P, Dicker D, Leibowitz M, Hoshen M, Gofer I, et al. Association of Bariatric Surgery Using Laparoscopic Banding, Roux-en-Y Gastric Bypass, or Laparoscopic Sleeve Gastrectomy vs Usual Care Obesity Management With All-Cause Mortality. JAMA. 2018 Jan 16;319(3):279-90.

46. Sjostrom L, Peltonen M, Jacobson P, Sjostrom $\mathrm{CD}$, Karason $\mathrm{K}$, Wedel $\mathrm{H}$, et al. Bariatric surgery and long-term cardiovascular events. JAMA. 2012 Jan 4;307(1):56-65.

47. Sjostrom L, Peltonen M, Jacobson P, Ahlin $\mathrm{S}$, Andersson-Assarsson J, Anveden A, et al. Association of bariatric surgery with long-term remission of type 2 diabetes and with microvascular and macrovascular complications. JAMA. 2014 Jun 11;311(22):2297-304

48. Ribaric G., Buchwald J.N., McGlennon T.W. Diabetes and weight in comparative studies of bariatric surgery vs conventional medical therapy: A systematic review and meta-analysis. Obes Surg. 2014;24(3):437-55

49. Angrisani L, Santonicola A, lovino P, Vitiello A, Zundel N, Buchwald H, et al. Bariatric Surgery and Endoluminal Procedures: IFSO Worldwide Survey 2014. Obes Surg. 2017 Apr 13

50. De Luca M, Angrisani L, Himpens J, Busetto L, Scopinaro N, Weiner R, et al. Indications for Surgery for Obesity and Weight-Related Diseases: Position Statements from the International Federation for the Surgery of Obesity and Metabolic Disorders (IFSO). Obes Surg. 2016 Aug:26(8):1659-96.

51. Busetto L, Dixon J, De Luca M, Shikora S, Pories W, Angrisani L. Bariatric Surgery in Class I Obesity : A Position Statement from the International Federation for the Surgery of Obesity and Metabolic Disorders (IFSO). Obes Surg. 2014 Apr;24(4):487-519.

52. Cohen R., Caravatto P.P., Petry T., Cummings D. Role of metabolic surgery in less obese or non-obese subjects with type 2 diabetes: Influence over cardiovascular events topical collection on lipid and metabolic effects of gastrointestinal surgery. Curr Atheroscler Rep. 2013;15(10).

53. ASMBS Clinical Issues Committee. Bariatric surgery in class I obesity (body mass index 30-35 kg/m(2)). Surg Obes Relat Dis. 2013 Jan-Feb;9(1):e1-10.

54. Abdeen G, le Roux CW. Mechanism Underlying the Weight Loss and Complications of Roux-en-Y Gastric Bypass. Review. Obes Surg. 2016 Feb;26(2):410-21.

55. Jain AK, le Roux CW, Puri P, Tavakkoli A, Gletsu-Miller N, Laferrere B, et al. Proceedings of the 2017 ASPEN Research Workshop-Gastric Bypass: Role of the Gut. JPEN J Parenter Enteral Nutr. 2018 Feb;42(2):279-95.

56. Sinclair P, Docherty N, le Roux CW. Metabolic Effects of Bariatric Surgery. Clin Chem. 2018 Jan;64(1):72-81.

57. Geubbels N, Roell EA, Acherman YI, Bruin SC, van de Laar AW, de Brauw LM. Internal Herniation After Laparoscopic Roux-en-Y Gastric Bypass Surgery: Pitfalls in Diagnosing and the Introduction of the AMSTERDAM Classification. Obes Surg. 2016 Jan 19.

58. Parrott J, Frank L, Rabena R, Craggs-Dino L, Isom KA, Greiman L. American Society for Metabolic and Bariatric Surgery Integrated Health Nutritional Guidelines for the Surgical Weight Loss Patient 2016 Update: Micronutrients. Surg Obes Relat Dis. 2017 May;13(5):727-41.

59. $\quad$ Altieri MS, Yang J, Nie L, Docimo S, Talamini $\mathrm{M}$, Pryor AD. Incidence of cholecystectomy after bariatric surgery. Surg Obes Relat Dis. 2018 Mar 30.

60. Dogan K, Homan J, Aarts EO, de Boer H, van Laarhoven CJ, Berends FJ. Long-term nutrie tional status in patients following Roux-en-Y gastric bypass surgery. Clin Nutr. 2017 Feb 3.

61. Lupoli R, Lembo E, Saldalamacchia G, Avola CK, Angrisani L, Capaldo B. Bariatric surgery and long-term nutritional issues. World $\mathrm{J}$ Diabetes. 2017 Nov 15;8(11):464-74.

62. van der Beek ES, Monpellier VM, Eland I, Tromp E, van Ramshorst B. Nutritional deficiencies in gastric bypass patients; incidence, time of occurrence and implications for post-operative surveillance. Obes Surg. 2015 May;25(5):818-23.

63. Ledoux S., Riviare P., Breuil M.C., Bogard C., Castel B., Msika S., et al. Impact of adherence to medical care on long-term nutritional deficiencies after gastric bypass. Obes Facts. 2012;5:186.

64. Ledoux S, Larger E. Nutritional deficiencies after Roux-en-Y gastric bypass can be prevented by standard multivitamin supplementation. Am J Clin Nutr. 2008 Oct;88(4):1176; author reply 1176-7.

65. Brethauer SA, Kim J, El Chaar M, Papasavas P, Eisenberg D, Rogers A, et al. Standardized outcomes reporting in metabolic and bariatric surgery. Obes Surg. 2015 Apr;25(4):587-606. 
66. van de Laar AW. Algorithm for weight loss after gastric bypass surgery considering body mass index, gender, and age from the Bariatric Outcome Longitudinal Database (BOLD). Surg Obes Relat Dis. 2014 JanFeb;10(1):55-61.

67. Corcelles R, Boules M, Froylich D, Hag A, Daigle CR, Aminian A, et al. Total Weight Loss as the Outcome Measure of Choice After Roux-en-Y Gastric Bypass. Obes Surg. 2016 2016/01:1-5.

68. Courcoulas AP, King WC, Belle SH, Berk P, Flum DR, Garcia L, et al. Seven-Year Weight Trajectories and Health Outcomes in the Longitudinal Assessment of Bariatric Surgery (LABS) Study. JAMA Surg. 2017 Dec 6.

69. Karlsson J, Taft C, Ryden A, Sjostrom L Sullivan M. Ten-year trends in health-related quality of life after surgical and conventional treatment for severe obesity: the SOS intervention study. Int J Obes (Lond). 2007 Aug;31(8):1248-61.

70. Lindekilde N, Gladstone BP, Lubeck M, Nielsen J, Clausen L, Vach W, et al. The impact of bariatric surgery on quality of life: a systematic review and meta-analysis. Obes Rev. 2015 Aug;16(8):639-51.

71. Sarwer DB, Steffen KJ. Quality of Life, Body Image and Sexual Functioning in Bariatric Surgery Patients. Eur Eat Disord Rev. 2015 Nov;23(6):504-8.

72. Kroes M, Osei-Assibey G, Baker-Searle R, Huang J. Impact of weight change on quality of life in adults with overweight/obesity in the United States: a systematic review. Curr Med Res Opin. 2016 Mar;32(3):485-508.

73. Dymek MP, Le Grange D, Neven K, Alverdy J. Quality of life after gastric bypass surgery: a cross-sectional study. Obes Res. 2002 Nov;10(11):1135-42

74. Strain GW, Kolotkin RL, Dakin GF, Gagner M, Inabnet WB, Christos P, et al. The effects of weight loss after bariatric surgery on health-related quality of life and depression. Nutr Diabetes. 2014 Sep 1;4:e132.

75. Nedelcu M, Khwaja HA, Rogula TG. Weight regain after bariatric surgery-how should it be defined? Surg Obes Relat Dis. 2016 Jun;12(5):1129-30.

76. Laurino Neto RM, Herbella FA, Tauil RM, Silva FS, de Lima SE,Jr. Comorbidities remission after Roux-en-Y Gastric Bypass for morbid obesity is sustained in a long-term follow-up and correlates with weight regain. Obes Surg. 2012 Oct;22(10):1580-5.

77. de Hollanda A, Jimenez A, Corcelles R, Lacy AM, Patrascioiu I, Vidal J. Gastrointestinal hormones and weight loss response after Roux-en-Y gastric bypass. Surg Obes Relat Dis. 2014 Sep-Oct;10(5):814-9.

78. Coleman KJ, Brookey J. Gender and racial/ ethnic background predict weight loss after Roux-en-Y gastric bypass independent of health and lifestyle behaviors. Obes Surg. 2014 Oct;24(10):1729-36.

79. Livhits M, Mercado C, Yermilov I, Parikh JA, Dutson E, Mehran A, et al. Preoperative predictors of weight loss following bariatric surgery: systematic review. Obes Surg. 2012 Jan;22(1):70-89.

80. Shantavasinkul PC, Omotosho P, Corsino L, Portenier D, Torquati A. Predictors of weight regain in patients who underwent Roux-en-Y gastric bypass surgery. Surg Obes Relat Dis. 2016 Nov;12(9):1640-5.

81. Hatoum I., Greenawalt D., Kemp D.M., Reitman M., Lum P., Kaplan L.M. Genetic factors predict weight loss after roux-en-y gastric bypass. Gastroenterology. 2010;138(5):S71.
82. Dogan K, Homan J, Aarts EO, van Laarhoven CJ, Janssen IM, Berends FJ. A short or a long Roux limb in gastric bypass surgery: does it matter? Surg Endosc. 2017 Apr;31(4):188290.

83. Fried M., Yumuk V., Oppert J.-M., Scopinaro N., Torres A.J., Weiner R., et al. Interdisciplin: ary European guidelines on metabolic and bariatric surgery. Obes Facts. 2013;6(5):44968.

84. Sarwer DB, Wadden TA, Foster GD. Assessment of body image dissatisfaction in obese women: specificity, severity, and clinical significance. J Consult Clin Psychol. 1998 Aug;66(4):651-4.

85. Sarwer DB, Thompson JK, Mitchell JE, Rubin JP. Psychological considerations of the bariatric surgery patient undergoing body contouring surgery. Plast Reconstr Surg. 2008 Jun;121(6):423e-34e.

86. Pataky Z, Carrard I, Golay A. Psychological factors and weight loss in bariatric surgery. Curr Opin Gastroenterol. 2011 Mar;27(2):16773.

87. Wimmelmann CL, Dela F, Mortensen EL. Psychological predictors of weight loss after bariatric surgery: a review of the recent research. Obes Res Clin Pract. 2014 JulAug;8(4):e299-313.

88. Hrabosky JI, Masheb RM, White MA, Rothschild BS, Burke-Martindale CH, Grilo CM. A prospective study of body dissatisfaction and concerns in extremely obese gastric bypass patients: 6- and 12-month postoperative outcomes. Obes Surg. 2006 Dec;16(12):1615-21. Sallet PC, Sallet JA, Dixon JB, Collis E, Pisani CE, Levy A, et al. Eating behavior as a prognostic factor for weight loss after gastric bypass. Obes Surg. 2007 Apr;17(4):445-51.

90. Kim HJ, Madan A, Fenton-Lee D. Does Patient Compliance with Follow-up Influence Weight Loss After Gastric Bypass Surgery? A Systematic Review and Meta-Analysis. Obes Surg. 2014 Apr;24(4):647-51.

91. Egberts K, Brown WA, Brennan L, O'Brien $\mathrm{PE}$. Does exercise improve weight loss after bariatric surgery? A systematic review. Obes Surg. 2012 Feb;22(2):335-41.

92. Livhits M, Mercado C, Yermilov I, Parikh JA, Dutson E, Mehran A, et al. Exercise following bariatric surgery: systematic review. Obes Surg. 2010 May;20(5):657-65.

93. Livhits M, Mercado C, Yermilov I, Parikh JA, Dutson E, Mehran A, et al. Patient behaviors associated with weight regain after laparoscopic gastric bypass. Obes Res Clin Pract. 2011 Jul-Sep;5(3):e169-266.

94. Cash TF. Body image: past, present, and future. Body Image. 2004 Jan;1(1):1-5.

95. Adami GF, Meneghelli A, Bressani A, Scopinaro $\mathrm{N}$. Body image in obese patients before and after stable weight reduction following bariatric surgery. J Psychosom Res. 1999 Mar;46(3):275-81.

96. Dixon JB, Dixon ME, O'Brien PE. Body image: appearance orientation and evaluation in the severely obese. Changes with weight loss. Obes Surg. 2002 Feb;12(1):65-71.

97. Neven K, Dymek M, leGrange D, Maasdam H, Boogerd AC, Alverdy J. The effects of Rouxen-Y gastric bypass surgery on body image. Obes Surg. 2002 Apr;12(2):265-9.

98. Biorserud C, Olbers T, Fagevik Olsen M. Patients' experience of surplus skin after laparoscopic gastric bypass. Obes Surg. 2011 Mar;21(3):273-7.

99. Kubik JF, Gill RS, Laffin M, Karmali S. The impact of bariatric surgery on psychological health. J Obes. 2013;2013:837989. 
100. Klassen AF, Cano SJ, Scott A, Johnson J, Pusic AL. Satisfaction and quality-of-life issues in body contouring surgery patients: a qualitative study. Obes Surg. 2012 Oct;22(10):1527-34.

101. van der Beek ES, Geenen R, de Heer FA, van der Molen AB, van Ramshorst B. Quality of life long-term after body contouring surgery following bariatric surgery: sustained improvement after 7 years. Plast Reconstr Surg. 2012 Nov; 130(5):1133-9.

102. Cintra W,Jr, Modolin ML, Gemperli R, Gobbi Cl, Faintuch J, Ferreira MC. Quality of life after abdominoplasty in women after bariatric surgery. Obes Surg. 2008 Jun;18(6):728-32.

103. Coriddi MR, Koltz PF, Chen R, Gusenoff JA. Changes in quality of life and functional status following abdominal contouring in the massive weight loss population. Plast Reconstr Surg. 2011 Aug;128(2):520-6.

104. Modarressi A, Balague N, Huber O, Chilcott $M$, Pittet-Cuenod B. Plastic surgery after gastric bypass improves long-term quality of life. Obes Surg. 2013 Jan;23(1):24-30.

105. Song P, Patel NB, Gunther S, Li CS, Liu Y, Lee CY, et al. Body Image \& Quality of Life: Changes With Gastric Bypass and Body Contouring. Ann Plast Surg. 2016 May;76 Suppl 3:S216-21.

106. Stuerz K, Piza H, Kinzl JF. The impact of abdominoplasty after massive weight loss: a qualitative study. Ann Plast Surg. 2013 Nov;71(5):547-9.

107. Balague N, Combescure C, Huber O Pittet-Cuenod B, Modarressi A. Plastic surgery improves long-term weight control after bariatric surgery. Plast Reconstr Surg. 2013 Oct;132(4):826-33.

108. Wiser I, Avinoah E, Ziv O, Parnass AJ, Averbuch Sagie R, Heller L, et al. Body contouring surgery decreases long-term weight regain following laparoscopic adjustable gastric banding: A matched retrospective cohort study. J Plast Reconstr Aesthet Surg. 2016 Nov;69(11):1490-6.

109. Azin A, Zhou C, Jackson T, Cassin S, Sockalingam S, Hawa R. Body contouring surgery after bariatric surgery: a study of cost as a barrier and impact on psychological well-being. Plast Reconstr Surg. 2014 Jun;133(6):776e-82e.

110. Gusenoff JA, Messing S, O'Malley W, Langstein HN. Patterns of plastic surgical use after gastric bypass: who can afford it and who will return for more. Plast Reconstr Surg. 2008 Sep;122(3):951-8.

111. Richtlijn Contourherstellende post-bariatrische chirurgie (Guideline post-bariatric bodycontouring surgery) [Internet]. Utrecht: Nederlandse Vereniging voor Plastische Chirurgie (Dutch society for Plastic Surgery); 2015 [updated 14-05-2015; ]. Available from: https://www.nvpc.nl/stand.php? flag=richt\&portion $=9$.

112. Song AY, Jean RD, Hurwitz DJ, Fernstrom $\mathrm{MH}$, Scott JA, Rubin JP. A classification of contour deformities after bariatric weight loss: the Pittsburgh Rating Scale. Plast Reconstr Surg. 2005 Oct;116(5):1535,44; discussion 1545-6.

113. van der Beek ES, Verveld CJ, van Ramshorst $B$, Kon M, Mink van der Molen AB. ClassifiA cation of contour deformities after massive weight loss: the applicability of the Pittsburgh Rating Scale in The Netherlands. J Plast Reconstr Aesthet Surg. 2013 Aug;66(8):1039-44.

114. Biorserud C, Fagevik Olsen M, Elander A, Wiklund M. Objective measurements of excess skin in post bariatric patients--in- ter-rater reliability. J Plast Surg Hand Surg. 2016;50(2):68-73.

115. Mukherjee S, Kamat S, Adegbola S, Agrawal S. Funding for postbariatric body-contouring (bariplastic) surgery in England: a postcode lottery. Plast Surg Int. 2014;2014:153194.

116. Soldin M, Mughal M, Al-Hadithy N, Department of Health, British association of Plastic, Reconstructive and Aesthetic Surgeons, Royal College of Surgeons England. National commissioning guidelines: body contouring surgery after massive weight loss. J Plast Reconstr Aesthet Surg. 2014 Aug;67(8):1076-81. 
PSYCHOLOGICAL FACTORS

AND

WEIGHT CHANGE 



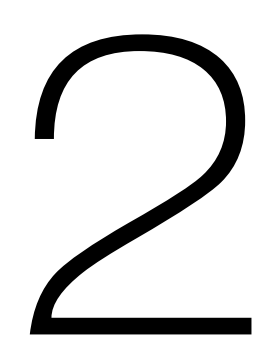

Influence of psychological factors on weight loss after Roux-and-Y gastric bypass: systematic review and meta-analysis.

Valerie M. Monpellier Ignace M. C. Janssen Evangelia E. Antoniou Anita T. M. Jansen 


\section{ABSTRACT}

\section{INTRODUCTION}

Insufficient weight loss after Roux-en-Y gastric bypass (RYGB), might be influenced by behavioral and psychopathology related factors. This review studies the moderating influence of several behavioral and psychopathology related factors on weight loss.

\section{METHOD}

The search was carried out using four electronic databases. Preoperative Body Mass Index and percentage Excess Weight Loss (\%EWL) were calculated for all moderator and non-moderator groups of variables.

\section{RESULTS}

A total of 61 articles were included; 35 studies had sufficient data for meta-analysis. Eight studies were included to study the relationship between compliance and weight loss, compliant patients had a significantly higher EWL than non-compliant patients; difference $7.6 \%(p<0.001)$. Ten studies were included for physical activity, active patients had a significantly higher EWL, $71.3 \%$ versus $63.7 \%(p<0.001)$. Weight loss was not significantly influenced by depression $(p=0.246)$ or binge eating $(p=0.256)$.

\section{CONCLUSION}

This meta-analysis shows that good compliance and higher physical activity have a positive effect on weight loss after RYGB. However, symptoms of depression and binge eating do seem to not influence weight loss. Psychological evaluation varies greatly and efforts should be made to form consensus on how to conduct this evaluation. For now, decisions regarding bariatric surgery should be made based on a multidisciplinary screening of each single patient. 


\section{INTRODUCTION}

The Roux-en-Y gastric bypass (RYGB) is currently the most popular type of bariatric surgery ${ }^{1-3}$. It results in long-term weight loss; improvement of obesity related comorbidities and it positively affects quality of life (QoL) ${ }^{3-5}$. Percentage excess weight loss (\%EWL) is generally used to describe weight loss after RYGB ${ }^{6}$. The average patient reaches an EWL of $60-70 \%$; in $10-20 \%$ of the patients $\mathrm{EWL}$ is below $50 \%$, which has been claimed as unsuccessful weight loss by some authors ${ }^{6,7}$. Now that the RYGB has proven to be a successful and safe treatment for morbid obesity, further research should focus on the questions why not all patients lose a substantial amount of weight and why some patients relapse.

Some factors influencing weight loss are age, race, the presence of diabetes mellitus and gastrointestinal hormone levels ${ }^{8-10}$. In addition to these "medical" factors, cognitive and behavioral factors might influence the results of bariatric surgery. Cognitive mechanisms related to the behavior of obese patients might sabotage successful weight loss and its maintenance ${ }^{11}$. Also, co-morbid psychopathology, like depression and (binge) eating disorders, could influence weight loss ${ }^{10,11}$.

Obese patients frequently report negative perceptions towards their own body, a negative body image, and related cognitive-behavioral consequences ${ }^{12-16}$, such as severe avoidance of social situations and low self-esteem, leading to a low QoL 12-14. Experts argue that psychological problems, a lack of physical activity and non-compliance to life-style change have a negative impact on weight loss after RYGB ${ }^{1,17}$. Though these "moderators" have been studied before, systematic reviews and meta-analyses are scarce. Moreover, previous reviews generally include different types of bariatric surgery, while it cannot be ruled out that weight loss is differently influenced by the type of surgery ${ }^{5}$. The aim of this study is to review and analyze the cognitive, behavioral and psychopathology related moderators of weight loss after primary RYGB.

\section{MATERIALS AND METHODS}

\section{Search strategy}

The search strategy was developed with an information specialist. The search was carried out using the following electronic databases: Pubmed, Embase, Cochrane and Psycinfo. Searches were performed until $31^{\text {th }}$ of January 2016. The following terms were used for the search: gastric bypass, bariatric surgery, compliance, physical activity, psychopathology, depressive disorder, eating disorder, binge eating disorder, body image, quality of life and outcome. Reference lists of systematic reviews were hand searched for additional publications. Subsequently titles and abstract were screened for eligibility. Case control studies, cohort studies, cross-sectional and randomized controlled trials were included. If it was unclear if the article was suitable 
for inclusion in the review, the whole paper was obtained and assessed. The search was performed by one reviewer (VM) and inclusion was double checked by a second reviewer (EA).

\section{Eligibility criteria}

Studies were only included if the study population consisted of adult patients undergoing RYGB for morbid obesity and when weight loss was the outcome. When studies described results of multiple types of bariatric surgery, the study was only included if results of the RYGB patients were presented separately. Studies were included when one or more of the following moderators was assessed: compliance to follow-up, physical activity, general psychopathology, depressive disorders, binge eating disorder, general eating disorder, quality of life and body image. Only articles published in academic journals in English were included.

\section{Data extraction}

The following data were extracted from the included papers: number of patients, gender, age, study design, follow-up time and weight loss data. Since up to recently there was no guideline for reporting weight loss after bariatric surgery all available weight loss data was selected and or calculated in accordance with current guidelines: height, bodyweight and Body Mass Index (BMI) before and after RYGB, \%EWL, $\%$ excess BMI loss (\%EBMIL), \% total weight loss (\%TWL) ${ }^{18}$. If insufficient data was provided in the article the author was contacted at least three times for additional data. In addition, all data regarding the moderator of interest was acquired: methods of assessment of moderator and timing of assessment.

In current practice there is no guideline on how to evaluate behavioral and psychological factors in bariatric patients ${ }^{18,19}$. Therefore, all papers assessing one or more of the moderators were included, independently from the methods of assessment. Thus, moderators could either be evaluated via direct measurement of physical activity or compliance to follow-up, via validated or non-validated questionnaires or via clinical interviews.

\section{RESULTS}

\section{Search results}

After removing duplicates, 3825 articles were identified, with hand searches of the (systematic) reviews 9 articles were added (Figure 1). Titles of 3834 articles were reviewed, 3477 were excluded. Abstracts of 357 records were reviewed, and 108 fulltext articles were read. A total of 61 articles were included in this review, 20 studies reported the effect of multiple moderators (Table 1).

For the following moderators there was sufficient data to be included in the review: compliance, physical activity, psychological evaluation, depressive symptoms and 
self-reported binge eating. Since studies on body image $(n=2)$ and $Q \circ L(n=2)$ were scarce, these moderators were not included in the review.

Figure 1: Flowchart of literature search

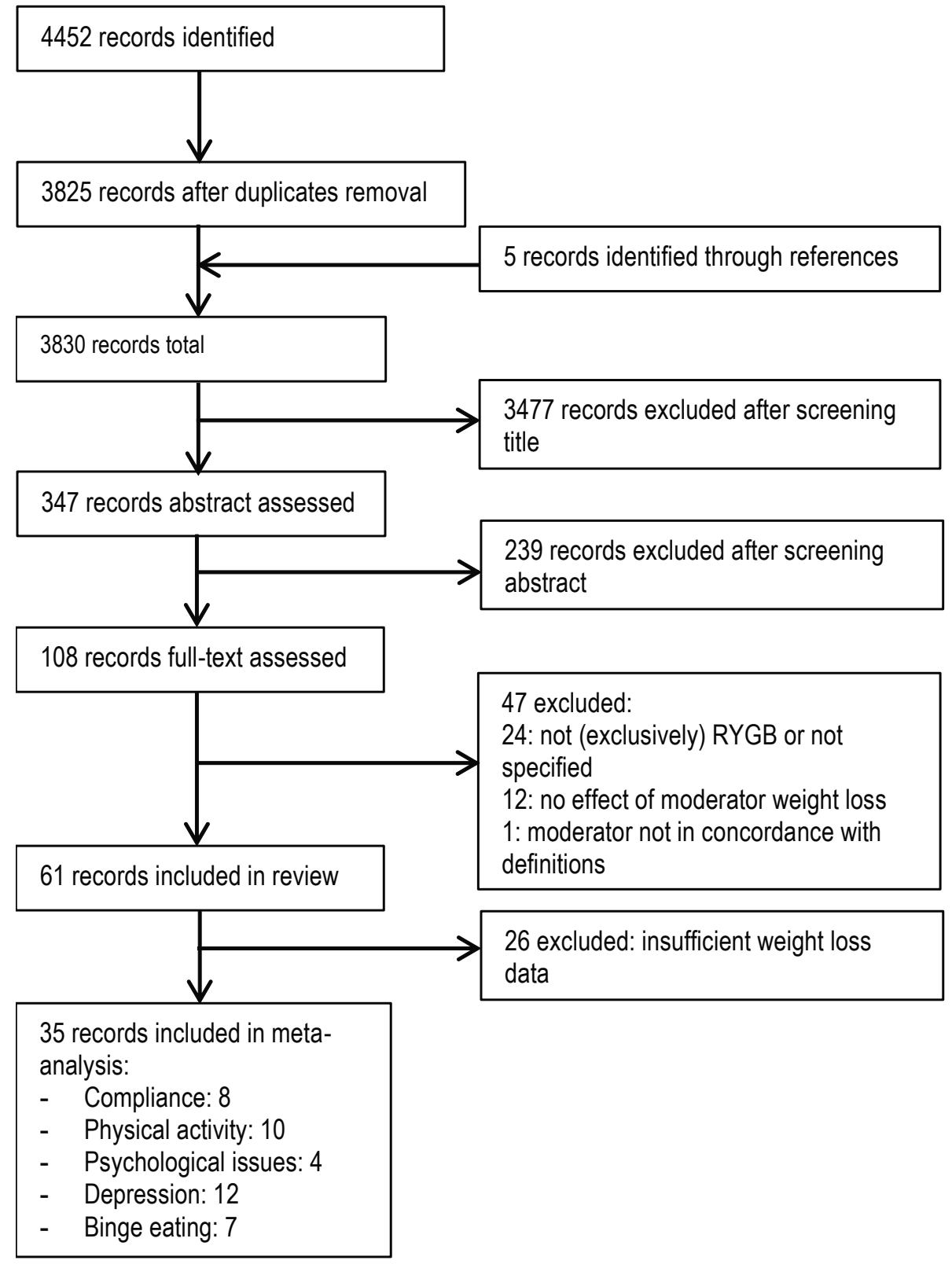




\begin{tabular}{|c|c|c|c|c|c|c|c|c|c|c|c|c|c|c|c|c|}
\hline & 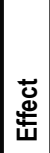 & 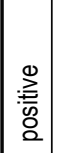 & 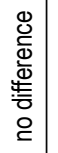 & 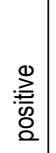 & $\begin{array}{l}\stackrel{0}{\geq} \\
\stackrel{ \pm}{0} \\
\stackrel{0}{a}\end{array}$ & 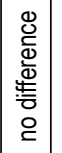 & 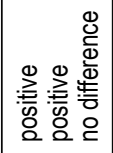 & 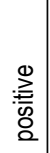 & 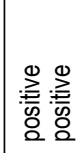 & 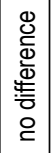 & 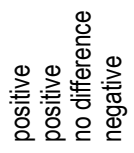 & 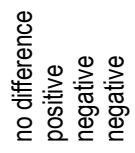 & 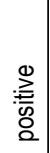 & 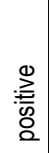 & 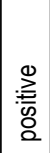 & : \\
\hline & 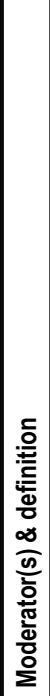 & 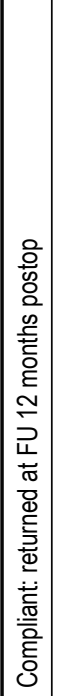 & 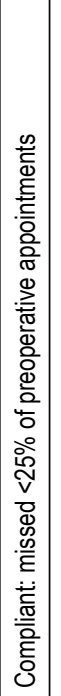 & 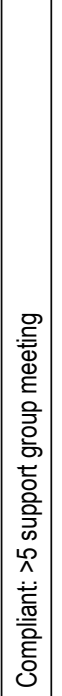 & 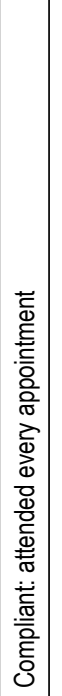 & 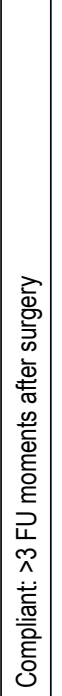 & 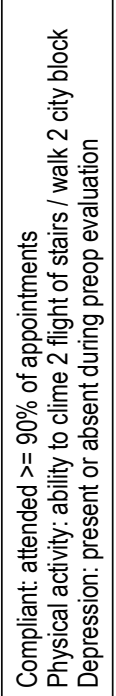 & 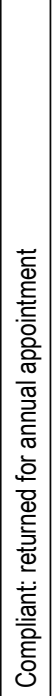 & 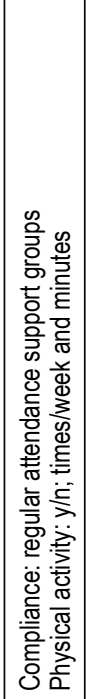 & 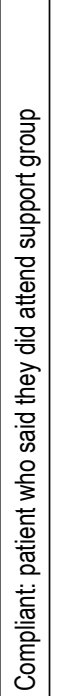 & 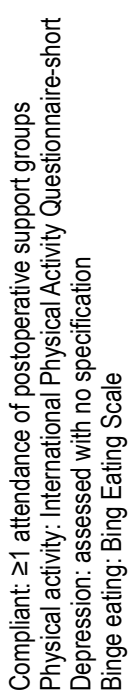 & 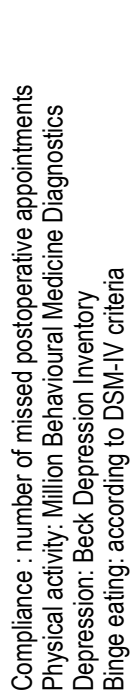 & 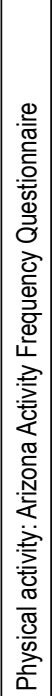 & 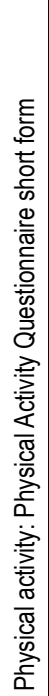 & 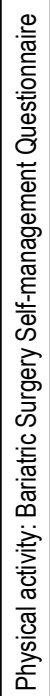 & 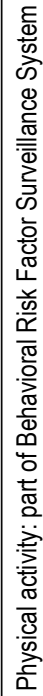 \\
\hline & $\sum_{\boldsymbol{D}}$ & 윰 & $\stackrel{\mathbb{x}}{=}$ & 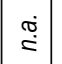 & 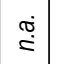 & $\hat{F}$ & $\begin{array}{l}\circ \\
\text { ơ }\end{array}$ & $\stackrel{\circ}{\circ} \underset{+}{\infty}$ & లై & 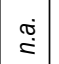 & ֶָ & $\begin{array}{l}\stackrel{\rho}{g} \\
\stackrel{g}{q}\end{array}$ & $\stackrel{\oplus}{=}$ & $\begin{array}{l}\infty \\
\stackrel{g}{q} \\
\text { g. }\end{array}$ & 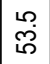 & $\begin{array}{l}\infty \\
\text { o } \\
\text { qu }\end{array}$ \\
\hline & $z$ & 8 & $\stackrel{શ}{\triangleq}$ & $\infty$ & $\mathscr{\infty}$ & $\stackrel{\circ}{=}$ & $\stackrel{O}{\sim}$ & 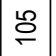 & $\underset{\sim}{\stackrel{N}{N}}$ & ণ & 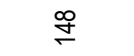 & 읃 & ఠ઼ & 음 & 유 & 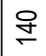 \\
\hline 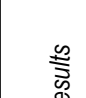 & 군 & 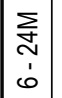 & $\underset{工}{\leftrightarrows}$ & $\underset{\Sigma}{\Sigma}$ & $\begin{array}{l}\sum_{00} \\
\stackrel{e}{0} \\
\cong\end{array}$ & હ & $\underset{\text { N }}{(}$ & $\underset{N}{(}$ & $\begin{array}{l}> \\
\infty \\
\infty \\
i \infty\end{array}$ & $\stackrel{\text { ஜே }}{\check{\Sigma}}$ & 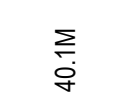 & $\underset{N}{\stackrel{N}{N}}$ & $\begin{array}{l}\Sigma \\
10 \\
\text { × } \\
\stackrel{x}{E}\end{array}$ & $\underset{\simeq}{\stackrel{\sim}{\simeq}}$ & \begin{tabular}{l}
$\sum$ \\
10 \\
\multirow{1}{*}{}
\end{tabular} & $\sum_{\substack{\Sigma \\
\sim}}$ \\
\hline 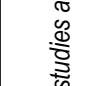 & $\begin{array}{l}\overline{\bar{\sigma}} \\
\overline{\mathbf{g}} \\
\bar{\Delta}\end{array}$ & $\begin{array}{l}\dot{d} \\
\stackrel{0}{0} \\
\frac{0}{0}\end{array}$ & $\begin{array}{l}\dot{0} \\
\stackrel{0}{2}\end{array}$ & 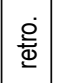 & 迹 & 兽 & ஜ̋ & 总 & 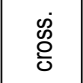 & $\begin{array}{l}\mathscr{d} \\
\stackrel{0}{0} \\
\stackrel{0}{0}\end{array}$ & 일 & 过 & $\begin{array}{l}\stackrel{\oplus}{0} \\
\stackrel{0}{0}\end{array}$ & ஜூ̀ & 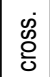 & $\begin{array}{l}\mathscr{0} \\
\stackrel{0}{0}\end{array}$ \\
\hline 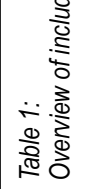 & $\begin{array}{l}\dot{\bar{\lambda}} \\
\dot{2} \\
\stackrel{0}{5} \\
\dot{z}\end{array}$ & 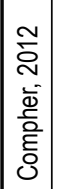 & 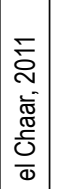 & $\mid$\begin{tabular}{l|}
$\infty$ \\
0 \\
0 \\
0 \\
$\check{c}$ \\
0 \\
$\infty$
\end{tabular} & 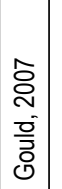 & 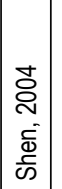 & 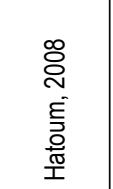 & 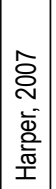 & 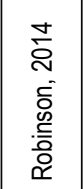 & 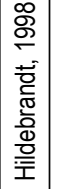 & 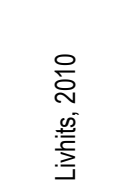 & 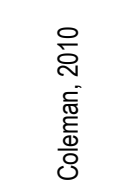 & 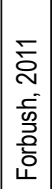 & 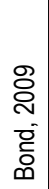 & 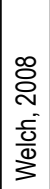 & 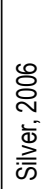 \\
\hline
\end{tabular}




\begin{tabular}{|c|c|c|c|c|c|c|c|c|c|c|c|c|c|c|}
\hline & & & 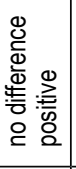 & & 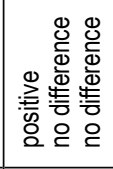 & 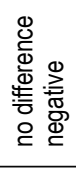 & 产 & 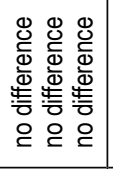 & 产 & 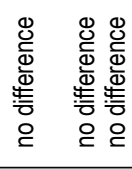 & 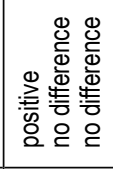 & 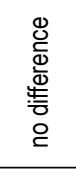 & 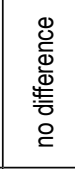 & \\
\hline 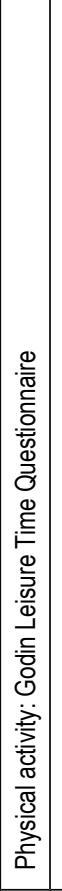 & . & 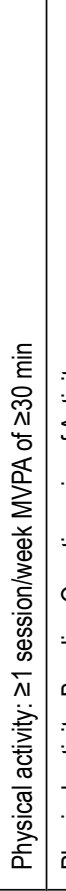 & 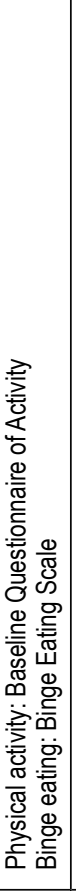 & & 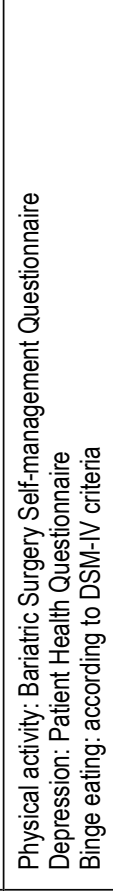 & 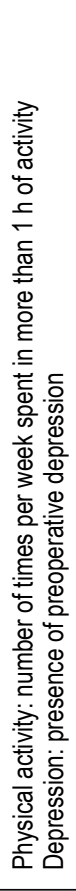 & 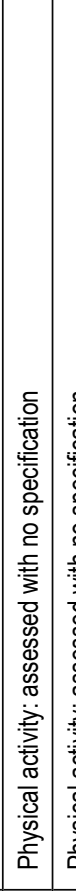 & 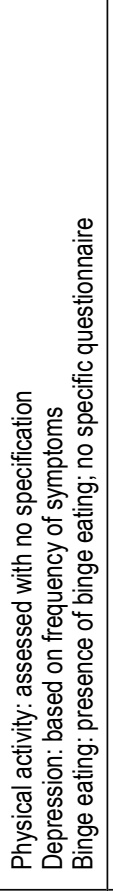 & 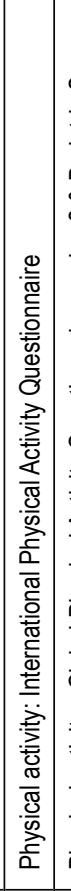 & 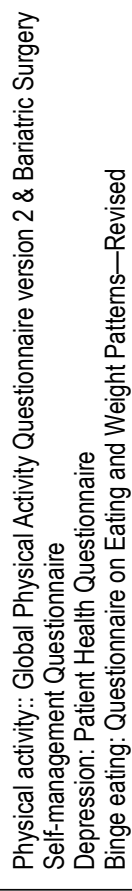 & 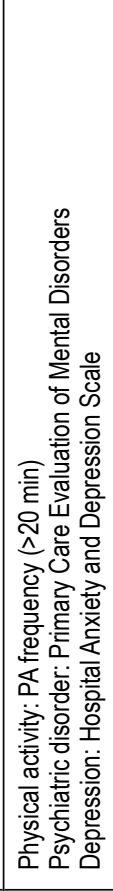 & 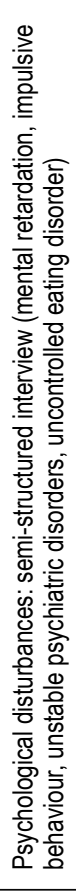 & 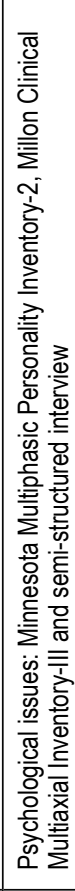 & 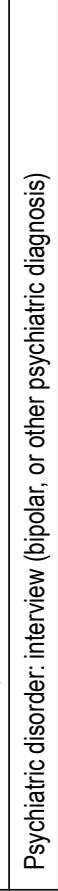 \\
\hline 足 & $\begin{array}{l}\stackrel{\circ}{\circ} \\
\dot{q}\end{array}$ & 茫 & ๙్రి & 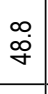 & $\begin{array}{l}\infty \\
\stackrel{\sigma}{\sigma}\end{array}$ & స్త & $\mid \begin{array}{c}\infty \\
\dot{q} \\
\dot{q}\end{array}$ & 怘 & 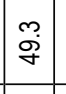 & $\underset{\sim}{\infty}$ & & 草 & 奇 & 80 \\
\hline$\overline{\underline{g}}$ & \pm & 足 & q & g & & 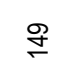 & 总 & 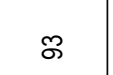 & & & $\ddot{\circ}$ & $\delta$ & $¥$ & \\
\hline 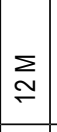 & $\vec{\infty}$ & 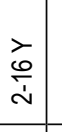 & ह & $>$ & 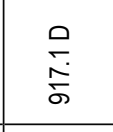 & 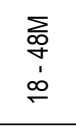 & \begin{tabular}{|l|l|}
5 \\
I
\end{tabular} & $\begin{array}{c}3 \\
\substack{0 \\
0 \\
0} \\
\end{array}$ & & $\begin{array}{l}< \\
\infty \\
\infty \\
\infty\end{array}$ & 悥 & 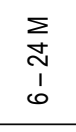 & $\sum_{0}$ & \\
\hline 㝘 & 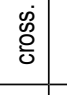 & 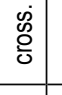 & $\frac{\dot{m}}{8}$ & 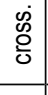 & $\begin{array}{l}\stackrel{\mathscr{b}}{0} \\
\frac{0}{\sigma}\end{array}$ & $\frac{\dot{\theta}}{\frac{0}{2}}$ & $\frac{\dot{\rho}}{\underline{\underline{e}}}$ & $\stackrel{\mathscr{b}}{8}$ & & 㞻 & 产 & $\frac{\dot{\rho}}{\underline{\underline{e}}}$ & $\frac{\mathscr{O}}{2}$ & \begin{tabular}{|l|} 
\\
\end{tabular} \\
\hline 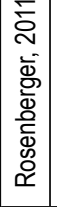 & 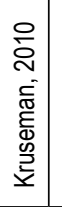 & 胥 & & & 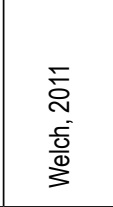 & 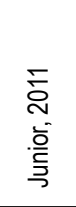 & 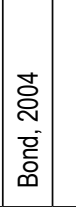 & 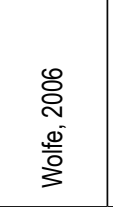 & & 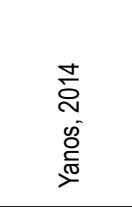 & 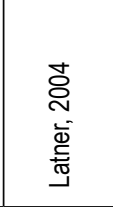 & 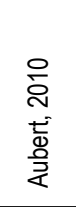 & 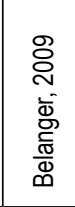 & 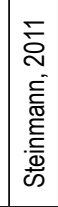 \\
\hline
\end{tabular}




\begin{tabular}{|c|c|c|c|c|c|c|c|c|c|c|c|c|c|c|c|c|c|c|}
\hline $\begin{array}{l}\stackrel{0}{\stackrel{D}{0}} \\
\text { 总 }\end{array}$ & 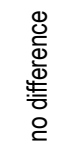 & 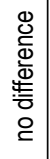 & 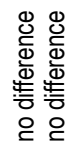 & 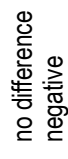 & 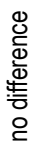 & 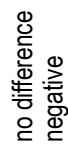 & 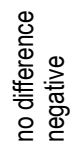 & 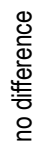 & 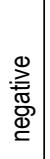 & 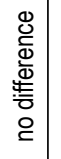 & 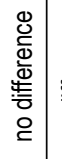 & 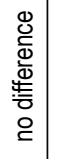 & 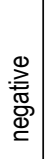 & 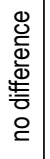 & 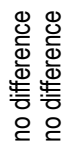 & 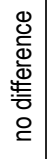 & 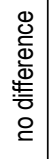 & 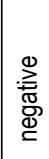 \\
\hline 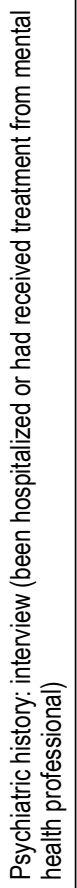 & 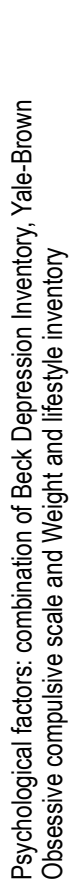 & 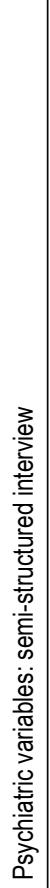 & 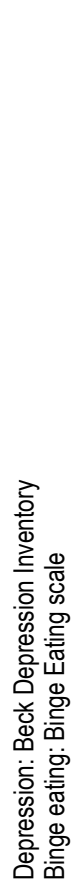 & 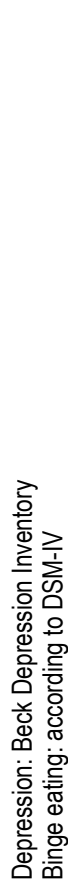 & 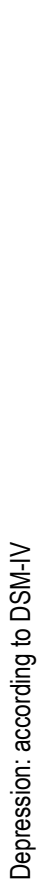 & 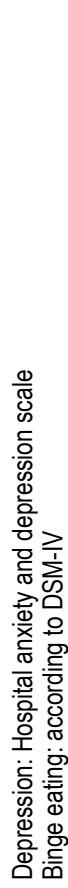 & 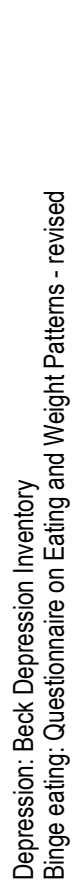 & 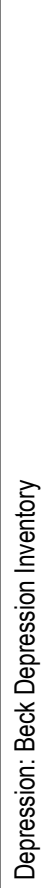 & 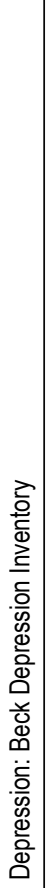 & 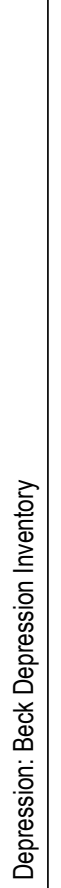 & 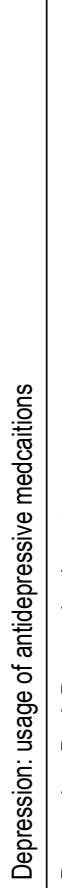 & 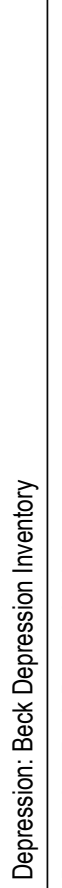 & 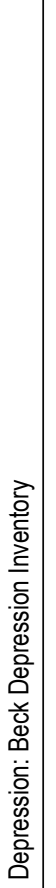 & 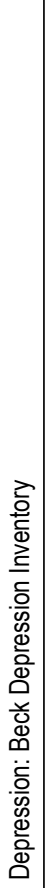 & 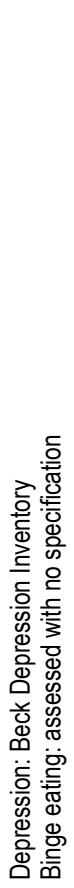 & 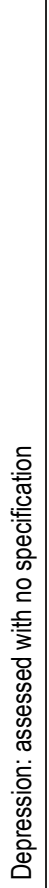 & 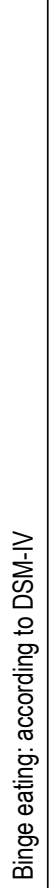 & 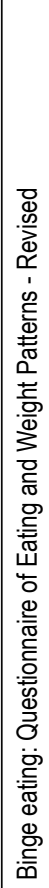 \\
\hline 유ํ & 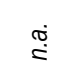 & $\stackrel{\oplus}{=}$ & 용 & 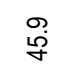 & \begin{tabular}{c}
$\stackrel{N}{F}$ \\
\multirow{F}{*}{}
\end{tabular} & ¿্og & $\frac{10}{50}$ & 范 & ્ָતి & $\underset{5}{5}$ & $\stackrel{\oplus}{\check{C}}$ & $\stackrel{\mathbb{S}}{=}$ & $\stackrel{\oplus}{=}$ & $\stackrel{\oplus}{\stackrel{\check{C}}{=}}$ & ஸ̃ & $\begin{array}{l}\stackrel{\circ}{*} \\
\text { 广 }\end{array}$ & $\begin{array}{l}\infty \\
0 \\
\dot{q}\end{array}$ & 官 \\
\hline$\infty$ & $\stackrel{\swarrow}{\leftarrow}$ & $\stackrel{10}{\frac{10}{d}}$ & in & $\stackrel{\bullet}{\sim}$ & $\stackrel{8}{\circ}$ & \& & ๗ & ¿ి & F & 䓫 & $\stackrel{œ}{\risingdotseq}$ & 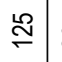 & ㄱ. & $\stackrel{\text { 吊 }}{\circ}$ & $\stackrel{d}{\mathbb{2}}$ & f & R & 产 \\
\hline 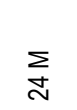 & $\begin{array}{l}\sum_{0}^{\infty} \\
\stackrel{0}{1} \\
0\end{array}$ & $\underset{\sim}{\stackrel{\Sigma}{\sim}}$ & 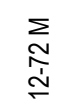 & $\begin{array}{l}\sum \\
\text { c } \\
1 \\
1 \\
1\end{array}$ & $\sum_{0}$ & $\underset{\sim}{\underset{N}{N}}$ & $\underset{\sim}{\stackrel{\Sigma}{\sim}}$ & $\underset{\text { శె }}{3}$ & $\underset{\sim}{\stackrel{\Sigma}{\simeq}}$ & $\underset{\simeq}{\stackrel{2}{\simeq}}$ & $\underset{\sim}{\stackrel{\Xi}{\sim}}$ & $\begin{array}{l}\sum_{\infty} \\
\stackrel{\sim}{\sim}\end{array}$ & 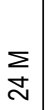 & $\begin{array}{l}\sum \\
0 \\
\infty \\
\sim\end{array}$ & $\underset{\sim}{\stackrel{(}{N}}$ & $\begin{array}{l}\underset{\Xi}{\simeq} \\
0\end{array}$ & $\begin{array}{l}\sum \\
\infty \\
\tilde{N} \\
\stackrel{N}{N}\end{array}$ & $\underset{\sim}{\sim}$ \\
\hline 这 & 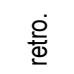 & $\frac{\dot{e}}{\stackrel{0}{0}}$ & ஜூ & 曽 & 递 & $\begin{array}{l}\text { o. } \\
\stackrel{0}{0}\end{array}$ & ஜே & 兽 & 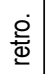 & 递 & 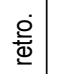 & 京 & $\begin{array}{l}\dot{0} \\
\stackrel{0}{0} \\
\stackrel{0}{0}\end{array}$ & $\begin{array}{l}\dot{d} \\
\stackrel{0}{0} \\
\stackrel{0}{0}\end{array}$ & $\frac{\dot{e}}{0}$ & 일 & 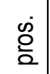 & \begin{tabular}{|l}
$\mathscr{O}$ \\
$\stackrel{0}{0}$
\end{tabular} \\
\hline 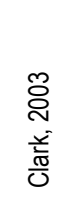 & $\begin{array}{l}\forall \\
\dot{D} \\
\bar{\delta} \\
\vdots\end{array}$ & 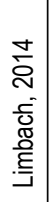 & 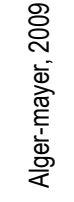 & 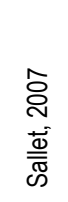 & 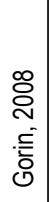 & 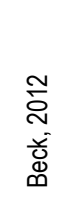 & 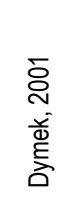 & 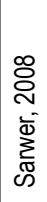 & 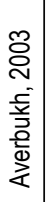 & $\begin{array}{l}8 \\
0 \\
i \\
\sum^{\infty}\end{array}$ & 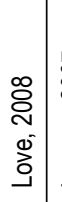 & 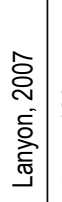 & 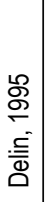 & 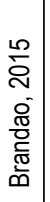 & 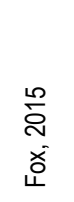 & 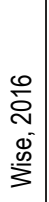 & 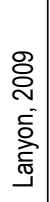 & 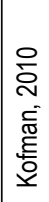 \\
\hline
\end{tabular}




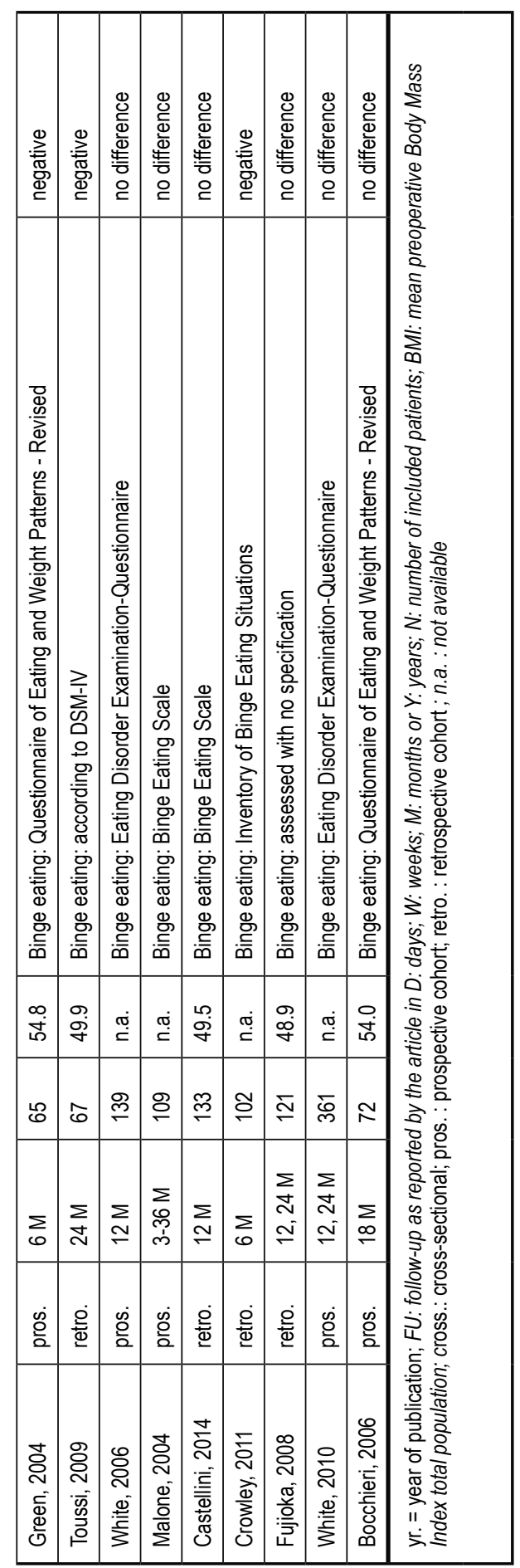




\section{Compliance}

Eleven studies evaluated the effect of compliance to follow-up on weight loss ${ }^{20-30}$. Compliance was calculated using attendance in postoperative appointments ${ }^{20,23-27,30}$, postoperative support group meetings ${ }^{22,28,29}$ or preoperative appointments ${ }^{21}$ (Table 1). Study population ranged from 60-274 patients, mean preoperative BMI ranged from $44.7 \mathrm{~kg} / \mathrm{m}^{2}$ to $54.5 \mathrm{~kg} / \mathrm{m}^{2}$ and mean follow-up ranged from 1 to 5.8 years. In seven studies compliance was associated with significantly more weight loss and/or successful weight loss 20,22,23,25-27,29.

Data of eight studies with a combined total of 13 follow-up moments and 1,447 patients were included in the meta-analysis (Table 2) ${ }^{20-27}$. Mean pre-operative BMI of the compliant group was $51.8 \mathrm{~kg} / \mathrm{m}^{2}( \pm 2.9)$ versus $48.8 \mathrm{~kg} / \mathrm{m}^{2}( \pm 2.5)$ in the non-compliant group. Follow-up ranged from 6 months to 5.8 years. Compliant patients had a significantly higher EWL than non-compliant patients; effect size 7.6\%, $p<0.001$ (Figure 2). Subsequently the effect of compliance was assessed for different follow-up moments. Three studies reported on weight loss 6 months after surgery, a total of 253 patients were included; mean EWL was significantly higher in the compliant group when compared to the non-compliant group, respectively $52.6 \%$ and $48.5 \%(p=0.006)^{20,22,24}$. Six studies including 668 patients reported on 12 month weight loss; compliant patients had an EWL of $64.8 \%$ versus $58.5 \%$ for non-compliant patients $\left(p=0.038\right.$ ) ${ }^{20-23,25,26}$. Four studies with a total of 448 patients reported weight loss more than 24 months after surgery ${ }^{20,23,27}$. Weight loss was significantly higher in compliant patients compared to the non-complaint patients, $70.3 \%$ versus $57.3 \%(p<0.001)$.

Table 2:

Meta-analysis on effect of compliance on weight loss in RYGB patients

\begin{tabular}{l|l|l|l|l|l|l|l|l|l}
\hline \multirow{2}{*}{ Author, yr. } & \multirow{2}{*}{ FU } & \multicolumn{3}{l}{ Compliant patients } & \multicolumn{2}{l}{ Non-compliant patients } & \multirow{2}{*}{ ES } \\
\cline { 3 - 10 } & & BMI & EWL & N & BMI & EWL & N & & \\
\hline Compher, 2012 & $6 \mathrm{M}$ & 54.50 & 46.40 & 32 & 49.20 & 45.30 & 28 & 6.66 & $5.01,8.31$ \\
\hline Compher, 2012 & $12 \mathrm{M}$ & 54.50 & 68.50 & 32 & 49.20 & 55.50 & 28 & 16.92 & $15.27,18.57$ \\
\hline Compher, 2012 & $24 \mathrm{M}$ & 54.50 & 70.70 & 32 & 49.20 & 68.50 & 28 & 12.84 & $11.19,14.49$ \\
\hline El Chaar, 2011 & $12 \mathrm{M}$ & 45.30 & 61.70 & 138 & 41.20 & 60.80 & 39 & 0.90 & $-0.57,2.37$ \\
\hline Song, 2008 & $6 \mathrm{M}$ & 52.78 & 45.40 & 28 & 49.66 & 41.30 & 50 & 4.10 & $2.49,5.71$ \\
\hline Song, 2008 & $12 \mathrm{M}$ & 52.78 & 55.50 & 28 & 49.66 & 47.10 & 50 & 8.40 & $6.79,10.01$ \\
\hline Gould, 2007 & $12 \mathrm{M}$ & 51.00 & 70.00 & 34 & 51.00 & 65.00 & 41 & 5.00 & $3.36,6.64$ \\
\hline Gould, 2007 & $36 \mathrm{M}$ & 51.00 & 74.00 & 34 & 51.00 & 61.00 & 41 & 13.00 & $11.36,14.64$ \\
\hline Gould, 2007 & $36 \mathrm{M}$ & 51.00 & 74.00 & 34 & 50.00 & 64.00 & 51 & 10.00 & $8.37,11.63$ \\
\hline Shen, 2004 & $6 \mathrm{M}$ & 48.70 & 67.60 & 62 & 47.00 & 66.10 & 53 & 1.50 & $-0.15,3.15$ \\
\hline Harper, 2007 & $12 \mathrm{M}$ & 48.00 & 76.00 & 42 & 49.00 & 65.00 & 57 & 11.00 & $9.36,12.64$ \\
\hline Hatoum, 2008 & $12 \mathrm{M}$ & 52.31 & 63.56 & 183 & 51.06 & 67.71 & 74 & -4.15 & $-5.70,-2.60$ \\
\hline Robinson, 2014 & $5.8 \mathrm{Y}$ & 47.61 & 67.78 & 104 & 47.43 & 55.51 & 124 & 12.17 & $10.52,13.82$ \\
\hline Overall effect & & 51.08 & 64.70 & 783 & 48.82 & 58.68 & 664 & 7.56 & $4.29,10.83$ \\
\hline
\end{tabular}

yr. = year of publication; FU: follow-up in months $(\mathrm{M})$ or years $(\mathrm{Y})$; BMI: Body Mass Index; EWL: percentage excess weight loss; $\mathrm{N}=$ number of patients; $\mathrm{ES}$ : effect size; Cl: confidence interval 
Figure 2: Results of meta-analysis on effect of compliance on weight loss in RYGB patients

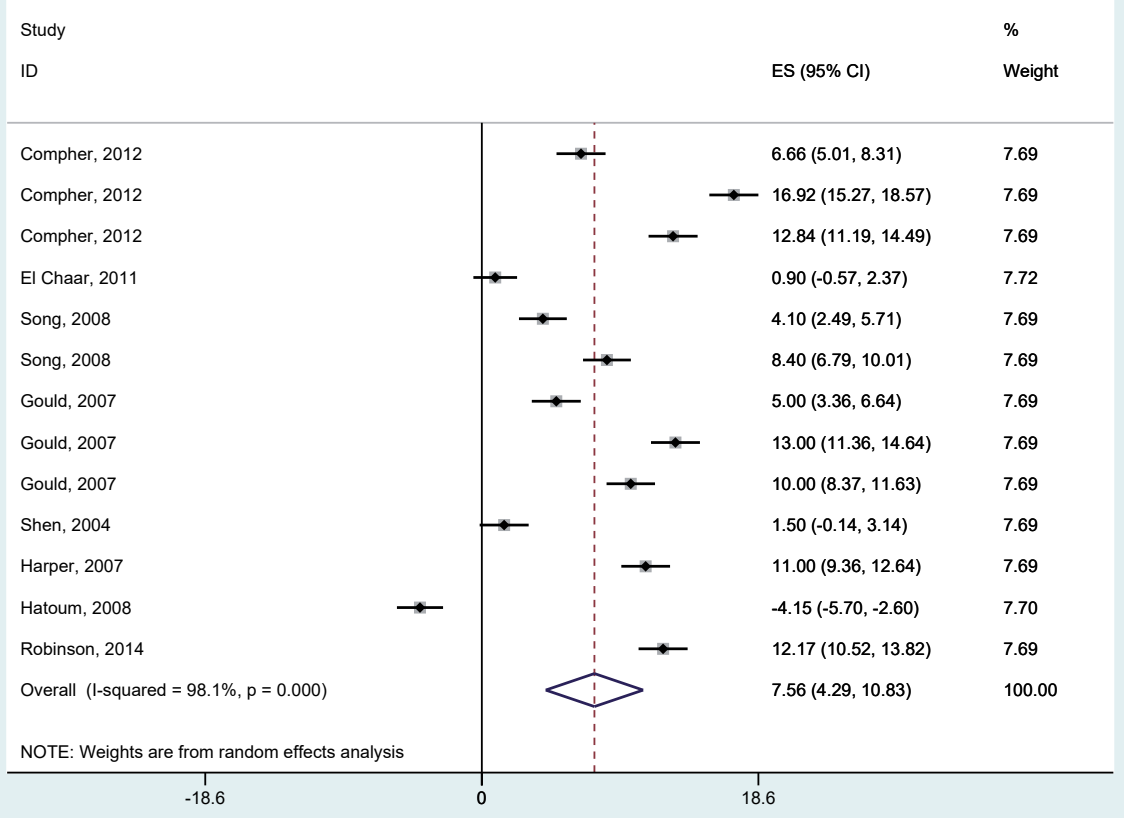

\section{Physical activity}

There were 21 studies evaluating the association between physical activity (PA) and weight loss $25,27,29-47$. Three studies measured PA ${ }^{36,39,45}$, in twelve studies PA was assessed with questionnaires ${ }^{27,29-35,38,40,44}$ and in six studies patients were asked about their PA ${ }^{25,37,41-43,46}$ (Table 1). In one study PA was assessed prior to RYGB ${ }^{25}$, in one study it was assessed both before and after surgery ${ }^{32}$; all other studies assessed PA after surgery. Mean BMI prior to surgery ranged from $46.0-54.1 \mathrm{~kg} / \mathrm{m}^{2}$, number of patients ranged from 40-303, maximum follow-up was 16 years. In fifteen studies PA and intensity of PA were significant predictors of weight loss and limited PA was associated with less weight loss 25,29-31,33-37,39,40,42,45-47.

There were sufficient data in ten studies with 12 follow-up moments; these data were pooled for meta-analysis (Table 3) $25,27,31,32,34,37,39,42,44,47$. A total number of 3,558 patients were included. Active patients had a mean preoperative BMI of $49.6 \mathrm{~kg} / \mathrm{m}^{2}( \pm 1.3)$; this was $50.3 \mathrm{~kg} / \mathrm{m}^{2}( \pm 2.3)$ in inactive patients. Active patients had a significantly higher EWL, effect size $6.8 \%(p<0.001$, Figure 3$)$.

Subsequently the effect of PA was assessed for different follow-up moments. Three studies reported on weight loss 12 months post-surgery, data of 220 patients were pooled; weight loss was higher in active patients $(69.4 \%$ in versus $65.6 \%, p<0.001$ ) $25,32,47$. Follow-up was 24 months or longer in seven studies, active patients had EWL 
of $76.0 \%$ versus $67.2 \%$ for the inactive patients $(p<0.001) 27,31,34,37,39,42,44$.

\begin{tabular}{|c|c|c|c|c|c|c|c|c|c|}
\hline \multirow{2}{*}{ Author, yr. } & \multirow{2}{*}{ FU } & \multicolumn{3}{|c|}{ Active patients } & \multicolumn{3}{|c|}{ Non-active patients } & \multirow{2}{*}{ ES } & \multirow{2}{*}{$95 \% \mathrm{Cl}$} \\
\hline & & BMI & EWL & $\mathrm{N}$ & BMI & EWL & $\mathrm{N}$ & & \\
\hline Hatoum, 2008 & $12 \mathrm{M}$ & 51.32 & 69.34 & 206 & 55.31 & 65.18 & 40 & 4.16 & $2.79,0.53$ \\
\hline Josbeno, 2010 & $2-5 Y$ & 49.25 & 71.29 & 26 & 50.64 & 55.62 & 14 & 15.67 & $14.07,17.27$ \\
\hline Forbush, 2011 & $3-5 Y$ & 47.40 & 84.93 & 99 & 47.75 & 77.75 & 161 & 7.06 & $5.44,8.68$ \\
\hline Bond, 2009 & $12 \mathrm{M}$ & 49.80 & 75.36 & 68 & 50.50 & 66.54 & 39 & 1.70 & $0.09,3.31$ \\
\hline Evans, 2007 & $3 \mathrm{M}$ & 49.00 & 41.21 & 90 & 49.70 & 39.57 & 83 & 1.64 & $-0.01,3.29$ \\
\hline Evans, 2007 & $6 \mathrm{M}$ & 49.10 & 59.95 & 64 & 49.60 & 53.43 & 88 & 5.50 & $3.85,7.15$ \\
\hline Evans, 2007 & $12 \mathrm{M}$ & 50.20 & 71.31 & 120 & 49.30 & 65.76 & 64 & 5.70 & $4.06,7.34$ \\
\hline Silver, 2006 & $24.2 \mathrm{M}$ & 49.21 & 86.00 & 116 & 46.86 & 79.76 & 24 & 4.24 & $2.86,5.63$ \\
\hline Bond, 2004 & $24 \mathrm{M}$ & 49.80 & 68.20 & 1479 & 49.60 & 63.90 & 106 & 4.30 & $3.22,5.38$ \\
\hline Herman, 2014 & $2-16 Y$ & 51.20 & 73.60 & 146 & 51.60 & 66.80 & 157 & 6.80 & $5.15,8.45$ \\
\hline Yanos, 2014 & $8.6 \mathrm{Y}$ & 51.93 & 85.18 & 43 & 54.25 & 75.51 & 54 & 9.67 & $8.03,11.31$ \\
\hline Robinson, 2014 & $5.8 Y$ & 47.50 & 69.56 & 217 & 48.88 & 54.36 & 54 & 15.20 & $13.77,16.64$ \\
\hline Overall effect & & 49.64 & 71.33 & 2674 & 50.33 & 63.68 & 884 & 6.80 & $4.23,9.37$ \\
\hline
\end{tabular}

yr. = year of publication; FU: follow-up in months (M) or years (Y); BMI: Body Mass Index; EWL: percentage excess weight loss; $N=$ number of patients; ES: effect size; Cl: confidence interval

Figure 3: Results of meta-analysis on effect of physically activity on weight loss in RYGB patients.

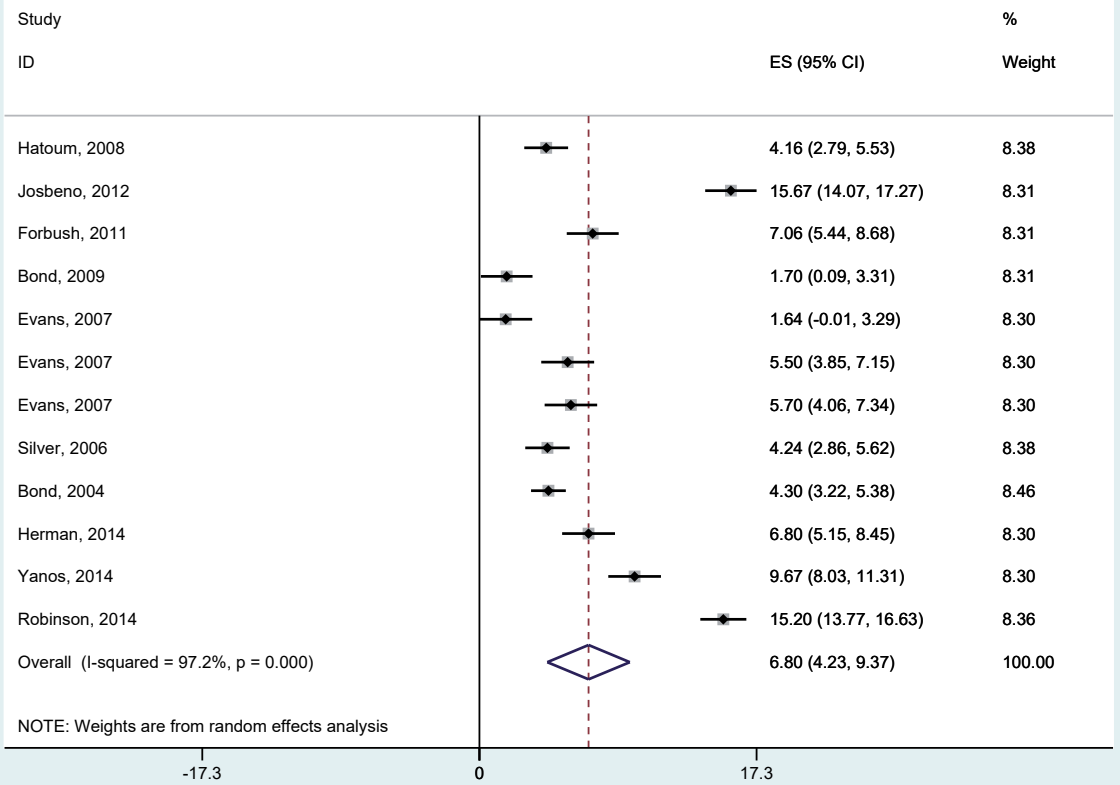




\section{Psychological evaluation}

There were seven studies reporting on preoperative psychological evaluation and weight loss ${ }^{46,48-53}$. Preoperative psychological evaluation was conducted by semi-structured interviews ${ }^{48,50,51,53}$ or an interview in combination with validated questionnaires ${ }^{46,49,52}$. The definition of psychologic and/or psychiatric disturbances ranged from psychological disturbances to psychiatric disorders (Table 1). Included number of patients ranged from 65-485, follow-up was 6-24 months. In six studies weight loss was not influenced by the presence of psychological/psychiatric problems ${ }^{46,48-50,52,53}$. In one study patients who had participated in mental health treatment before bariatric surgery had higher weight loss ${ }^{51}$. Since definitions of psychologic evaluation varied greatly no meta-analysis was conducted.

\section{Depressive symptoms}

A total of 24 studies analyzed the effect of self-reported depressive symptoms on weight loss $25,29,30,34,36,40,41,43,44,54-68$. Twelve studies used a validated questionnaire to measure symptoms of depression: the Beck Depression Inventory in eight ${ }^{54,55,58-61,63-}$ ${ }^{67}$, the Hospital Anxiety and Depression Scale in two ${ }^{36,57}$ and the Patient Health Questionnaire in two studies ${ }^{40,44}$. Other studies defined symptoms of depression by DSMIV ${ }^{30,56}$, preoperative questions about symptoms ${ }^{25,34}$, frequency of symptoms 43 , or antidepressant use ${ }^{62}$ (Table 1). In three studies it was unclear how depression was determined 29,41,68. Number of patients ranged from 47-494 and maximum follow-up was 8.9 years. Depressive symptoms were measured preoperatively in 15 studies, postoperatively in 6 studies and both before and after surgery in 2 studies. In three studies the weight loss was negatively influenced by the preoperative symptoms of depression ${ }^{30,41,60}$. In two studies postoperative symptoms of depression negatively correlated with \%EWL ${ }^{64,67}$. In all other studies neither pre- nor postoperative depressive symptoms were associated with weight loss.

Data of twelve studies with 24 follow-up moments could be pooled for meta-analysis (Table 4) $25,34,36,44,54-57,62,65,66,68$. This included 3,701 patients with a mean pre-surgical BMI $48.4 \mathrm{~kg} / \mathrm{m}^{2}( \pm 2.8)$ in the group with depressive symptoms and $48.6 \mathrm{~kg} / \mathrm{m}^{2}( \pm 2.8)$ in the group without depressive symptoms (Figure 4). Mean weight loss was not significantly different between these groups, respectively $66.9 \%$ in the patients with symptoms and $65.4 \%$ in the patients without symptoms $(p=0.246)$.

At 12 months follow-up patients with depressive symptoms had higher weight loss, effect size $1.7 \%(p=0.036)$. This analysis included 595 patients of 4 studies with a mean baseline BMl of $48.6 \mathrm{~kg} / \mathrm{m}^{2}$ in the depressive symptoms group and $49.0 \mathrm{~kg} / \mathrm{m}^{2}$ in the non-depressive symptoms group ${ }^{25,54,55,62}$. Four studies reported on 6 month follow-up, \%EWL was not significant different $(p=0.336){ }^{54-56,62}$. Two studies reported on 24 and 36 months follow-up, weight loss was the same in the depressive symptoms and non-depressive symptoms group $(p=0.276 \text { and } p=0.477)^{54,55}$. 


\begin{tabular}{|c|c|c|c|c|c|c|c|c|c|}
\hline \multirow{2}{*}{ Author, yr. } & \multirow{2}{*}{ FU } & \multicolumn{3}{|c|}{ Depressive symptoms } & \multicolumn{3}{|c|}{ No depressive symptoms } & \multirow{2}{*}{ ES } & \multirow{2}{*}{$95 \% \mathrm{Cl}$} \\
\hline & & $\mathrm{BMI}$ & EWL & $\mathrm{N}$ & BMI & EWL & $\mathrm{N}$ & & \\
\hline Hatoum, 2008 & $12 \mathrm{M}$ & 51.38 & 67.20 & 111 & 52.52 & 63.99 & 140 & 3.21 & $1.57,4.85$ \\
\hline Silver, 2006 & $24.2 \mathrm{M}$ & 47.43 & 82.82 & 69 & 49.97 & 83.65 & 71 & -0.83 & $-2.48,0.82$ \\
\hline Kruseman, 2010 & $8 y$ & 46.73 & 65.90 & 80 & 45.46 & 71.50 & 48 & -5.60 & $-7.22,-3.98$ \\
\hline Alger-Mayer, 2009 & $3 \mathrm{M}$ & 50.50 & 47.91 & 64 & 51.14 & 47.24 & 93 & 0.67 & $-0.96,2.30$ \\
\hline Alger-Mayer, 2009 & $6 \mathrm{M}$ & 50.50 & 64.02 & 64 & 51.14 & 60.44 & 93 & 3.58 & $1.95,5.21$ \\
\hline Alger-Mayer, 2009 & $12 \mathrm{M}$ & 50.50 & 73.83 & 64 & 51.14 & 70.12 & 93 & 3.71 & $2.08,5.34$ \\
\hline Alger-Mayer, 2009 & $24 \mathrm{M}$ & 50.50 & 71.84 & 41 & 51.14 & 65.83 & 54 & 6.01 & $4.37,7.65$ \\
\hline Alger-Mayer, 2009 & $36 \mathrm{M}$ & 50.50 & 75.43 & 25 & 51.14 & 59.47 & 36 & 15.96 & $14.33,17.59$ \\
\hline Alger-Mayer, 2009 & $48 \mathrm{M}$ & 50.50 & 71.06 & 16 & 51.14 & 56.66 & 23 & 14.40 & $12.77,16.03$ \\
\hline Alger-Mayer, 2009 & $60 \mathrm{M}$ & 50.50 & 67.39 & 9 & 51.14 & 58.12 & 14 & 9.27 & $7.65,10.89$ \\
\hline Alger-Mayer, 2009 & $72 \mathrm{M}$ & 50.50 & 66.11 & 9 & 51.14 & 59.73 & 11 & 6.38 & $4.74,8.02$ \\
\hline Sallet, 2007 & $6 \mathrm{M}$ & 45.03 & 57.19 & 70 & 44.95 & 57.24 & 119 & -0.05 & $-1.66,1.56$ \\
\hline Sallet, 2007 & $12 \mathrm{M}$ & 45.03 & 73.51 & 65 & 44.95 & 70.80 & 117 & 2.71 & $1.10,4.32$ \\
\hline Sallet, 2007 & $24 \mathrm{M}$ & 45.03 & 78.83 & 42 & 44.95 & 78.54 & 73 & 0.29 & $-1.32,1.90$ \\
\hline Sallet, 2007 & $36 \mathrm{M}$ & 45.03 & 66.63 & 8 & 44.95 & 69.33 & 14 & -2.70 & $-4.31,-1.09$ \\
\hline Gorin, 2009 & $6 \mathrm{M}$ & 46.50 & 56.80 & 47 & 47.40 & 58.90 & 57 & -2.10 & $-3.74,-0.46$ \\
\hline Love, 2008 & $6 \mathrm{M}$ & 46.40 & 51.16 & 48 & 48.42 & 49.23 & 68 & 1.93 & $0.30,3.56$ \\
\hline Love, 2008 & $12 \mathrm{M}$ & 46.40 & 74.88 & 48 & 48.42 & 75.43 & 68 & -0.55 & $-2.18,1.08$ \\
\hline Beck, 2012 & $23.2 \mathrm{M}$ & 47.46 & 77.57 & 14 & 45.54 & 78.42 & 29 & -0.85 & $-2.43,0.73$ \\
\hline Yanos, 2014 & $8.6 y$ & 55.39 & 73.41 & 27 & 52.47 & 82.35 & 70 & -8.94 & $-10.48,-7.40$ \\
\hline Fox, 2016 & $12 \mathrm{M}$ & 45.44 & 63.33 & 67 & 44.77 & 64.43 & 30 & -1.10 & $-2.67,0.47$ \\
\hline Wise, 2015 & $6 \mathrm{M}$ & 49.14 & 53.66 & 56 & 48.41 & 52.78 & 591 & 0.88 & $-0.28,2.04$ \\
\hline Wise, 2015 & $12 \mathrm{M}$ & 49.14 & 71.31 & 56 & 48.41 & 68.97 & 591 & 2.34 & $0.89,3.79$ \\
\hline Brandao, 2015 & $28.6 \mathrm{M}$ & 44.79 & 53.96 & 18 & 45.34 & 67.28 & 80 & -13.33 & $-14.99,-11.67$ \\
\hline pooled ES & & 48.35 & 66.91 & 1118 & 48.59 & 65.44 & 2583 & 1.47 & $-1.01,3.95$ \\
\hline
\end{tabular}

yr. = year of publication; FU: follow-up in months $(\mathrm{M})$ or years $(\mathrm{Y})$; BMI: Body Mass Index; EWL: percentage excess weight loss; $\mathrm{N}=$ number of patients; $\mathrm{ES}$ : effect size; $\mathrm{Cl}$ : confidence interval 
Figure 4: Results of meta-analysis effect of depressive symptoms on weight loss in RYGB patients

\begin{tabular}{|c|c|c|c|}
\hline \multicolumn{2}{|l|}{ Study } & \multirow{3}{*}{$\begin{array}{l}\text { ES }(95 \% \mathrm{Cl}) \\
3.21(1.57,4.85)\end{array}$} & \multirow{3}{*}{$\begin{array}{l}\% \\
\text { Weight } \\
4.16\end{array}$} \\
\hline ID & & & \\
\hline Hatoum, 2008 & - & & \\
\hline Silver, 2006 & & $-0.83(-2.48,0.82)$ & 4.16 \\
\hline Kruseman, 2010 & & $-5.60(-7.22,-3.98)$ & 4.17 \\
\hline Alger-Mayer, 2009 & & $0.67(-0.96,2.30)$ & 4.16 \\
\hline Alger-Mayer, 2009 & $\rightarrow$ & $3.58(1.95,5.21)$ & 4.16 \\
\hline Alger-Mayer, 2009 & $1 \rightarrow$ & $3.71(2.08,5.34)$ & 4.16 \\
\hline Alger-Mayer, 2009 & $1 \rightarrow$ & $6.01(4.37,7.65)$ & 4.16 \\
\hline Alger-Mayer, 2009 & $\rightarrow$ & $15.96(14.33,17.59)$ & 4.16 \\
\hline Alger-Mayer, 2009 & $\rightarrow$ & $14.40(12.77,16.03)$ & 4.16 \\
\hline Alger-Mayer, 2009 & $\rightarrow$ & $9.27(7.65,10.89)$ & 4.16 \\
\hline Alger-Mayer, 2009 & $\rightarrow$ & $6.38(4.74,8.02)$ & 4.16 \\
\hline Sallet, 2007 & & $-0.05(-1.66,1.56)$ & 4.17 \\
\hline Sallet, 2007 & & $2.71(1.10,4.32)$ & 4.17 \\
\hline Sallet, 2007 & & $0.29(-1.32,1.90)$ & 4.17 \\
\hline Sallet, 2007 & & $-2.70(-4.31,-1.09)$ & 4.17 \\
\hline gorin & & $-2.10(-3.74,-0.46)$ & 4.16 \\
\hline Love, 2008 & & $1.93(0.30,3.56)$ & 4.16 \\
\hline Love, 2008 & & $-0.55(-2.18,1.08)$ & 4.16 \\
\hline Beck, 2012 & & $-0.85(-2.43,0.73)$ & 4.17 \\
\hline Yanos, 2014 & & $-8.94(-10.48,-7.40)$ & 4.17 \\
\hline Fox, 2015 & & $-1.10(-2.67,0.47)$ & 4.17 \\
\hline Wise, 2015 & 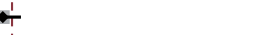 & $0.88(-0.28,2.04)$ & 4.20 \\
\hline Wise, 2015 & $\frac{1}{12}$ & $2.34(0.89,3.79)$ & 4.18 \\
\hline Brandao, 2015 & & $-13.33(-14.99,-11.67)$ & 4.16 \\
\hline Overall $($ I-squared $=98.3 \%, p=0.000)$ & & $1.47(-1.01,3.95)$ & 100.00 \\
\hline NOTE: Weights are from random effects analysis & & & \\
\hline $\begin{aligned} & \\
&-17.6\end{aligned}$ & 17. & & \\
\hline
\end{tabular}

\section{Binge eating}

Twenty-four studies assessed self-reported binge eating 29,30,38,40,43,44,46,54,55,57,58,63,66,6979. Binge eating symptomatology was assessed with the Questionnaire of Eating and Weight Patterns - Revised in five studies $44,58,70,71,79$, the DSM-IV in seven studies $^{30,40,55,57,63,69,72}$, the Eating Disorder Examination-Questionnaire in three ${ }^{46,73,78}$, Binge Eating Scale in five ${ }^{29,38,54,74,75}$ and the Inventory of Binge Eating Situations in one ${ }^{76}$ (Table 1). In three studies binge eating was assessed without a specified questionnaire ${ }^{43,66,77}$. Eighteen studies focused on the effect of self-reported binge eating prior to surgery, 20-361 patients were included, follow-up ranged from 6-72 months. Nine studies found no effect of binge eating on outcome ${ }^{46,54,63,66,74,75,77,78}$. In one study binge eating prior to surgery was associated with higher weight loss ${ }^{38}$. In six studies binge eating was significantly correlated with less weight loss ${ }^{55,58,69,71,72,76}$. In one study successful patients $\left(<30 \mathrm{~kg} / \mathrm{m}^{2}\right.$ at 1 -year post RYGB) were less likely to report binge eating though this difference disappeared when successful weight loss was defined otherwise ${ }^{30}$. The effect of binge-eating post-surgery was described in five studies; in 
three studies self-reported binge eaters had lower weight loss ${ }^{29,57,70}$ and in two there was no difference ${ }^{40,43}$.

Results of seven studies, all with pre-operative analysis of binge eating symptomatology, could be pooled for meta-analysis ${ }^{54,55,66,71,74,75,79}$ (Table 4). Data included 1360 patients with a mean preoperative BMl of $49.1 \mathrm{~kg} / \mathrm{m}^{2}( \pm 2.7)$ in the binge eating group and $47.8 \mathrm{~kg} / \mathrm{m}^{2}( \pm 3.8)$ in the non-binge eaters (Figure 4). EWL was not significantly different, $61.3 \%$ for binge eaters and $58.7 \%$ for non-binge eaters $(p=0.256)$. Five studies including 353 patients reported on 6 month weight loss, there was no significant difference in weight loss, binge eaters $49.6 \%$ versus $53.2 \%$ in non-binge eaters $(p=0.817)^{54,55,71}$. Four studies reported on 12 months weight loss, there was no significant difference in weight loss $(p=0.935)^{54,55,66,74,75}$. Also at 18,24 and 36 months there were also no significant differences $(p=0.109, p=0.887 \text { and } p=0.773)^{54,55,74}$.

\begin{tabular}{|c|c|c|c|c|c|c|c|c|c|}
\hline \multirow{2}{*}{ Author, yr. } & \multirow{2}{*}{ FU } & \multicolumn{3}{|c|}{ Binge eating } & \multicolumn{3}{|c|}{ None binge eating } & \multirow{2}{*}{ ES } & \multirow{2}{*}{$95 \% \mathrm{Cl}$} \\
\hline & & BMI & EWL & $\mathrm{N}$ & BMI & EWL & $\mathrm{N}$ & & \\
\hline Alger-mayer, 2009 & $3 \mathrm{M}$ & 50.73 & 43.08 & 32 & 50.92 & 44.91 & 70 & -1.83 & $-3.40,-0.26$ \\
\hline Alger-mayer, 2009 & $6 \mathrm{M}$ & 50.73 & 61.21 & 32 & 50.92 & 58.85 & 70 & 2.36 & $0.79,3.93$ \\
\hline Alger-mayer, 2009 & $12 \mathrm{M}$ & 50.73 & 73.25 & 32 & 50.92 & 68.24 & 70 & 5.01 & $3.44,6.58$ \\
\hline Alger-mayer, 2009 & $24 \mathrm{M}$ & 50.73 & 75.56 & 19 & 50.92 & 63.25 & 44 & 12.31 & $10.75,13.87$ \\
\hline Alger-mayer, 2009 & $36 \mathrm{M}$ & 50.73 & 85.75 & 13 & 50.92 & 54.03 & 23 & 31.72 & $30.11,33.33$ \\
\hline Alger-mayer, 2009 & $48 \mathrm{M}$ & 50.73 & 83.65 & 9 & 50.92 & 52.53 & 14 & 31.11 & $29.49,32.74$ \\
\hline Alger-mayer, 2009 & $60 \mathrm{M}$ & 50.73 & 68.69 & 3 & 50.92 & 59.25 & 9 & 9.45 & $7.94,10.96$ \\
\hline Alger-mayer, 2009 & $72 \mathrm{M}$ & 50.73 & 62.24 & 2 & 50.92 & 69.46 & 8 & -7.22 & $-8.65,-5.78$ \\
\hline Sallet, 2007 & $6 \mathrm{M}$ & 45.90 & 53.58 & 43 & 41.60 & 55.20 & 44 & -1.62 & $-3.27,0.03$ \\
\hline Sallet, 2007 & $12 \mathrm{M}$ & 45.90 & 63.44 & 44 & 41.60 & 73.34 & 41 & -9.90 & $-11.55,-8.25$ \\
\hline Sallet, 2007 & $24 \mathrm{M}$ & 45.90 & 65.49 & 34 & 41.60 & 85.37 & 33 & -19.88 & $-21.53,-18.23$ \\
\hline Sallet, 2007 & $36 \mathrm{M}$ & 45.90 & 56.53 & 8 & 41.60 & 87.24 & 7 & -30.71 & $-32.36,-29.06$ \\
\hline Dymek, 2001 & $6 \mathrm{M}$ & n.a. & 38.50 & 10 & n.a. & 53.90 & 22 & -5.60 & $-7.25,-3.95$ \\
\hline Green, 2004 & $6 \mathrm{M}$ & 56.70 & 44.78 & 33 & 52.80 & 51.20 & 32 & 3.00 & $1.39,4.61$ \\
\hline Malone, 2004 & $3 \mathrm{M}$ & 48.10 & 33.00 & 26 & 47.70 & 34.00 & 52 & 8.00 & $6.45,9.55$ \\
\hline Malone, 2004 & $6 \mathrm{M}$ & 48.10 & 50.00 & 24 & 48.10 & 50.00 & 24 & 11.00 & $9.43,12.57$ \\
\hline Malone, 2004 & $9 \mathrm{M}$ & 48.10 & 61.00 & 16 & 47.70 & 53.00 & 40 & 13.00 & $11.47,14.53$ \\
\hline Malone, 2004 & $12 \mathrm{M}$ & 48.10 & 66.00 & 17 & 47.70 & 55.00 & 37 & 12.00 & $10.49,13.51$ \\
\hline Malone, 2004 & $18 \mathrm{M}$ & 48.10 & 69.00 & 9 & 47.70 & 56.00 & 24 & -1.36 & $-2.99,0.266$ \\
\hline Malone, 2004 & $24 \mathrm{M}$ & 48.10 & 68.00 & 6 & 47.70 & 56.00 & 18 & 15.00 & $13.41,16.59$ \\
\hline Malone, 2004 & $36 \mathrm{M}$ & 48.10 & 69.00 & 5 & 47.70 & 54.00 & 10 & 3.00 & $1.41,4.59$ \\
\hline Bocchieri,2002 & $18 \mathrm{M}$ & 54.70 & 60.00 & 24 & 53.60 & 57.00 & 48 & -3.30 & $-4.95,-1.65$ \\
\hline Castellini, 2014 & $12 \mathrm{M}$ & 50.66 & 56.91 & 43 & 53.60 & 60.21 & 40 & -1.00 & $-2.59,0.59$ \\
\hline Fox, 2015 & $12 \mathrm{M}$ & 46.30 & 62.31 & 38 & 44.99 & 63.67 & 58 & -1.83 & $-3.40,-0.26$ \\
\hline pooled ES & & 49.12 & 61.29 & 522 & 47.81 & 58.99 & 838 & 3.24 & $-2.35,8.83$ \\
\hline
\end{tabular}

yr. = year of publication; FU: follow-up in months $(\mathrm{M})$ or years $(\mathrm{Y})$; BMI: Body Mass Index; EWL: percentage excess weight loss; $\mathrm{N}=$ number of patients; $\mathrm{ES}$ : effect size; Cl: confidence interval 
Figure 5: Results of meta-analysis on effect of binge eating on weight loss in RYGB patients

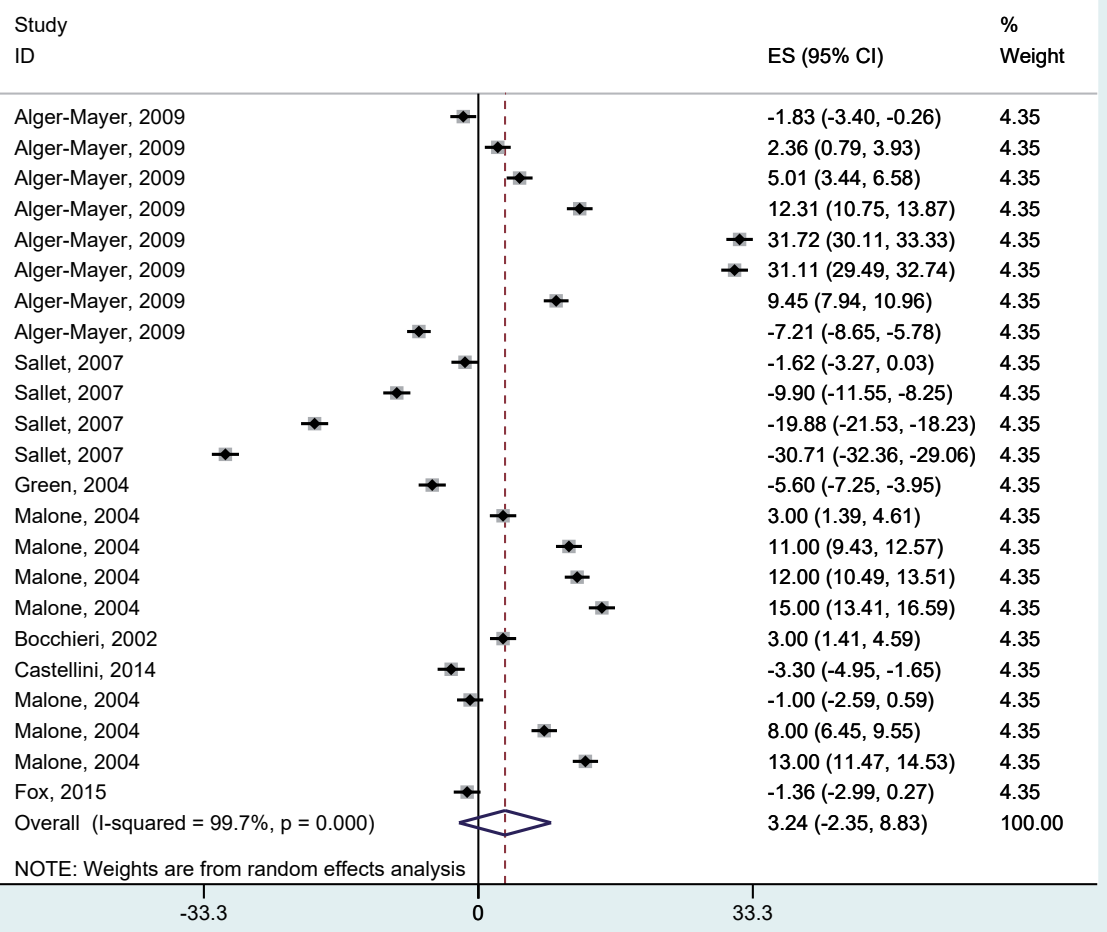

\section{DISCUSSION}

The goal of this systematic review and meta-analysis is to give an overview of behavioral and psychopathology related moderators of weight loss after RYGB. The results show that compliance to follow up and taking part in physical activity are associated with more weight loss after surgery. Psychopathology related issues were however not associated with less weight loss.

The importance of compliance to follow-up has been well established in laparoscopic adjustable gastric band (LAGB) patients. In one study more than half of the patients lost to follow up had an EWL $<25 \%{ }^{1,80}$. The effect by which compliance to follow-up leads to more weight loss in these patients has been attributed to adjustment of the band ${ }^{1}$. For RYGB is it assumed that the effect of compliance to follow-up is less. However, a previous meta-analysis with four studies also showed a positive effect of compliance to follow-up in RYGB patients ${ }^{17}$. In six studies included in this meta-analysis \%EWL was higher in compliant patients on each of the follow up moments, this 
difference was even seen up to 5.8 years after surgery. The authors of the previous review suggest that follow-up rates are lower in patients with less weight loss ${ }^{17}$. Another explanation can be that motivated patients have a better compliance to both the consultation as well as the lifestyle adherence, with more weight loss as a consequence. For future treatment it is essential to get more insight in how the improve compliance of these patients.

The effect of compliance is in concordance with the higher weight loss in patients who endorse in physical activity after surgery, which is also a form of compliance to postoperative advice. In the general population the positive effect of psychical activity on weight loss and weight maintenance is already well established ${ }^{81}$. In our analysis the pre-operative BMI difference between the active and non-active patients was less than one BMI point, and still the mean difference in EWL was almost $7 \%$. When comparing all included studies, the effect of PA seems to be more pronounced on long-term. One study with 2-5 years follow-up even showed $15 \%$ more weight loss in active patients ${ }^{39}$. Although this meta-analysis was only conducted with studies on RYGB, we want to emphasize that previous research has also shown a positive effect of PA on weight loss in patients undergoing different types of bariatric surgery 82. In addition to weight loss, physical activity has shown to have a positive effect on cardiac and pulmonary function and body composition ${ }^{83-85}$. As described in previous guidelines, physical activity should be promoted in all post-bariatric patients ${ }^{1}$.

Regarding the psychological predictors the results of the meta-analysis are not in concordance with common belief, which generally link psychological issues and eating disorders to less weight loss after surgery ${ }^{1}$. Binge eating is present in a significant part of the pre-bariatric surgery population and a common reason for delaying and refusal of surgery ${ }^{1}$. However previous reviews did never find a negative effect of binge eating on weight loss after bariatric surgery; one review even found a positive effect 10. This in in concordance with our results, which also show slightly more weight loss in binge eaters. When looking at the individual studies, there is a great variation in assessing binge eating symptoms. Seven different questionnaires were used, in only in a few studies a structured interview was conducted. In addition, the groups with long term outcomes were very small, ranging from 10-36 patients ${ }^{54,55,74}$. Independently of these possible biases, it seems that pre-operative binge eating symptoms do not have a significant negative influence on weight loss.

To our knowledge no meta-analysis has ever been conducted to assess the effect of depressive symptoms on weight loss after RYGB or any other bariatric procedure. Our results show no difference in weight loss between patients self-reporting depressive symptoms vs patients who do not report symptoms. Several other studies have suggested that there is no effect of depression on weight loss ${ }^{10,86}$. Herpertz et al. even 
concluded that depression disorders have a positive effect of weight loss, mediated by the positive effect on $\mathrm{QOL}{ }^{87}$. A somewhat surprising finding is that in four out of six studies with a negative effect of depression on weight loss, depressive symptoms was assessed postoperatively ${ }^{34,36,44,57}$. Depression has been linked to changes in eating behavior in the obese population before ${ }^{11,12}$. Thus, it might be that post-operative occurrence of depression has effect on bodyweight. Follow-up of RYGB patients and timely treatment of post-operative depression might be the most important in this population.

Although the number of studies that could be included in the meta-analysis were sufficient, the findings of this study are somewhat restricted by the number of publications with sufficient weight loss data. Most studies were conducted in the past decade and $\% E W L$ was generally used as a weight loss variable, however this outcome measurement was not available in a substantial number of studies. The recently published guideline on reporting outcome after bariatric surgery should avoid this problem in future meta-analysis ${ }^{18}$.

The variance in assessment and definition of the moderators might have contributed to the fact that there was no difference in weight loss in the analysis of depressive and binge eating symptoms. And although in six studies weight loss was not influenced by the presence of psychological/psychiatric problems ${ }^{46,48-50,52,53}$. Because of the variations in psychological evaluation a meta-analysis could not be conducted. The most recent guideline does state that psychosocial evaluation before bariatric surgery is essential, however the best method to conduct this assessment is yet to be identified

1 . Thus, our results do give good insight in current everyday practice.

In the future, more effort should be made for consensus on psychological screening of bariatric patients ${ }^{1}$. It seems that current screening is mostly conducted with questionnaires and without structured interviews. This could lead to the fact that patient might now be included in the depressive symptoms group, but do not actually have a depression. The same is possible for binge eating symptomatology. When accurate diagnosis of psychological issues is conducted, then definitive conclusions of the impact on weight loss can be made.

In this consensus there also should be attention for what psychologists' call: positive faking. Patients who are screened for bariatric surgery, usually know the contra-indications and might behave differently to "get" the surgery.

\section{CONCLUSION}

A decade ago van Hout et al. stated that more research was needed to fully understand the influence of patient related factors on weight loss ${ }^{88}$. This study shows that 
more research has been conducted. Based on this meta-analysis there is no evidence that patients with symptoms of depression and binge eating have lower weight loss after RYGB. Symptoms other than depression and binge eating are not systematically studied so it cannot be ruled out that they influence surgery effects. Therefore, we advise that decisions regarding bariatric surgery should not be made based on a single psychological diagnosis or questionnaire outcome, but on a thorough screening of each patient by a multidisciplinary team, including a mental health professional. Compliance and physical activity do seem to positively influence weight loss, and treatment regime should be focused on improving these factors. In addition, follow-up should address psychological problems that might arise post-surgery and affect weight loss on the long-term. 


\section{References}

1. Mechanick JI, Youdim A, Jones DB, Garvey WT, Hurley DL, McMahon MM, et al. Clinical practice guidelines for the perioperative nutritional, metabolic, and nonsurgical support of the bariatric surgery patient--2013 update: cosponsored by American Association of Clinical Endocrinologists, The Obesity Society, and American Society for Metabolic \& Bariatric Surgery. Obesity (Silver Spring). 2013 Mar;21 Suppl 1:S1-27.

2. Benoit S.C., Francis D.M., Hunter T.D. Analysis of bariatric outcomes longitudinal database (BOLD) to predict percent bmi loss after bariatric surgery. Value Health. 2012;15(4):A73-4.

3. Colquitt JL, Pickett K, Loveman E, Frampton GK. Surgery for weight loss in adults. Cochrane Database Syst Rev. 2014 Aug 8;(8):CD003641. doi(8):CD003641.

4. Kubik JF, Gill RS, Laffin M, Karmali S. The impact of bariatric surgery on psychological health. J Obes. 2013;2013:837989.

5. Sjostrom L. Review of the key results from the Swedish Obese Subjects (SOS) trial - a prospective controlled intervention study of bariatric surgery. J Intern Med. 2013 Mar;273(3):219-34.

6. Karmali S, Brar B, Shi X, Sharma AM, de Gara C, Birch DW. Weight recidivism post-bariatric surgery: a systematic review. Obes Surg. 2013 Nov;23(11):1922-33.

7. Rosenthal RJ. Failure of weight loss or weight regain after baratric surgery. Bariatric Times. 2012;9(10).

8. de Hollanda A, Jimenez A, Corcelles R, Lacy AM, Patrascioiu I, Vidal J. Gastrointestinal hormones and weight loss response after Roux-en-Y gastric bypass. Surg Obes Relat Dis. 2014 SepOct;10(5):814-9.

9. Coleman KJ, Brookey J. Gender and racial/ethnic background predict weight loss after Roux-en-Y gastric bypass independent of health and lifestyle behaviors. Obes Surg. 2014 Oct;24(10):1729-36.

10. Livhits M, Mercado C, Yermilov I, Parikh JA, Dutson E, Mehran A, et al. Preoperative predictors of weight loss following bariatric surgery: systematic review. Obes Surg. 2012 Jan;22(1):70-89.

11. Jansen A, Houben K, Roefs A. A Cognitive Profile of Obesity and Its Translation into New Interventions. Front Psychol. 2015 Nov 27;6:1807.

12. Cargill BR, Clark MM, Pera V, Niaura RS, Abrams DB. Binge eating, body image, depression, and self-efficacy in an obese clinical population. Obes Res. 1999 Jul;7(4):379-86

13. Stunkard AJ, Wadden TA. Psychological aspects of severe obesity. Am J Clin Nutr. 1992 Feb;55(2 Suppl):524S-32S

14. Bocchieri LE, Meana M, Fisher BL. Perceived psychosocial outcomes of gastric bypass surgery: a qualitative study. Obes Surg. 2002 Dec;12(6):781-8.

15. Adami GF, Gandolfo P, Campostano A, Meneghelli A, Ravera G, Scopinaro N. Body image and body weight in obese patients. Int J Eat Disord. 1998 Nov;24(3):299-306

16. Malik S., Mitchell J.E., Engel S., Crosby R., Wonderlich S. Psychopathology in bariatric surgery candidates: A review of studies using structured diagnostic interviews. Compr Psychiatry. 2014;55(2):248-59.

17. Kim HJ, Madan A, Fenton-Lee D. Does Patient Compliance with Follow-up Influence Weight Loss After Gastric Bypass Surgery? A Systematic Review and Meta-Analysis. Obes Surg. 2014 Apr;24(4):647-51.

18. Brethauer SA, Kim J, El Chaar M, Papasavas P, Eisenberg D, Rogers A, et al. Standardized outcomes reporting in metabolic and bariatric surgery. Obes Surg. 2015 Apr;25(4):587-606.

19. Fried M., Yumuk V., Oppert J.M., Scopinaro N. Torres A., Weiner R., et al. Interdisciplinary European guidelines on metabolic and bariatric surgery. Obes Surg. 2014;24(1):42-55.

20. Compher CW, Hanlon A, Kang Y, Elkin L, Williams
NN. Attendance at clinical visits predicts weight loss after gastric bypass surgery. Obes Surg. 2012 Jun;22(6):927-34.

21. El Chaar M, McDeavitt K, Richardson S, Gersin KS Kuwada TS, Stefanidis D. Does patient compliance with preoperative bariatric office visits affect postoperative excess weight loss? Surg Obes Relat Dis. 2011 Nov-Dec;7(6):743-8.

22. Song Z, Reinhardt K, Buzdon M, Liao P. Association between support group attendance and weight loss after Roux-en-Y gastric bypass. Surg Obes Relat Dis. 2008 Mar-Apr;4(2):100-3.

23. Gould JC, Beverstein G, Reinhardt S, Garren MJ. Impact of routine and long-term follow-up on weight loss after laparoscopic gastric bypass. Surg Obes Relat Dis. 2007 Nov-Dec;3(6):627,30; discussion 630.

24. Shen R, Dugay G, Rajaram K, Cabrera I, Siegel $\mathrm{N}$, Ren CJ. Impact of patient follow-up on weight loss after bariatric surgery. Obes Surg. 2004 Apr;14(4):514-9.

25. Hatoum IJ, Stein HK, Merrifield BF, Kaplan LM. Cat pacity for physical activity predicts weight loss after Roux-en-Y gastric bypass. Obesity (Silver Spring). 2009 Jan; 17(1):92-9.

26. Harper J, Madan AK, Ternovits CA, Tichansky DS. What happens to patients who do not follow-up after bariatric surgery? Am Surg. 2007 Feb;73(2):181-4.

27. Robinson AH, Adler S, Stevens HB, Darcy AM, Morton JM, Safer DL. What variables are associated with successful weight loss outcomes for bariatric surgery after 1 year? Surg Obes Relat Dis. 2014 JulAug;10(4):697-704.

28. Hildebrandt SE. Effects of participation in bariatric support group after Roux-en-Y gastric bypass. Obes Surg. 1998 Oct;8(5):535-42.

29. Livhits M, Mercado C, Yermilov I, Parikh JA, Dutson E, Mehran A, et al. Behavioral factors associated with successful weight loss after gastric bypass. Am Surg. 2010 Oct;76(10):1139-42.

30. Coleman KJ, Toussi R, Fujioka K. Do gastric bypass patient characteristics, behavior, and health differ depending upon how successful weight loss is defined? Obes Surg. 2010 Oct;20(10):1385-92.

31. Forbush S, Nof L, Echternach J, Hill C, Rainey J. Influence of activity levels and energy intake on percent excess weight loss after Roux-en-Y gastric bypass. Obes Surg. 2011 Nov;21(11):1731-8.

32. Bond DS, Phelan S, Wolfe LG, Evans RK, Meador JG, Kellum JM, et al. Becoming physically active after bariatric surgery is associated with improved weight loss and health-related quality of life. Obesity (Silver Spring). 2009 Jan;17(1):78-83.

33. Welch G, Wesolowski C, Piepul B, Kuhn J, Romanelli J, Garb J. Physical activity predicts weight loss following gastric bypass surgery: findings from a support group survey. Obes Surg. 2008 May;18(5):517-24.

34. Silver HJ, Torquati A, Jensen GL, Richards WO. Weight, dietary and physical activity behaviors two years after gastric bypass. Obes Surg. 2006 Jul;16(7):859-64.

35. Rosenberger PH, Henderson KE, White MA, Masheb RM, Grilo CM. Physical activity in gastric bypass patients: associations with weight loss and psychosocial functioning at 12-month follow-up. Obes Surg. 2011 Oct;21(10):1564-9.

36. Kruseman M, Leimgruber A, Zumbach F, Golay A. Dietary, weight, and psychological changes among patients with obesity, 8 years after gastric bypass. J Am Diet Assoc. 2010 Apr:110(4):527-34.

37. Herman KM, Carver TE, Christou NV, Andersen RE. Keeping the Weight Off: Physical Activity, Sitting Time, and Weight Loss Maintenance in Bariatric Surgery Patients 2 to 16 Years Postsurgery. Obes Surg. 2014 Feb 28.

38. Boan J, Kolotkin RL, Westman EC, McMahon RL, Grant JP. Binge eating, quality of life and physical activity improve after Roux-en-Y gastric bypass for morbid obesity. Obes Surg. 2004 Mar;14(3):341-8. 
39. Josbeno DA, Jakicic JM, Hergenroeder A, Eid GM. Physical activity and physical function changes in obese individuals after gastric bypass surgery. Surg Obes Relat Dis. 2010 Jul-Aug;6(4):361-6.

40. Welch G, Wesolowski C, Zagarins S, Kuhn J, Romanelli J, Garb J, et al. Evaluation of clinical outcomes for gastric bypass surgery: results from a comprehensive follow-up study. Obes Surg. 2011 Jan;21(1):18-28.

41. Junior WS, do Amaral JL, Nonino-Borges CB. Factors related to weight loss up to 4 years after bariatric surgery. Obes Surg. 2011 Nov;21(11):1724-30.

42. Bond DS, Evans RK, Wolfe LG, Meador JG, Sugerman HJ, Kellum JM, et al. Impact of self-reported physical activity participation on proportion of excess weight loss and BMI among gastric bypass surgery patients. Am Surg. 2004 Sep;70(9):811-4

43. Wolfe BL, Terry ML. Expectations and outcomes with gastric bypass surgery. Obes Surg. 2006 Dec;16(12):1622-9.

44. Yanos BR, Saules KK, Schuh LM, Sogg S. Predictors of Lowest Weight and Long-Term Weight Regain Among Roux-en-Y Gastric Bypass Patients. Obes Surg. 2015 Aug;25(8):1364-70.

45. Woodlief TL, Carnero EA, Standley RA, Distefano G, Anthony SJ, Dubis GS, et al. Dose response of exercise training following roux-en-Y gastric bypass surgery: A randomized trial. Obesity (Silver Spring). 2015 Dec;23(12):2454-61.

46. Latner JD, Wetzler S, Goodman ER, Glinski J. Gastric bypass in a low-income, inner-city population: eating disturbances and weight loss. Obes Res. 2004 Jun;12(6):956-61.

47. Evans RK, Bond DS, Wolfe LG, Meador JG, Herrick $\mathrm{JE}$, Kellum JM, et al. Participation in $150 \mathrm{~min} / \mathrm{wk}$ of moderate or higher intensity physical activity yields greater weight loss after gastric bypass surgery. Surg Obes Relat Dis. 2007 Sep-Oct;3(5):526-30.

48. Aubert N., Lyon-Pages I., Carrard I., Suter M., Stiefel F., Giusti V. The predictive value of psychological assessment of candidates for gastric bypass: A medical chart review. Eur J Psychiatry. 2010;24(2):114-23.

49. Belanger SB, Wechsler FS, Nademin ME, Virden TB,3rd. Predicting outcome of gastric bypass surgery utilizing personality scale elevations, psychosocial factors, and diagnostic group membership. Obes Surg. 2010 Oct;20(10):1361-71.

50. Steinmann WC, Suttmoeller K, Chitima-Matsiga R, Nagam N, Suttmoeller NR, Halstenson NA. Bariatric surgery: 1-year weight loss outcomes in patients with bipolar and other psychiatric disorders. Obes Surg. 2011 Sep;21(9):1323-9.

51. Clark MM, Balsiger BM, Sletten CD, Dahlman KL, Ames G, Williams DE, et al. Psychosocial factors and 2-year outcome following bariatric surgery for weight loss. Obes Surg. 2003 Oct;13(5):739-45.

52. Won EJ, Tran TT, Rigby A, Rogers AM. A Comparative Study of Three-Year Weight Loss and Outcomes After Laparoscopic Gastric Bypass in Patients with "Yellow Light" Psychological Clearance. Obes Surg. 2014 Apr 24.

53. Limbach KE, Ashton K, Merrell J, Heinberg LJ. Relative Contribution of Modifiable Versus Non-Modifiable Factors as Predictors of Racial Variance in Roux-en-Y Gastric Bypass Weight Loss Outcomes. Obes Surg. 2014 Feb 22.

54. Alger-Mayer S, Rosati C, Polimeni JM, Malone M. Preoperative binge eating status and gastric bypass surgery: a long-term outcome study. Obes Surg. 2009 Feb;19(2):139-45.

55. Sallet PC, Sallet JA, Dixon JB, Collis E, Pisani CE, Levy A, et al. Eating behavior as a prognostic factor for weight loss after gastric bypass. Obes Surg. 2007 Apr;17(4):445-51.

56. Gorin AA, Raftopoulos I. Effect of mood and eating disorders on the short-term outcome of laparoscopic Roux-en-Y gastric bypass. Obes Surg. 2009 Dec;19(12):1685-90.

57. Beck NN, Mehlsen M, Stoving RK. Psychologi- cal characteristics and associations with weight outcomes two years after gastric bypass surgery: Postoperative eating disorder symptoms are associated with weight loss outcomes. Eat Behav. 2012 Dec;13(4):394-7.

58. Dymek MP, le Grange D, Neven K, Alverdy J. Quality of life and psychosocial adjustment in patients after Roux-en-Y gastric bypass: a brief report. Obes Surg. 2001 Feb;11(1):32-9.

59. Sarwer DB, Wadden TA, Moore RH, Baker AW, Gibbons LM, Raper SE, et al. Preoperative eating behavior, postoperative dietary adherence, and weight loss after gastric bypass surgery. Surg Obes Relat Dis. 2008 Sep-Oct;4(5):640-6.

60. Averbukh Y, Heshka S, El-Shoreya H, Flancbaum L, Geliebter A, Kamel S, et al. Depression score predicts weight loss following Roux-en-Y gastric bypass. Obes Surg. 2003 Dec;13(6):833-6.

61. Ma Y, Pagoto SL, Olendzki BC, Hafner AR, Perugini RA, Mason R, et al. Predictors of weight status following laparoscopic gastric bypass. Obes Surg. 2006 Sep;16(9):1227-31.

62. Love RJ, Love AS, Bower S, Carlos Poston WS Impact of antidepressant use on gastric bypass surgery patients' weight loss and health-related quality-of-life outcomes. Psychosomatics. 2008 NovDec;49(6):478-86

63. Lanyon RI, Maxwell BM. Predictors of outcome after gastric bypass surgery. Obes Surg. 2007 Mar;17(3):321-8.

64. Delin CR, Watts JM, Bassett DL. An Exploration of the Outcomes of Gastric Bypass Surgery for Morbid Obesity: Patient Characteristics and Indeces of Success. Obes Surg. 1995 May;5(2):159-70.

65. Brandao I, Ramalho S, Pinto-Bastos A, Arrojado F, Faria G, Calhau C, et al. Metabolic profile and psychological variables after bariatric surgery: association with weight outcomes. Eat Weight Disord. 2015 Dec;20(4):513-8.

66. Fox B, Chen E, Suzo A, Jolles S, Greenberg JA, Campos GM, et al. Dietary and psych predictors of weight loss after gastric bypass. J Surg Res. 2015 Aug;197(2):283-90.

67. White MA, Kalarchian MA, Levine MD, Masheb RM, Marcus MD, Grilo CM. Prognostic Significance of Depressive Symptoms on Weight Loss and Psychosocial Outcomes Following Gastric Bypass Surgery: A Prospective 24-Month Follow-Up Study. Obes Surg. 2015 Oct;25(10):1909-16.

68. Wise ES, Hocking KM, Kavic SM. Prediction of excess weight loss after laparoscopic Roux-en-Y gastric bypass: data from an artificial neural network. Surg Endosc. 2016 Feb;30(2):480-8.

69. Lanyon RI, Maxwell BM, Kraft AJ. Prediction of longterm outcome after gastric bypass surgery. Obes Surg. 2009 Apr;19(4):439-45

70. Kofman MD, Lent MR, Swencionis C. Maladaptive eating patterns, quality of life, and weight outcomes following gastric bypass: results of an Internet survey. Obesity (Silver Spring). 2010 Oct;18(10):1938-43.

71. Green AE, Dymek-Valentine M, Pytluk S, Le Grange D, Alverdy J. Psychosocial outcome of gastric bypass surgery for patients with and without binge eating. Obes Surg. 2004 Aug;14(7):975-85.

72. Toussi R, Fujioka K, Coleman KJ. Pre- and posti surgery behavioral compliance, patient health, and postbariatric surgical weight loss. Obesity (Silver Spring). 2009 May;17(5):996-1002.

73. White MA, Masheb RM, Rothschild BS, Burke-Martindale $\mathrm{CH}$, Grilo $\mathrm{CM}$. The prognostic significance of regular binge eating in extremely obese gastric bypass patients: 12-month postoperative outcomes. J Clin Psychiatry. 2006 Dec;67(12):1928-35.

74. Malone M, Alger-Mayer S. Binge status and quality of life after gastric bypass surgery: a one-year study. Obes Res. 2004 Mar;12(3):473-81.

75. Castellini G, Godini L, Amedei SG, Faravelli C, Lucchese M, Ricca V. Psychological effects and outcome predictors of three bariatric surgery interventions: 
a 1-year follow-up study. Eat Weight Disord. 2014 Apr 16.

76. Crowley N, Budak A, Byrne TK, Thomas S. Patients who endorse more binge eating triggers before gastric bypass lose less weight at 6 months. Surg Obes Relat Dis. 2011 Jan-Feb;7(1):55-9.

77. Fujioka K, Yan E, Wang HJ, Li Z. Evaluating preoperative weight loss, binge eating disorder, and sexual abuse history on Roux-en-Y gastric bypass outcome. Surg Obes Relat Dis. 2008 Mar-Apr;4(2):137-43.

78. White MA, Kalarchian MA, Masheb RM, Marcus MD, Grilo CM. Loss of control over eating predicts outcomes in bariatric surgery patients: a prospective, 24-month follow-up study. J Clin Psychiatry. 2010 Feb;71(2):175-84.

79. Bocchieri-Ricciardi LE, Chen EY, Munoz D, Fischer S, Dymek-Valentine M, Alverdy JC, et al. Pre-surgery binge eating status: effect on eating behavior and weight outcome after gastric bypass. Obes Surg. 2006 Sep;16(9):1198-204.

80. te Riele WW, Boerma D, Wiezer MJ, Borel Rinkes IH van Ramshorst B. Long-term results of laparoscopic adjustable gastric banding in patients lost to follow-up. Br J Surg. 2010 Oct;97(10):1535-40.

81. Donnelly JE, Blair SN, Jakicic JM, Manore MM, Rankin JW, Smith BK, et al. American College of Sports Medicine Position Stand. Appropriate physical activity intervention strategies for weight loss and prevention of weight regain for adults. Med Sci Sports Exerc. 2009 Feb;41(2):459-71.

82. Livhits M, Mercado C, Yermilov I, Parikh JA, Dutson $E$, Mehran A, et al. Exercise following bariatric surgery: systematic review. Obes Surg. 2010 May;20(5):657-65.

83. Shang E. Aerobic endurance training improves weight loss and body composition in post-bariatric patients. Obes Surg. 2011;21(8):1042.

84. Castello-Simoes V, Polaquini Simoes R, Beltrame T, Bassi D, Maria Catai A, Arena R, et al. Effects of aerobic exercise training on variability and heart rate kinetic during submaximal exercise after gastric bypass surgery--a randomized controlled trial. Disabil Rehabil. 2013 Feb;35(4):334-42.

85. Castello V, Simoes RP, Bassi D, Catai AM, Arena R, Borghi-Silva A. Impact of aerobic exercise training on heart rate variability and functional capacity in obese women after gastric bypass surgery. Obes Surg. 2011 Nov;21(11):1739-49.

86. Wimmelmann C.L., Dela F., Mortensen E.L. Psychological predictors of mental health and health-related quality of life after bariatric surgery: A review of the recent research. Obes Res Clin Pract. 2013.

87. Herpertz S, Kielmann R, Wolf AM, Hebebrand J, Senf W. Do psychosocial variables predict weight loss or mental health after obesity surgery? A systematic review. Obes Res. 2004 Oct;12(10):1554-69.

88. van Hout GC, Verschure SK, van Heck GL. Psychosocial predictors of success following bariatric surgery. Obes Surg. 2005 Apr;15(4):552-60. 



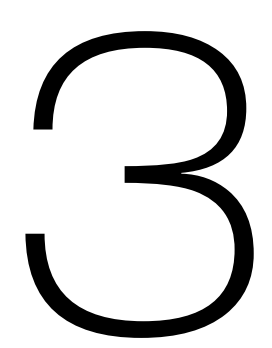

Weight change after Roux-en-Y gastric bypass, physical activity and eating style: is there a relationship?

Valerie M. Monpellier Ignace M. C. Janssen Evangelia E. Antoniou Anita T. M. Jansen

Published in Obesity Surgery (ObesSur;2019 February; 29(2):26-533) 


\section{ABSTRACT}

\section{BACKGROUND}

Insufficient weight loss and weight regain is seen in $20-30 \%$ of the post-bariatric population. More knowledge about the effect of physical activity and eating style on weight change after Roux-en-Y gastric bypass is essential since behaviour can be modified and thereby results improved. The goal of this study is to determine the relationship between weight change, self-reported physical activity and eating style.

\section{METHODS}

Weight, physical activity (PA) and eating style (ES) were assessed before surgery and $15,24,36$ and 48 months after surgery. A linear mixed model was performed to assess the association between the change in PA and ES and percentage total weight loss (\%TWL).

\section{RESULTS}

4,569 Patients were included. Preoperative PA and ES were not related to weight change. Change in PA was positively associated with \%TWL at 15, 36 and 48 months follow-up. Change in emotional eating was negatively related to \%TWL at all follow-up moments. Change in external eating was only negatively related to weight loss at 24 months follow-up. Change in restrained eating was negatively associated with weight loss up to 36 months follow-up. More restrained eating at 36 months follow-up was related to higher weight regain, and more emotional eating at 48 months to 48 -month weight regain.

\section{CONCLUSION}

Preoperative self-reported PA and ES did not predict weight change after RYGB. Being are more physically active and showing less emotional and restrained eating was related to a higher weight loss. Emotional and restrained eating were related to higher weight regain. 


\section{INTRODUCTION}

Bariatric surgery has proven to effectively treat morbid obesity and its comorbidities 1,2 . However, in $20-30 \%$ of the bariatric population insufficient weight loss $(<50 \%$ excess weight loss) or substantial weight regain is observed; both can lead to re-emerging of comorbidities and secondary and/or tertiary bariatric procedures ${ }^{3,4}$. Behavioural factors can be modified and thereby reoperations could be avoided. A recent review focussed on the association between behaviour, mainly physical activity and eating, on weight change after bariatric surgery ${ }^{5}$. This review showed that these factors have only been studied sparsely.

Physical activity is considered an important way to achieve weight loss and maintain a healthy weight ${ }^{6-8}$. Therefore, bariatric patients are advised to engage in regular physical activity ${ }^{8-11}$. Previous studies indicate that low physical activity after bariatric surgery is related to less weight loss and more weight regain ${ }^{12-14}$, though more recent studies question whether weight loss is positively influenced by adherence to a healthy lifestyle with regular physical activity ${ }^{15,16}$.

Self-reported eating styles, like emotional, restrained or external eating, have not been studied frequently in the bariatric population. Emotional eating, in which patients report to eat more in response to emotions, has been linked to less weight loss in two studies ${ }^{17,18}$. However, others did not support this association ${ }^{12,13}$. Studies on self-reported external and restrained eating show the same conflicting results; some suggest a negative effect on weight change, while other studies show no effect ${ }^{12,13,17,19}$. In addition to these conflicting results, most of the previous studies, assessing the physical activity and eating style, include small populations and relatively short follow-ups ${ }^{12,13,17,18}$. A longer follow up is of interest since weight loss plateaus around 18 months after surgery ${ }^{20}$.

In the present study, the relationship between weight change and self-reported physical activity and eating style was examined in a large bariatric population (primary RYGB) with a longer follow-up (15, 24, 36 and 48 months). It was hypothesized that patients with better physical activity and better eating styles have higher weight loss and less weight regain. 


\section{METHODS}

\section{Standard treatment}

This is a retrospective analysis of prospectively collected data of patients who were treated at the Nederlandse Obesitas Kliniek (NOK, Dutch Obesity Clinic). Data were collected until $22^{\text {nd }}$ February 2017. The NOK is the largest outpatient clinic for bariatric surgery in the Netherlands, with eight locations throughout the country. In addition to the bariatric procedure, the treatment program entails group counselling by a multidisciplinary team. Group counselling starts before surgery and is focused on behavioural change. After 15-month follow-up, patients are invited yearly for consultation with the whole multidisciplinary team.

Routine assessment (as part of the treatment program) of self-reported physical activity and eating style was enrolled over the different locations at several time points during 2012 and 2013.

\section{Patients}

4,829 Patients who had undergone a primary RYGB between 2012 and 2015 and had a follow-up of 24 months or more were selected from the prospective database. A total of 260 patients (5.6\%) patients were excluded because they were lost to follow-up before 12 months post-surgery and/or no results were available for the questionnaires (see below).

\section{Assessments}

\section{Physical Activity}

Physical activity was evaluated preoperatively (baseline) and at 15, 24, 36 and 48 months after surgery with the Baecke questionnaire ${ }^{21}$. This questionnaire has shown good test-retest reliability and validity, and was used in the bariatric population before ${ }^{14,21,22}$. The Baecke consists of 22 questions assessing physical activity at work, during sports and during leisure time. A total score can be calculated, which ranges from 3 to 15, with higher scores indicating increasing self-reported activity. For this analysis, the scores at baseline and follow-up were used. Based on weight loss plateau around 18 months, the maximum change in physical activity $(\triangle \mathrm{PA})$ from baseline to 15 or 24 months follow-up was calculated.

\section{Eating style}

Eating style was evaluated at the same time points as the physical activity measurements, using the Dutch Eating Behaviour Questionnaire (DEBQ) ${ }^{23}$. The DEBQ is a widely used questionnaire to measure eating style ${ }^{23}$. It consists of 33 questions assessing three styles of eating: emotional eating, external eating and restrained eating. Emotional eating means eating in response to negative emotions. External eating refers to eating in response to external cues (like seeing food). Restrained eating refers 
to the intention to eat less. For all subscales, total scores can be calculated. These scores range from 1 to 5 ; a higher score means the patient indicates being a more emotional, external and/or restrained eater. For the DEBQ score, a maximum change score was also calculated using baseline and 15 or 24 months follow-up scores: $\triangle E M E$ for change in emotional eating; $\triangle E X E$ for change in external eating and $\triangle R E E$ for change in restrained eating.

\section{Weight change}

Body weight was assessed preoperatively (baseline) and at 12, 15, 24, 36 and 48 months after surgery; height was assessed during preoperative screening. Weight loss was calculated and reported as stated in the most recent guidelines: Body Mass Index $\left(\mathrm{BMl}\right.$ in $\mathrm{kg} / \mathrm{m}^{2}$ ) and percent total weight loss (\%TWL) ${ }^{24}$. New variables were created for maximum weight loss and weight regain, since up to date, there are no uniform definitions to report this ${ }^{3,25}$. First, nadir boy weight was defined as the lowest weight up to 24 months post-surgery. Based on that, maximum postoperative weight loss (TWLmax) was calculated using the following formula:

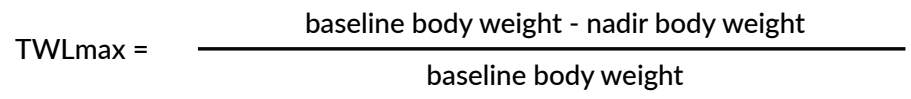

Since weight regain usually develops after the weight plateau, weight regain (WR) was calculated for 36 and 48 months follow-up with the following formulas:

$36 \mathrm{mWR}=\quad \frac{36-\text { month body weight }- \text { nadir body weight }}{\text { nadir body weight }}$
$48 \mathrm{mWR}=\quad \frac{48 \text {-month body weight }- \text { nadir body weight }}{\text { nadir body weight }}$




\section{Statistical analyses}

Descriptive statistics were used to summarize patients' baseline and follow-up characteristics. Changes in body weight and scores of Baecke and DEBQ were analysed using repeated measures ANOVA. Quartiles for preoperative physical activity and eating style were calculated and a MANCOVA analysis was conducted to assess the different weight loss trajectories. Creating weight loss trajectories in four groups ranging from low preoperative physical activity to high preoperative physical activity and four groups ranging from low preoperative emotional, external and restrained eating to high preoperative emotional, external and restrained eating. Plots were created to visualize the differences between these groups. All above analyses were performed using SPSS software, version 23 (IBM Corp. Released 2015. IBM SPSS Statistics for Windows, Version 23.0. Armonk, NY: IBM Corp.).

Regression analyses were used to investigate the relationship between baseline self-reported physical activity / eating style and weight change (TWLmax, 36mWR and $48 \mathrm{mWR}$ ) and between physical activity and eating style at follow-up and weight regain at 36 and 48 months.

A linear mixed model was conducted to assess the association between physical activity and \%TWL over all the follow-up moments. This model compared Baecke scoring at the specific follow-up moment with the baseline score, thus focussing on how Baecke scores changed. The relationship between Baecke scores and \%TWL over all follow-up moments was assessed with random intercept, thereby the model takes into account different intercepts for each patient. Then baseline score, gender and age were added to the model as fixed effects. In the last part of the model effect modification of time on Baecke was assessed. First calculating if the interaction of Baecke and time had a significant impact on the model and then assessing on which follow-up moments this was. The same model was performed for each of the eating styles (separately). All assumptions for regression analysis were met. These analyses were performed using STATA, version 13 (StataCorp. 2013. Stata 13 Base Reference Manual. College Station, TX: Stata Press.).

Findings were considered statistically significant if the $p$-value was $<0.05$.

\section{RESULTS}

\section{Study population}

The patients included in the analysis $(n=4,569)$ had a mean age of 47.1 years $( \pm 10.7)$, which was higher compared to those who were excluded from the analysis (mean age $44.3( \pm 11.2), p<0.001)$. More females $(81.7 \%)$ were observed in the included population compared to the excluded population $(69.2 \%, p<0.001)$. Mean follow-up (FU) since surgery was 38.7 months (range $24-59$ months), which was shorter compared to the excluded population (42.3 months, $p<0.001)$. 


\section{Weight change}

Mean baseline BMI was $44.4 \mathrm{~kg} / \mathrm{m}^{2}$ (range $30.3-75.7 \mathrm{~kg} / \mathrm{m}^{2}$, Table 1). Mean TWL at 12 months after surgery was $30.8 \%$, at 15 months this was $31.6 \%$ and at 24 month $31.4 \%$. Mean TWLmax was $32.7 \%( \pm 7.9)$.

Mean TWL was $29.2 \%$ at 36 -month FU and $27.3 \%$ at 48 -month FU $(p<0.001)$. Mean $36 \mathrm{mWR}$ was $5.3 \% \pm 6.7$ and the mean $48 \mathrm{mWR}$ was $7.2 \% \pm 9.2(p<0.001)$.

\begin{tabular}{lllll}
\hline $\begin{array}{l}\text { Table 1: } \\
\text { Weight change of the included population }(\mathrm{n}=4,569) \text { and availability of data per follow-up moment, } \\
\text { data presented as mean } \pm \text { standard deviation. }\end{array}$ & & & \\
\hline Follow-up & Available data & $\mathrm{BMI}, \mathrm{kg} / \mathrm{m}^{2}$ & $\% \mathrm{TWL}$ & $\% \mathrm{WR}$ \\
Baseline & 4569 & $44.4 \pm 5.7^{* * *}$ & & \\
12-month & $4079 / 4569(90 \%)$ & $30.7 \pm 4.9^{* * *}$ & $30.8 \pm 7.2^{* * *}$ & \\
15-month & $4359 / 4569(95 \%)$ & $30.4 \pm 5.0^{* * *}$ & $31.6 \pm 7.7^{* * *}$ & \\
24-month & $3786 / 4569(83 \%)$ & $30.3 \pm 5.1^{* * *}$ & $31.4 \pm 8.6^{* * *}$ & \\
36-month & $1620 / 2636(61 \%)$ & $31.4 \pm 5.3^{* * *}$ & $29.2 \pm 8.9^{* * *}$ & $5.3 \pm 6.7^{* * *}$ \\
48-month & $479 / 1020(47 \%)$ & $32.4 \pm 5.6$ & $27.3 \pm 9.6$ & $7.2 \pm 9.2$ \\
\hline
\end{tabular}

*** significant difference compared to next follow-up, p $\leq 0.001$.BMl: body mass index, $\%$ TWL: \% total weight loss; \%WR: \% weight regain

\section{Physical activity}

Mean Baecke scores were lowest before surgery (8.12 \pm 1.39$)$ and highest 15 months after surgery, mean score $8.66 \pm 1.29(0<0.001$, Table 2). At 24 months, the mean score was $8.54 \pm 1.31$, which was significantly lower than the score at 15 -month FU $(p=0.042)$. And at 36-month FU the mean score was $8.38 \pm 1.34$, which was lower than the score at 24 months $(p=0.006)$. Mean maximum change in Baecke score, $\triangle \mathrm{PA}$, was 0.76 (range -6.25 to 7.62 ).

\section{Eating style}

For emotional eating, the lowest score was observed 15 months after surgery ( mean score: $1.94 \pm 0.77$, Table 2). This score was significantly lower compared to the mean score before surgery $(2.43 \pm 0.82, p<0.001)$ and compared to the score at 24 months $(2.09 \pm 0.78, p<0.001)$.

For external eating, the mean score was highest before surgery, $2.84 \pm 0.58$, and lowest at 15 -month FU $(2.23 \pm 0.56, p<0.001)$. There was also a significant difference when comparing scores at 15 and $24-$ month FU $(2.35 \pm 0.54, p<0.001)$.

For restrained eating, there was only a significant difference when comparing baseline score $(3.01 \pm 0.60)$ and score 15 months after surgery $(2.49 \pm 0.75, p<0.001)$. Mean score at 24 months was $2.56 \pm 0.75$.

Patients reported less emotional eating after surgery, mean maximum change, $\triangle E M E$, was -0.32 (range -3.54 to 2.39). External eating also decreased after surgery, mean maximum change, $\triangle E X E$, was -0.61 (range -3.00 to 1.80). For restrained eating the maximum change, $\triangle \mathrm{REE}$, was -0.53 (range -3.60 to 3.30 ). 


\begin{tabular}{|c|c|c|c|c|c|c|}
\hline \multirow[t]{2}{*}{ Follow-up } & \multicolumn{2}{|r|}{ Baecke } & \multicolumn{2}{|r|}{ Emotional eating } & \multirow{2}{*}{$\begin{array}{c}\text { External eating } \\
\text { Mean } \pm \text { SD }\end{array}$} & \multirow{2}{*}{$\begin{array}{l}\text { Restrained } \\
\text { eating } \\
\text { Mean } \pm s d\end{array}$} \\
\hline & $\mathrm{N}$ & Mean \pm SD & $\mathrm{N}$ & Mean \pm SD & & \\
\hline Baseline & 4384 & $8.12 \pm 1.39^{\star \star *}$ & 2028 & $2.43 \pm 0.82^{* * *}$ & $2.84 \pm 0.58^{\star * *}$ & $3.01 \pm 0.60^{* * *}$ \\
\hline 15-month & 4162 & $8.66 \pm 1.29^{*}$ & 1939 & $1.94 \pm 0.77^{\star * *}$ & $2.23 \pm 0.56^{\star \star \star}$ & $2.49 \pm 0.75$ \\
\hline 24-month & 3525 & $8.54 \pm 1.31^{* *}$ & 1401 & $2.09 \pm 0.78$ & $2.35 \pm 0.54$ & $2.56 \pm 0.75$ \\
\hline 36-month & 1470 & $8.38 \pm 1.34$ & 388 & $2.27 \pm 0.82$ & $2.43 \pm 0.57$ & $2.59 \pm 0.70$ \\
\hline 48-month & 416 & $8.29 \pm 1.28$ & 112 & $2.35 \pm 0.86$ & $2.54 \pm 0.59$ & $2.58 \pm 0.67$ \\
\hline Change & 4199 & $0.76 \pm 1.22$ & 1946 & $-0.32 \pm 0.73$ & $-0.46 \pm 0.57$ & $-0.36 \pm 0.82$ \\
\hline
\end{tabular}

* significant difference compared to next follow-up, $p<0.05$; * significant difference compared to next follow-up, $p<0.01 ;{ }^{* * *}$ significant difference compared to next follow-up, $p \leq 0.001$.

\section{Preoperative physical activity and eating style}

Preoperative Baecke and DEBQ scores were not related to TWLmax or WR at 36 and 48 months. Figure 1.a shows the weight loss trajectories for the four group of patients based on the quartiles of preoperative Baecke scores, ranging from the group with the lowest physical activity ( $1^{\text {st }}$ quartile) to the group with the highest physical activity ( $4^{\text {th }}$ quartile). Weight loss was not significantly different between these groups $(p=0.238)$. Weight loss trajectories for the four groups based quartiles of preoperative DEBQ scores are shown in Figure 1.b-d. A lower quartile means a patient has less emotional, restrained or external eating. Weight loss was not significantly different between the four groups for emotional eating ( $p=0.699)$. There was also no significant difference for restrained eating $(p=0.586)$ and for external eating $(p=0.526)$. 
Figure 1: Weight loss trajectories for preoperative Baecke and DEBQ scores.

1. Weight loss trajectories for preoperative physical activity in the four quartiles (lower quartile means lower physical activity: $1^{\text {st }}$ quartile score up to $7.12,2^{\text {nd }} 7.13$ to $8.12,3^{\text {th }} 8.13$ to 9.12 and $4^{\text {th }}$ higher than 9.13 )

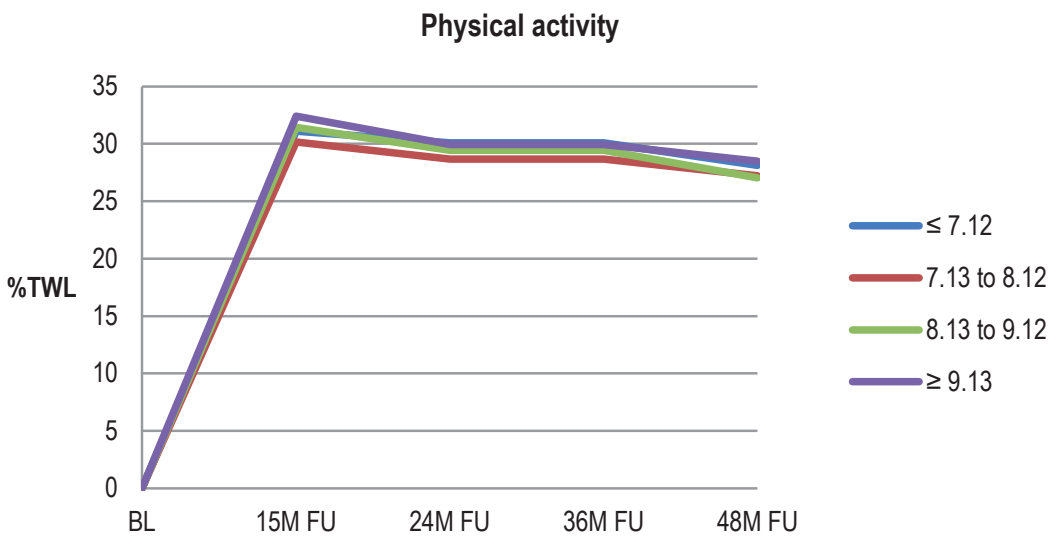

2. Weight loss trajectories for preoperative emotional eating in the four quartiles (lower quartile means less emotional eating: $1^{\text {st }}$ quartile score up to $1.84,2^{\text {nd }} 1.85$ to $2.44,3^{\text {th }} 2.45$ to 2.99 and $4^{\text {th }}$ higher than 3.00 )

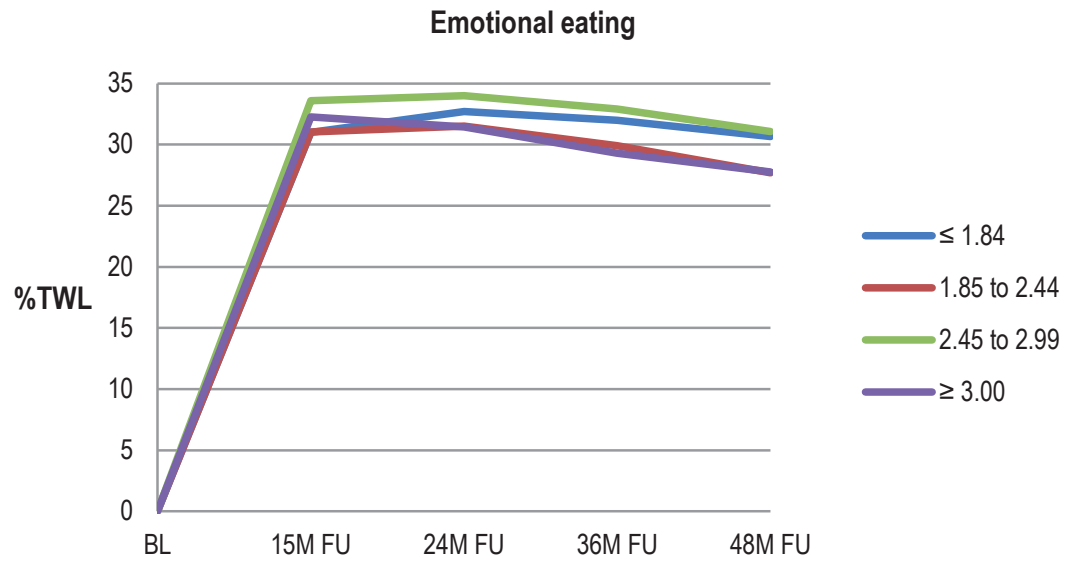


3. Weight loss trajectories for preoperative external eating in the four quartiles (lower quartile means less external eating: $1^{\text {st }}$ quartile score up to $2.49,2^{\text {nd }} 2.50$ to $2.89,3^{\text {th }} 2.90$ to 3.19 and $4^{\text {th }}$ higher than 3.20 )

\section{External eating}

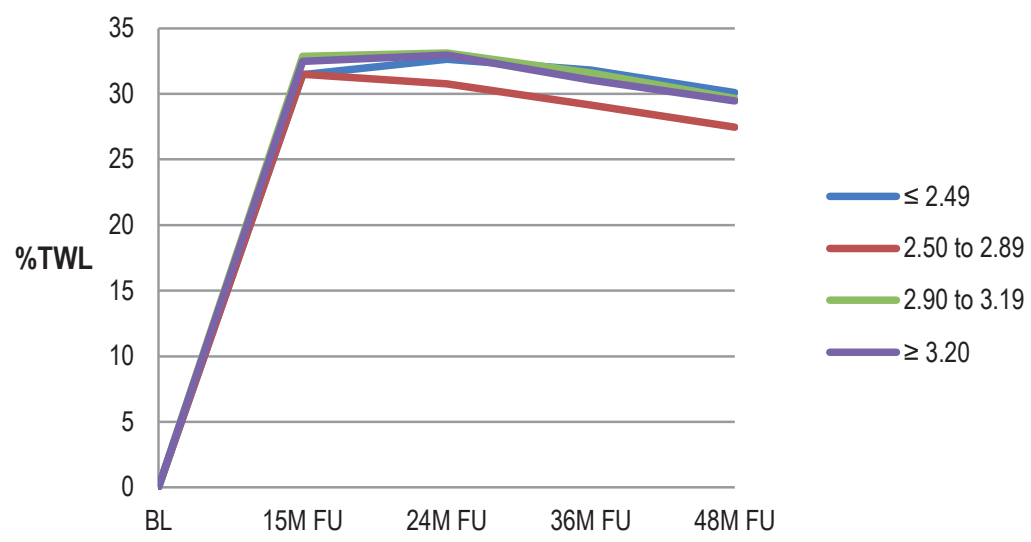

4. Weight loss trajectories for preoperative restrained eating in the four quartiles (lower quartile means less external eating: $1^{\text {st }}$ quartile score up to $2.69,2^{\text {nd }} 2.70$ to $2.99,3^{\text {th }} 3.00$ to 3.39 and $4^{\text {th }}$ higher than 3.40 )

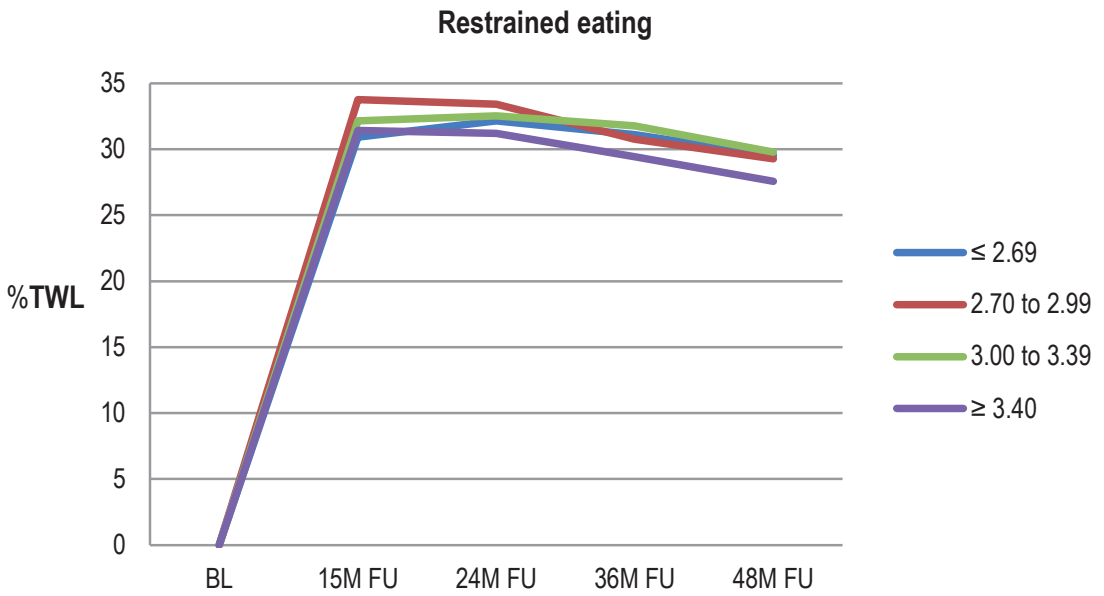

BL: baseline, 15M FU: 15-month follow-up, 24M FU: 24 months follow-up, 36M FU: 36 months follow-up; 48M FU: 48 months follow-up 


\section{Weight regain}

Restrained eating at 36 months was significantly, positively related to $36 \mathrm{mWR}$ $(\beta=1.10, p=0.025)$. Thus, more restrained eating at 36 -month $\mathrm{FU}$ was related to higher weight regain. Emotional eating at 48-month FU was significantly, positively related to 48mWR ( $\beta=3.89, p=0.002$ ); patients who reported more emotional eating 48 months after RYGB, regained more weight. None of the other Baecke and DEBQ scores at 15 , 24,36 and 48 months were related to 36 or 48 months weight regain.

\section{Mixed model for physical activity}

There was a significant, positive relationship between change in physical activity and \%TWL. Looking at the specific follow-up moments, there was a significant, positive association between physical activity and \%TWL at 15 months follow-up ( $\beta=0.22$, $p=0.012$, Table 3). Patients who engaged in more physical activity at 15 -months follow-up compared to baseline had higher weight loss. There was also a significant association at 36 months $(\beta=0.39, p=0.002)$ and 48 months $(\beta=0.62, p=0.005)$. Gender and age did not significantly influence the model; baseline Baecke score did and thus, the aforementioned models were adjusted for baseline score.

\section{Mixed model for eating styles}

For emotional eating there was a significant, negative association with \%TWL at all follow-up moments, with the most prominent association at 48 months $F U$ ( $\beta=-1.66$, $p=0.014$, Table 3). Patients who experienced more emotional eating compared to baseline had less weight loss.

There was a negative association between external eating and \%TWL. Patients who experienced more external eating had less weight loss, this association was only significant at 24 months FU ( $\beta=-1.06, p=0.003)$. For restrained eating there was also a negative association with \%TWL; more restrained eating was associated with less weight loss. This association was significant at 15, 24 and 36-month follow-up, it was not significant at 48 months after surgery. In all eating style models baseline score of the specific eating style influenced the model, above results are thus adjusted for baseline score. 
Table 3:

Linear mixed model was used to assess the relationship between physical activity and \%TWL and eating style and \%TWL.

\begin{tabular}{lcrccc}
\hline & Follow-up & Coefficient & \multicolumn{2}{c}{ P-value } & \multicolumn{2}{c}{$95 \%$ confidence intervals } \\
\hline \multirow{3}{*}{ Physical } & 15-month & 0.22 & 0.012 & 0.05 & 0.39 \\
activity & 24-month & 0.13 & 0.163 & -0.05 & 0.31 \\
& 36-month & 0.39 & 0.002 & 0.15 & 0.63 \\
& 48-month & 0.62 & 0.005 & 0.19 & 1.05 \\
\hline \multirow{3}{*}{ Emotional } & 15-month & -0.76 & 0.000 & -1.18 & -0.34 \\
eating & 24-month & -0.95 & 0.000 & -1.41 & -0.48 \\
& 36-month & -0.91 & 0.015 & -1.65 & -0.18 \\
& 48-month & -1.66 & 0.014 & -2.98 & -0.33 \\
\hline \multirow{3}{*}{ External eating } & 15-month & -0.60 & 0.058 & -1.22 & 0.02 \\
& 24-month & -1.06 & 0.003 & -1.76 & -0.36 \\
& 36-month & -0.89 & 0.110 & -1.99 & 0.20 \\
& 48-month & -1.42 & 0.136 & -3.29 & 0.45 \\
\hline \multirow{3}{*}{ Restrained } & 15-month & -0.81 & 0.006 & -1.39 & -0.23 \\
eating & 24-month & -1.80 & 0.000 & -2.42 & -1.19 \\
& 36-month & -1.51 & 0.002 & -2.45 & -0.56 \\
& 48-month & -0.94 & 0.238 & -2.50 & 0.62 \\
\hline
\end{tabular}

* adjusted for baseline score, as gender/age were no significant confounders

\section{DISCUSSION}

The goal of this study was to evaluate the effect of physical activity and self-reported eating style on weight change up to 48 months after primary RYGB. The results suggest that patients' activity and eating style before RYGB are not related to weight loss or weight regain after surgery. In general patients became more active after surgery and had less emotional, external and restrained eating. Physical activity at 15, 36 and 48 months follow-up was positively associated with weight loss; patients who became more active after surgery had higher weight loss. Emotional eating was related to weight loss at all follow-up moments; patients with more emotional eating compared to baseline had less weight loss. The reporting of higher emotional eating at 48 months follow-up was also related to higher weight regain at 48 months. External eating only related to weight loss at 24 months follow-up; patients who reported more external eating at follow-up had less weight loss. Restrained eating was also negatively associated with weight loss up to 36 months follow-up; patients who reported more restrained eating at follow-up had less weight loss. Patients who experienced more restrained eating at 36 months follow-up also had higher weight regain at this FU moment. Since the mixed model compared scores on the questionnaire with baselines scoring, the model in fact shows that the post-surgery change in physical activity and self-reported eating style was related to weight loss. 
Preoperative screening of eligible patients is standard part of bariatric treatment. According to the IFSO criteria, motivation to follow-up and adherence to, non-specified, behavioural changes is part of the pre-operative assessment ${ }^{26}$. Thus, preoperative behaviour of the patients is, at least partly, used to decide whether a patient is suitable for bariatric surgery. Thereby, it is assumed that current preoperative behaviours influence behaviour and weight change after surgery. This has been questioned before ${ }^{27}$. The results of the current study show that preoperative physical activity and self-reported eating style are not related to weight loss or weight regain at any of the follow-up moments. This indicates that questionnaires evaluating physical activity and eating style do not provide information that should be used to decide whether a patient is suitable for bariatric surgery. Preoperative scores did influence the association between changes in physical activity / eating styles and weight loss after surgery and changing of physical activity and eating style should thus be focus of post-operative care.

Like in the non-bariatric population, regular physical activity is advised to all bariatric patients ${ }^{8-11}$. In previous publications higher physical activity after surgery was related to better weight loss ${ }^{28-34}$. In our population, patients who became increasingly active showed higher weight loss at almost all follow-up moments. This has been shown before, even when looking at preoperative change in physical activity ${ }^{22,35}$.

Emotional eating is thought to negatively influence weight loss results, after non-surgical and surgical weight loss treatments ${ }^{18,36,37}$. There was a decrease in emotional eating after surgery, this decrease was mostly observed between baseline and 15 months; after that, emotional eating scores gradually increased. The mixed model showed that patients who experienced more emotional eating after surgery had lower weight loss. In addition, at 48- month follow-up, reporting more emotional eating was related to more weight regain. These data do not permit conclusions about causality: self-reported emotional eating might be a factor that contributes to weight regain though it is also possible that people who regain weight increase eating in response to emotions, and even other factors might play a role.

For external and restrained eating, studies assessing the effect on weight loss in bariatric patients are scarce and show conflicting results ${ }^{12,13,17,19}$. In the large population of the current study, an increase in self-reported restrained eating at 15, 24 and 36 months after RYGB was related with a less weight loss. Higher restrained eating was also related to more weight regain 36 months after surgery. It was interesting that, like emotional and external eating, restrained eating scores decreased after surgery and that higher restrained had a negative relationship with weight loss. These results again show that self-reported restrained eating seems to reflect intentions to restrain intake instead of actual restrained eating ${ }^{38}$. For external eating there was only a significant 
relationship with 24 months weight loss; patients had a higher decrease in external eating lost more weight. Contrary to previous research, in our study external eating was not related to more weight regain ${ }^{12}$.

A surprising result was that the mean changes in self-reported physical activity $(0.76)$ and eating styles (-0.32 to -0.61$)$ were quite small. Other studies have also shown a small change in physical activity ${ }^{39}$. For eating style, results are hard to compare since this was the first large study using the DEBQ. Other studies, using other questionnaires, show variable results in changes of eating style ${ }^{12,19,40}$. We did see a large range in the changes in physical activity and eating style. Another explanation for the small changes can be that in our treatment program patients are educated on physical activity and eating styles, patients might overestimate physical activity and underestimate eating style before surgery and, with the education of the program, their own estimations change.

Although we included more than four thousand post-bariatric patients in this longitudinal study, our data cannot be interpreted in a causal way. It could be that an increase in physical activity is causal to an increase in weight loss, but the association might as well be the other way around; a decrease in weight loss facilitating physical activity. Another limitation is the lost to follow-up of $39 \%$ and $53 \%$ of the patients at respectively 36 and 48-month follow up. Nonetheless, this is the first study assessing the effect of self-reported physical activity, emotional, external and restrained eating in such a large population with a follow-up until 48 months.

\section{CONCLUSION}

Based on our results we could argue that success after RYGB is not related to self-reported preoperative physical activity or eating behaviour. Therefore, the decision whether a patient is suitable for surgery should not be made on these self-reports of physical activity and eating style. In addition, professionals working in the bariatric field should be aware that these specific preoperative behaviours are not predictive of results.

Changes in self-reported physical activity, emotional eating and restrained eating and were related to increased weight loss. Future research should study whether changes in self-reported physical activity and/or eating style are causal to weight change after surgery. Lastly, efforts should be made in order to predict which patients will experience weight regain in an earlier stage. 


\section{References}

1. Chang SH, Stoll CR, Song J, Varela JE, Eagon CJ, Colditz GA. The effectiveness and risks of bariatric surgery: an updated systematic review and meta-analysis, 2003-2012. JAMA Surg. 2014 Mar;149(3):275-87.

2. Courcoulas AP, King WC, Belle SH, Berk P, Flum DR Garcia L, et al. Seven-Year Weight Trajectories and Health Outcomes in the Longitudinal Assessment of Bariatric Surgery (LABS) Study. JAMA Surg. 2018 May 1;153(5):427-34.

3. Karmali S, Brar B, Shi X, Sharma AM, de Gara C, Birch DW. Weight recidivism post-bariatric surgery: a systematic review. Obes Surg. 2013 Nov;23(11):1922-33.

4. Kuzminov A, Palmer AJ, Wilkinson S, Khatsiev B, Venn AJ. Re-operations after Secondary Bariatric Surgery: a Systematic Review. Obes Surg. 2016 Sep;26(9):2237-47.

5. Pinto-Bastos A, Conceicao EM, Machado PPP. Reoperative Bariatric Surgery: a Systematic Review of the Reasons for Surgery, Medical and Weight Loss Outcomes, Relevant Behavioral Factors. Obes Surg. 2017 Oct;27(10):2707-15.

6. Swift DL, Johannsen NM, Lavie CJ, Earnest CP, Church TS. The role of exercise and physical activity in weight loss and maintenance. Prog Cardiovasc Dis. 2014 Jan-Feb;56(4):441-7.

7. Donnelly JE, Blair SN, Jakicic JM, Manore MM, Rankin JW, Smith BK, et al. American College of Sports Medicine Position Stand. Appropriate physical activity intervention strategies for weight loss and prevention of weight regain for adults. Med Sci Sports Exerc. 2009 Feb;41(2):459-71.

8. Mechanick JI, Youdim A, Jones DB, Garvey WT, Hurley DL, McMahon MM, et al. Clinical practice guidelines for the perioperative nutritional, metabolic, and nonsurgical support of the bariatric surgery patient--2013 update: cosponsored by American Association of Clinical Endocrinologists, The Obesity Society, and American Society for Metabolic \& Bariatric Surgery. Obesity (Silver Spring). 2013 Mar;21 Suppl 1:S1-27.

9. Faria SL, Faria OP, Buffington C, de Almeida Cardeal M, Ito MK. Dietary protein intake and bariatric surgery patients: a review. Obes Surg. 2011 Nov;21(11):1798-805

10. van Baak MA, van Mil E, Astrup AV, Finer N, Van Gaal LF, Hilsted J, et al. Leisure-time activity is an important determinant of long-term weight maintenance after weight loss in the Sibutramine Trial on Obesity Reduction and Maintenance (STORM trial). Am J Clin Nutr. 2003 Aug;78(2):209-14.

11. van Baak MA. Physical activity and energy balance. Public Health Nutr. 1999 Sep;2(3A):335-9.

12. Amundsen T, Strommen M, Martins C. Suboptima Weight Loss and Weight Regain after Gastric Bypass Surgery-Postoperative Status of Energy Intake, Eating Behavior, Physical Activity, and Psychometrics. Obes Surg. 2017 May;27(5):1316-23.

13. Colles SL, Dixon JB, O'Brien PE. Hunger control and regular physical activity facilitate weight loss after laparoscopic adjustable gastric banding. Obes Surg. 2008 Jul;18(7):833-40.

14. Livhits M, Mercado C, Yermilov I, Parikh JA, Dutson E, Mehran A, et al. Exercise following bariatric surgery: systematic review. Obes Surg. 2010 May;20(5):657-65.

15. Bergh I, Kvalem IL, Mala T, Hansen BH, Sniehotta FF. Predictors of Physical Activity After Gastric Bypass-a Prospective Study. Obes Surg. 2017 Aug;27(8):20507.

16. Sherf Dagan S, Keidar A, Raziel A, Sakran N, Goitein D, Shibolet O, et al. Do Bariatric Patients Follow Dietary and Lifestyle Recommendations during the First Postoperative Year? Obes Surg. 2017 Sep;27(9):2258-71.

17. Mathus-Vliegen EM. Long-term health and psy- chosocial outcomes from surgically induced weight loss: results obtained in patients not attending protocolled follow-up visits. Int J Obes (Lond). 2007 Feb;31(2):299-307.

18. Castellini G, Godini L, Amedei SG, Faravelli C, Lucchese M, Ricca V. Psychological effects and outcome predictors of three bariatric surgery interventions: a 1-year follow-up study. Eat Weight Disord. 2014 Jun;19(2):217-24.

19. Konttinen H, Peltonen M, Sjostrom L, Carlsson L Karlsson J. Psychological aspects of eating behavior as predictors of $10-y$ weight changes after surgical and conventional treatment of severe obesity: results from the Swedish Obese Subjects intervention study. Am J Clin Nutr. 2015 Jan;101(1):16-24.

20. Sjostrom L. Review of the key results from the Swedish Obese Subjects (SOS) trial - a prospective controlled intervention study of bariatric surgery. J Intern Med. 2013 Mar;273(3):219-34.

21. Baecke JA, Burema J, Frijters JE. A short questionnaire for the measurement of habitual physical activity in epidemiological studies. Am J Clin Nutr. 1982 Nov;36(5):936-42.

22. Ledoux S, Sami O, Breuil MC, Delapierre M, Calabrese D, Msika S, et al. Relevance of Self-reported Behavioral Changes Before Bariatric Surgery to Predict Success After Surgery. Obes Surg. 2017 Jun;27(6):1453-9.

23. van Strien T, Frijters JER, Bergers GPA, Defares PB. The Dutch Eating Behavior Questionnaire (DEBQ) for assessment of restrained, emotional, and external eating behavior. Int J Eat Disord. 1986;5(2):295-315.

24. Brethauer SA, Kim J, El Chaar M, Papasavas P, Eisenberg D, Rogers A, et al. Standardized outcomes reporting in metabolic and bariatric surgery. Obes Surg. 2015 Apr:25(4):587-606.

25. Nedelcu M, Khwaja HA, Rogula TG. Weight regain after bariatric surgery-how should it be defined? Surg Obes Relat Dis. 2016 Jun;12(5):1129-30.

26. Fried M., Yumuk V., Oppert J.M., Scopinaro N. Torres A., Weiner R., et al. Interdisciplinary European guidelines on metabolic and bariatric surgery. Obes Surg. 2014;24(1):42-55.

27. Mahawar KK, Parmar C, Carr WR, Jennings N, Schroeder N, Balupuri S, et al. Preoperative Interventions for Patients Being Considered for Bariatric Surgery: Separating the Fact from Fiction. Obes Surg. 2015 Aug;25(8):1527-33.

28. Bond DS, Evans RK, Wolfe LG, Meador JG, Sugerman HJ, Kellum JM, et al. Impact of self-reported physical activity participation on proportion of excess weight loss and BMI among gastric bypass surgery patients. Am Surg. 2004 Sep;70(9):811-4

29. Forbush S, Nof L, Echternach J, Hill C, Rainey J. Influence of activity levels and energy intake on percent excess weight loss after Roux-en-Y gastric bypass. Obes Surg. 2011 Nov;21(11):1731-8.

30. Livhits M, Mercado C, Yermilov I, Parikh JA, Dutson E, Mehran A, et al. Behavioral factors associated with successful weight loss after gastric bypass. Am Surg. 2010 Oct;76(10):1139-42.

31. Coleman KJ, Toussi R, Fujioka K. Do gastric bypass patient characteristics, behavior, and health differ depending upon how successful weight loss is defined? Obes Surg. 2010 Oct;20(10):1385-92.

32. Silver HJ, Torquati A, Jensen GL, Richards WO. Weight, dietary and physical activity behaviors two years after gastric bypass. Obes Surg. 2006 Jul;16(7):859-64.

33. Rosenberger PH, Henderson KE, White MA, Masheb RM, Grilo CM. Physical activity in gastric bypass patients: associations with weight loss and psychosocial functioning at 12-month follow-up. Obes Surg. 2011 Oct;21(10):1564-9.

34. Welch G, Wesolowski C, Piepul B, Kuhn J, Romanelli J, Garb J. Physical activity predicts weight loss following gastric bypass surgery: findings from a support group survey. Obes Surg. 2008 May;18(5):517-24. 
Chapter 3

35. Bond DS, Phelan S, Wolfe LG, Evans RK, Meador JG, Kellum JM, et al. Becoming physically active after bariatric surgery is associated with improved weight loss and health-related quality of life. Obesity (Silver Spring). 2009 Jan;17(1):78-83.

36. Canetti L, Berry EM, Elizur Y. Psychosocial predictors of weight loss and psychological adjustment following bariatric surgery and a weight-loss program: the mediating role of emotional eating. Int J Eat Disord. 2009 Mar;42(2):109-17.

37. Braden A, Flatt SW, Boutelle KN, Strong D, Sherwood NE, Rock CL. Emotional eating is associated with weight loss success among adults enrolled in a weight loss program. J Behav Med. 2016 Aug;39(4):727-32.

38. Jansen A. Eating disorders need more experimental psychopathology. Behav Res Ther. 2016 Nov;86:210.

39. Josbeno DA, Jakicic JM, Hergenroeder A, Eid GM. Physical activity and physical function changes in obese individuals after gastric bypass surgery. Surg Obes Relat Dis. 2010 Jul-Aug;6(4):361-6.

40. Conceicao EM, Utzinger LM, Pisetsky EM. Eating Disorders and Problematic Eating Behaviours Before and After Bariatric Surgery: Characterization, Assessment and Association with Treatment Outcomes. Eur Eat Disord Rev. 2015 Nov;23(6):417-25. 




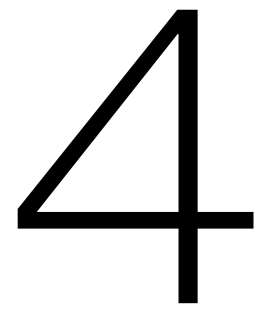

Improvement of health-related quality of life after Roux-en-Y gastric bypass related to weight loss.

Valerie M. Monpellier Evangelia E. Antoniou Edo O. Aarts Ignace M. C. Janssen Anita T. M. Jansen

Published in Obesity Surgery (ObesSur;2017 May;27(5):1168-1173.) 


\section{ABSTRACT}

\section{INTRODUCTION}

Effect of bariatric surgery on health-related quality of life (HRQoL) varies greatly. This might be caused by the diversity in questionnaires used to assess HRQoL and the weight loss of the studied population. This study assesses the relationship between weight loss and HRQoL in primary Roux-en-Y gastric bypass (RYGB) patients by using an obesity-specific (Impact of Weight on Quality of Life-lite, IWQOL-lite) and a generic (RAND-36) questionnaire.

\section{METHODS}

HRQoL and weight parameters were assessed before and 15 and 24 months after RYGB surgery. HRQoL was assessed by using IWQOL-lite (an obesity-specific questionnaire consisting of one total score and five domains) and RAND-36 (a generic questionnaire consisting of 2 subtotal scores, the physical health summary (PHS) and mental health summary (MHS) and 9 scales).

\section{RESULTS}

2,137 Patients were included. HRQoL improved significantly after RYGB. Preoperative BMI was negatively related to baseline PHS $(p<0.001)$ and IWQOL-lite total $(p<0.001)$. Percentage total weight loss $(\% T W L)$ was positively related to HRQoL score at both follow-up moments. Change in HRQoL from baseline to 24 months was related to \%TWL at 24 months in both subtotals of RAND-36 and IWQOL-lite total score $(p<0.001$ in all).

\section{CONCLUSION}

HRQoL improves after RYGB. Higher \%TWL is related to greater improvement in HRQoL and better HRQoL 15 and 24 months after RYGB. The variance in the effect of RYGB surgery on HRQoL can be explained by the questionnaire used and weight loss of the population. 


\section{INTRODUCTION}

Health-related quality of life (HRQoL) is currently considered a vital parameter after medical treatment worldwide ${ }^{1}$. In obese patients HRQoL is significantly impaired, therefore HRQoL improvement is one of the primary outcome measurements after bariatric surgery ${ }^{2-5}$. Common belief is that bariatric surgery positively affects HRQoL, however recent publications question this positive effect ${ }^{5-8}$. These publications show great variance in the effect of bariatric surgery and address two possible causes for this. First, HRQoL is assessed with numerous questionnaires, since there is no specific questionnaire to assess $\mathrm{HRQOL}$ in bariatric surgery patients ${ }^{5,6}$. Second, weight loss might also influence HRQoL ${ }^{7,8}$.

HRQoL questionnaires can be divided in two groups: obesity-specific questionnaires, like Impact of Weight on Quality of Life-lite (IWQOL-lite); and general questionnaires, like the RAND-36. In the obese population body weight was the main determinant of improvement of HRQoL when IWQOL-lite was used; outcome of a general questionnaire was only partially dependent on body weight $2,9,10$.

Strikingly the relationship between weight loss and HRQoL has been studied only sparsely in the bariatric population, and with conflicting results ${ }^{8,11,12}$. Even fewer studies have assessed the effect of bariatric surgery with a general and an obesity-specific questionnaire ${ }^{8,13}$.

In total, HRQoL is an important outcome after bariatric surgery. However, there is still a knowledge gap regarding the effect of bariatric surgery on HRQoL and the influence of weight loss on HRQoL. This study evaluated HRQoL before and after primary laparoscopic Roux-en-Y gastric bypass (RYGB) by using the IWQOL-lite and the RAND36. Secondly, the relationship between HRQoL and weight loss was assessed.

\section{METHODS}

\section{Patient selection and standard treatment}

This is a retrospective analysis of prospectively collected data, data was collected up to July 2015. Patients were selected from the database of the Nederlandse Obesitas Kliniek (Dutch Obesity Clinic); the largest, outpatient clinic for treatment of bariatric patients in the Netherlands which provides the structured care for over $50 \%$ of the Dutch bariatric population. All patients were screened according to IFSO-criteria. In addition to bariatric surgery, the treatment program consists of pre- and postoperative group counselling by a multidisciplinary team (dietician, a psychologist, a physical therapist and a medical doctor).

Since $2012 \mathrm{HRQoL}$ was routinely assessed in the treatment program; staring with the RAND-36 and later also adding IWQOL-lite. This treatment program was enrolled over the different clinics at several time points during 2012 and 2013. The questionnaires were administered at pre-operative screening and at 15 and 24 months after surgery. 


\section{Inclusion criteria}

All 2,562 patients who had undergone a primary RYGB before 2014 were selected from the database. Patients were included when IWQOL-lite or RAND-36 results were available before surgery and at least one-time post-surgery.

\section{Health-related Quality of Life IWQOL-lite}

The IWQOL-lite is a 31-item questionnaire which assesses the impact of weight on quality of life in five domains. This questionnaire has shown good validity and reliability in obese patients (test-rest reliability $r=0.74-0.91$; internal consistency, Cronbach's alpha 0.85 ) and was used before in the bariatric population ${ }^{5,14}$. In addition to a total score, there are scores on five scales: physical function, self-esteem, sexual life, public distress and work ${ }^{15}$.

\section{RAND-36}

The RAND-36 is a general HRQoL questionnaire with 36 questions and 9 scales: emotional role functioning, social functioning, vitality, physical functioning, mental health, bodily pain, general health perceptions, health change and physical role functioning. From these scales two subtotals can be calculated: physical health summary (PHS) and mental health summary (MHS) ${ }^{16}$. The RAND-36 has also been validated for the obese population (test-rest reliability $r=0.94$; internal consistency, Cronbach's alpha $0.96)^{16}$.

For both questionnaires a high score represents a higher HRQoL and scores range from 0-100. The smallest difference in score, which the patient perceives as beneficial, is the minimal clinically important difference (MCID). In previous research with bariatric patients the MCID threshold for RAND-36 was 5, for IWQOL-lite this threshold was $12{ }^{17}$.

\section{Body weight and other parameters}

Body weight was assessed at the same time points as HRQoL; height was assessed during preoperative screening. Weight loss was calculated and reported as stated in the most recent guidelines: Body Mass Index (BMI in $\left.\mathrm{kg} / \mathrm{m}^{2}\right)$, BMI difference $(\triangle \mathrm{BMI})$ and percent total weight loss (\%TWL) ${ }^{5}$. The following parameters were also registered: gender, age and comorbidities (diabetes mellitus, hypertension, obstructive sleep apnoea syndrome, hypercholesterolemia and osteoarthritis) at baseline.

\section{Statistical analysis}

Descriptive statistics summarized the patients' characteristics. Differences from baseline to follow-up points in HRQoL were analyzed with repeated measures ANOVA. Dif- 
ferences from 15 to 24 follow-up points in HRQoL were analyzed with paired sample T-tests. A regression analysis was performed to examine the relationship between BMI at baseline (BL), 15 months (15M) and 24 months (24M) and HRQoL total scores. Linear regression was also performed to study the relationship between weight change (\%TWL) and HRQOL-scores at 15 and at 24-month follow-up. In addition, change in HRQoL ( $\triangle \mathrm{HRQOL}$ ) from baseline to both follow-up moments, 15 and 24 months, was calculated. And two new variables were created, $\triangle \mathrm{HRQ}$ oL15 and $\triangle \mathrm{HRQ}$ LL24:

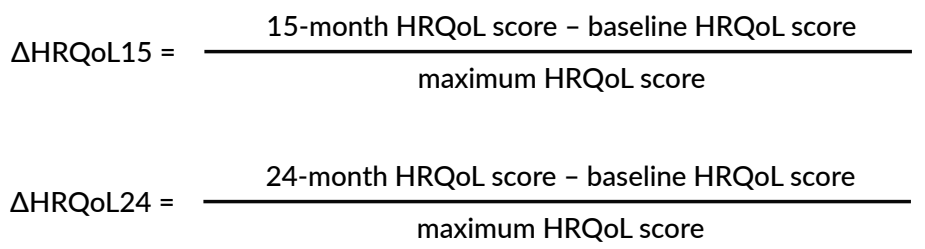

The relationship of $\triangle \mathrm{HRQ}$ oL and \%TWL at both follow-up moments was first examined with a bivariate analysis for total scores. Secondly a multiple regression was performed adjusting for baseline BMI, gender, age and comorbidities (diabetes mele litus, hypertension, obstructive sleep apnoea syndrome, hypercholesterolemia and osteoarthritis).

All statistical analysis was performed using the SPSS (version 23) statistical software. In all analysis a $p$ value $<0.05$ was considered statistically significant.

\section{RESULTS}

\section{Study population}

The study population consisted of 2,137 patients, 425 patients were excluded because of insufficient data. All patients had a follow-up longer than 15 months; in 44 patients $(2.1 \%)$ no weight loss data was available at 15 months. Follow-up was longer than 24 months in 1,411 patients, in $23.5 \%(n=332)$ no weight loss data were available.

Preoperative RAND-36 scores were available in 2,133 patients, at 15 months for 2074 patients and at 24 months for 1036 patients. For IWQOL-lite results of 2,130 patients were available preoperatively, at 15 months there were 1,953 results and at 24 months 612 results.

Mean age was 45.8 years and $82.5 \%$ of the population was female (Table 1). Mean baseline BMI was $44.5 \mathrm{~kg} / \mathrm{m}^{2}( \pm 5.8)$. At $15 \mathrm{M}$ follow-up, mean BMl was $30.7 \mathrm{~kg} / \mathrm{m}^{2}$ $( \pm 5.1)$ and TWL was $31.0 \%$; at $24 \mathrm{M}$ mean BMl was $30.7 \mathrm{~kg} / \mathrm{m}^{2}( \pm 5.2)$ and mean TWL was $31.1 \%$. 
Table 1:

Demographics of included population at baseline $(n=2,137), 15$ months $(n=2,093)$ and 24 months $(n=1,079)$

\begin{tabular}{l|c|c}
\hline & Mean \pm SD & Percentage (no.) \\
Age, years & $45.8 \pm 10.7$ & \\
Follow up, months & $26.8 \pm 5.9$ & \\
Female gender & & $82.5 \%(1762)$ \\
\hline Diabetes Mellitus & & $23.5 \%(503)$ \\
Hypertension & & $39.2 \%(838)$ \\
Obstructive Sleep Apnoea Syndrome & & $11.1 \%(237)$ \\
Hypercholesterolemia & & $20.1 \%(429)$ \\
Osteoarthritis & & $12.8 \%(274)$ \\
No comorbidity & $44.5 \pm 5.8$ & $43.3 \%(925)$ \\
\hline BL BMI, $\mathrm{kg} / \mathrm{m}^{2}$ & $30.7 \pm 5.1$ & \\
$15 \mathrm{M}$ BMI, $\mathrm{kg} / \mathrm{m}^{2}$ & $30.7 \pm 5.2$ & \\
$24 \mathrm{M} \mathrm{BMI}, \mathrm{kg} / \mathrm{m}^{2}$ & $13.8 \pm 4.1$ & \\
\hline $15 \mathrm{M} \Delta \mathrm{BMI}, \mathrm{kg} / \mathrm{m}^{2}$ & $13.9 \pm 4.3$ & \\
$24 \mathrm{M} \Delta \mathrm{BMI}, \mathrm{kg} / \mathrm{m}^{2}$ & $31.0 \pm 7.9$ & \\
\hline $15 \mathrm{M}$ TWL, \% & $31.1 \pm 8.4$ & \\
$24 \mathrm{M} \mathrm{TWL}, \%$ & & \\
\hline
\end{tabular}

$\mathrm{BL}=$ baseline; $15 \mathrm{M}=15$-month follow-up; $24 \mathrm{M}=24$-month follow-up; $\mathrm{BMI}=$ Body Mass Index; $\Delta \mathrm{BMI}=$ change in $\mathrm{BMI} ; \% \mathrm{TWL}=\%$ total weight loss

\section{Health-related Quality of Life}

All total scores and subscales of RAND-36 significantly improved in both when comparing $B L$ with $15 \mathrm{M}$ and $B L$ with $24 \mathrm{M}(p<0.001$ in all, Table 2). RAND-36 scores of all scales at $15 \mathrm{M}$ were significantly higher $(p<0.05$ in all) than at $24 \mathrm{M}$. IWQOL-lite scores also improved significantly in all scales, when comparing BL with both follow-up moments $(p<0.001$ in all, Table 2). IWQOL-lite scores at 24M follow-up were lower than at $15 \mathrm{M}$, this difference was not statistically significant.

\begin{tabular}{|c|c|c|c|c|c|c|}
\hline \multirow{2}{*}{ RAND-36 } & \multicolumn{2}{|c|}{$B L(n=2137)$} & \multicolumn{2}{|c|}{$15 M(n=2074)$} & \multicolumn{2}{|c|}{$24 M(n=1036)$} \\
\hline & Mean & $\pm S D$ & Mean & $\pm S D$ & Mean & $\pm S D$ \\
\hline physical health summary & 52.2 & 22.2 & $80.3^{*}$ & 19.0 & $78.6 * \dagger$ & 20.7 \\
\hline mental health summary & 65.8 & 19.3 & $78.1^{*}$ & 19.1 & $75.3^{*} \dagger$ & 20.0 \\
\hline emotional role functioning & 76.9 & 37.3 & 86.6 * & 30.6 & $83.2{ }^{*} \dagger$ & 33.9 \\
\hline social functioning & 68.4 & 25.6 & $83.3^{*}$ & 23.1 & $80.8 * \dagger$ & 23.7 \\
\hline vitality & 48.2 & 18.5 & 65.4 * & 20.1 & $62.5^{*} \dagger$ & 20.5 \\
\hline physical functioning & 51.9 & 24.5 & 86.9 * & 20.1 & $85.4^{* \circ}$ & 21.7 \\
\hline mental health & 69.7 & 17.0 & 77.0 * & 18.4 & $74.5^{*} \dagger$ & 18.3 \\
\hline bodily pain & 59.5 & 26.2 & $78.3^{*}$ & 25.2 & $77.2^{* 0}$ & 26.2 \\
\hline general health perceptions & 42.7 & 18.8 & 71.2 * & 19.5 & $69.3^{*} \dagger$ & 20.3 \\
\hline health change & 35.4 & 24.9 & 92.7 * & 18.6 & $76.2{ }^{*} \dagger$ & 26.9 \\
\hline physical role functioning & 54.7 & 41.7 & $85.1^{*}$ & 30.8 & $82.6^{*} \dagger$ & 32.6 \\
\hline
\end{tabular}




\begin{tabular}{l|cc|cc|cc}
\hline \multirow{2}{*}{ IWQOL-lite } & \multicolumn{2}{|c|}{$\mathrm{BL}(\mathrm{n}=2130)$} & \multicolumn{2}{c|}{$15 \mathrm{M}(\mathrm{n}=1953)$} & \multicolumn{2}{c}{$24 \mathrm{M}(\mathrm{n}=612)$} \\
& Mean & $\pm \mathrm{SD}$ & Mean & $\pm \mathrm{SD}$ & Mean & $\pm \mathrm{SD}$ \\
\hline Total & 56.9 & 18.7 & $91.1^{*}$ & 12.5 & $89.9^{*}$ & 12.7 \\
\hline physical function & 42.6 & 21.3 & $89.8^{*}$ & 13.7 & $88.7^{*}$ & 13.1 \\
self-esteem & 48.3 & 26.3 & $87.5^{*}$ & 18.3 & $85.7^{*}$ & 19.0 \\
sexual life & 60.0 & 31.6 & $88.8^{*}$ & 20.2 & $86.8^{*}$ & 22.3 \\
public distress & 62.0 & 24.1 & $94.2^{*}$ & 12.8 & $93.6^{*}$ & 12.7 \\
work & 71.3 & 22.4 & $94.9^{*}$ & 12.1 & $94.7^{*}$ & 12.0 \\
\hline
\end{tabular}

${ }^{*}$ significant difference compared to baseline, $p<0.001$; †significant difference compared to 15 -month follow-up, $p \leq 0.001 ;{ }^{\circ}$ significant difference compared to 15 -month follow-up, $p \leq 0.05$

$\mathrm{BL}=$ baseline; $15 \mathrm{M}=15$-month follow-up; $24 \mathrm{M}=24$-month follow-up

\section{Baseline BMI and HRQoL}

A higher baseline BMI was significantly associated with a lower baseline PHS-score $\left(R^{2}=0.005, F(1,2131)=10.539, p<0.001\right)$. There was no significant association between baseline BMI and baseline MHS score. IWQOL-lite total score was also negatively associated with $\mathrm{BMI}\left(\mathrm{R}^{2}=0.037, \mathrm{~F}(1,2128)=82.420, p<0.001\right)$.

\section{Follow-up weight and HRQoL}

PHS-score was significantly negatively related to $\mathrm{BMI}$ at $15 \mathrm{M}\left(\mathrm{R}^{2}=0.013, \mathrm{~F}(1,2056)\right.$ $=26.355, p<0.001)$ and $24 \mathrm{M}\left(\mathrm{R}^{2}=0.005, \mathrm{~F}(1,1019)=5.403, p=0.020\right)$. MHS was only associated with $\mathrm{BMI}$ at $24 \mathrm{M}\left(\mathrm{R}^{2}=0.004, \mathrm{~F}(1,2056)=3.956, p=0.047\right)$; this was also negative. IWQOL-lite total score was negatively associated with $\mathrm{BMI}$ at both $15 \mathrm{M}$ $\left(R^{2}=0.094, F(1,1935)=201.653, p<0.001\right)$ and $24 M\left(R^{2}=0.139, F(1,601)=97.412\right.$, $p<0.001)$. A higher BMI was associated with a lower HRQoL in both RAND-36 subtotals and the IWQOL-lite total score.

$15 \mathrm{M}$ and $24 \mathrm{M}$ scores of PHS, MHS and IWQOL-lite total score were significantly associated with \%TWL $(p<0.001$ in all). A higher \%TWL was associated with a higher HRQoL in all RAND-36 subtotals and the IWQOL-lite total score.

\section{Weight loss and change in HRQoL}

At 15 months $\triangle \mathrm{HRQ}$ oL ranged from 0.07 to 0.57 for RAND-36 scores and for IWQOLlite $\triangle H R Q \circ L 15$ ranged from 0.23 to 0.47 for IWQOL-lite scores. Significant correlations with \%TWL were found in the physical functioning scale $\left(r_{s}(2054)=0.096, p<0.001\right)$ and general health perception scale $\left(r_{s}(2054)=0.091, p<0.001\right)$ of RAND-36. For the IWQOL-lite all scales had significant correlations; highest correlation was with selfesteem scale $\left(r_{s}(1931)=0.147, p<0.001\right)$.

$\triangle \mathrm{HRQ}$ L15 of PHS and IWQOL-lite total score were significantly associated with $\%$ TWL ( $p<0.001$ in both). Also, after adjusting for baseline BMI, gender, age and comorbidities (diabetes mellitus, hypertension, obstructive sleep apnoea syndrome, hypercholesterolemia and osteoarthritis), \%TWL was still significantly related to $\triangle H R Q$ oL15 for PHS and IWQOL-lite total score (Table 3). For $\triangle H R Q$ LL15 of MHS there was no significant association $(p=0.213)$. 
$\triangle \mathrm{HRQ}$ oL24 ranged from 0.05 to 0.42 for RAND-36 scores and from 0.24 to 0.47 for IWQOL-lite scores. At 24 months, highest correlation with \%TWL was found in the physical functioning scale $\left(r_{s}(1034)=0.128, \mathrm{p}<0.001\right)$ and general health perception scale $\left(r_{s}(1034)=0.124, p<0.001\right)$ of RAND-36. In the IWQOL-lite the highest correlation was with self-esteem scale $\left(r_{s}(609)=0.230, p=0.104\right)$.

$\triangle \mathrm{HRQ}$ L24 of PHS, MHS and IWQOL-lite total score were all significantly associated with \%TWL $(p<0.001$ in all). After adjusting for baseline BMI, gender, age and comorbidities (diabetes mellitus, hypertension, obstructive sleep apnoea syndrome, hypercholesterolemia and osteoarthritis), \%TWL remained significantly related to $\triangle$ HRQoL24 for all total scores (Table 3).

\begin{tabular}{|c|c|c|c|c|c|}
\hline \multicolumn{6}{|c|}{$\begin{array}{l}\text { Table 3: } \\
\text { Linear regression analysis for } \triangle H R Q 0 L \text { based on \%TWL at both follow-up moments. }\end{array}$} \\
\hline \multirow{2}{*}{\multicolumn{6}{|c|}{15 months }} \\
\hline & & & & & \\
\hline RAND-36 PHS & .002 & .001 & $.001-.004$ & $<.001$ & .024 \\
\hline RAND-36 MHS & .001 & .001 & $.000-.002$ & .169 & .004 \\
\hline IWQOL-lite total & .003 & .001 & $.002-.004$ & $<.001$ & .055 \\
\hline \multicolumn{6}{|l|}{24 months } \\
\hline RAND-36 PHS & .003 & .001 & $.002-.005$ & $<.001$ & .038 \\
\hline RAND-36 MHS & .002 & .001 & $.001-.004$ & .003 & .026 \\
\hline IWQOL-lite total & .004 & .001 & $.003-.006$ & $<.001$ & .079 \\
\hline
\end{tabular}

\section{DISCUSSION}

The purpose of this study was to evaluate the effect of primary RYGB on HRQoL and assess the relationship between weight loss and HRQoL with two HRQoL questionnaires. Our results show that HRQoL significantly improves after primary RYGB when assessed with both a generic (RAND-36) and an obesity-specific (IWQOL-lite) questionnaire. A higher BMI is associated with a lower HRQoL before and after surgery. While more weight loss is associated with higher improvement of HRQoL and better HRQoL score at 15- and 24-months follow-up. The correlations between weight (loss) and HRQoL were higher with the IWQOL-lite compared to the RAND-36.

The effect of bariatric surgery on HRQoL was questioned in recent literature ${ }^{6,8}$. This study shows that HRQoL significantly improves after RYGB. After 15 months follow-up there was a statistically significant decline for all RAND-36 scores. This effect was also observed up to 5 years post-surgery in the SOS-study ${ }^{18}$. However, the reduction was only clinically relevant for one scale, the health change scale. The mean score of this scale at 24 months was still higher than the mean score of the normal 
population sample ${ }^{19}$. For the IWQOL-lite, there was also a slight decline, but none of the differences were statistically significant or clinically relevant. It seems that HRQoL stabilized 15 months post-surgery. This might be explained by the fact that patients experience an enormous improvement in HRQoL in the first 15 months. But after 12 - 15 months, in most patients weight stabilizes and thereby the additional changes that the patients experience in the months afterwards seem only small. Moreover, the HRQoL scores at 15 months are higher than the normal population scores; maybe there is no room left for further improvement.

Patients with a lower BMI before and after RYGB surgery generally had a better HRQoL. Total IWQOL-lite was related to presurgical BMI and BMI at both follow-up moments. In the obese population it was shown before that BMI was the more related to the IWQOL-lite scores compared to RAND-36 scores ${ }^{9,10}$. This study is the first to show that this also applies in the pre- and post-bariatric population.

For the generic questionnaire, BMI was associated physical health. This is in concordance with more studies assessing RAND-36 scores in post-bariatric patients ${ }^{8}$. It is likely that the physical effects of morbid obesity are substantial and thereby also influence general HRQoL. Mental health of the RAND-36 was only negatively associated with BMI at 24 months post-surgery.

Patients with a higher weight loss had a better HRQoL; total scores of RAND-36 and IWQOL-lite were all significantly positively associated with \%TWL. The effect of weight loss on HRQoL has been evaluated in several studies with various questionnaires, however the expected outcome had not been as clear as in our study ${ }^{11,12}$, 20-23. In addition, TWL was $31.1 \%$ at 24 months in our population, which might explain the greater association of weight loss and HRQoL. Other studies had much smaller populations and generally used percentage excess weight loss as a weight loss parameter. The higher number of patients in our study, and the use of \%TWL might have influenced the results.

Our results show that the variation in effect of bariatric surgery on HRQoL which was described recently, can at least in part be explained by the diversity in questionnaires used to assess HRQoL ${ }^{6}$. Change in HRQoL was highest in the IWQOL-lite scales, ranging from $23-47 \%$. For RAND-36, mean change ranged from $5-57 \%$. The correlations between \%TWL and $\triangle \mathrm{HRQOL}$ were also highest in the IWQOL-lite scales at 15 and 24-month follow-up. And RAND-36 MHS was not significantly associated with $\triangle \mathrm{HRQOL}$ at 15 months. To avoid influence of baseline HRQoL on outcome we calculated a $\triangle \mathrm{HRQ}$ oL.

In our study population maximum weight loss was achieved at an average of 15 months, therefore we chose to use 15 and 24 months to evaluate HRQoL. The large sample size enabled us to identify even small effects of weight loss on HRQoL. In previous research there was deterioration in HRQoL seen, which was explained by 
weight regain ${ }^{18}$. However, due to the strict follow up protocol our study population had underwent, no weight regain occurred (yet); weight was still declining or remained stable in all patients at 24 months. Looking at previous research it is very interesting to further investigate HRQoL and identify other factors which could influence the stabilization of HRQoL.

Only RYGB patients were included in this analysis to ensure accurate data-analysis without the bias of difference in weight loss. Because of the increase in the number of patients receiving other types of surgery, such as gastric sleeve, future research should focus on the effect of gastric sleeve surgery on HRQoL.

Because the studied population was the first population in which HRQoL was systematically assessed not all patients completed HRQoL at all follow-up moments. Despite this, the included population is still the largest bariatric population in which two types of HRQoL questionnaires were assessed.

\section{CONCLUSION}

Reported variance in the effect of RYGB on HRQoL can be explained by both the questionnaire used and the weight loss of the researched population; this should be taken into account when the effect of bariatric surgery on HRQoL is studied. HRQoL of pre-bariatric patients is low, and even lower in patients with a higher BMI. HRQoL improves significantly after RYGB when measured with both a specific and a generic questionnaire. However, the improvement in HRQoL is higher when an obesity specific questionnaire is used. The positive effect on HRQoL is greater in patients with a lower BMI and higher \% TWL up to 24 months after RYGB. Thus, more weight loss not only has a beneficial effect on medical comorbidities, it also positively influences patient's well-being. For future studies reporting HRQoL after surgery, mean weight loss and preoperative score should be taken into account. 


\section{References}

1. P. Fayers RH. Assessing Quality of Life in clinical trails. New York: Oxford Press; 2005.

2. van Nunen AM, Wouters EJ, Vingerhoets AJ, Hox JJ, Geenen R. The health-related quality of life of obese persons seeking or not seeking surgical or non-surgical treatment: a meta-analysis. Obes Surg. 2007 Oct;17(10):1357-66.

3. Stunkard AJ, Wadden TA. Psychological aspects of severe obesity. Am J Clin Nutr. 1992 Feb;55(2 Suppl):524S-32S.

4. Sarwer DB, Wadden TA, Fabricatore AN. Psychosocial and behavioral aspects of bariatric surgery. Obes Res. 2005 Apr;13(4):639-48.

5. Brethauer SA, Kim J, El Chaar M, Papasavas P, Eisenberg D, Rogers A, et al. Standardized outcomes reporting in metabolic and bariatric surgery. Obes Surg. 2015 Apr;25(4):587-606.

6. Lindekilde N, Gladstone BP, Lubeck M, Nielsen J, Clausen L, Vach W, et al. The impact of bariatric surgery on quality of life: a systematic review and meta-analysis. Obes Rev. 2015 Aug;16(8):639-51.

7. Sarwer DB, Steffen KJ. Quality of Life, Body Image and Sexual Functioning in Bariatric Surgery Patients. Eur Eat Disord Rev. 2015 Nov;23(6):504-8

8. Kroes M, Osei-Assibey G, Baker-Searle R, Huang $\mathrm{J}$. Impact of weight change on quality of life in adults with overweight/obesity in the United States: a systematic review. Curr Med Res Opin. 2016 Mar;32(3):485-508.

9. Kolotkin RL, Crosby RD, Williams GR, Hartley GG, Nicol S. The relationship between health-related quality of life and weight loss. Obes Res. 2001 Sep;9(9):564-71.

10. Kolotkin RL, Norquist JM, Crosby RD, Suryawanshi S, Teixeira PJ, Heymsfield SB, et al. One-year health-related quality of life outcomes in weight loss trial participants: comparison of three measures. Health Qual Life Outcomes. 2009 Jun 9;7:53,75257-53.

11. Dymek MP, Le Grange D, Neven K, Alverdy J. Quality of life after gastric bypass surgery: a cross-sectional study. Obes Res. 2002 Nov;10(11):1135-42.

12. Strain GW, Kolotkin RL, Dakin GF, Gagner M, Inabnet WB, Christos P, et al. The effects of weight loss after bariatric surgery on health-related quality of life and depression. Nutr Diabetes. 2014 Sep 1;4:e132.

13. De Zwaan M, Mitchell JE, Howell LM, Monson N, Swan-Kremeier L, Roerig JL, et al. Two measures of health-related quality of life in morbid obesity. Obes Res. 2002 Nov;10(11):1143-51.

14. Kolotkin RL, Crosby RD. Psychometric evaluation of the impact of weight on quality of life-lite questionnaire (IWQOL-lite) in a community sample. Qual Life Res. 2002 Mar;11(2):157-71.

15. Kolotkin RL, Crosby RD, Kosloski KD, Williams GR. Development of a brief measure to assess quality of life in obesity. Obes Res. $2001 \mathrm{Feb} ; 9(2): 102-11$.

16. van der Zee KI, Sanderman R, Heyink JW, deHaes $\mathrm{H}$, VanderZee K, de Haes H. Psychometric qualities of the RAND 36-item health survey 1.0: A multidimensional measure of general health status. International Journal of Behavioral Medicine. 1996;3(2):104.

17. Warkentin LM, Majumdar SR, Johnson JA, Agborsangaya CB, Rueda-Clausen CF, Sharma AM, et al. Weight loss required by the severely obese to achieve clinically important differences in health-related quality of life: two-year prospective cohort study. BMC Med. 2014 Oct 15;12:175,014-0175-5.

18. Karlsson J, Taft C, Ryden A, Sjostrom L, Sullivan M. Ten-year trends in health-related quality of life after surgical and conventional treatment for severe obesity: the SOS intervention study. Int J Obes (Lond). 2007 Aug;31(8):1248-61.

19. Karen I. van der Zee, Robbert Sanderman. Het meten van de algemene gezondheidstoestand met de RAND-36: een handleiding. ; 2012.

20. Klingemann J, Pataky Z, Iliescu I, Golay A. Relation- ship between quality of life and weight loss 1 year after gastric bypass. Dig Surg. 2009;26(5):430-3.

21. Major P, Matlok M, Pedziwiatr M, Migaczewski M, Budzynski P, Stanek M, et al. Quality of Life After Bariatric Surgery. Obes Surg. 2015 Sep;25(9):170310.

22. Rea JD, Yarbrough DE, Leeth RR, Leath TD, Clements $\mathrm{RH}$. Influence of complications and extent of weight loss on quality of life after laparoscopic Roux-en-Y gastric bypass. Surg Endosc. 2007 Jul;21(7):1095-100.

23. Julia C, Ciangura C, Capuron L, Bouillot JL, Basdevant A, Poitou C, et al. Quality of life after Rouxen-Y gastric bypass and changes in body mass index and obesity-related comorbidities. Diabetes Metab. 2013 Apr;39(2):148-54. 



\section{BODY IMAGE, EXCESS SKIN}

AND

BODY CONTOURING SURGERY 
Chapter 4 


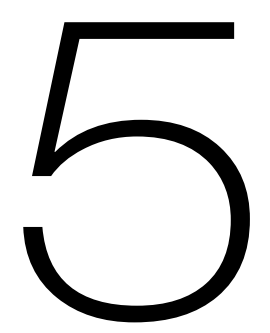

Body image dissatisfaction and depression in post-bariatric patients is associated with less weight loss and a desire for body contouring surgery.

Valerie M. Monpellier

Evangelia E. Antoniou

Sandra Mulkens

Ignace M. C. Janssen

Aebele B. Mink van der Molen

Anita T. M. Jansen

Published in Surgery for Obesity and Related Diseases

(SOARD.2018;14(10):1507-1515.) 


\section{ABSTRACT}

\section{BACKGROUND}

Overhanging skin in post-bariatric patients leads to a negative body image. In patients with obesity a negative body image is related to more depressive symptoms and a higher body weight. This relationship might also be important in post-bariatric patients, since improvement of body image, via body contouring surgery (BCS) could lead to better weight loss results. The objective was to evaluate the relationship between body image, depressive symptoms and weight loss in a post-bariatric population, focusing on desire for BCS.

\section{METHODS}

1024 Primary bariatric surgery patients were contacted; 590 patients agreed to participate and filled in online questionnaires regarding body image (Body Shape Questionnaire and Multidimensional Body-Self Relations Questionnaire-Appearance Scales) and depression (Beck Depression Inventory-II). Differences between patients who had BCS, patients who desired BCS and patients who did not desire BCS were studied. The mediating role of body image in the association between percentage Total Weight Loss (\%TWL) and depressive symptoms was assessed via a two-mediator model.

\section{RESULTS}

There was a desire for BCS in 368 patients (62.4\%); these patients had significantly lower scores on appearance evaluation and body image satisfaction scales and they showed more depressive symptoms. Patients without a desire $(n=157,26.6 \%)$ had lowest rates of depressive symptoms and a more positive body image. Sixty-five patients (11.0\%) had undergone BCS. In the patients who desired BCS, \%TWL was negatively affected by depressive symptoms via appearance evaluation and body-area satisfaction.

\section{CONCLUSION}

There are striking differences regarding body image satisfaction and depressive symptoms when comparing post-bariatric patients by desire for BCS. Body image satisfaction is associated with less depressive symptoms in all post-bariatric patients. In patients who desired BCS, body image is one of the mediators of the relationship between \%TWL and depressive symptoms. Therefore, body image should be taken seriously and be part of outcome assessment in post-bariatric patients. 


\section{INTRODUCTION}

The positive effects of bariatric surgery (BS), including significant weight loss and resolution of comorbidities, have been well established ${ }^{1,2}$. However, the massive weight loss can lead to excess skin, which may negatively affect patients' well-being by causing medical, functional and psychological problems ${ }^{3-6}$. Body contouring surgery (BCS) is the only treatment for restoration of the contour of the body and is desired by a large part of the post-bariatric population ${ }^{6-14}$. Yet, only a small portion (18-33\%) of the post-bariatric patients actually undergoes BCS; the high costs of this procedures are considered a major reason for this reluctance ${ }^{6,8,12,15}$.

After BCS, patients show an improved functional status, a better body image and a higher quality of life, both on the short and long term ${ }^{12,16-26}$. More importantly, BCS patients have better weight loss maintenance than patients who do not undergo BCS after bariatric surgery ${ }^{14,21,27}$. Why BCS results in better weight loss maintenance has never been studied.

Body weight and depression are strongly correlated in patients with obesity (higher weight indicating more depressive symptoms), and several studies found that this relationship is, at least partly, mediated by body image ${ }^{28-33}$. In obese patients there are more depressive symptoms when body image satisfaction is low. Depressive symptoms, in turn, are known to negatively affect body weight 14,21,28-31,34.

In post-bariatric patients extensive overhanging skin leads to a negative body image, and could thereby lead to (more) depressive symptoms. However, research regarding the relationship between body image and depressive symptoms in post-bariatric patients is scarce. One study assessed body image in post-bariatric patients with complaints of excess skin; it was found that a negative body image was related to more depressive symptoms and secondarily to weight regain ${ }^{34}$. Although this study was carried out in a relatively small sample, it does show that body image might play an important role in the well-being of post-bariatric patients. It is unknown, though, whether this is true for all post-bariatric patients. Do patients who desire BCS differ from patients who have no desire for BCS with regard to body image? In addition, to the best of our knowledge, no studies have been conducted assessing the role of body image in the relationship between weight loss and depressive symptoms, in a post-bariatric population.

Therefore, the goal of this study is to evaluate body image, depressive symptoms and weight loss in a post-bariatric population, and to compare patients who had BCS with patients who desire BCS and patients who do not desire BCS on these variables. Secondly, we will study the mediating role of body image in the relationship between weight loss and depressive symptoms for these groups.

We hypothesized that the relationship between weight loss and depressive symptoms would be partly mediated by body image in the population who has not undergone BCS. This hypothesis was based on previous research in patients with obesity, 
in which the relationship between weight and depression was partially mediated by body image ${ }^{28-33}$. In the population who already had BCS we expected a better body image and no relationship between weight and depressive symptoms.

\section{MATERIALS AND METHODS}

\section{Standard treatment}

Patients were all treated at the Nederlandse Obesitas Kliniek (Dutch Obesity Clinic). The NOK is the largest outpatient clinic for treatment of bariatric patients in the Netherlands. All patients follow pre- and postoperative group counselling by a specialized multidisciplinary team consisting of a dietician, a psychologist, a physical therapist and a medical doctor. The data used for this study were part of a large cross-sectional study. The study was approved by the Psychology Ethics Committee of Maastricht University (ECP 06_11_2014).

\section{Patient selection}

Patients were selected from a prospective database. Since BCS is usually performed 12 months after stabilization of the bodyweight, patients who had a primary bariatric procedure two to three years before the start of the study were selected for participation. Study start was January $2^{\text {nd }} 2015$, to ensure follow-up was at least 2 years, patients who had undergone a bariatric procedure between October 2011 and November 2012 were selected. Patients were excluded if body weight measures before and/or one year after bariatric surgery were not available.

There were 1,334 patients eligible for inclusion in the study; 1,024 patients were successfully contacted by electronic invitations. A total of 689 patients responded and $590 / 1024$ patients $(58 \%)$ agreed to participate, signed informed consent and were included in the study.

\section{Data collection}

Demographics and weight measurements before and at 12 and 24 months after bariatric surgery were collected from the prospective database. Body Mass Index (BMI), change in $\mathrm{BMI}(\triangle \mathrm{BMI})$, percentage total weight loss (\%TWL) and percentage excess weight loss (\%EWL) were calculated according to current guidelines ${ }^{(35)}$.

Results for the questionnaires were electronically collected after patients agreed to participation.

\section{Questionnaires}

\section{Body contouring surgery}

To assesses desire for BCS, patients were asked whether they wanted to undergo plastic surgery because of overhanging skin. It was also assessed if they had already 
undergone plastic surgery for overhanging skin. Current body weight was also assessed here.

\section{Body image}

The Body Shape Questionnaire (BSQ) was used to evaluate concerns about body shape ${ }^{36}$. This questionnaire consists of 16 questions, to be answered on a 6-point Likert scale; resulting in a total score ranging from 16 to 96 points. A higher score means more concerns about body shape (Table 1). The BSQ has been used for both obese and post-bariatric population and has shown good validity and reliability ${ }^{36-38}$.

The Multidimensional Body-Self Relations Questionnaire-Appearance Scales (MBSRQ-AS) gives insight in body image concerns; it has good validity and reliability ${ }^{39,40}$. The MBSRQ-AS has been used in both bariatric and body contouring populations ${ }^{23,32,41}$. This questionnaire consists of 34 items which are scored on a 5-point Likert scale; for each subscale scores range from 1-5 points (Table 1). There are 5 subscales:

1. appearance evaluation: assesses feelings of physical attractiveness (higher score indicates more positive feelings of attractiveness)

2. appearance orientation: assesses extend of investment in appearance (higher score indicates more investment)

3. overweight preoccupation: reflects the preoccupation with overweight cognitions (higher score indicates more preoccupation)

4. self-classified weight: reflects how the patient perceives and labels body weight (higher score indicates higher body weight)

5. body-area satisfaction scale: satisfaction with several aspects of appearance (higher score indicates more satisfaction).

\section{Depressive symptoms}

The Beck Depression Inventory-II (BDI-II) was used to evaluate depressive symptoms 42,43 . The questionnaire consists of 21 items, and each item can be scored from 0 to 3 points (Table 1). A score below 13 indicates no or minimal depressive symptoms, a score between 14 and 19 indicates light symptoms, a score between 20-28 indicates moderate symptoms and a score above 29 indicates severe depressive symptoms ${ }^{42}$. 


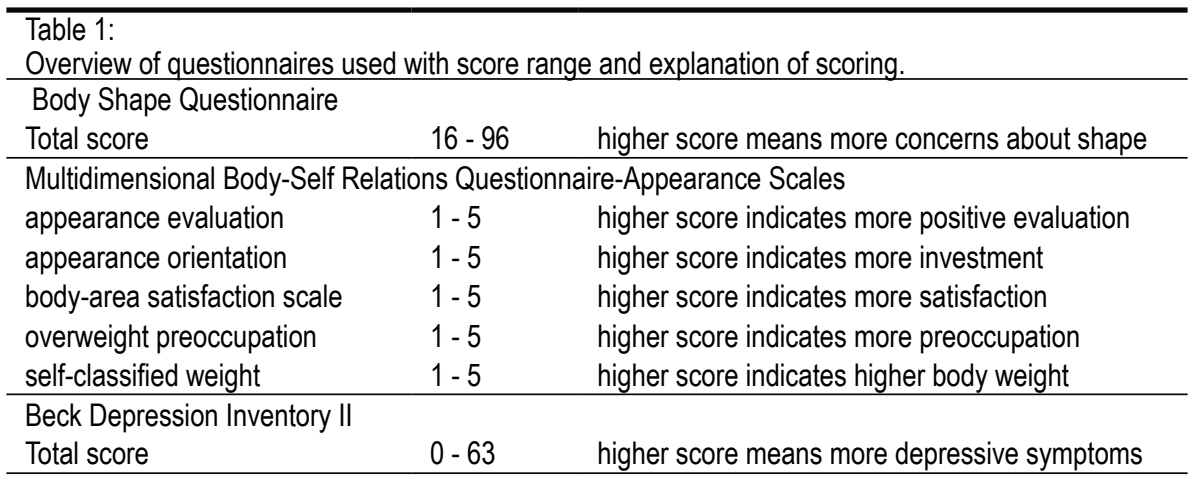

\section{Statistical analyses}

Descriptive statistics were calculated to summarize baseline characteristics. Independent samples t-tests and chi-square tests were used to compare the characteristics of the patients who were included and the patients who were excluded, to ensure this did not influence the results.

Subsequently, the included population was divided into three groups:

1. patients who already underwent $B C S=B C S$-group

2. patients who desired $B C S=D$-group

3. patients without a desire for BCS $=$ ND-group

Differences in age, weight change before and after bariatric surgery, body image, and depressive symptoms between the three groups were calculated using one-way ANOVA. Gender and type of bariatric surgery were compared using a chi-square analysis.

Subsequently, the relationship between depressive symptoms and \%TWL was assessed with a mediation analysis. A mediation analysis assesses how an independent variable affects a dependent variable, through intervening variables (the mediators) ${ }^{44}$. In this study, the mediating role of body image on the relationship between \%TWL and depressive symptoms was assessed via a two-mediator model (Figure 1). The appearance evaluation scale and body-area satisfaction scale were chosen as mediators. First, because these scales reflect how patients feel about their bodies; lower scores reflect more negative body image ${ }^{39}$. Secondly, because these variables are known to change after bariatric surgery and BCS ${ }^{20,23,32,45}$. Pearson's correlations between $\%$ TWL, depressive symptoms and body image (appearance evaluation and body-area satisfaction scale) were calculated for each of the groups. In case of significant correlations, a mediation analysis was conducted for that specific group. Baseline $\mathrm{BMI}$ and gender were included as covariates in this analysis. Bootstrapping was used to obtain confidence intervals $(\mathrm{Cls})^{44}$. Mediation was considered to have occurred if the $95 \%$ bias corrected Cls for the effects generated did not contain zero. Findings of other analysis were considered statistically significant if the $p$-value was $<0.05$.

All analyses were performed using SPSS, version 23 (IBM Corp. Released 2015. IBM 
SPSS Statistics for Windows, Version 23.0. Armonk, NY: IBM Corp.).

Figure 1: Two-mediator model of the relationship between percentage of total weight loss (\%TWL) and depressive symptoms.

$\% T W L$ indirectly effects depressive symptoms ( c') via appearance evaluation and body area satisfaction. The specific indirect effect through appearance evaluation is $a 1+b 1$ and through body area satisfaction $a 2+b 2$.

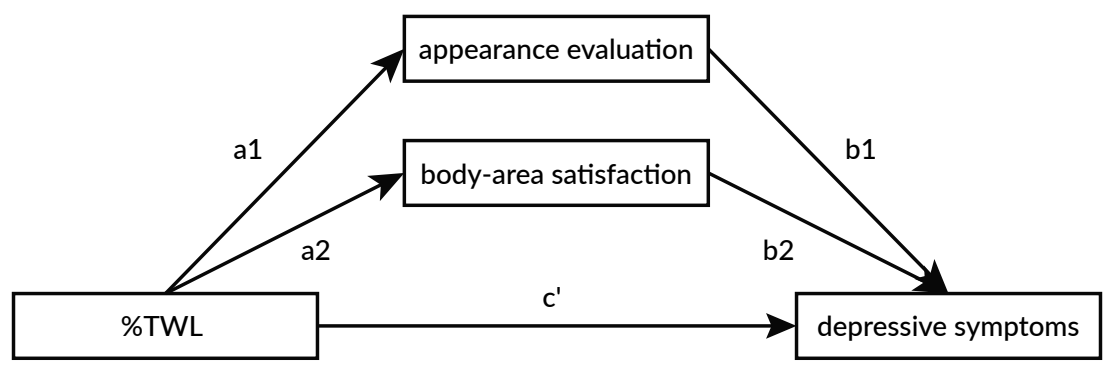

\section{RESULTS}

\section{Study population}

There were no significant differences between the included $(n=590)$ and excluded $(n=744)$ patients with regards to age, follow-up time since bariatric surgery, baseline $\mathrm{BMI}$ and BMI at 12 and 24 months after bariatric surgery. There were significantly more females in the included population: $81.2 \%$ compared to $75.3 \%(p=0.01)$. Mean age of the included patients was 47.7 years. Before bariatric surgery, the mean BMI was $45.4 \mathrm{~kg} / \mathrm{m}^{2}$. Most patients had undergone a RYGB ( $\left.\mathrm{n}=511,86.9 \%\right), 66$ patients (11.2\%) had undergone a gastric sleeve and 11 patients (1.9\%) had undergone laparoscopic adjustable banding. Mean BMI was $31.8 \mathrm{~kg} / \mathrm{m}^{2}$ at 12 months follow-up and $31.1 \mathrm{~kg} / \mathrm{m}^{2}$ at 24-month follow-up. At the time of the current survey the mean follow-up was 32 months, BMl was $30.7 \mathrm{~kg} / \mathrm{m}^{2}$ and TWL was $32.1 \%$.

\section{Patient characteristics}

A total of 65 patients (11.0\%) had undergone BCS (BCS-group). There was a desire for BCS in 368 patients (62.4\%, D-group), and no desire for BCS in $26.6 \%$ of the patients ( $\mathrm{n}=157$, ND-group).

The ND-group contained the lowest rate of females $(68.2 \%, p<0.001)$, compared to the D-group (84.5\%) and the BCS-group (93.8\%) (Table 2). Age, follow-up time and type of bariatric procedure were not significantly different between the three groups.

BMI before bariatric surgery was $46.2 \mathrm{~kg} / \mathrm{m}^{2}$ in the D-group, which was significantly higher compared to the ND-group (mean: $44.1 \mathrm{~kg} / \mathrm{m}^{2}, p=0.001$ ) and the BCS-group (mean: $43.9 \mathrm{~kg} / \mathrm{m}^{2}, p=0.011$ ). Patients who underwent BCS had the lowest BMI at all 
follow-up moments. Weight loss was higher in the D-group when compared to the ND-group: $\triangle \mathrm{BMI} 15.1 \mathrm{~kg} / \mathrm{m}^{2}$ versus $12.8 \mathrm{~kg} / \mathrm{m}^{2}(p<0.001)$ and TWL $32.6 \%$ versus $28.9 \%(p<0.001)$. In the BCS-group weight loss was highest; TWL $36.8 \%$.

\section{Table 2:}

Demographic characteristics of the three groups, presented in mean \pm standard deviation or percentage (no).

\begin{tabular}{l|c|c|c}
\hline & BCS-group $(\mathrm{n}=65)$ & D-group $(\mathrm{n}=368)$ & ND-group $(\mathrm{n}=157)$ \\
\hline Females, \% (no.) & $93.8 \%(61) \mathrm{\alpha}$ & $84.5 \%(311) \beta$ & $68.2 \%(107) \delta$ \\
Age, years & $45.0 \pm 11.4$ & $47.1 \pm 10.6 \beta$ & $49.8 \pm 10.5 \delta$ \\
RYGB, \% (no.) & $85.9 \%(55)$ & $87.8 \%(323)$ & $84.7 \%(133)$ \\
FU, months & $32.6 \pm 3.7$ & $32.3 \pm 3.9$ & $32.4 \pm 3.7$ \\
BMl before BS, $\mathrm{kg} / \mathrm{m}^{2}$ & $43.9 \pm 6.1 \mathrm{a}$ & $46.2 \pm 5.8 \beta$ & $44.1 \pm 6.3$ \\
BMl 12-month FU, $\mathrm{kg} / \mathrm{m}^{2}$ & $29.8 \pm 5.3 \mathrm{a}$ & $32.2 \pm 5.2$ & $31.6 \pm 5.7$ \\
BMl 24-month FU, $\mathrm{kg} / \mathrm{m}^{2}$ & $28.5 \pm 4.6 \mathrm{a}$ & $31.2 \pm 5.4$ & $31.9 \pm 6.0 \delta$ \\
Current BMI, $\mathrm{kg} / \mathrm{m}^{2}$ & $27.6 \pm 4.5 \mathrm{a}$ & $31.1 \pm 5.6$ & $31.3 \pm 5.6 \delta$ \\
$\Delta$ BMI, $\mathrm{kg} / \mathrm{m}^{2}$ & $16.3 \pm 5.1$ & $15.1 \pm 4.9 \beta$ & $12.8 \pm 4.6 \delta$ \\
Current EWL, \% & $89.1 \pm 20.1 \mathrm{a}$ & $73.9 \pm 22.6$ & $69.9 \pm 24.7 \delta$ \\
Current TWL, \% & $36.8 \pm 8.0 \mathrm{a}$ & $32.6 \pm 9.1 \beta$ & $28.9 \pm 9.3 \delta$ \\
\hline
\end{tabular}

a significant difference compared to D-group, $p<0.05 ; \beta$ significant difference compared to ND-group, $p<0.05 ; \delta$ significant difference compared to BCS-group, $p<0.05$. RYGB: Roux-en-y gastric bypass; FU: follow-up, BMI: body mass index, BS: bariatric surgery, $\triangle B M I$ : change in BMI; EWL: excess weight loss; TWL: total weight loss

\section{Body image}

The mean BSQ score was 49.5 in the D-group, which was significantly higher compared to the BCS-group $(40.2 ; p<0.001)$ and the ND-group $(30.1 ; p<0.001)$ (Table $3)$. The difference between the BCS-group and the ND-group was also significant $(p<0.001)$. There was a marked concern about shape (score above 66$)$ in $15.7 \%$ of the D-group; in the ND-group 1.4\% had a marked concern and in BCS-group this was $10.0 \%$ of the population $(p<0.001)$.

For the MBSRQ-AS, patients in the D-group had a mean score of 2.58 on appearance evaluation, which was significantly lower than the ND-group (mean 3.26, $p<0.001$ ) and the BCS-group (mean 3.23, $p<0.001$ ) (Table 3). They also had a significantly lower average score on the body area satisfaction scale: 2.68 versus 3.22 in the ND-group and 3.14 in BCS-group ( $p<0.001$ in all). Patients with no desire for BCS scored lowest on the appearance orientation (mean score 3.27) and overweight pre-occupation (mean score 2.41). Patients in the D-group had the highest score (mean 3.86) on the weight classification; the BCS-group scored significantly lower with a mean score of $3.24(p<0.001)$.

\section{Depressive symptoms}

BDI score was higher in the D-group (14.6), compared to the ND-group $(9.1, p<0.001)$ (Table 3). The BCS-group had a mean score of 12.1; this was not significantly different from either of the other groups. Subsequently, BDI scores were divided into four cate- 
gories, ranging from mild to severe depressive symptoms. In the D-group $26.9 \%$ had moderate to severe depressive symptoms compared to only $10.4 \%$ in the ND-group and $28.3 \%$ in the BCS-group $(p<0.001)$.

\section{Table 3:}

Body image and depressive symptoms of the three groups, presented as mean scores \pm standard deviation.

\begin{tabular}{|c|c|c|c|}
\hline & $\begin{array}{c}\text { BCS-group } \\
(n=65)\end{array}$ & $\begin{array}{l}\text { D-group } \\
(n=368)\end{array}$ & $\begin{array}{c}\text { ND-group } \\
(n=157)\end{array}$ \\
\hline Body Shape Questionnaire* & $40.2 \pm 18.4 a$ & $49.5 \pm 16.9 \beta$ & $30.1 \pm 12.8 \delta$ \\
\hline \multicolumn{4}{|c|}{ Multidimensional Body-Self Relations Questionnaire-Appearance Scales } \\
\hline appearance evaluation $^{* *}$ & $3.23 \pm 0.67 a$ & $2.58 \pm 0.72 \beta$ & $3.26 \pm 0.58$ \\
\hline appearance orientation $^{\star *}$ & $3.58 \pm 0.53$ & $3.74 \pm 0.56 \beta$ & $3.27 \pm 0.61 \delta$ \\
\hline body-area satisfaction scale ${ }^{* *}$ & $3.14 \pm 0.68 a$ & $2.68 \pm 0.56 \beta$ & $3.22 \pm 0.57$ \\
\hline overweight preoccupation* & $2.89 \pm 0.76$ & $2.98 \pm 0.83 \beta$ & $2.41 \pm 0.79 \delta$ \\
\hline self-classified weight* & $3.24 \pm 0.64 a$ & $3.86 \pm 0.74$ & $3.76 \pm 0.73 \delta$ \\
\hline Beck Depression Inventory II* & $12.1 \pm 11.0$ & $14.6 \pm 11.8 \beta$ & $9.1 \pm 11.0$ \\
\hline
\end{tabular}

a significant difference compared to D-group, $p \leq 0.005 ; \beta$ significant difference compared to ND-group, $p \leq 0.001 ; \delta$ significant difference compared to BCS-group, $p \leq 0.001$.

\section{Correlations}

In the patients with a desire for BCS \%TWL correlated negatively with depressive symptoms $(r=-0.196, p<0.001)$ and positively with appearance evaluation $(r=0.159$, $p=0.003)$ and body area satisfaction $(r=0.223, p<0.001)$. This means that more weight loss is associated with less depression and a more positive body image. Appearance evaluation and body area satisfaction both correlated negatively with BDI ( $r=-0.361$, $p<0.001$ and $r=-0.439, p<0.001$, respectively), meaning that a more negative body evaluation is associated with more depressed symptoms.

In the ND-group, \%TWL was significantly (positively) related to appearance evaluation $(r=0.227, p=0.006)$, meaning that more weight loss was significantly associated with a more positive appearance evaluation. There were no significant correlations of \% TWL with BDI and body area satisfaction, meaning that weight loss was not associated with depressive symptoms and body area satisfaction. There was a negative correlation between appearance evaluation and BDI $(r=-0.398, p<0.001)$ and body area satisfaction and $\mathrm{BDI}(\mathrm{r}=-0.432, p<0.001)$; lower appearance evaluation and lower body area satisfaction were related to more depressive symptoms.

In the BCS-group, there was a significant correlation of \%TWL with body area satisfaction ( $r=0.302, p=0.019)$, meaning that more weight loss is associated with higher body area satisfaction. No significant correlation of \%TWL with appearance evaluation or BDI was found, so the weight loss was not related to appearance evaluation or depression in this group. Again, there was a significant, negative correlation between 
the appearance evaluation and $\mathrm{BDI}(\mathrm{r}=-0.519, p<0.001)$ and body area satisfaction and BDI $(r=-0.557, p<0.001)$.

\section{Mediation effect of body image}

Since in the D-group all variables (\%TWL, depressive symptoms, appearance evaluation and body area satisfaction) were significantly correlated, a mediation analysis was conducted for this group. The total indirect effect of \%TWL on depressive symptoms was -0.15 , which leads to the rejection of the null hypothesis that the total indirect effect is zero $(p=0.003)$. Therefore, depressive symptoms are partly, via the mediators: appearance evaluation and body-area satisfaction, influenced by \%TWL. This means that a higher \%TWL results in less depressive symptoms, via more positive feelings of attractiveness and higher body-area satisfaction. The specific indirect effect through appearance evaluation is -0.04 and through body-area satisfaction is -0.11 (Table 4). Of the mediators examined, both appearance evaluation $(p=0.003)$ and body-area satisfaction $(p<0.001)$ were important mediators. This relationship was not influenced by baseline BMI $(p=0.267)$ or gender $(p=0.996)$.

Table 4:

Mediation effect of appearance evaluation and body-area satisfaction on the association between depression and percentage total weight loss in the desire-group.

\begin{tabular}{|c|c|c|c|c|}
\hline & \multirow[b]{2}{*}{ Coefficient } & \multirow{2}{*}{$\begin{array}{l}\text { Product of } \\
\text { Coefficients } \\
\text { Standard error }\end{array}$} & \multicolumn{2}{|c|}{$\begin{array}{l}\text { Bootstrapping } \\
\text { Bias Corrected } \\
95 \% \text { Confidance interval }\end{array}$} \\
\hline & & & Lower & Upper \\
\hline \multicolumn{5}{|l|}{ Indirect effects } \\
\hline appearance evaluation & $-0.04^{* *}$ & 0.02 & -0.10 & -0.01 \\
\hline body-area satisfaction & $-0.11^{* * *}$ & 0.04 & -0.20 & -0.04 \\
\hline total & $-0.15^{* * *}$ & 0.04 & -0.23 & -0.07 \\
\hline \multicolumn{5}{|l|}{ Contrast } \\
\hline $\begin{array}{l}\text { appearance evaluation } \\
\text { vs. } \\
\text { body-area satisfaction }\end{array}$ & 0.07 & 0.05 & -0.02 & 0.18 \\
\hline
\end{tabular}

\section{DISCUSSION}

The current study assessed body image, depressive symptoms, weight loss and the relationship between these factors in a large post-bariatric population, focusing on the desire for BCS. Our results show striking differences between patients who had BCS, patients who desired BCS and patients who did not desire BCS. Patients with a desire for BCS had a more negative body image than patients who already had BCS and patients without a desire for BCS. The patients with a desire also showed more depressive symptoms than patients without a desire. Moreover, in the population with 
a desire for BCS, a higher \%TWL was related in less depressive symptoms, via more positive feelings of attractiveness and higher body-area satisfaction. Thus, the relationship between weight loss and depressive symptoms was partly explained by body image. In all patients a better body image was related to less depressive symptoms. There was a desire for BCS in more than $60 \%$ of the study population, which is in concordance with previous research ${ }^{3,6-9}$. The patients who desire BCS showed a higher prevalence of depressive symptoms compared to patients who did not desire BCS. Several studies have shown higher appearance evaluation and body-area satisfaction after bariatric surgery and BCS 20,23,32,45. Our 'desire' population had more concerns about their body, felt less attractive and less satisfied with their appearance compared to patients who had no desire for BCS and patients who already had BCS. The characteristics of the desire-group (negative body image and more depressive symptoms) are known to negatively impact bodyweight in patients with obesity ${ }^{28-33}$.

Surprisingly, the patients who had undergone BCS showed some similarities with the patients who desired BCS. They both show higher appearance concerns and were both more pre-occupied with overweight stigmata. Research has shown that after bariatric surgery and body contouring, appearance evaluation and body area satisfaction improve, but the overweight pre-occupation might remain ${ }^{20,23}$. Thus, it could well be that the patients who desire BCS and the patients who have had BCS are basically the same type of patients, but body image in the BCS group have improved partly as a consequence of the body contouring procedure(s). Though these data are correlational and therefore causal conclusions cannot be drawn.

Interestingly more than a quarter of the studied patients did not have a desire for BCS; this group differs considerably from patients who already had BCS and the patients with a desire for BCS. These patients are less focused on their appearance and less preoccupied by overweight cognitions; even though they had the lowest weight loss and highest current BMI. Patients with a desire for BCS were even more preoccupied although they lost more weight and had a comparable BMI.

In the group with a desire for BCS, \%TWL, depressive symptoms, appearance evaluation and body area satisfaction were all significantly correlated. Higher weight loss was related to less depressive symptoms and a more positive body image. And in all three groups more positive feelings of physical attractiveness and higher satisfaction with the body were related to less depressive symptoms. Thus, even in the population without a desire for BCS a more negative body image is related to negative affect, like in the obese (pre-bariatric) population ${ }^{28,30}$.

Our hypothesis was that, like in patients with obesity, body image would partly mediate the relationship between weight loss and depressive symptoms in the post-bariatric patients who had not undergone $\mathrm{BCS}{ }^{30,31}$. Our results show that only in the 
patients who have a desire for BCS the association between \%TWL and depressive symptoms is indeed partially mediated by body image: a higher weight loss was related to less depressive symptoms via a more positive body image. This was independent of gender and BMI before bariatric surgery. These results show the close relationship between body weight, negative affect and body image. This is the first step into analyzing the pathways by which patients who undergo BCS might have better weight loss maintenance.

The three groups of patients had a similar follow-up time, and the number of patients who underwent RYGB was equal. But BMI before bariatric surgery was significantly different between the groups. Although this might have influenced preoperative body image and depressive symptoms, we cannot be certain about this, since preoperative data collection was not part of this study.

A weakness of the current study is its cross-sectional design, making it impossible to draw conclusions about the causal nature of the associations. As a consequence of the cross-sectional nature, we have no knowledge of the body image and depressive symptoms before bariatric surgery. In addition, it could be discussed that we did not assess the actual amount of overhanging skin. However, our goal was to show the differences in the psychological consequences of the experience of excess skin in the post-bariatric population. Moreover, research has shown that estimating excess skin is very difficult and does not correlate with the perception of the patient ${ }^{46}$.

A strength is the large number of participants and the relatively high response rate of this nationwide post-bariatric population, with almost no differences between the included and excluded population.

\section{CONCLUSION}

This study shows that post-bariatric patients differ in general body satisfaction. It seems that some post-bariatric patients are rather satisfied with their bodies without BCS, while another group is not happy with their body and desires BCS. The study further shows that body image is an important indicator of a patient's well-being after bariatric surgery, independently of the desire for BCS. However, up to date body image has not been a standard part of outcome analysis in this population. And until recently there was no specific questionnaire to assess body image in the (post-)bariatric patient. It is therefore unknown whether patients with a pre-operative negative body image are also the patients who desire BCS the most and who will also benefit the most from it.

Body image should be considered an outcome parameter in assessing health-related quality of life in post-bariatric patients. Future research should focus on body image both before and after bariatric surgery, and study the pathway by which BCS 
improves long-term weight loss maintenance. It might also be of interest to find out whether interventions that increase body satisfaction, should be part of pre- and postoperative care in this group of patients. 


\section{References}

1. Colquitt JL, Pickett K, Loveman E, Frampton GK. Surgery for weight loss in adults. Cochrane Database Syst Rev. 2014 Aug 8;(8):CD003641. doi(8):CD003641.

2. Sjostrom L. Review of the key results from the Swedish Obese Subjects (SOS) trial - a prospective controlled intervention study of bariatric surgery. J Intern Med. 2013 Mar;273(3):219-34.

3. Kitzinger HB, Abayev S, Pittermann A, Karle B, Bohdjalian A, Langer FB, et al. After massive weight loss: patients' expectations of body contouring surgery. Obes Surg. 2012 Apr;22(4):544-8.

4. Pecori L, Serra Cervetti GG, Marinari GM, Migliori F, Adami GF. Attitudes of morbidly obese patients to weight loss and body image following bariatric surgery and body contouring. Obes Surg. 2007 Jan;17(1):68-73.

5. Klopper E.M., Kroese-Deutman H.C., Berends F.J. Massive weight loss after bariatric surgery and the demand (desire) for body contouring surgery. Eur $\mathrm{J}$ Plast Surg. 2014;37(2):103-8.

6. Staalesen T, Fagevik Olsen M, Elander A. Experience of excess skin and desire for body contouring surgery in post-bariatric patients. Obes Surg. 2013 Oct;23(10):1632-44

7. Aldaqal SM, Samargandi OA, El-Deek BS, Awan BA Ashy AA, Kensarah AA. Prevalence and desire for body contouring surgery in postbariatric patients in saudi arabia. N Am J Med Sci. 2012 Feb;4(2):94-8.

8. Gusenoff JA, Messing S, O'Malley W, Langstein HN. Temporal and demographic factors influencing the desire for plastic surgery after gastric bypass surgery. Plast Reconstr Surg. 2008 Jun;121(6):2120-6.

9. Giordano S, Victorzon M, Stormi T, Suominen E. Desire for body contouring surgery after bariatric surgery: do body mass index and weight loss matter? Aesthet Surg J. 2014 Jan 1;34(1):96-105.

10. Wagenblast AL, Laessoe L, Printzlau A. Self-reported problems and wishes for plastic surgery after bariatric surgery. J Plast Surg Hand Surg. 2014 Apr;48(2):115-21.

11. Abela C, Stevens T, Reddy M, Soldin M. A multidisciplinary approach to post-bariatric plastic surgery. Int J Surg. 2011;9(1):29-35.

12. Azin A, Zhou C, Jackson T, Cassin S, Sockalingam $S$, Hawa R. Body contouring surgery after bariatric surgery: a study of cost as a barrier and impact on psychological well-being. Plast Reconstr Surg. 2014 Jun;133(6):776e-82e.

13. Gilmartin J, Bath-Hextall F, Maclean J, Stanton W, Soldin M. Quality of life among adults following bariatric and body contouring surgery: a systematic review. JBI Database System Rev Implement Rep. 2016 Nov;14(11):240-70.

14. Wiser I, Avinoah E, Ziv O, Parnass AJ, Averbuch Sagie R, Heller L, et al. Body contouring surgery decreases long-term weight regain following laparoscopic adjustable gastric banding: A matched retrospective cohort study. J Plast Reconstr Aesthet Surg. 2016 Nov;69(11):1490-6.

15. Gusenoff JA, Messing S, O'Malley W, Langstein HN. Patterns of plastic surgical use after gastric bypass: who can afford it and who will return for more. Plast Reconstr Surg. 2008 Sep;122(3):951-8.

16. Singh D, Zahiri HR, Janes LE, Sabino J, Matthews JA, Bell RL, et al. Mental and physical impact of body contouring procedures on post-bariatric surgery patients. Eplasty. 2012;12:e47.

17. Stuerz K, Piza H, Kinzl JF. The impact of abdominoplasty after massive weight loss: a qualitative study. Ann Plast Surg. 2013 Nov;71(5):547-9.

18. Koller M, Schubhart S, Hintringer T. Quality of life and body image after circumferential body lifting of the lower trunk: a prospective clinical trial. Obes Surg. 2013 Apr;23(4):561-6.

19. Coriddi MR, Koltz PF, Chen R, Gusenoff JA. Changes in quality of life and functional status following ab- dominal contouring in the massive weight loss population. Plast Reconstr Surg. 2011 Aug;128(2):520-6.

20. Song P, Patel NB, Gunther S, Li CS, Liu Y, Lee CY, et al. Body Image \& Quality of Life: Changes With Gastric Bypass and Body Contouring. Ann Plast Surg. 2016 May;76 Suppl 3:S216-21.

21. Balague N, Combescure C, Huber O, Pittet-Cuenod $B$, Modarressi A. Plastic surgery improves long-term weight control after bariatric surgery. Plast Reconstr Surg. 2013 Oct;132(4):826-33.

22. Modarressi A, Balague N, Huber O, Chilcott M, Pittet-Cuenod B. Plastic surgery after gastric bypass improves long-term quality of life. Obes Surg. 2013 Jan;23(1):24-30.

23. de Zwaan M, Georgiadou E, Stroh CE, Teufel M, Kohler $\mathrm{H}$, Tengler $\mathrm{M}$, et al. Body image and quality of life in patients with and without body contouring surgery following bariatric surgery: a comparison of pre- and post-surgery groups. Front Psychol. 2014 Nov 18;5:1310.

24. van der Beek ES, Geenen R, de Heer FA, van der Molen AB, van Ramshorst B. Quality of life long-term after body contouring surgery following bariatric surgery: sustained improvement after 7 years. Plast Reconstr Surg. 2012 Nov;130(5):1133-9.

25. van der Beek ES, Te Riele W, Specken TF, Boerma D, van Ramshorst B. The impact of reconstructive procedures following bariatric surgery on patient well-being and quality of life. Obes Surg. 2010 Jan;20(1):36-41.

26. Vierhapper MF, Pittermann A, Hacker S, Kitzinger HB. Patient satisfaction, body image, and quality of life after lower body lift: a prospective pre- and postoperative long-term survey. Surg Obes Relat Dis. 2017 Jan 11.

27. Froylich D, Corcelles R, Daigle CR, Aminian A, Isakov $R$, Schauer PR, et al. Weight loss is higher among patients who undergo body contouring procedures after bariatric surgery. Surg Obes Relat Dis. 2016 Nov;12(9):1731-6.

28. Stunkard AJ, Wadden TA. Psychological aspects of severe obesity. Am J Clin Nutr. 1992 Feb;55(2 Suppl):524S-32S.

29. Wardle J, Waller J, Rapoport L. Body dissatisfaction and binge eating in obese women: the role of restraint and depression. Obes Res. 2001 Dec;9(12):778-87.

30. Friedman KE, Reichmann SK, Costanzo PR, Musante GJ. Body image partially mediates the relationship between obesity and psychological distress. Obes Res. 2002 Jan;10(1):33-41.

31. Sarwer DB, Wadden TA, Foster GD. Assessment of body image dissatisfaction in obese women: specificity, severity, and clinical significance. J Consult Clin Psychol. 1998 Aug;66(4):651-4.

32. Dixon JB, Dixon ME, O'Brien PE. Body image: appearance orientation and evaluation in the severely obese. Changes with weight loss. Obes Surg. 2002 Feb;12(1):65-71.

33. Jansen A, Havermans R, Nederkoorn C, Roefs A. Jolly fat or sad fat? Subtyping non-eating disordered overweight and obesity along an affect dimension. Appetite. 2008 Nov;51(3):635-40.

34. Ramalho S, Bastos AP, Silva C, Vaz AR, Brandao I, Machado PP, et al. Excessive Skin and Sexual Function: Relationship with Psychological Variables and Weight Regain in Women After Bariatric Surgery. Obes Surg. 2015 Jul;25(7):1149-54.

35. Brethauer SA, Kim J, El Chaar M, Papasavas P, Eisenberg D, Rogers A, et al. Standardized outcomes reporting in metabolic and bariatric surgery. Obes Surg. 2015 Apr;25(4):587-606.

36. Cooper PJ, Taylor MJ, Cooper Z, Fairburn CG. The development and Validation of the Body Shape Questionnaire. International Journal of Eating Disorders. 1987;6(4):485.

37. White MA, Masheb RM, Rothschild BS, Burke-Martindale $\mathrm{CH}$, Grilo $\mathrm{CM}$. The prognostic significance of regular binge eating in extremely obese gastric 
bypass patients: 12-month postoperative outcomes.

J Clin Psychiatry. 2006 Dec;67(12):1928-35.

38. Hrabosky JI, Masheb RM, White MA, Rothschild

BS, Burke-Martindale CH, Grilo CM. A prospec-

tive study of body dissatisfaction and concerns in extremely obese gastric bypass patients: 6 - and 12-month postoperative outcomes. Obes Surg. 2006 Dec;16(12):1615-21.

39. Cash TF, Wood KC, Phelps KD, Boyd K. New assessments of weight-related body image derived from extant instruments. Percept Mot Skills. 1991 Aug;73(1):235-41.

40. Brown TA, Cash TF, Mikulka PJ. Attitudinal body-image assessment: factor analysis of the Body-Self Relations Questionnaire. J Pers Assess. 1990 Fall;55(1-2):135-44

41. Neven K, Dymek M, leGrange D, Maasdam H, Boogerd AC, Alverdy J. The effects of Roux-en-Y gastric bypass surgery on body image. Obes Surg. 2002 Apr;12(2):265-9.

42. Beck AT, Steer RA, Brown GK. Manual for the Beck Depression Inventory-II. San Antonio: Psychological Corporation; 1996.

43. Beck AT, Steer RA, Ball R, Ranieri W. Comparison of Beck Depression Inventories -IA and -II in psychiatric outpatients. J Pers Assess. 1996 Dec;67(3):588-97.

44. Preacher KJ, Hayes AF. Asymptotic and resampling strategies for assessing and comparing indirect effects in multiple mediator models. Behav Res Methods. 2008 Aug;40(3):879-91.

45. Song AY, Rubin JP, Thomas V, Dudas JR, Marra KG, Fernstrom $\mathrm{MH}$. Body image and quality of life in post massive weight loss body contouring patients. Obesity (Silver Spring). 2006 Sep;14(9):1626-36.

46. Biorserud C, Olbers T, Staalesen T, Elander A, Olsen MF. Understanding excess skin in postbariatric patients: objective measurements and subjective experiences. Surg Obes Relat Dis. 2016 Feb 2. 

Body Contouring Surgery After Massive Weight Loss: excess skin, body satisfaction and qualification for reimbursement in a Dutch post-bariatric population.

Valerie M. Monpellier

Evangelia E. Antoniou

Sandra Mulkens

Ignace M. C. Janssen

Aebele B. Mink van der Molen

Anita T. M. Jansen

Accepted for publication in Plastic and Reconstructive Surgery 


\section{ABSTRACT}

\section{BACKGROUND}

Body contouring surgery (BCS) improves quality of life, weight loss and body image after bariatric surgery. It is unclear why only a minority of the post-bariatric population undergoes BCS. In this study, we assess overhanging skin, body satisfaction and qualification for reimbursement of BCS in a Dutch post-bariatric population and study the differences between patients who have undergone BCS, patients who desire BCS and patients who do not.

\section{METHODS}

Post-bariatric patients at the Nederlandse Obesitas Kliniek were selected from a prospective database. Electronic questionnaires evaluated demographics, desire for BCS, excess skin and satisfaction with their body.

\section{RESULTS}

A total of 590 patients were included: 368 patients (62.4\%) desired BCS, 157 (26.6\%) did not desire BCS and 65 (11.0\%) had undergone BCS. There were no significant differences between the groups regarding the percentage of patients who met the qualifications for reimbursement. Patients who desired BCS had more body parts affected by overhanging skin and more often rated the overhanging skin with a Pittsburg Rating Scale grade 3 compared to patients without a desire. The plastic surgeon was never consulted by $39.1 \%$ of the "desire" population; $44.1 \%$ of these patients met the weight criteria.

\section{CONCLUSIONS}

Post-bariatric patients who desired BCS had more excess skin than patients without a desire and were less satisfied with their body. Almost half of these patients never consulted a plastic surgeon, partly because of incorrect assumptions regarding reimbursement. Plastic surgeons (together with bariatric teams) should better inform post-bariatric patients about BCS possibilities. 


\section{INTRODUCTION}

In 2014 bariatric surgery was performed in 579,517 patients worldwide ${ }^{1}$. Bariatric surgery causes massive weight loss, leading to overhanging skin in up to $96 \%$ of the patients ${ }^{2-5}$. This overhanging skin can result in several problems, ranging from skin conditions to physical discomfort, but also serious psychological issues ${ }^{2,5-8}$. Body contouring surgery (BCS) is the only treatment to restore the body's contour. After BCS patients have improved quality of life, body image and weight loss maintenance 8-15. Despite these positive effects, BCS is not a standard part of the post-bariatric treatment regime and only a minority of the population undergoes $B C S^{5,8,16}$. Patients frequently address that they cannot be treated because they do not get reimbursed by the insurance company, although this was barely studied ${ }^{3,8}$. To qualify for reimbursement in the Netherlands, patients must meet the following criteria: bariatric procedure over 18 months ago, stable weight for more than 12 months, body mass index $(\mathrm{BMI})<35 \mathrm{~kg} / \mathrm{m}^{2}$. In addition, patients should have a serious impairment of bodily function in daily life or a grade 3 excess skin in the Pittsburg Rating Scale (PRS), which is graded by the plastic surgeon ${ }^{17,18}$. Insurance companies then verify, and sometimes adjust, this grading and finally decide whether a patient will get reimbursed.

It appears that a significant number of the post-bariatric individuals who desire BCS do not undergo a procedure, partly because of the current reimbursement system in the Netherlands. However, exact numbers of patients who desire BCS and who undergo BCS are unknown. In addition, there might be other reasons why patients do not undergo BCS, like the extent of complaints and dissatisfaction with their body. The goal of this study is to gain more insight into the differences between patients who have undergone BCS, patients who desire BCS and patients who do not. This study looks at demographics, overhanging skin, body satisfaction and qualification for reimbursement. Secondly, we will investigate the perceived reasons why patients have not undergone BCS.

\section{METHODS}

\section{Standard treatment}

Patients were all in treatment at the Nederlandse Obesitas Kliniek (NOK, Dutch Obesity Clinic). This is the largest outpatient clinic for bariatric patients in the Netherlands, offering multidisciplinary pre- and postoperative group counselling in combination with bariatric surgery. This study was part of a larger research project on body contouring surgery in the post-bariatric population ${ }^{19}$. The study was approved by the Ethical Research Committee of the Faculty of Psychology and Neuroscience, Maastricht University (ECP 06_11_2014). 


\section{Patients}

Patients were selected from a prospective database if they had undergone a primary bariatric procedure between October 2011 and October 2012. When body weight measures before and/ or one year after bariatric surgery were not available patients were excluded. Patients who could be included were invited to participate through an electronic mail request via the Qualtrics platform (Qualtrics, Provo, UT). Before they could start the questionnaires, patients gave electronic informed consent. A total of 1,334 patients were eligible for inclusion; 1,024 patients were successfully contacted and asked to participate. The response rate was $67 \%(689 / 1024)$ and 590 patients (58\% of the contacted population) agreed to participate and were included.

\section{Questionnaires}

\section{General information}

Patients were asked to report their current body weight, educational level, employment, and income. Educational level was subdivided into 'low' (no schooling, secondary school, or intermediate vocational education), 'medium' (secondary vocational education or high school) and 'high' (higher professional education or university degree). Employment was subdivided into 'working', 'unemployed', 'retired' or 'student'. An annual income of $€ 34,085$ was considered a median income in the Netherlands at the time of the study.

\section{Body contouring surgery and skin surplus}

Our self-developed questionnaire inquired whether patients had undergone BCS or whether there was a desire for BCS. Patients were asked to indicate their reasons for not undergoing BCS. Patients estimated the amount of overhanging skin by comparing their body to pictures of the PRS, ranging from ' 0 ' (appearance in normal range) to ' 3 ' (most sever deformity) ${ }^{17}$. Pictures of arms, breasts (for women), abdomen and flanks were used. In addition, patients indicated in which of the following body parts they had overhanging skin: arms, inside thighs, outside thighs, abdomen, breasts/ chest, buttocks, back, flanks and other body parts. They were also asked to indicate their top three of body parts for which they would like to have BCS.

\section{Body Satisfaction}

A short version of an unpublished questionnaire developed by the authors (AJ) was used to assess satisfaction with their body (Appendix 1). Patients rated their total body and 16 body parts on a scale from ' 1 ' (not satisfied with body) to '10' (extremely satisfied with body). Subsequently, patients were asked about the importance of all these body parts on a 4-point Likert scale ${ }^{20}$. In a Likert scale responses are scored along a range, in this case ranging from ' 1 ' (not important) to ' 4 ' (very important). Patients could also indicate how satisfied they were with the proportions of their body. 


\section{Body weight}

Body weight measurements before bariatric surgery and 12, 24, and 36 months after were retrieved from the database. BMI, percentage excess weight loss (\%EWL) and percentage total weight loss (\%TWL) were calculated ${ }^{21}$. Stability of weight was defined as current weight $+/-5 \%$ in the last 12 months, compared to the weight in the existing database. Subsequently, it was assessed whether a patient met the weight qualifications for reimbursement in the Netherlands (i.e., stable weight for $\square 12$ months and $\mathrm{BMI}<35 \mathrm{~kg} / \mathrm{m}^{2}$ ).

\section{Statistical analyses}

Descriptive statistics were calculated to summarize baseline characteristics. For further analysis, patients were divided into three groups: the BCS-group, consisting of patients who already had BCS; the desire-group, consisting of patients with a desire for BCS and the no desire-group, consisting of patients without a desire for BCS. Differences between these groups were calculated using ANOVAs for continuous variables and Chi-square tests for discrete variables. For ANOVAs post hoc analysis were performed when there were significant differences. Pearson's correlation was calculated to study the relationship between body satisfaction and PRS grading. Findings were considered statistically significant when $p$ was $<0.05$. All analyses were performed using SPSS software version 23.

\section{RESULTS}

\section{Study population}

Of the included population ( $n=590), 81.2 \%$ was female. Mean age was 47.7 years. Education was low in $39.5 \%(n=232)$, medium in $40.7 \%(n=240)$ and high in $19.7 \%$ $(n=116)$. Most patients had a part-time or full-time job $(n=369,62,5 \%)$. Income was $€ 20,070$ or lower in 108 patients (18.3\%), between $€ 20,070$ and $€ 34,085$ in 132 patients (22.4\%), between $€ 34,085$ and $€ 43,602$ in $12.9 \%$ ( $n=76)$ and $€ 43,602$ or higher in $14.9 \%(n=88)$. A total of $31.5 \%$ of the patients did not want to disclose their income. Most patients had undergone Roux-en- $Y$ gastric bypass $(n=511,86.7 \%)$ and mean follow-up was 32 months (range 26-39 months). Mean current BMl was $30.7 \mathrm{~kg} / \mathrm{m}^{2}$; this was $45.4 \mathrm{~kg} / \mathrm{m}^{2}$ before bariatric surgery. Mean TWL was $32.1 \%$ and mean EWL was $74.5 \%$.

\section{Patient characteristics}

The majority of patients desired BCS ( $n=368 ; 62.4 \%)$, while $26.6 \%(n=157)$ did not desire BCS and $11.0 \%(n=65)$ already had undergone BCS. In the BCS-group, $93.8 \%$ was female; this was higher than in the desire-group (84.5\%) and the no desire-group $(68.2 \%)(p<0.001$, Table 1). Patients without a desire (49.8 yrs.) were significantly older compared to the BCS-group (45.1 yrs., $p=0.008$ ) and the desire-group (47.2 yrs., 
$p=0.029$ ).

In the desire-group the rate of unemployment was higher $(34.9 \%)$ compared to the no desire-group (26.1\%, $p=0.026)$. There were also significantly more patients with an income below median (64.6\%) in the desire-group, compared the BCS-group (55.6\%) and to the no desire-group $(48.6 \%, p=0.017)$. Unemployment was lowest in the BCSgroup $(24.6 \%, p=0.026)$. There were no significant differences in education level.

\section{Body weight}

Follow-up was not significantly different between the three groups, nor was type of bariatric procedure (Table 1). Current BMI was lowest in the BCS-group, $27.6 \mathrm{~kg} / \mathrm{m}^{2}$, versus $31.1 \mathrm{~kg} / \mathrm{m}^{2}$ in the desire-group $(p<0.001)$ and $31.3 \mathrm{~kg} / \mathrm{m}^{2}$ in the no desire-group $(p<0.001)$.

\section{Table 1:}

Demographic characteristics of patients who desire BCS (desire group), patients who have no desire (no desire group) and patients who had BCS (BCS group).

\begin{tabular}{|c|c|c|c|}
\hline & \multicolumn{3}{|c|}{ Percentage (n) } \\
\hline & $\begin{array}{c}\text { Desire group } \\
n=368\end{array}$ & $\begin{array}{c}\text { No desire group } \\
n=157\end{array}$ & $\begin{array}{c}\text { BCS group } \\
n=65\end{array}$ \\
\hline Female gender & $84.5 \%(311)$ & $68.2 \%(107)$ & $93.8 \%(61)$ * \\
\hline Low education & $38.9 \%(61)$ & $41.0 \%(150)$ & $32.3 \%(21)$ \\
\hline Unemployed & $34.9 \%(128)$ & $26.1 \%(41)$ & $24.6 \%(16)^{*}$ \\
\hline Income below median & $64.6 \%(164)$ & $48.6 \%(51)$ & $55.6 \%(25)$ * \\
\hline Roux-en-Y gastric bypass & $87.8 \%(323)$ & $84.7 \%(133)$ & $85.9 \%(55)$ \\
\hline \multicolumn{4}{|c|}{ *significant difference between 3 groups, $p<0.05$} \\
\hline & \multicolumn{3}{|c|}{ Mean \pm standard deviation } \\
\hline & Desire group & No desire group & BCS group \\
\hline Age, years & $47.2 \pm 10.6 a$ & $49.8 \pm 10.5 \beta$ & $45.1 \pm 11.4$ \\
\hline Follow-up, months & $32.3 \pm 3.9$ & $32.4 \pm 3.7$ & $32.6 \pm 3.7$ \\
\hline Baseline BMI, $\mathrm{kg} / \mathrm{m}^{2}$ & $46.2 \pm 5.8 a$ & $44.1 \pm 6.3$ & $43.9 \pm 6.1 \delta$ \\
\hline Current BMl, kg/m² & $31.1 \pm 5.6$ & $31.3 \pm 5.6 \beta$ & $27.6 \pm 4.5 \delta$ \\
\hline Current TWL, \% & $32.6 \pm 9.1 a$ & $28.9 \pm 9.3 \beta$ & $36.8 \pm 8.0 \delta$ \\
\hline Current EWL, \% & $73.9 \pm 22.6$ & $69.9 \pm 24.7 \beta$ & $89.1 \pm 20.1 \delta$ \\
\hline
\end{tabular}

\section{Weight qualification}

In the BCS-group $95.3 \%$ had a BMI $<35 \mathrm{~kg} / \mathrm{m}^{2}$, compared to $77.3 \%$ in the desire-group and $74.4 \%$ in the no desire-group ( $p=0.002$, Table 2$)$. The proportion of patients with a stable weight did not differ between the groups. In the desire-group, $44.1 \%$ met the weight qualifications, there was no significant difference compared to the BCS-group and the no desire-group.

\section{Skin surplus}


Mean number of body parts affected by overhanging skin ranged was 2.7 (Table 2). In the desire-group, 3.1 body parts were affected, compared to 1.7 in the no desire-group $(p<0.001)$. Most affected were abdomen $(72.5 \%)$, inside of thighs $(50.0 \%)$, upper arms (46.1\%) and breasts/chest (43.4\%). The abdomen was also the most desired body part for BCS ( $n=250,58.8 \%$ ).

The mean PRS grade for abdomen was highest in all patients (Table 2). The desire-group had a significantly higher PRS grade for the abdomen (2.0 \pm 0.5$)$, compared to the BCS-group $(1.6 \pm 1.0, p<0.001)$ and the no desire-group $(1.6 \pm 0.6, p<0.001)$. Rating for flank $(1.4 \pm 0.9)$ and breasts $(1.5 \pm 0.7)$ in the desire-group were significantly higher than in the no desire-group; respectively, $0.9 \pm 0.9(p<0.001)$ and $1.0 \pm 0.9(p<0.001)$. For the arms, the desire-group gave the same rating as the BCS-group $(1.7 \pm 0.8)$; these scores were significantly higher than in the no desire-group $(1.2 \pm 0.8, p<0.001$ in both).

Table 2:

Body weight qualification, satisfaction with body and skin surplus grading of patients who desire BCS (desire group), patients who have no desire (no desire group) and patients who had BCS (BCS group).

\begin{tabular}{lccc}
\hline & Desire group & Percentage $(\mathrm{n})$ & No desire group \\
$\mathrm{n}=368$ & $\mathrm{n}=157$ & BCS group \\
$\mathrm{n}=65$ \\
$\mathrm{BMI}<35 \mathrm{~kg} / \mathrm{m}^{2}, \%(\mathrm{n})$. & $77.3 \%(282)$ & $74.4 \%(116)$ & $95.3 \%(61){ }^{*}$ \\
Stable weight, \% (n.) & $58.7 \%(216)$ & $61.8 \%(97)$ & $52.3 \%(34)$ \\
Qualification, \% (n.) & $44.1 \%(161)$ & $45.5 \%(71)$ & $50.0 \%(32)$ \\
${ }^{*}$ significant difference between 3 groups, $\mathrm{p}<0.05$ & \multicolumn{3}{c}{} \\
\hline \multicolumn{4}{c}{ Mean \pm standard deviation } \\
Satisfaction with body & Desire group & No desire group & BCS group \\
Body parts affected & $7.0 \pm 1.7$ & $7.3 \pm 1.2$ & $7.3 \pm 1.4$ \\
PRS arm & $3.1 \pm 1.6 \mathrm{a}$ & $1.7 \pm 1.2 \beta$ & $2.5 \pm 1.4 \delta$ \\
PRS abdomen & $1.7 \pm 0.8 \mathrm{a}$ & $1.2 \pm 0.8 \beta$ & $1.7 \pm 0.8$ \\
PRS flank & $2.0 \pm 0.5 \mathrm{a}$ & $1.6 \pm 0.6$ & $1.6 \pm 1.0 \delta$ \\
PRS breasts & $1.4 \pm 0.9 \mathrm{a}$ & $0.9 \pm 0.9$ & $1.1 \pm 1.0$ \\
\hline
\end{tabular}

a significant difference compared to ND-group, $p<0.05$; $\beta$ significant difference compared to BCS-group, $p<0.05$; $\delta$ significant difference compared to D-group, $p<0.05$

BMI: body mass index, PRS: Pittsburgh Rating Scale

\section{Body Satisfaction}

Mean rating for satisfaction with the total body was $7.0 \pm 1.7$ in the desire-group, there was no significant difference compared to the no desire-group $(7.3 \pm 1.2, p=0.135)$ or the BCS-group (7.3 $\pm 1.4, p=0.321)$. The BCS-group retrospectively rated their body before BCS with $3.9 \pm 2.0$, which was significantly lower $(p<0.001)$ than the current score.

The desire-group rated their abdomen with $2.7 \pm 1.7$, which was significantly lower than the no desire-group $(4.7 \pm 1.7 ; p<0.001)$. They also gave a lower rating for the hips 
(4.2 \pm 2.0 versus $5.8 \pm 1.7 ; p<0.001)$, waist $(4.0 \pm 2.0$ versus $5.5 \pm 1.6, p<0.001)$, buttocks $(4.4 \pm 2.0$ versus $5.9 \pm 1.7, p<0.001)$ and thighs $(3.7 \pm 2.1$ versus $5.7 \pm 1.7, p<0.001)$.

The abdomen was the body part that was most often rated as very important, by $36.3 \%$ of the patients. The breasts/chest was rated as very important in $29.2 \%$ of the patients and the waist in $24.2 \%$ of the patients. In the desire-group $35.6 \%(n=115)$ was very unsatisfied with the proportions of their body, in the BCS-group this was $10.9 \%(n=6)$ and in the no desire-group this was $5.5 \%(n=7)$.

\section{Correlations}

The PRS abdomen correlated negatively with rating of the abdomen $(r=-0.486$, $p<0.001)$, thus higher PRS grading was related to lower satisfaction with the abdomen. The PRS flank also correlated negatively with rating of hips $(r=-0.406, p<0.001)$ and waist $(r=-0.435, p<0.001)$. Correlation for PRS breasts with breasts/chest rating was $r=-0.035(p=0.476)$; and for the PRS arms where the rating of the arms was $r=-$ $0.087(p=0.057)$.

\section{Reasons for not having BCS}

In the desire-group, the most commonly stated reason for not undergoing BCS was non-reimbursement by the insurance company; these patients stated that they had consulted a plastic surgeon and the insurance company did not reimburse BCS $(n=105,28.5 \%)$ (Table 3). In the group of patients who stated this, $39 \%(n=40)$ met the weight qualifications. The second most common reason was that patients did not ask for a referral $(n=101,27.7 \%) ; 48 \%(n=48)$ of these patients met the weight qualifications. The third most common reason was that patients thought they did not qualify, but never checked with a physician $(n=43,11.7 \%)$. A total of 22 of these patients (51\%) met the weight criteria. There was also a group that assumed they could not afford a procedure $(n=36,9.8 \%), 61 \%$ of these patients met the qualifications. In the desire-group, 144 patients (39.1\%) had never consulted a plastic surgeon. Of these patients $84.7 \%(n=122)$ had a BMl $<35 \mathrm{~kg} / \mathrm{m}^{2}$ and $61.1 \%(n=88)$ had a stable weight. A total of $49.3 \%$ (71 patients) met the weight criteria.

In the no desire-group the most common reason for not undergoing BCS was 'no complaints' and/or minimal skin surplus ( $n=72,45.9 \%)$. In addition, 51 patients $(32.5 \%)$ stated they had no skin surplus at all. Nineteen patients $(13.2 \%)$ did not want to undergo BCS because of medical issues. 
Table 3:

Reasons for not undergoing body contouring surgery in desire group ( $n=368)$ and number of patients within that group who meet the weight qualification.

\begin{tabular}{lcc}
\hline Reason & Desire group & Qualification* \\
No insurance coverage & $105(28.5 \%)$ & $40(39 \%)$ \\
Did not ask for referral & $101(27.7 \%)$ & $48(48 \%)$ \\
I don't qualify & $43(11.7 \%)$ & $22(51 \%)$ \\
I cannot afford it & $36(9.8 \%)$ & $22(61 \%)$ \\
Need/want to lose more weight & $35(9.5 \%)$ & $3(9 \%)$ \\
Afraid of complications/operation & $32(8.7 \%)$ & $15(47 \%)$ \\
Medical reasons and pregnancy & $20(5.4 \%)$ & $9(45 \%)$ \\
Plastic surgeon decided against BCS & $11(3.0 \%)$ & $5(46 \%)$ \\
Need more information & $9(2.4 \%)$ & $4(44 \%)$ \\
Still in doubt & $8(2.2 \%)$ & $3(38 \%)$ \\
General practitioner does not want to refer & $2(0.5 \%)$ & $2(100 \%)$ \\
\hline${ }^{*}$ stable weight for $\geq 12$ months and BMI $<35 \mathrm{~kg} / \mathrm{m}^{2}$ & \\
\hline
\end{tabular}

\section{DISCUSSION}

This study of a post-bariatric population with approximately 2.5 years follow-up shows that there were no differences in the percentage of patients meeting the Dutch criteria for reimbursement, when comparing patients who had a desire for BCS with patients who had BCS. Almost half of the patients who desired BCS met these criteria and, in principle, qualified for reimbursement. However, a significant part of these patients never consulted a plastic surgeon. Part of these patients assume that they will not get reimbursed for BCS and/or are not aware of the current guidelines in the Netherlands. The included population is comparable to populations in previous research. A large part $(62.4 \%)$ of the post-bariatric patients desired BCS, while only $11 \%$ of the population actually had BCS ${ }^{4,22}$. Patients who desired BCS were younger and more often female ${ }^{23}$. They reported more body parts affected by excess skin than patients without a desire and graded the amount of excess higher. The abdomen was most commonly affected by excess skin, as were the thighs, arms and breasts/chest ${ }^{5,22,24-26}$.

Satisfaction with the whole body was similar when comparing the three groups. However, patients with a desire were less satisfied with several body parts and unsatisfied with the proportions of their body. It might be that patients are overall satisfied with their body, but especially dissatisfied with specific areas (for which they desire BCS). Or that patients are more focused on the proportions of their body, which can be very variable when excess skin is only present in one or two body parts.

Patients who had undergone BCS were more satisfied with their body now than they were before BCS. Although these data might be biased, because of the retrospective ratings, the difference was very large (3.9 versus 7.3 on a scale from $0-10)$ and this 
has been shown before ${ }^{10,14,27,28}$.

Patients with a desire also graded their overhanging skin highest for all body parts assessed. A higher PRS score was related to lower rating of body parts in all patients, meaning that more excess skin is clearly considered less attractive. Since there are no studies assessing the prevalence of excess skin with PRS, we cannot compare our results. But we can conclude that the PRS (or a scale like this) can be used to assess how patient perceive their excess skin. Future research could then also focus on whether the perceived excess skin correlates with the estimation and/or measurement of the plastic surgeon.

It is striking that almost $40 \%$ of the patients who had a desire for BCS never consulted a plastic surgeon, although many of these patients did meet the weight criteria. Income rates were linked to the use of BCS in previous studies, and the group with a desire for BCS had the highest rating of unemployment and the lowest income ${ }^{3,8,16}$. Thus, costs seem to be the main reason for not undergoing BCS, and/or not consulting a plastic surgeon ${ }^{3,8}$. However, looking more closely at the reasons there are some distinct differences. There is a substantial population of patients $(27.7 \%)$ who did not even ask for a referral, and a total of $20 \%$ of the population didn't consult the plastic surgeon because they anticipated that they would not get reimbursement. Almost half of the patients in these groups qualified according to the weight loss results. Although we don't know the exact amount of overhanging skin, the results do partly confirm what we see in daily practice: there is a group of patients who might be reimbursed by their insurance company, but never tries to get the surgery.

Health insurance in the Netherlands is mandatory. Patients are free to choose a private company for the basic health insurance. In addition, patients can choose a more expensive insurance which reimburses more treatments. To qualify for reimbursement of BCS there is a nationwide guideline. Patients must meet the following criteria: (a) $>18$ months past bariatric surgery, (b) stable weight for $\geq 12$ months, (c) a BMI < 35 $\mathrm{kg} / \mathrm{m}^{2}$ and (d) skin excess grade 3 according to the PRS and/or serious impairment of bodily function ${ }^{18,29}$. This information is sent to the insurance company by the plastic surgeon and the insurance company decides whether a patient will be reimbursed. Since there is great variability in rating with the PRS, reimbursement decisions are also variable. This results in an unfair situation for patients. There is a possibility for patients to oppose the decision of the insurance company, but understandably, for this the patient will need to have the resources and abilities.

The issue of unfair/unclear reimbursement is not confined to the Netherlands; several publications have described similar problems all over the world ${ }^{8,16,30,31}$. In the United States and in Canada, BCS is usually not reimbursed by insurance companies and no clear guidelines exist ${ }^{8,16}$. In Great Britain, decision making for reimbursement of 
BCS was described as a lottery ${ }^{30}$. The British Association of Plastic, Reconstruce tive and Aesthetic Surgeons (BAPRAS) has therefore developed a guideline to define which post-bariatric patients qualify for referral and reimbursement of BCS ${ }^{32}$. In this guideline, a questionnaire is used to decide if the patient qualifies for reimbursement using questions regarding weight loss, complaints of excess skin, and history of the patients. In Mexico, Iglesias et al set up a classification system using only the amount of overhanging skin ${ }^{31}$.

Considering all above, there seem to be two main problems. First, the problem we see in daily practice: the current criteria are not interpreted in a uniform way. As a result, some patients get reimbursement and some patients do not; even though the amount of excess skin is the same. Second, the problem that is masked: only a minority of patients consult the plastic surgeon because they assume that they will not get reimbursed. This is, at least partially, caused by the fact that patients are unaware of the current guidelines. Patients with a poor financial status might be too afraid or unequipped to stand up for themselves and try to get a reimbursement. Psychological factors like self-esteem and self-worth could also influence whether a patient will ask for a referral and/or react against the insurance companies. A more extensive analysis of these patients should therefore be a part of future research.

Thus, there is a worldwide need for an objective and reproducible guideline to decide which patients should qualify for referral and reimbursement of BCS. This guideline has to be broadly spread and properly communicated to the bariatric population. Such a guideline will also be helpful for the plastic surgeons, as it reduces the amount of consultations with patients who do not qualify for BCS. It should not only include a questionnaire, but also an objective measurement of the amount of excess skin. Different countries can then decide their own qualification norms for reimbursement, depending on the system in the country and available funding for BCS.

For now, in our clinic, we have started informing patients about the current qualifications for BCS reimbursement before bariatric surgery. At the follow-up after bariatric surgery, excess skin is a standard part of assessment, urging people to visit a plastic surgeon when they qualify according to current guidelines. Patients respond very positive to the fact that so much attention is paid to these complaints.

A limitation is that we did not use a validated questionnaire and patients were not examined. Therefore, we do not know the exact extent of overhanging skin and can't conclude which patients should be reimbursed per the current Dutch guidelines. Our goal was to show how post-bariatric patients perceive their overhanging skin and which patients meet the weight criteria. The study was set up based on the complaints of post-bariatric patients we encounter in the clinic. We specifically choose to set up a questionnaire with open questions to assess how the patients really feel and 
think about BCS, reimbursement and their body. The results seem to show that most patients do meet the weight qualifications that are set by insurance companies. And because the NOK treats a significant proportion of patients who undergo bariatric surgery in our country, the current sample seems to be a good representation of the post-bariatric population.

\section{CONCLUSION}

This study shows that there is a significant number of post-bariatric patients who have a desire for BCS and meet the weight criteria for reimbursement. However, the majority of these patients never consulted the plastic surgeon, making the problem of excess skin invisible for treating doctors, such as plastic surgeons and bariatric surgeons, but also for government and insurance companies. And more importantly, patients will not get a treatment that decreases complaints, and improves well-being and weight loss maintenance. Therefore, post-bariatric patients should be better informed by (cooperating) plastic and bariatric surgeons about BCS. Consisting of information regarding excess skin and BCS reimbursement before bariatric surgery and assessment of complaints at follow-up. In addition, plastic surgeons and bariatric teams should properly communicate guidelines regarding reimbursement to the patients and develop objective criteria to decide which patients qualify for reimbursement of BCS. 


\section{References}

1. Angrisani L, Santonicola A, lovino P, et al. Bariatric surgery and endoluminal procedures: IFSO worldwide survey 2014. Obes Surg. 2017.

2. Kitzinger HB, Abayev S, Pittermann A, et al. After massive weight loss: Patients' expectations of body contouring surgery. Obes Surg. 2012;22(4):544-548.

3. Klopper E.M., Kroese-Deutman H.C., Berends F.J. Massive weight loss after bariatric surgery and the demand (desire) for body contouring surgery. Eur $J$ Plast Surg. 2014;37(2):103-108.

4. Pecori L, Serra Cervetti GG, Marinari GM, Migliori F Adami GF. Attitudes of morbidly obese patients to weight loss and body image following bariatric surgery and body contouring. Obes Surg. 2007;17(1):6873.

5. Staalesen T, Fagevik Olsen M, Elander A. Experience of excess skin and desire for body contouring surgery in post-bariatric patients. Obes Surg. 2013;23(10):1632-1644.

6. Giordano S, Victorzon M, Koskivuo I, Suominen E. Physical discomfort due to redundant skin in post-bariatric surgery patients. J Plast Reconstr Aesthet Surg. 2013;66(7):950-955.

7. Wagenblast AL, Laessoe L, Printzlau A. Self-reported problems and wishes for plastic surgery after bariatric surgery. J Plast Surg Hand Surg. 2014;48(2):115121.

8. Azin A, Zhou C, Jackson T, Cassin S, Sockalingam S, Hawa R. Body contouring surgery after bariatric surgery: A study of cost as a barrier and impact on psychological well-being. Plast Reconstr Surg. 2014;133(6):776e-782e.

9. Wiser I, Avinoah E, Ziv O, et al. Body contouring surgery decreases long-term weight regain following laparoscopic adjustable gastric banding: A matched retrospective cohort study. J Plast Reconstr Aesthet Surg. 2016;69(11):1490-1496.

10. Song P, Patel NB, Gunther S, et al. Body image \& quality of life: Changes with gastric bypass and body contouring. Ann Plast Surg. 2016;76 Suppl 3:S216-21.

11. Balague N, Combescure C, Huber O, Pittet-Cuenod $\mathrm{B}$, Modarressi A. Plastic surgery improves long-term weight control after bariatric surgery. Plast Reconstr Surg. 2013;132(4):826-833.

12. Modarressi A, Balague N, Huber O, Chilcott M, Pittet-Cuenod B. Plastic surgery after gastric bypass improves long-term quality of life. Obes Surg. 2013;23(1):24-30.

13. van der Beek ES, Geenen R, de Heer FA, van der Molen AB, van Ramshorst B. Quality of life long-term after body contouring surgery following bariatric surgery: Sustained improvement after 7 years. Plast Reconstr Surg. 2012;130(5):1133-1139.

14. de Zwaan M, Georgiadou E, Stroh CE, et al. Body image and quality of life in patients with and without body contouring surgery following bariatric surgery: A comparison of pre- and post-surgery groups. Front Psychol. 2014;5:1310.

15. Aherrera AS, Pandya SN. A cohort analysis of postbariatric panniculectomy--current trends in surgeon reimbursement. Ann Plast Surg. 2016;76(1):99-101.

16. Gusenoff JA, Messing S, O'Malley W, Langstein HN. Patterns of plastic surgical use after gastric bypass: Who can afford it and who will return for more. Plast Reconstr Surg. 2008;122(3):951-958.

17. Song AY, Jean RD, Hurwitz DJ, Fernstrom MH, Scott JA, Rubin JP. A classification of contour deformities after bariatric weight loss: The pittsburgh rating scale. Plast Reconstr Surg. 2005;116(5):1535-44; discussion 1545-6.

18. Association of Advising Doctors of Health insurance Companies (Vereniging Adviserend Geneeskundigen bij Zorgverzekeraars). Guideline for judgement of plastic surgery (werkwijzer beoordeling behandelingen van plastisch-chirurgische aard). 2018.

19. Monpellier VM, Antoniou EE, Mulkens S, Janssen
IMC, van der Molen ABM, Jansen ATM. Body image dissatisfaction and depression in postbariatric patients is associated with less weight loss and a desire for body contouring surgery. Surg Obes Relat Dis. 2018 Oct; $14(10): 1507-15$.

20. Likert R. A technique for the measurement of attitudes. Archives of Psychology. 1932;140:1-55.

21. Brethauer SA, Kim J, El Chaar M, et al. StandardF ized outcomes reporting in metabolic and bariatric surgery. Obes Surg. 2015;25(4):587-606.

22. Kitzinger HB, Abayev S, Pittermann A, et al. The prevalence of body contouring surgery after gastric bypass surgery. Obes Surg. 2012;22(1):8-12.

23. Gusenoff JA, Messing S, O'Malley W, Langstein HN. Temporal and demographic factors influencing the desire for plastic surgery after gastric bypass surgery. Plast Reconstr Surg. 2008;121(6):2120-2126.

24. Biorserud C, Olbers T, Fagevik Olsen M. Patients' experience of surplus skin after laparoscopic gastric bypass. Obes Surg. 2011;21(3):273-277.

25. Lazar CC, Clerc I, Deneuve S, Auquit-Auckbur I, Milliez PY. Abdominoplasty after major weight loss: Improvement of quality of life and psychological status. Obes Surg. 2009;19(8):1170-1175.

26. Stuerz K, Piza H, Kinzl JF. The impact of abdominot plasty after massive weight loss: A qualitative study. Ann Plast Surg. 2013;71(5):547-549.

27. Vierhapper MF, Pittermann A, Hacker S, Kitzinger HB. Patient satisfaction, body image, and quality of life after lower body lift: A prospective pre- and postoperative long-term survey. Surg Obes Relat Dis. 2017.

28. Singh D, Zahiri HR, Janes LE, et al. Mental and physical impact of body contouring procedures on post-bariatric surgery patients. Eplasty. 2012;12:e47.

29. Nederlandse Vereniging voor Plastische Chirurgie. Richtlijn contourherstellende post-bariatrische chirurgie (guideline post-bariatric bodycontouring surgery). https://www.nvpc.nl/stand.php?flag=richt\&portion=9. Updated 2015.

30. Mukherjee S, Kamat S, Adegbola S, Agrawal S. Funding for postbariatric body-contouring (bariplastic) surgery in england: A postcode lottery. Plast Surg Int. 2014;2014:153194

31. Iglesias M, Butron P, Abarca L, Perez-Monzo MF, de Rienzo-Madero B. An anthropometric classification of body contour deformities after massive weight loss. Ann Plast Surg. 2010;65(2):129-134.

32. Soldin M, Mughal M, Al-Hadithy N, Department of Health, British association of Plastic, Reconstructive and Aesthetic Surgeons, Royal College of Surgeons England. National commissioning guidelines: Body contouring surgery after massive weight loss. J Plast Reconstr Aesthet Surg. 2014;67(8):1076-1081. 


\section{APPENDIX 1: BODY APPRECIATION LIST - SHORT}

Please indicate below how attractive you find your body and the different parts of your body. Grade the attractiveness of each body part with a 'Dutch school grade' between 1 (very unattractive) and 10 (very attractive). Grade 5 means insufficient, grade 6 is just sufficient. Circle the good number.

Some body parts are more important than others for how you think about your body as a whole. Please indicate in the right column how important the body part is for the general evaluation of your own body.

\begin{tabular}{|c|c|c|c|c|c|c|c|c|c|c|}
\hline my... & \multicolumn{10}{|c|}{ grade } \\
\hline $\begin{array}{l}\text {... body as a } \\
\text { whole }\end{array}$ & 1 & 2 & 3 & 4 & 5 & 6 & 7 & 8 & 9 & 10 \\
\hline ... face & 1 & 2 & 3 & 4 & 5 & 6 & 7 & 8 & 9 & 10 \\
\hline ... chin & 1 & 2 & 3 & 4 & 5 & 6 & 7 & 8 & 9 & 10 \\
\hline $\begin{array}{l}\ldots . \text { hair (head } \\
\text { hair) }\end{array}$ & 1 & 2 & 3 & 4 & 5 & 6 & 7 & 8 & 9 & 10 \\
\hline ... shoulders & 1 & 2 & 3 & 4 & 5 & 6 & 7 & 8 & 9 & 10 \\
\hline ... upper arms & 1 & 2 & 3 & 4 & 5 & 6 & 7 & 8 & 9 & 10 \\
\hline ... lower arms & 1 & 2 & 3 & 4 & 5 & 6 & 7 & 8 & 9 & 10 \\
\hline ... breasts/chest & 1 & 2 & 3 & 4 & 5 & 6 & 7 & 8 & 9 & 10 \\
\hline ... belly & 1 & 2 & 3 & 4 & 5 & 6 & 7 & 8 & 9 & 10 \\
\hline ... waist & 1 & 2 & 3 & 4 & 5 & 6 & 7 & 8 & 9 & 10 \\
\hline ... hips & 1 & 2 & 3 & 4 & 5 & 6 & 7 & 8 & 9 & 10 \\
\hline ... buttocks & 1 & 2 & 3 & 4 & 5 & 6 & 7 & 8 & 9 & 10 \\
\hline ... thighs & 1 & 2 & 3 & 4 & 5 & 6 & 7 & 8 & 9 & 10 \\
\hline ... lower legs & 1 & 2 & 3 & 4 & 5 & 6 & 7 & 8 & 9 & 10 \\
\hline
\end{tabular}

\begin{tabular}{|l|l|l|l|}
\hline \multicolumn{4}{|l|}{ importance } \\
\hline \multicolumn{3}{l}{ for the general evaluation of } \\
your body \\
\hline not & a little & quite & very \\
\hline not & a little & quite & very \\
\hline not & a little & quite & very \\
\hline not & a little & quite & very \\
\hline not & a little & quite & very \\
\hline not & a little & quite & very \\
\hline not & a little & quite & very \\
\hline not & a little & quite & very \\
\hline not & a little & quite & very \\
\hline not & a little & quite & very \\
\hline not & a little & quite & very \\
\hline not & a little & quite & very \\
\hline not & a little & quite & very \\
\hline
\end{tabular}

${ }^{1}$ This is a shortened version of the original Body Appreciation List (Jansen, 2012) 


\begin{tabular}{|l|l|l|l|l|l|l|l|l|l|l|}
\hline my... & \multicolumn{6}{|l|}{ grade } \\
\hline$\ldots$ knees & 1 & 2 & 3 & 4 & 5 & 6 & 7 & 8 & 9 & 10 \\
\hline$\ldots$ ankles & 1 & 2 & 3 & 4 & 5 & 6 & 7 & 8 & 9 & 10 \\
\hline$\ldots$ feet & 1 & 2 & 3 & 4 & 5 & 6 & 7 & 8 & 9 & 10 \\
\hline$\ldots$ body weight & 1 & 2 & 3 & 4 & 5 & 6 & 7 & 8 & 9 & 10 \\
\hline
\end{tabular}

\begin{tabular}{|l|l|l|l|}
\hline \multicolumn{3}{|c|}{ importance } \\
\hline not & a little & quite & very \\
\hline not & a little & quite & very \\
\hline not & a little & quite & very \\
\hline not & a little & quite & very \\
\hline
\end{tabular}

Are you satisfied with the proportions between the different parts of your body?

$\neg$ very dissatisfied

a little dissatisfied

not dissatisfied, not satisfied

$\checkmark$ a little satisfied

$\neg$ very satisfied

When you indicated to be dissatisfied, can you explain about which proportions you are dissatisfied and why?

Reference: Jansen, A. (2012). Body Appreciation List. Unpublished work. 



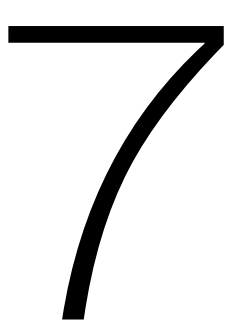

Evaluation and modification of the BAPRAS screening tool for reimbursement of post-bariatric body contouring surgery.

Valerie M. Monpellier Claire E.E. de Vries, Ignace M. C. Janssen Aebele B. Mink van der Molen Eva S.J. van der Beek Maarten. M. Hoogbergen Berend van der Lei

Submitted to Journal of Plastic, Reconstructive \& Aesthetic Surgery 


\section{ABSTRACT}

\section{INTRODUCTION}

Reimbursement of body contouring surgery (BCS) is a worldwide problem: there is no objective instrument to decide which post-bariatric patients should qualify for reimbursement. The British Association of Plastic, Reconstructive and Aesthetic Surgeons (BAPRAS) has developed a screening tool for this purpose. Goal of this study was to test a modified version of this screening tool in a post-bariatric population.

\section{METHODS}

Post-bariatric patients were asked to fill in an online questionnaire based on the BAPRAS screening tool with questions regarding complaints of overhanging skin and medical history. Weight loss data were extracted from a prospective database. The BODY-Q was added to assess patient reported outcome.

\section{RESULTS}

A total of 120 patients were included, 96 patients wanted to undergo BCS (80\%) and 24 patients did not (20\%). In the group who wanted BCS, 25 patients $(26 \%)$ qualified for reimbursement according to our criteria. Patients who qualified had higher weight loss (33.5\% versus $28.1 \%, \mathrm{p}=0.014)$, lower BMl $(29.3 \mathrm{~kg} / \mathrm{m} 2$ versus $31.4 \mathrm{~kg} / \mathrm{m} 2$, $\mathrm{p}=0.062$ ) and more medical (3.4 versus $2.2, \mathrm{p}=0.002)$ and psychological complaints ( $88 \%$ versus $61 \%, p=0.009$ ). There was a significant, negative correlation between the screening tool scores and almost all BODY-Q scales.

\section{CONCLUSIONS}

With the modified BAPRAS screening tool post-bariatric patients with the best weight (loss) and most complaints of excess skin qualified for referral and reimbursement of $B C S$. The BODY-Q showed the significant impact of excess skin on well-being and should be a standard part of evaluation. 


\section{INTRODUCTION}

Body contouring surgery (BCS) is the only available treatment for overhanging skin after massive weight loss. Numerous studies have shown that post-bariatric patients who undergo BCS have significant improvements in quality of life (QoL), body image and psychological status 1-8. In addition, these patients have better long-term weight loss maintenance, thus BCS seems to prolong the effect of bariatric surgery 9-11. However, reimbursement of BCS is a worldwide issue, because of the absence of an instrument to objectively decide which patients should qualify for reimbursement ${ }^{12-15}$. Ideally, such an instrument would include all aspects of patients' well-being that are affected by the overhanging skin.

In the Netherlands, BCS is only reimbursed when there is "mutilation" or a "serious impairment of bodily function in daily life" ${ }^{16}$. According to the Dutch guidelines mutilation is defined as a grade 3 excess skin on the Pittsburgh Rating Scale (PRS) and impairment of bodily function as a chronic skin condition, or a specific, measured amount of overhanging skin ${ }^{17}$. However, the PRS was only created to visually evaluate excess skin on photographs and it has been proven to be an unreliable tool for this purpose ${ }^{18,19}$. Resulting in inconsistent qualification for reimbursement and unfair decision making: patients with the most complaints are not always reimbursed. Unfortunately, a good tool to physically measure and calculate skin excess (in $\mathrm{cm}^{2}$ ) instead of photographs is not available so far. An additional item missing in the current guideline is the evaluation of QoL and psychological items.

In Great Britain, decisions regarding reimbursement for BCS were compared to a winning a lottery ${ }^{20}$. Therefore, the British Association of Plastic, Reconstructive and Aesthetic Surgeons (BAPRAS) developed a screening tool which includes weight loss, the medical, physical and psychological problems caused by excess skin and medical history ${ }^{21}$. In addition, a patient reported outcome measure (PROM) was added. However, this tool has never been tested in daily practice, nor really been implemented ${ }^{22}$. The goal of this study is to evaluate a modified version of the BAPRAS screening tool in a post-bariatric population. We will also study QoL and its relationship with the screening tool scores. The results will be used to further improve the questionnaire and develop an improved screening tool to select post-bariatric patients for referral and reimbursement of BCS.

\section{METHODS}

\section{Standard treatment}

All patients were recruited at the Nederlandse Obesitas Kliniek (NOK, Dutch Obesity Clinic). The NOK is the largest, outpatient clinic for treatment of patients with morbid obesity in the Netherlands. Treatment program consists of bariatric surgery with clearly protocolled pre- and postoperative group counselling by a multidisciplinary team up 
to 1.5 years after bariatric surgery. Starting at 2 years after bariatric surgery, patients have a yearly follow-up with the whole team, up to 5 years after surgery.

\section{Patient selection}

Study start was in October 2016. Patients were informed and recruited at regular 2- and 3-years follow-up visits after bariatric surgery (because of presumed weight stability and Dutch criteria). Patients who could not read Dutch were not invited for participation. If a patient agreed to participate an electronic invitation with informed consent form was send using Qualtrics software (Qualtrics, Provo, UT). Patients who signed this consent form were subsequently included in this study. The study was approved by the Ethical Research Committee of the Radboud University Medical Center, Nijmegen the Netherlands (2016-2781).

Participation in this study had no effect on further treatment and/or referral to a plastic surgeon.

\section{Body weight}

Demographics and weight measurements before and after bariatric surgery were collected from the prospective database of the NOK. Body Mass Index (BMI) and percent total weight loss (\%TWL) were calculated ${ }^{23}$. In addition, it was assessed whether a patient would qualify for referral and reimbursement for BCS according to the current Dutch weight criteria: stable weight $>12$ months and a $\mathrm{BMl}<35 \mathrm{~kg} / \mathrm{m}^{2}$.

\section{Questionnaires}

Body contouring surgery

Patients were asked if they wanted to have BCS and if not, asked for the reasons why not (yet).

\section{Screening tool score}

Each patient was asked to fill out a modified version of the BAPRAS questionnaire (Appendix 1). The BAPRAS questionnaire was modified with regard to several aspects:

1. percentage excess weight loss (\%EWL) was replaced by $\% \mathrm{TWL}^{28,29}$;

2. stable weight was defined by current weight $+/-5 \%$ instead of 5 kilograms;

3. one question was used for evaluating recent life-events;

4. body dysmorphic disorder was not evaluated with schematic drawings ${ }^{30}$.

A score was calculated for each patient (Appendix 1). The lowest possible score was minus 21 and the highest possible score was plus 15. Like in the BAPRAS guideline, a score $\geq 8$ was defined as being qualified for possible reimbursement and referral to a plastic surgeon ${ }^{21}$. 
$B O D Y-Q$

The BODY-Q is the best validated questionnaire for evaluating QoL and appearance in (post-) bariatric patients and was added as a PROM in our modified screenings tool 26. The questionnaire consists of 18 scales divided in three domains: QoL, appearance and patient experience ${ }^{27}$. It has shown good validity and reliability (test-re-test reliability $r=0.87$ for 17 of 18 scales; internal consistency, Cronbach $\alpha=0.90$ for 18 of 18 scales) ${ }^{27}$. For the purpose of this study we used all scales of the QoL domain (body image, physical function, psychological function, sexual function, social function, obesity-specific physical symptoms) and five scales of the appearance domain (appraisal of excess skin, satisfaction with abdomen, arms, hips and breasts). Scores for each scale ranges from 0-100; higher scores indicate more positive results.

\section{Statistical analysis}

Descriptive statistics were used to summarize baseline characteristics and weight change of the studied patient population. Included patients were divided in two groups: patients who wanted BCS and patients who did not want BCS. Baseline characteristics, questionnaire scores and BODY-Q score were compared between these groups. Correlations between the BODY-Q and screeningtool questions were studied with Pearson's correlations. Subsequently patients who wanted BCS and qualified for referral (score $\geq 8$ ) were compared to patients who wanted BCS and did not qualify (score $\leq 7$ ). Continuous variables were compared using independent t-tests; for dichotomous data chi-square or fishers' exact tests were used. Findings were considered statistically significant if the $p$-value was $<0.05$. All analyses were performed using SPSS, version 23 (IBM Corp. Released 2015. IBM SPSS Statistics for Windows, Version 23.0. Armonk, NY: IBM Corp.).

\section{RESULTS}

\section{Study population}

Invitations for the study were sent out to 168 patients; 120 patients $(71 \%)$ responded, signed informed consent and were included in this study. Age, BMI before bariatric surgery, current BMI, \%TWL and follow-up time did not significantly differ when comparing responders and non-responders. In the non-responder group there were significant less females $(73 \%$ versus $90 \%, p=0.011)$.

Mean age of the included population was 46 years; $90 \%$ was female. Patients had a mean BMI of $44.2 \mathrm{~kg} / \mathrm{m}^{2}$ (range 27.1 to $65.6 \mathrm{~kg} / \mathrm{m}^{2}$ ) before bariatric surgery. Most patients underwent a primary Roux-en-y Gastric Bypass (83.3\%). Follow-up was 2 years in 86 patients and 3 years in 34 patients. Mean current BMI was $30.8 \mathrm{~kg} / \mathrm{m}^{2}$ and current TWL was $29.9 \%$; 78 patients $(65.0 \%)$ met the Dutch weight criteria (stable weight and $\mathrm{BMI}<35 \mathrm{~kg} / \mathrm{m}^{2}$ ). 


\section{Body contouring surgery}

A total of 96 patients $(80 \%)$ wanted BCS and 24 patients did not want BCS (20\%). Patients who wanted BCS were significantly younger (mean age $44.9 \mathrm{yrs}$. versus 50.1 yrs., $p=0.021$, Table 1). There was no significant difference between the groups regarding gender, type of bariatric procedure, BMI before bariatric surgery, current BMI, $\%$ TWL and percentage of patients who met the Dutch weight criteria.

Table 1:

Demographics of the group who wanted for body contouring surgery $(n=96)$ and the group who did not want BCS $(n=24)$, presented as mean \pm standard deviation or percentage $(n)$.

\begin{tabular}{l|c|c|c|}
\hline Parameter & Want BCS & Does not want BCS & p-value \\
\hline Age, years & $44.9 \pm 8.2$ & $50.1 \pm 10.6$ & 0.031 \\
\cline { 2 - 4 } Female gender & $90 \%(86)$ & $92 \%(22)$ & 0.761 \\
\cline { 2 - 4 } RYGB & $95 \%(91)$ & $92 \%(22)$ & 0.559 \\
\cline { 2 - 4 } Baseline BMI, $\mathrm{kg} / \mathrm{m}^{2}$ & $43.9 \pm 6.6$ & $45.3 \pm 6.0$ & 0.362 \\
\cline { 2 - 4 } Current BMI, $\mathrm{kg} / \mathrm{m}^{2}$ & $30.8 \pm 5.4$ & $30.7 \pm 3.9$ & 0.971 \\
\cline { 2 - 4 } BMI change, $\mathrm{kg} / \mathrm{m}^{2}$ & $13.1 \pm 4.9$ & $14.5 \pm 4.6$ & 0.210 \\
\cline { 2 - 4 } Current TWL, \% & $29.5 \pm 9.5$ & $31.6 \pm 8.3$ & 0.329 \\
\cline { 2 - 4 } $\begin{array}{l}\text { Current EWL, } \% \\
\text { Stable weight }>12 \text { months }\end{array}$ & $72.2 \pm 25.0$ & $72.0 \pm 18.5$ & 0.982 \\
\cline { 2 - 4 } BMl $<35 \mathrm{~kg} / \mathrm{m}^{2}$ & $79.2 \%(76)$ & $83.3 \%(20)$ & 0.648 \\
\cline { 2 - 4 } Qualification & $77.1 \%(74)$ & $79.2 \%(19)$ & 0.827 \\
\hline & $60.4 \%(58)$ & $70.8 \%(17)$ & 0.324 \\
\hline
\end{tabular}

RYGB = Roux-en-Y gastric bypass; $\mathrm{BMI}=$ Body Mass Index; Baseline BMI = BMI before bariatric surgery; $\mathrm{TWL}=$ total weight loss; $\mathrm{EWL}=$ Excess weight loss.

*Defined as a stable weight $\geq 12$ months and $\mathrm{BMI}<35 \mathrm{~kg} / \mathrm{m}^{2}$

\section{$B O D Y-Q$}

The BODY-Q results were available of 119 patients, one patient did not complete the questionnaire. Patients who wanted BCS scored lower on all BODY-Q scales (Table 2). In the QoL domain differences were significant for body image: mean score 33.4 $( \pm 18.9)$ in patients who want BCS and $55.6( \pm 22.7)$ in patients with no interest in BCS $(p<0.001)$. Scores were also significantly lower for sexual functioning $(37.6$ versus $54.0, p=0.003$ ) and social functioning (61.9 versus $73.0, p=0.010)$. For the appearance domain, scores in patients who wanted BCS were significantly lower on all scales. The highest difference was on the appraisal of excess skin scale: patients who wanted BCS scored 33.2 while the patients who weren't interested in BCS scored 70.5 $(p<0.001)$. 
Table 2:

Comparison of BODY-Q scores for patients who wanted BCS $(n=96)$ and patients who did not want $B C S(n=24)$, presented as mean \pm standard deviation.

\begin{tabular}{l|c|c|c}
\hline BODY-Q & Want BCS & Does not want BCS & p-value \\
\hline HRQoL domain & & & \\
Body image & $33.4 \pm 18.9$ & $55.6 \pm 22.7$ & $<0.001$ \\
Physical function & $74.0 \pm 21.7$ & $82.9 \pm 22.8$ & 0.076 \\
Psychological health & $59.2 \pm 17.9$ & $67.4 \pm 20.3$ & 0.053 \\
Sexual health & $37.6 \pm 21.8$ & $54.0 \pm 29.1$ & 0.003 \\
Social function & $61.9 \pm 18.5$ & $73.0 \pm 19.0$ & 0.010 \\
Obesity-specific symptoms & $34.2 \pm 5.4$ & $36.5 \pm 5.5$ & 0.063 \\
\hline Appearance domain & & & \\
Skin & $33.2 \pm 20.7$ & $70.5 \pm 23.3$ & $<0.001$ \\
Abdomen & $24.5 \pm 26.2$ & $53.4 \pm 26.5$ & $<0.001$ \\
Arms & $34.0 \pm 28.6$ & $50.2 \pm 25.0$ & 0.012 \\
Hips and outer thighs & $42.4 \pm 29.7$ & $56.8 \pm 27.3$ & 0.037 \\
Breasts & $34.2 \pm 22.4$ & $53.6 \pm 20.9$ & $<0.001$ \\
\hline
\end{tabular}

\section{Screening tool score}

In the total population mean score on the modified BAPRAS questionnaire was 5.3 (range -5 to 12 ). Patients who wanted BCS scored significantly higher $(5.7 \pm 2.9)$ compared to the group, which did not want BCS $(3.8 \pm 2.9, p=0.004)$. In the group of patients who wanted BCS, 25 patients $(26 \%)$ had a score $\geq 8$ and thus qualified for referral and reimbursement.

\section{BODY-Q \& Screening tool score}

There was a significant, negative correlation between the screening tool scores and the BODY-Q scales (Table 3). For the total screening tool highest correlation was with the appraisal of excess skin scale of the BODY-Q $(r=-0.390, p<0.001)$. For the medical score of the screening tool highest correlation was also with the appraisal of excess skin scale $(r=-0.488, p<0.001)$. There was a significant correlation between physical issues of excess skin and the BODY-Q physical functioning score $(r=-0.256, p=0.005)$. Psychological issues on the screening tool were significantly related to the appraisal of excess skin scale $(r=-0.491, p<0.001)$. 
Table 3:

Correlations between BODY-Q scales and screening tool scores in the total population.

\begin{tabular}{l|l|l|l|l}
\hline BODY-Q scale & $\begin{array}{c}\text { Total } \\
\text { score }\end{array}$ & $\begin{array}{c}\text { Medical } \\
\text { score }\end{array}$ & $\begin{array}{c}\text { Psychological } \\
\text { issues }\end{array}$ & $\begin{array}{c}\text { Functional } \\
\text { issues }\end{array}$ \\
\hline Body image & $-0.271^{* *}$ & $-0.338^{* *}$ & $-0.448^{* *}$ & $-0.386^{* *}$ \\
\hline Physical function & -0.152 & $-0.360^{* *}$ & -0.150 & $-0.258^{* *}$ \\
\hline Psychological function & $-0.202^{*}$ & -0.164 & $-0.349^{* *}$ & $-0.256^{* *}$ \\
\hline Sexual function & $-0.210^{*}$ & $-0.215^{*}$ & $-0.392^{* *}$ & $-0.432^{* *}$ \\
\hline Social function & $-0.207^{*}$ & $-0.228^{*}$ & $-0.322^{* *}$ & $-0.239^{* *}$ \\
\hline Physical symptoms & -0.156 & $0.365^{* *}$ & $-0.283^{* *}$ & $-0.244^{* *}$ \\
\hline Excess skin & $-0.390^{* *}$ & $-0.488^{* *}$ & $-0.491^{* *}$ & $-0.482^{* *}$ \\
\hline
\end{tabular}

** significant correlation $p<0.01$; * significant correlation $p<0.05$

\section{Qualification for reimbursement}

Age, gender, BMI before bariatric surgery, and type of bariatric surgery were not significantly different when comparing the patients who qualified for BCS $(n=25)$ with the patients who did not qualify $(n=71)$.

Patients who qualified for reimbursement had a TWL of $33.5 \%$, whereas patients who did not had a TWL of $28.1 \%$ ( $p=0.014$, Table 4). Mean BMI was also lower: $29.3 \mathrm{~kg} / \mathrm{m}^{2}$ versus $31.4 \mathrm{~kg} / \mathrm{m}^{2}(\mathrm{p}=0.062)$. Twenty-one patients who qualified also met the Dutch weight criteria; the patients who did not meet the criteria all had a BMI $>35 \mathrm{~kg} / \mathrm{m}^{2}$. Scores on the modified BAPRAS questionnaire ranged from 9-10 points in this group. BMI before bariatric surgery ranged from $49.8 \mathrm{~kg} / \mathrm{m}^{2}$ to $65.6 \mathrm{~kg} / \mathrm{m}^{2}$. Mean score for skin conditions was $3.4( \pm 1.7)$ in the patients who qualified and $2.2( \pm 1.6)$ in patients who did not $(\mathrm{p}=0.002)$. In addition, $88 \%$ of the patients who qualified for BCS experienced psychological complaints because of the excess skin, compared to $61 \%$ in the patients with a score $\leq 7(\mathrm{p}=0.009)$.

In the group with a score $\geq 8$ one patient was an active smoker and none of the patients had a recent life-event. There were two patients with current psychological issues in the group with a score $\geq 8$. 
Table 4:

Comparison of screening tool items of the patients who wanted BCS and qualify for referral and reimbursement $(n=25)$ and the patients who want BCS and do not qualify $(n=71)$, presented as mean \pm standard deviation or percentage $(\mathrm{n})$.

\begin{tabular}{l|c|c|c}
\hline Parameter & Qualify & Does not qualify & p-value \\
\hline Current \%TWL & $28.1 \pm 10.1$ & $33.5 \pm 6.2$ & 0.014 \\
Current BMI, kg/m² & $29.1 \pm 5.6$ & $31.4 \pm 5.2$ & 0.062 \\
Stable weight $>12$ months & $25(100 \%)$ & $51(72 \%)$ & 0.011 \\
Medical score & $3.4 \pm 1.7$ & $2.2 \pm 1.6$ & 0.002 \\
Psychological issues & $22(88 \%)$ & $43(61 \%)$ & 0.009 \\
Functional issues & $24(96 \%)$ & $60(85 \%)$ & 0.123 \\
\hline
\end{tabular}

TWL = total weight loss; $\mathrm{BMI}=$ Body Mass Index .

\section{Qualification and BODY-Q}

Patients who qualified scored lower on all BODY-Q scales. There was a significant difference on the appraisal of excess skin scale: mean score was 29.9 in patients who qualified and 44.1 in the patients who did not $(p=0.011)$.

\section{DISCUSSION}

Reimbursement of body contouring procedures is a worldwide issue, because there is no instrument available to objectively select which patients should qualify for reimbursement. Therefore, the goal of this study was to assess a modified version of the BAPRAS screeningtool. This is the first screening tool developed to decide which patients qualify for reimbursement, based on a broad array of parameters.

Our study clearly demonstrated that patients who want BCS have a significantly higher score on the screening tool compared to patients who do not want BCS. These patients had a stable weight, higher weight loss (\%TWL), lower current BMI and more medical and psychological complaints compared to patients who did not qualify for referral. The screeningtool scores significantly correlated with almost all BODY scales, showing that these 'simple' questions reflect the impact of complaints on patients. Thus, our modified BAPRAS screening tool selects the patients who have the best weight loss results and are most impacted by excess skin in their daily lives.

A large part of the study population wanted BCS and had a wide range of problems caused by the excess skin ${ }^{13,15,28-30}$. These patients were mostly bothered by excess skin on the abdomen, breasts/chest and inner thighs ${ }^{13,31}$. Medical issues like intertrigo (68.3\%), hidradenitis $(31.7 \%)$ and dermatitis (55.8\%) were frequently reported ${ }^{13,32}$. In addition, many patients had functional complaints of their excess skin (78.3\%), such as hindrance in daily activities and sporting ${ }^{32-34}$. And almost $60 \%$ of our population suffered from psychological issues, such as depressive feelings and shame, which is in concordance with the low scores on the BODY-Q ${ }^{13,35,36}$. This aspect clearly demonstrates that overhanging skin significantly negatively influences patients' well-being. 
The fact that the excess skin impacts several aspects of the patients' life makes it even more important to include all these aspects in a screening tool for reimbursement for BCS.

In our opinion the modified BAPRAS questionnaire can be combined with the Dutch weight criteria, thereby creating the final version of the tool: the Dutch ReBoc tool (Referral and Reimbursement for Body Contouring tool, Appendix 2). In the Dutch Reboc tool patients, who do not have a stable weight cannot be referred; in the BAPRAS guideline these patients could still apply for reimbursement. Weight fluctuations can negatively impact complication rates and all of the patients who qualified had a stable weight before surgery ${ }^{37}$. A recent pregnancy or planning to have children in the future is also an exclusion criterion for referral, because this will negatively influence the post-operative result. Last but not least, all patients with a recent life-event, a history of psychological issues and/or addiction, should be evaluated by the psychologist (of the bariatric team) in order to decide whether these issues can be seen as a contra-indication for BCS. This psychologist should also evaluate other aspects, such as body dysmorphic disorder symptoms.

The BODY-Q should be a part of the Dutch Reboc tool, as it is the most suitable instrument to objectively evaluate the impact of overhanging skin on patients' well-being ${ }^{26}$. Ideally, the BODY-Q should also be evaluated after BCS to evaluate the effect of body contouring procedures.

Like in the BAPRAS guideline, patients with a very high initial BMI (>50 kg/m²) who want a functional panniculectomy are an exception in the criteria according to the Dutch Reboc tool. In the study population, four patients qualified for referral, but had a BMI $>35 \mathrm{~kg} / \mathrm{m}^{2}$. Before bariatric surgery, these four patients all had a BMI $>50 \mathrm{~kg} /$ $\mathrm{m}^{2}$, which implicates that they will never be able reach a $\mathrm{BMI}<35 \mathrm{~kg} / \mathrm{m}^{2}$ after bariatric surgery ${ }^{38}$. A panniculectomy will bring these patients to another level of exercise freedom, which subsequently will lead to further lowering of their BMI. Therefore, patients with a starting $\mathrm{BMI}>50 \mathrm{~kg} / \mathrm{m}^{2}$ should be evaluated separately with regard to an abdominal debulking (panniculectomy) procedure.

A limitation of the current study is that all questionnaires were filled out at home by the patients. Therefore, we were not able to examine the patients and objectify the complaints like skin conditions and physical limitations. However, since all patients were informed that the questionnaires were anonymous and that the answers did not have any effect on possible BCS, we think this potential bias has been low. 


\section{CONCLUSION}

In conclusion, we have demonstrated that with the modified version of the BAPRAS screening tool post-bariatric patients with the best weight (loss) and most complaints of excess skin are selected for reimbursement for BCS. Future research should focus on validating the final proposed version, the Dutch Reboc tool. In addition, an objective measurement instrument for excess skin should be developed. 


\section{References}

1. de Zwaan M, Georgiadou E, Stroh CE, et al. Body image and quality of life in patients with and without body contouring surgery following bariatric surgery: A comparison of pre- and post-surgery groups. Front Psychol. 2014;5:1310.

2. van der Beek ES, Geenen R, de Heer FA, van der Molen AB, van Ramshorst B. Quality of life long-term after body contouring surgery following bariatric surgery: Sustained improvement after 7 years. Plast Reconstr Surg. 2012;130(5):1133-1139.

3. van der Beek ES, Te Riele W, Specken TF, Boerma $D$, van Ramshorst B. The impact of reconstructive procedures following bariatric surgery on patient well-being and quality of life. Obes Surg. 2010;20(1):36-41.

4. Modarressi A, Balague N, Huber O, Chilcott M, Pittet-Cuenod B. Plastic surgery after gastric bypass improves long-term quality of life. Obes Surg. 2013;23(1):24-30.

5. Song AY, Rubin JP, Thomas V, Dudas JR, Marra KG Fernstrom $\mathrm{MH}$. Body image and quality of life in post massive weight loss body contouring patients. Obesity (Silver Spring). 2006;14(9):1626-1636.

6. Lazar CC, Clerc I, Deneuve S, Auquit-Auckbur I, Milliez PY. Abdominoplasty after major weight loss: Improvement of quality of life and psychological status. Obes Surg. 2009;19(8):1170-1175.

7. Stuerz K, Piza H, Kinzl JF. The impact of abdominoplasty after massive weight loss: A qualitative study. Ann Plast Surg. 2013;71(5):547-549.

8. Cintra W,Jr, Modolin ML, Gemperli R, Gobbi Cl, Faintuch J, Ferreira MC. Quality of life after abdominoplasty in women after bariatric surgery. Obes Surg. 2008;18(6):728-732.

9. Balague N, Combescure C, Huber O, Pittet-Cuenod $\mathrm{B}$, Modarressi A. Plastic surgery improves long-term weight control after bariatric surgery. Plast Reconstr Surg. 2013;132(4):826-833.

10. Wiser I, Avinoah E, Ziv O, et al. Body contouring surgery decreases long-term weight regain following laparoscopic adjustable gastric banding: A matched retrospective cohort study. J Plast Reconstr Aesthet Surg. 2016;69(11):1490-1496.

11. Agarwal S, Shenaq D, Teven CM, Prachand V, Roughton M, Zachary L. Body contouring after obesity surgery is associated with a weight loss benefit among patients. J Plast Reconstr Aesthet Surg. 2017;70(9):1186-1190.

12. Azin A, Zhou C, Jackson T, Cassin S, Sockalingam $S$, Hawa R. Body contouring surgery after bariatric surgery: A study of cost as a barrier and impact on psychological well-being. Plast Reconstr Surg. 2014;133(6):776e-782e.

13. Staalesen T, Fagevik Olsen M, Elander A. Experience of excess skin and desire for body contouring surgery in post-bariatric patients. Obes Surg. 2013;23(10):1632-1644

14. Gusenoff JA, Messing S, O'Malley W, Langstein HN. Patterns of plastic surgical use after gastric bypass: Who can afford it and who will return for more. Plast Reconstr Surg. 2008;122(3):951-958.

15. Klopper E.M., Kroese-Deutman H.C., Berends F.J. Massive weight loss after bariatric surgery and the demand (desire) for body contouring surgery. Eur J Plast Surg. 2014;37(2):103-108.

16. Association of Advising Doctors of Healthinsurence Companies (Vereniging Adviserend Geneeskundigen bij Zorgverzekeraars). Guideline for judgement of plastic surgery (werkwijzer beoordeling behandelingen van plastisch-chirurgische aard). 2018.

17. Song AY, Jean RD, Hurwitz DJ, Fernstrom MH, Scott JA, Rubin JP. A classification of contour deformities after bariatric weight loss: The pittsburgh rating scale. Plast Reconstr Surg. 2005;116(5):1535-44; discussion 1545-6.

18. van der Beek ES, Verveld CJ, van Ramshorst B, Kon $M$, Mink van der Molen AB. Classification of contour deformities after massive weight loss: The applicability of the pittsburgh rating scale in the netherlands. $J$ Plast Reconstr Aesthet Surg. 2013;66(8):1039-1044.

19. Biorserud C, Fagevik Olsen M, Elander A, Wiklund M. Objective measurements of excess skin in post bariatric patients--inter-rater reliability. J Plast Surg Hand Surg. 2016;50(2):68-73.

20. Mukherjee S, Kamat S, Adegbola S, Agrawal S. Funding for postbariatric body-contouring (bariplastic) surgery in england: A postcode lottery. Plast Surg Int. 2014;2014:153194.

21. Soldin M, Mughal M, Al-Hadithy N, Department of Health, British association of Plastic, Reconstructive and Aesthetic Surgeons, Royal College of Surgeons England. National commissioning guidelines: Body contouring surgery after massive weight loss. J Plast Reconstr Aesthet Surg. 2014:67(8):1076-1081.

22. Dunne JA, Wormald JC, Ghedia R, Soldin M. Implementation of national body contouring surgery guidelines following massive weight loss: A national cross-sectional survey of commissioning in england. J Plast Reconstr Aesthet Surg. 2017;70(1):54-59.

23. Brethauer SA, Kim J, El Chaar M, et al. Standardized outcomes reporting in metabolic and bariatric surgery. Obes Surg. 2015;25(4):587-606.

24. van de Laar A. Bariatric outcomes longitudinal database (BOLD) suggests excess weight loss and excess BMI loss to be inappropriate outcome measures, demonstrating better alternatives. Obes Surg. 2012;22(12):1843-1847.

25. Brito MJ, Nahas FX, Cordas TA, et al. Prevalence of body dysmorphic disorder symptoms and body weight concerns in patients seeking abdominoplasty. Aesthet Surg J. 2016;36(3):324-332.

26. de Vries CEE, Kalff MC, Prinsen CAC, et al. Recommendations on the most suitable quality-of-life measurement instruments for bariatric and body contouring surgery: A systematic review. Obes Rev. 2018.

27. Klassen AF, Cano SJ, Alderman A, et al. The BODY-Q: A patient-reported outcome instrument for weight loss and body contouring treatments. Plast Reconstr Surg Glob Open. 2016;4(4):e679.

28. Giordano S, Victorzon M, Stormi T, Suominen E. Desire for body contouring surgery after bariatric surgery: Do body mass index and weight loss matter? Aesthet Surg J. 2014;34(1):96-105.

29. Al-Hadithy N, Mennie J, Magos T, Stewart K. Desire for post bariatric body contouring in south east scotland. J Plast Reconstr Aesthet Surg. 2013;66(1):8794.

30. Aldaqal SM, Samargandi OA, El-Deek BS, Awan BA, Ashy AA, Kensarah AA. Prevalence and desire for body contouring surgery in postbariatric patients in saudi arabia. N Am J Med Sci. 2012;4(2):94-98.

31. 31. Biorserud C, Olbers T, Fagevik Olsen M. Patients' experience of surplus skin after laparoscopic gastric bypass. Obes Surg. 2011;21(3):273-277.

32. 32. Biorserud C, Olbers T, Sovik TT, Mala T, Elander A, Olsen MF. Experience of excess skin after gastric bypass or duodenal switch in patients with super obesity. Surg Obes Relat Dis. 2014;10(5):891896.

33. Giordano S, Victorzon M, Koskivuo I, Suominen E. Physical discomfort due to redundant skin in post-bariatric surgery patients. J Plast Reconstr Aesthet Surg. 2013;66(7):950-955.

34. Baillot A, Asselin M, Comeau E, Meziat-Burdin A Langlois MF. Impact of excess skin from massive weight loss on the practice of physical activity in women. Obes Surg. 2013;23(11):1826-1834.

35. Song P, Patel NB, Gunther S, et al. Body image \& quality of life: Changes with gastric bypass and body contouring. Ann Plast Surg. 2016;76 Suppl 3:S216-21.

36. Gilmartin J. Body image concerns amongst massive weight loss patients. J Clin Nurs. 2013;22(910):1299-1309.

37. van der Beek ES, van der Molen AM, van Ramshorst 
B. Complications after body contouring surgery in post-bariatric patients: The importance of a stable weight close to normal. Obes Facts. 2011;4(1):61-66.

38. Varban OA, Cassidy RB, Bonham A, et al. Factors

associated with achieving a body mass index of less than 30 after bariatric surgery. JAMA Surg. 2017;152(11):1058-1064. 
Appendix 1: Modified BAPRAS questionnaire and calculation of the screening tool score.

1. Because of the excess skin I suffer of (please tick all that apply):

\begin{tabular}{|l|l|l|l|}
\hline \multirow{2}{*}{$\begin{array}{l}\text { Skin } \\
\text { condition }\end{array}$} & \multicolumn{3}{|c|}{$\begin{array}{l}\text { How often do you have these } \\
\text { complaints }\end{array}$} \\
\hline & Always & Sometimes & never \\
\hline Dermatitis & & & \\
\hline intertrigo & & & \\
\hline Infection & & & \\
\hline Ulceration & & & \\
\hline Lymphoedema & & & \\
\hline Hidradenitis & & & \\
\hline
\end{tabular}

2. The excess skin causes problems in:

Daily routine (like showering and getting dressed), at work and during physical activity

Only during physical activity

Never

3. The excess skin causes of worsens psychological issues (like fear, depression, sleep disturbance, stress):

Always

Sometimes

Never

4. Have you had changes in your weight fluctuations in the last 12 months?

No

$0-5$ kilograms

$5-10$ kilograms

$10-20$ kilograms

More than 20 kilograms

5. Do you smoke or have you ever smoked?

Yes, but I have quite (go on to question number 6 )

Yes, and I still smoke (go on to question number 8 )

No (go on to question number 9 )

6. When did you stop smoking?

7. What was the most you ever smoked?

Very rarely

Socially (less than 2 cigarettes per week)

less than 5 cigarettes per day

$5-10$ cigarettes per day

11-20 cigarettes per day

21-40 cigarettes per day

More than 40 cigarettes per day 
8. How much do you smoke?

Very rarely

Socially (less than 2 cigarettes per week)

less than 5 cigarettes per day

5-10 cigarettes per day

11-20 cigarettes per day

21-40 cigarettes per day

More than 40 cigarettes per day

9. Do you use drugs or have you used drugs (daily or weekly)?

Yes, but I have quite (go on to question number 10)

Yes, I use

No (go on to question number 11)

10. If you have quit, when did you quit?

11. Have you had a pregnancy in the last 12 months or do you want children in the near future?

yes

No

12. Have you experienced major live-events, like a divorce or death of a close family member, in last 12 months?

yes

No

13. How frequently do you exercise?

Not at all (go on to question number 16)

Once per month or less

Several times per month

Once per week

Several times per week

Once per day

Several times a day

14. If you exercise, how long do you exercise each time?

Less than 15 minutes

15-30 minutes

31-60 minutes

$61-120$ minutes

More than 120 minutes

15. Where do you do most of your exercise?

Inside

Outside

16. If you exercise, please indicate the types of exercise you do (fill in all that apply):

\begin{tabular}{|l|l|l|l|l|l|l|l|l|l|}
\hline Cycling & $\square$ & $\begin{array}{l}\text { Stationary } \\
\text { bike }\end{array}$ & $\square$ & Swimming & $\square$ & Stairmaster & $\square$ & Zumba & $\square$ \\
\hline
\end{tabular}




\begin{tabular}{|l|l|l|l|l|l|l|l|l|l|}
\hline Running & $\square$ & Treadmill & $\square$ & $\begin{array}{l}\text { In-line } \\
\text { skating }\end{array}$ & $\square$ & $\begin{array}{l}\text { Weight } \\
\text { training }\end{array}$ & $\square$ & Aerobics & $\square$ \\
\hline Walking & $\square$ & $\begin{array}{l}\text { Cross } \\
\text { trainer }\end{array}$ & $\square$ & Dancing & $\square$ & Yoga & $\square$ & Pilates & $\square$ \\
\hline
\end{tabular}

17. Please tick if there is any history of the following (and provide date of diagnosis and details)

\begin{tabular}{|c|l|l|}
\hline & Psychological issue & Date of diagnosis \& details \\
\hline$\square$ & $\begin{array}{l}\text { Active delusional or } \\
\text { schizophrenic illness }\end{array}$ & \\
\hline$\square$ & Body dysmorphic disorder & \\
\hline$\square$ & Eating disorder & \\
\hline$\square$ & History of self-harm & \\
\hline$\square$ & Major depressive illness & \\
\hline$\square$ & Obsessive compulsive disorder & \\
\hline
\end{tabular}

\section{Calculation of the score}

\begin{tabular}{|c|c|c|}
\hline Parameter & \multicolumn{2}{|c|}{ Scoring } \\
\hline Total Body Weight loss & $\begin{array}{c}<20 \% \\
20-39 \% \\
>39 \%\end{array}$ & $\begin{array}{l}0 \\
1 \\
2\end{array}$ \\
\hline Current BMI & $\begin{array}{c}>30 \mathrm{~kg} / \mathrm{m}^{2} \\
27-30 \mathrm{~kg} / \mathrm{m}^{2} \\
26-27 \mathrm{~kg} / \mathrm{m}^{2} \\
\leq 25 \mathrm{~kg} / \mathrm{m}^{2}\end{array}$ & $\begin{array}{c}-1 \\
0 \\
1 \\
2\end{array}$ \\
\hline Stable weight & $\begin{array}{l}\text { No } \\
\text { Yes }\end{array}$ & $\begin{array}{c}-2 \\
0\end{array}$ \\
\hline Duration stable weight & $\begin{array}{c}<12 \text { months } \\
\geq 12-18 \text { months } \\
>18 \text { months }\end{array}$ & $\begin{array}{l}0 \\
1 \\
2\end{array}$ \\
\hline $\begin{array}{l}\text { Skin condition caused by excess skin } \\
\text { (1 point for each condition*) }\end{array}$ & $\begin{array}{l}\text { No } \\
\text { Yes }\end{array}$ & $\begin{array}{c}0 \\
1 \text { to } 6\end{array}$ \\
\hline Functional complaints caused by excess skin & $\begin{array}{l}\text { No } \\
\text { Yes }\end{array}$ & $\begin{array}{l}0 \\
1 \\
\end{array}$ \\
\hline Psychological complaints caused by excess skin & $\begin{array}{l}\text { No } \\
\text { Yes }\end{array}$ & $\begin{array}{l}0 \\
1 \\
\end{array}$ \\
\hline $\begin{array}{l}\text { Psychological history } \\
\text { (-1 point for every psychological condition*) }\end{array}$ & $\begin{array}{l}\text { No } \\
\text { Yes }\end{array}$ & $\begin{array}{c}0 \\
-1 \text { to }-6\end{array}$ \\
\hline Recent life-events & $\begin{array}{l}\text { No } \\
\text { Yes }\end{array}$ & $\begin{array}{c}0 \\
-1\end{array}$ \\
\hline Recent pregnancy or children in near future & $\begin{array}{l}\text { No } \\
\text { Yes }\end{array}$ & $\begin{array}{c}0 \\
-1\end{array}$ \\
\hline Smoking & $\begin{array}{c}\text { Never } \\
\text { Quit } \\
<2 / \text { day } \\
<5 / \text { day } \\
5-10 / \text { day } \\
\text { 11-20/day } \\
21-40 / \text { day } \\
>40 / \text { day }\end{array}$ & $\begin{array}{c}1 \\
0 \\
-1 \\
-2 \\
-3 \\
-4 \\
-5 \\
-10\end{array}$ \\
\hline $\begin{array}{l}\text { * dermatitis, hidradenitis, Intertrigo, infectio } \\
\text { ** active delusional or schizophrenic illness } \\
\text { history of self-harm in last } 2 \text { years, major d } \\
\text { substance abuse problem }\end{array}$ & $\begin{array}{l}\text { ema, ulceration } \\
\text { orphic disorder, } \\
\text { ess, obsessive }\end{array}$ & $\begin{array}{l}\text { order, } \\
\text { e disorder, }\end{array}$ \\
\hline
\end{tabular}


Appendix 2: The Dutch ReBoc tool: a new screening tool for referral and possible reimbursement of post-bariatric body contouring surgery.

\section{STEP 1: CHECK CRITERIA}

Criteria for referral, the patient:

1. Is at least 18 months after bariatric surgery.

2. Has a stable weight for at least 12 months.

3. Has a $\mathrm{BMI}<35 \mathrm{~kg} / \mathrm{m}^{2}$ (except when BMI before bariatric surgery was $>50 \mathrm{~kg} / \mathrm{m}^{2}$ )

4. Has no recent life-events, psychological/psychiatric issues and/or drug use. If so, patient should have a consultation at the psychologist to decide whether there is a contra-indication for BCS.

5. Was not recently pregnant (<12 months ago) or has desire for children in the near future.

\section{STEP 2: CALCULATE SCORE}

\section{Total Body Weight loss}

\begin{tabular}{|c|c|c|}
\hline & $>39 \%$ & 2 \\
\hline \multirow{4}{*}{ Current BMI } & $>30 \mathrm{~kg} / \mathrm{m}^{2}$ & -1 \\
\hline & $27-30 \mathrm{~kg} / \mathrm{m}^{2}$ & 0 \\
\hline & $26-27 \mathrm{~kg} / \mathrm{m}^{2}$ & 1 \\
\hline & $\leq 25 \mathrm{~kg} / \mathrm{m}^{2}$ & 2 \\
\hline \multirow{2}{*}{$\begin{array}{l}\text { Skin condition caused by excess skin } \\
\text { (1 point for each condition*) }\end{array}$} & No & 0 \\
\hline & Yes & 1 to 6 \\
\hline \multirow{2}{*}{$\begin{array}{l}\text { Functional complaints caused by excess } \\
\text { skin }\end{array}$} & No & 0 \\
\hline & Yes & 1 \\
\hline \multirow{2}{*}{$\begin{array}{l}\text { Psychological complaints caused by } \\
\text { excess skin }\end{array}$} & No & 0 \\
\hline & Yes & 1 \\
\hline \multirow{8}{*}{ Smoking } & Never & 1 \\
\hline & Quit & 0 \\
\hline & $<2 /$ day & -1 \\
\hline & $<5 /$ day & -2 \\
\hline & 5-10/day & -3 \\
\hline & 11-20/day & -4 \\
\hline & 21-40/day & -5 \\
\hline & $>40 /$ day & -10 \\
\hline TOTAL SCORE & & \\
\hline
\end{tabular}

* dermatitis, hidradenitis, Intertrigo, infection, lymph oedema, ulceration

\section{STEP 3: SCORE $\geq 8$ : REFERRAL TO PLASTIC SURGEON}



DISCUSSION 
The main goal of this thesis was to study which psychological factors relate to weight loss after bariatric surgery. In the first part of the thesis we focused on the effect of compliance to follow-up, physical activity, psychopathology, depressive disorders, eating disorders, HRQoL and body image on weight loss after primary RYGB. The current literature regarding the effect of these factors was studied via a systematic review and meta-analysis (chapter 2). Then the effect of physical activity and eating style on weight loss and weight regain up to 48 months after RYGB was analysed (chapter 3). Additionally, the relationship between weight loss and HRQoL was studied, comparing an obesity-specific and a generic questionnaire for the evaluation of HRQoL (chapter 4).

Excess skin, BCS and body image were the main focus in the second part of the thesis. We compared patients with a desire for BCS, with patients who already had BCS and patients without a desire for BCS. First, we assessed the relationship between body image, weight loss and depressive symptoms in the three patient groups (chapter 5). Social economic status, complaints of overhanging skin, satisfaction with the body and qualification for BCS reimbursement according to Dutch weight criteria were also compared between these groups (chapter 6). In the last chapter we describe the development of a new screening tool for the reimbursement of BCS: the Dutch Reboc Tool (chapter 7).

\section{SUMMARY OF FINDINGS}

As a base for this thesis and to provide an overview of the available literature, the first study was a systematic review and meta-analysis assessing the effect of compliance, physical activity, depressive symptoms, binge eating, body image and HRQoL on weight loss after RYGB. The meta-analysis showed us that weight loss was significantly higher in compliant patients compared to non-compliant patients. And that active patients also had a higher weight loss, the difference was almost $7 \%$, compared to non-active patients. This effect of physical activity seemed to become more pronounced on long-term follow-up after RYGB.

Contrary to common believe, binge eating and depressive symptoms did not significantly affect weight loss. Twelve studies assessing depressive symptoms before and after surgery were included; EWL was not significantly different in the patients with symptoms (66.9\%) compared to patients without symptoms $(65.4 \%)$. For binge eating mean EWL was even higher in patients who reported binge eater before surgery (61.3\%) compared to the patients who did not report binge eating (58.7\%). From these results we can conclude that compliance to follow-up and physical activity should be focus of counselling in bariatric patients. Psychological issues like binge eating and depression might not be suitable to disqualify patients for bariatric surgery. The systematic review also showed that research regarding HRQoL and body image was sparse; for both there were only two studies assessing the effect on weight loss. 
This was insufficient data to conduct a meta-analysis and therefore we could not draw any conclusion regarding these factors.

The next step was to evaluate our own population, starting with the factor that has been shown to improve weight loss: physical activity. And since lifestyle change is the main focus of the treatment at NOK, we also added self-reported eating style to this study. A total of 4,569 patients were included, and, with a follow-up up to 48 months, we could study both weight loss and weight regain. We showed that self-reported physical activity and eating style before surgery were not related to weight loss or weight regain at any of the follow-up moments after primary RYGB. Hence, patients should not be denied surgery based on pre-operative physical activity and eating style.

Looking at the change of physical activity and eating style from before surgery to after surgery, the study showed that patients who became more active after surgery compared to before surgery had more weight loss. Patients with more emotional eating after surgery compared to baseline, had less weight loss at all follow-up moments. Patient who reported more external eating at 24 months follow-up showed less weight loss. Thus, patients who change their physical activity and eating style in a positive way, seem to have better weight loss results. Interestingly, there was also less weight loss in patients who reported to eat more restrained. And weight regain at 36 months after RYGB was higher in patient who showed more restrained eating at 36 months. This shows that while patients might have the intention to eat less, they might not. This study also revealed that patients who experienced emotional eating at 48 months had more weight regain.

Then we concentrated on the factors that were scarcely studied before: HRQoL and body image. Both these factors have been associated with weight loss in the obese population ${ }^{1-3}$. To evaluate the relationship between HRQoL and weight loss we compared the IWQOL-lite (an obesity specific questionnaire) and the RAND-36 (a generic questionnaire) in patients undergoing a primary RYGB. We studied weight and HRQoL before surgery and at 15 and 24 months after surgery. Patient with a higher BMI had a lower HRQoL, not only before but also after RYGB. Moreover, patients who lost more weight, had more improvement of HRQoL on both questionnaires. The correlations between weight (loss) and HRQoL were higher when HRQoL was measured with the IWQOL-lite compared to the RAND-36. These results showed that the reported variance in the effect of RYGB on HRQoL can be explained by both the weight loss of the researched population and the questionnaire used.

There is almost no knowledge about the relationship between body image, excess skin and desire for BCS in post-bariatric patients. This thesis showed that excess skin, desire for BCS and body image are important factors in the bariatric population, which can negatively influence patient well-being. In the studied post-bariatric pop- 
ulation, a majority had complaints of excess skin and desired BCS. Patients with a more positive body image had fewer depressive symptoms, even within the group of patients without a desire for BCS. Patients with a desire for BCS had a more negative body image and more depressive symptoms compared to patients without a desire for BCS. More interestingly, in these patients the relationship between weight loss and depressive symptoms was partly explained by body image. Patients with more weight loss had fewer depressive symptoms, via a more positive body image.

Patients who desired BCS were younger and more often female, compared to the group that already had BCS and the group that did not want BCS. The patients with a desire also experienced more excess skin and were less satisfied with their body compared to patients without a desire or patients who already had BCS. There were no differences between the three groups with regards to the percentage of patients who met the weight criteria for reimbursement for BCS in the Netherlands.

A large part of the patients who desired BCS never consulted a plastic surgeon for their overhanging skin, although almost half of these patients qualified for reimbursement according to the weight loss results. This confirms what we see in daily practice: there is a group of patients who might be reimbursed by their insurance company, but never take the necessary action to get surgery, i.e. consult a general practitioner, bariatric surgeon or plastic surgeon. This is, at least partially, caused by the fact that patients are not educated on the current guidelines. They might also feel unequipped or unsure to stand up for themselves and try to get a reimbursement.

\section{PRE-OPERATIVE PSYCHOLOGICAL FACTORS}

To qualify for bariatric surgery, patients have to go through a multidisciplinary screening. According to the IFSO criteria, assessment of motivation to follow-up and adherence to, non-specified, behavioural changes is an essential part of this screening 4,5 . Guidelines state that non-stabilized psychotic disorders, severe depression, personality and eating disorders are a contra-indication for bariatric surgery ${ }^{4,5}$. These criteria are based on the idea that these psychological issues have a negative impact on longterm weight loss and complication risk after bariatric surgery and that preoperative behaviour predicts behaviour and weight change after surgery ${ }^{4,5}$.

This research in this thesis shows that some common assumptions in the selection of patients for bariatric surgery are not based on facts, even untrue and in need of change. In chapter 2 , we showed that weight loss was not influenced by self-reported binge eating or depressive symptoms. Several other studies have suggested that there is no effect of depression on weight loss ${ }^{6,7}$. For binge eating another review even found a positive effect ${ }^{6}$. In chapter 3 , we showed that preoperative physical activity and self-reported eating style were also not related to weight loss up to 48 
months after RYGB. In addition, no relation could be found between preoperative behaviour and weight regain 36 or 48 months after RYGB.

In conclusion, there is not much evidence for a negative effect of preoperative, self-reported physical activity, eating style behaviour, depressive symptoms and binge eating on postoperative weight loss in patients undergoing bariatric surgery. Patients should not be denied access to bariatric surgery based on the outcome of only a questionnaire, since, we did not find any indications that there an absolute cut-off predicts which patients will fail after bariatric surgery. Normally psychological assessment is preferably done via structured interviews, because they are more valid and reliable than questionnaires. The outcome of screening of the pre-bariatric patients should also be based on a complete picture of the patient via a thorough screening by a multidisciplinary team, including a mental health professional. In this screening questionnaires can be helpful. Screening of bariatric patients remains to be important, also because participation in mental health treatment before bariatric surgery can improve weight loss results ${ }^{8}$.

Which assessments a team should use, is in important topic for future research. The review showed great variance in instruments of assessment and definition of psychological issues and/or symptoms and thus, probably also a great variation in acceptance of patients for bariatric surgery. This is caused by the fact that there is no consensus or guideline for psychological evaluation of the pre-bariatric patient $5,9,10$. More effort should be made to develop such a guideline or consensus.

\section{CHANGE IN BEHAVIOUR}

In chapter 2, we showed that patients with better compliance and higher physical activity had more weight loss. For both these parameters it seemed that the weight loss was even higher when follow-up after surgery was longer, but populations were too small to do a meta-analysis for the long-term follow-up.

Regular physical activity improves health and maintains body weight, and is advised to all bariatric patients ${ }^{9-12}$. In our population, (chapter 3 ), the patients who were more active 15, 24 and 36 months after surgery had a higher weight loss. This has been shown before, also when looking at preoperative change in physical activity ${ }^{13,14}$. For eating style, the opposite was true: overall patients who reported an increase in emotional, external or restrained eating from baseline (before surgery) to follow-up had less weight loss. For emotional eating this association was significant at all follow-up moments, from 15 to 48 months. Restrained eating was negatively associated with weight loss up to 36 months follow-up. External eating was only related to weight loss at 24 months follow-up.

Additionally, chapter 3 showed that patients who had higher restrained eating at 
3-year follow-up had higher weight regain 3 years after surgery. And patients with more emotional eating at 4 years follow-up had higher weight regain 4 years after surgery.

It is important to note that we could not interpret the data from chapter $\mathbf{3}$ in a causal way. It could be that an increase in physical activity or decrease in emotional eating is causal to an increase in weight loss, but the association might as well be the other way around. Further research should focus on the causal relationship and study effect of psychological problems (like depression) that arise on the mid to long-term after surgery. In the review four out of six studies showing a negative effect of depression on weight loss, depressive symptoms were assessed postoperatively ${ }^{24-27}$. Depression has been linked to changes in eating behaviour in the obese population before ${ }^{28,29}$. It might be that post-operative (re-) occurrence of depression does negatively affect bodyweight, like in the obese ${ }^{1,2,30,31}$. Whether this is also related to more emotional or restrained eating and negative body image is unknown in the bariatric population, but these factors are related in the obese population 1,2,28,30,32,33. Follow-up of bariatric patients and timely assessment and treatment of post-operative psychological problems thus seems important.

We can conclude that there is a relationship between the change in physical activity and eating style after surgery with weight loss results. Previous research links insufficient weight loss and weight regain to low psychical activity and non-compliance to eating advice ${ }^{15}$. And an exercise regime or postoperative counselling in addition to bariatric surgery seems to have a positive effect on weight loss and other outcome parameters, like psychological problems ${ }^{16-20}$. This is in line with our results. It was surprising that patients experienced less restrained eating after surgery and especially that more restrained eating was related to less weight loss. It seems that self-reported restrained eating reflects intentions to restrain intake instead of actual restrained eating [39].

Guidelines for treatment of bariatric patient's advice multidisciplinary counselling on nutrition, physical activity and psychological issues $5,9,10$. Patients themselves also describe that to achieve and maintain outcome after surgery, they needed to achieve lifelong changes, which are mostly difficult to accomplish ${ }^{21}$. Strangely enough, multidisciplinary counselling is usually not a standard part of treatment in bariatric clinics ${ }^{22,23}$. Since it seems that physical activity and eating style influence weight loss and weight regain, we think it is important that counselling in bariatric surgery patients should focus on all factors that induce or maintain obesity to improve outcome after surgery. 


\section{HEALTH RELATED QUALITY OF LIFE}

In bariatric surgery, most studies report outcome in terms of complication rate and weight loss ${ }^{34}$. Recently, the American Society for Metabolic and Bariatric Surgery (ASMBS) has defined HRQoL as one of the key outcomes in bariatric surgery; they advise to use a generic and a disease specific instrument to measure HRQoL ${ }^{35}$. There is also a core outcome set for bariatric surgery: an agreed minimum set of outcomes developed by patients and experts ${ }^{34,36}$. HRQoL is part of this core outcome. Because of the differences in HRQoL questionnaire used, the ASMBS questioned whether the effect of bariatric surgery on HRQoOL was indeed positive and to what extent ${ }^{35,37}$.

Using a large patient cohort and good follow-up rates we showed that all aspects of HRQoL improve greatly after RYGB (chapter 4). The improvement of HRQoL seems to follow the same curve as the weight loss: it reaches a plateau after 1-2 years and then decreases, but never below the HRQoL scores before surgery ${ }^{38-40}$. Like in the obese population undergoing non-surgical treatment, evaluating change in HRQoL with the RAND-36 and the IWQOL-lite showed that HRQoL measured by a specific "obesity" questionnaire was more related to the weight (loss) ${ }^{41}$. The fact that a higher weight loss was related to higher HRQoL on both scales shows the importance of maximizing weight loss after bariatric surgery. Especially, since a review assessing HRQoL after non-surgical weight loss showed that mental quality of life did not improve ${ }^{40}$.

HRQoL is defined as the functional effect of a medical condition and/or its consequent therapy upon a patient ${ }^{42}$. Thus, the purpose of HRQoL measurement is to quantify the degree to which the medical condition or its treatment impacts the individual's life in a valid and reproducible way. Although the IWQOL-lite is an obesity specific questionnaire, it was not created specifically for the changes that occur in patients after bariatric surgery ${ }^{43}$. Ideally, to quantify the degree to which bariatric surgery impacts the patients' life, we need a more specific questionnaire ${ }^{44}$. In this questionnaire not only the general psychological topics, like social problems, eating problems, self-esteem and depressive symptoms should be included, but also topics regarding the complications and/or negative side-effects that can occur after surgery, like excess skin and body image.

\section{BODY IMAGE}

Similar to studies conducted with obese patients, this thesis supports the importance of body image in all patients undergoing bariatric surgery. There were some distinct differences when comparing patients who desired BCS and patients who did not. Patients with a desire for BCS were more concerned about shape and, they were less satisfied with their body. But, they also were more focused on their appearance, 
more preoccupied with overweight stigmata and they classified their weight higher; even though BMI was the same for both groups. In the group with a desire for BCS, body image partially mediated the relationship between weight loss and depressive symptoms. Thus, in this group the excess skin might, via a more negative body image, cause more depressive symptoms, like Friedman et al. found ${ }^{1}$. These depressive symptoms may in turn because weight regain. Therefore, the patients with a desire for BCS might benefit most from BCS in terms of weight loss maintenance ${ }^{45,46}$.

Satisfaction with one's body and shape were significantly higher in the patients who already had BCS. Unexpectedly, they also scored quite high on overweight preoccupation, even though their BMI was quite low compared to the other groups. It seems that body image is a very broad construct in the bariatric population ranging from perception, and appearance, to perceived body size and space ${ }^{47}$. Depending on the "type" of body image that is assessed, the effect or bariatric and/or body contouring surgery might differ. For instance, focus on appearance does not seem to change after bariatric surgery, while satisfaction with appearance improves ${ }^{48-50}$. And like in our population, even after BCS overweight pre-occupation and appearance orientation can be high (i.e. not improve), while appearance evaluation and self-classified weight did ${ }^{51}$.

Appearance orientation and overweight preoccupation are developed in childhood and it is suggested that these parts of body image might be intrinsic to a person ${ }^{33,49}$. This can explain why these constructs do not change easily after either bariatric or body contouring surgery and are comparable between the patients who already had BCS and patients who desire BCS. It would be interesting to see whether improvement of body image through interventions (in addition to bariatric surgery), will also improve these concepts of body image. And thereby, eventually, outcome after bariatric surgery.

Since body image seems to be an important parameter, more information about the change in body image after bariatric surgery and the influence on patient well-being and weight loss is essential. We need to know whether and how body image changes after bariatric and body contouring surgery. And also, if the relationship between body image and depressive symptoms is causal and can be improved via cognitive behavioural therapy. Fortunate, there is currently more research directed at body image in the bariatric population. For example, body image is a standard part of assessment in the new PROM for the bariatric population, the BODY-Q, which we also used in chapter 7 of this thesis ${ }^{52}$. Prospective trials with this new PROM might provide more information on the change of body image during the total weight loss journey. 


\section{EXCESS SKIN}

In chapter 6, we studied the characteristics of the post-bariatric population in relation to desire for BCS. As in previous literature, almost two thirds of the patients desired $\mathrm{BCS}$ and about one in ten patients already had a body contouring procedure ${ }^{53-56}$. The most common locations for excess skin and severity of complaints were also similar 54, 57-59. Patients who desired BCS were usually younger, had lower income levels and a larger part was unemployed ${ }^{53,60,61}$. Interestingly, patients with a desire for BCS were usually quite satisfied with their total body, but rated specific body parts very low ${ }^{54,57}$. These body parts are probably also the parts in which they experience overhanging skin, since the extend of overhanging skin correlates with satisfaction of these body parts ${ }^{54}$. The fact that all our findings regarding excess skin and complaints are comparable to the post-bariatric populations in other countries suggests that our results can be extrapolated. But also, that there is a distinct "post-bariatric population" with the same problems worldwide.

\section{REIMBURSEMENT OF BODY CONTOURING SURGERY}

Reimbursement of BCS, or the lack of it, is a worldwide problem. In most countries, there is no clear and objective system to decide which patients qualify for reimbursement or the system is not implemented ${ }^{53,60,62-64}$. Therefore, it is essential that there are clear criteria for reimbursement of BCS that can be easily applied. Another important aspect is that these criteria are properly communicated to the bariatric patients.

The results of chapter 6 showed that patients are not well educated on the guidelines and they often wrongly assume that BCS will not be reimbursed. This results in a large population of patients who do meet the current Dutch weight criteria for reimbursement, but never consult a plastic surgeon. These are the patients who might regain weight on the long-term. It can be that financial status, self-esteem and having the power to stand up for themselves, also influences whether patients will consult a plastic surgeon. It is, therefore, essential to educate bariatric patients about the possibility of excess skin and guidelines for reimbursement. Ideally this education starts before the bariatric procedure, so that patients are aware of the problems they might face after surgery.

The current Dutch system lacks thorough evaluation of the post-bariatric patient: it does not include weight loss results, psychological complaints or physical complaints caused by the excess skin. In chapter 7 we developed a new screening tool for post-bariatric BCS in which all these parameters are included. The tool selected the patients with the highest weight loss and the most complaints of excess skin. We included the BODY-Q in this tool. The results demonstrated that patients with a desire 
for BCS had a lower HRQoL compared to patients who do desire BCS. Once again showing that the influence of excess skin on patient well-being is important; and thus, that the evaluation of influence of excess skin on patient well-being should be part of decision making for reimbursement.

\section{GASTRIC SLEEVE}

The first part of this thesis focused solely on the RYGB, which is the most performed type of bariatric surgery in the Netherlands ${ }^{65}$. Looking at the world trends in bariatric surgery, the question is whether the results of these chapters can be extrapolated to other types of bariatric surgery, such as the gastric sleeve (GS), which was the most performed type of surgery in 2014 worldwide ${ }^{66}$. Two recent studies have shown that effect on weight loss, HRQoL and comorbidities are comparable between RYGB and GS ${ }^{67,68}$. And thus, it would seem that the implications of results of the first part of this thesis could be similar to patients undergoing a GS.

\section{CONCLUSION}

This thesis proves that self-reported, preoperative binge eating, depressive symptoms, eating style and physical activity are not predictive of weight loss after surgery. It also shows that postoperative physical and psychological factors are related to weight loss and thereby HRQoL after bariatric surgery. Several of these factors, like depressive symptoms, body image and weight loss, are also related to each other. In order to improve weight loss results in the bariatric population, more focus should be directed to these factors. Not only in research, but also in pre- and post-operative counselling. Efforts should also be made to extensively inform the morbid obese patients of both the positive and negative side-effects of bariatric surgery, including excess skin and criteria for reimbursement of BCS.

In addition, excess skin seems to be a very important parameter in patient well-being after bariatric surgery, and thereby maybe also weight loss maintenance. In collaboration with the bariatric surgeons, plastic surgeon should improve Dutch reimbursement guidelines for BCS. Communication of these guidelines to bariatric patients should also be a joint effort. 


\section{References}

1. Friedman KE, Reichmann SK, Costanzo PR, Musante GJ. Body image partially mediates the relationship between obesity and psychological distress. Obes Res. 2002 Jan;10(1):33-41.

2. Stunkard AJ, Wadden TA. Psychological aspects of severe obesity. Am J Clin Nutr. 1992 Feb;55(2 Suppl):524S-32S.

3. Kolotkin RL, Crosby RD, Williams GR, Hartley GG, Nicol S. The relationship between health-related quality of life and weight loss. Obes Res. 2001 Sep;9(9):564-71.

4. Verdam FJ, de Jonge C, Greve JW. Practice guideline for the treatment of morbid obesity. Ned Tijdschr Geneeskd. 2012;156(23):A4630.

5. Fried M., Yumuk V., Oppert J.M., Scopinaro N., Torres A., Weiner R., et al. Interdisciplinary European guidelines on metabolic and bariatric surgery. Obes Surg. 2014;24(1):42-55

6. Livhits M, Mercado C, Yermilov I, Parikh JA, Dutson E, Mehran A, et al. Preoperative predictors of weight loss following bariatric surgery: systematic review. Obes Surg. 2012 Jan;22(1):70-89.

7. Wimmelmann C.L., Dela F., Mortensen E.L. Psychological predictors of mental health and health-related quality of life after bariatric surgery: A review of the recent research. Obes Res Clin Pract. 2013.

8. Clark MM, Balsiger BM, Sletten CD, Dahlman KL, Ames G, Williams DE, et al. Psychosocial factors and 2-year outcome following bariatric surgery for weight loss. Obes Surg. 2003 Oct;13(5):739-45.

9. Busetto L, Dicker D, Azran C, Batterham RL, Farpour-Lambert N, Fried M, et al. Practical Recommendations of the Obesity Management Task Force of the European Association for the Study of Obesity for the Post-Bariatric Surgery Medical Management. Obes Facts. 2017 Dec 6;10(6):597-632.

10. Mechanick JI, Youdim A, Jones DB, Garvey WT, Hurley DL, McMahon MM, et al. Clinical practice guidelines for the perioperative nutritional, metabolic, and nonsurgical support of the bariatric surgery patient--2013 update: cosponsored by American Association of Clinical Endocrinologists, The Obesity Society, and American Society for Metabolic \& Bariatric Surgery. Obesity (Silver Spring). 2013 Mar;21 Suppl 1:S1-27.

11. Faria SL, Faria OP, Buffington C, de Almeida Cardeal M, Ito MK. Dietary protein intake and bariatric surgery patients: a review. Obes Surg. 2011 Nov;21(11):1798-805.

12. Bariatric Surgery: postoperative concerns [Internet].: ASMBS; 2008 [updated 02/07/2008; ]. Available from: https://asmbs.org/resources/bariatric-surgery-postoperative-concerns-2.

13. Bond DS, Phelan S, Wolfe LG, Evans RK, Meador JG, Kellum JM, et al. Becoming physically active after bariatric surgery is associated with improved weight loss and health-related quality of life. Obesity (Silver Spring). 2009 Jan;17(1):78-83.

14. Ledoux S, Sami O, Breuil MC, Delapierre M, Calabrese D, Msika S, et al. Relevance of Self-reported Behavioral Changes Before Bariatric Surgery to Predict Success After Surgery. Obes Surg. 2017 Jun;27(6):1453-9.

15. Karmali S, Brar B, Shi X, Sharma AM, de Gara C, Birch DW. Weight recidivism post-bariatric surgery: a systematic review. Obes Surg. 2013 Nov;23(11):1922-33.

16. King WC, Bond DS. The importance of preoperative and postoperative physical activity counseling in bariatric surgery. Exerc Sport Sci Rev. 2013 Jan;41(1):26-35.

17. Gade H.G., Rosenvinge J.H.R., Friborg O.F., Hjelmesaeth J.H. Cognitive behavioural therapy significantly reduces emotional eating in bariatric surgery patients. A randomised controlled trial. Obes Facts. 2013;6:30-1.

18. Gade H, Friborg $\mathrm{O}$, Rosenvinge JH, Smastuen MC,
Hjelmesaeth J. The Impact of a Preoperative Cognitive Behavioural Therapy (CBT) on Dysfunctional Eating Behaviours, Affective Symptoms and Body Weight 1 Year after Bariatric Surgery: A Randomised Controlled Trial. Obes Surg. 2015 Nov;25(11):2112-9.

19. Marcon ER, Baglioni S, Bittencourt L, Lopes CL, Neumann CR, Trindade MR. What Is the Best Treatment before Bariatric Surgery? Exercise, Exercise and Group Therapy, or Conventional Waiting: a Randomized Controlled Trial. Obes Surg. 2017 Mar:27(3):763-73.

20. Sockalingam S, Cassin SE, Wnuk S, Du C, Jackson T, Hawa R, et al. A Pilot Study on Telephone Cognitive Behavioral Therapy for Patients SixMonths Post-Bariatric Surgery. Obes Surg. 2017 Mar;27(3):670-5.

21. Coulman KD, MacKichan F, Blazeby JM, Owen-Smith A. Patient experiences of outcomes of bariatric surgery: a systematic review and qualitative synthesis. Obes Rev. 2017 May;18(5):547-59.

22. Peacock JC, Zizzi SJ. Survey of bariatric surgical patients' experiences with behavioral and psychological services. Surg Obes Relat Dis. 2012 NovDec;8(6):777-83.

23. Reames BN, Birkmeyer NJ, Dimick JB. Variation in the Care of Surgical Conditions: Obesity, A Dartmouth Atlas of Health Care Series. . Lebanon, $\mathrm{NH}$ The Dartmouth Institute for Health Policy \& Clinical Practice; 2014.

24. Silver HJ, Torquati A, Jensen GL, Richards WO. Weight, dietary and physical activity behaviors two years after gastric bypass. Obes Surg. 2006 Jul;16(7):859-64.

25. Kruseman M, Leimgruber A, Zumbach F, Golay A. Dietary, weight, and psychological changes among patients with obesity, 8 years after gastric bypass. J Am Diet Assoc. 2010 Apr;110(4):527-34.

26. Beck NN, Mehlsen M, Stoving RK. Psychological characteristics and associations with weight outcomes two years after gastric bypass surgery: Postoperative eating disorder symptoms are associated with weight loss outcomes. Eat Behav. 2012 Dec;13(4):394-7

27. Yanos BR, Saules KK, Schuh LM, Sogg S. Predictors of Lowest Weight and Long-Term Weight Regain Among Roux-en-Y Gastric Bypass Patients. Obes Surg. 2015 Aug;25(8):1364-70.

28. Cargill BR, Clark MM, Pera V, Niaura RS, Abrams DB. Binge eating, body image, depression, and self-efficacy in an obese clinical population. Obes Res. 1999 Jul;7(4):379-86.

29. Jansen A, Houben K, Roefs A. A Cognitive Profile of Obesity and Its Translation into New Interventions. Front Psychol. 2015 Nov 27;6:1807.

30. Wardle J, Waller J, Rapoport L. Body dissatisfaction and binge eating in obese women: the role of restraint and depression. Obes Res. 2001 Dec;9(12):778-87.

31. Sarwer DB, Wadden TA, Foster GD. Assessment of body image dissatisfaction in obese women: specificity, severity, and clinical significance. J Consult Clin Psychol. 1998 Aug;66(4):651-4.

32. Malik S., Mitchell J.E., Engel S., Crosby R., Wonderlich S. Psychopathology in bariatric surgery candidates: A review of studies using structured diagnostic interviews. Compr Psychiatry. 2014;55(2):248-59.

33. Adami GF, Gandolfo P, Campostano A, Meneghelli A, Ravera G, Scopinaro N. Body image and body weight in obese patients. Int J Eat Disord. 1998 Nov:24(3):299-306.

34. Hopkins J, Howes N, Chalmers K, Whale K, Savovic $\mathrm{J}$, Coulman K, et al. What are important outcomes of bariatric surgery? An in-depth analysis to inform the development of a core outcome set and a comparison between the views of surgeons and other health professionals (the BARIACT study). Lancet. $2015 \mathrm{Feb}$ 26;385 Suppl 1:S43,6736(15)60358-0.

35. Brethauer SA, Kim J, El Chaar M, Papasavas P, Eisenberg D, Rogers A, et al. Standardized outcomes 
reporting in metabolic and bariatric surgery. Obes Surg. 2015 Apr;25(4):587-606.

36. Coulman KD, Hopkins J, Brookes ST, Chalmers K Main B, Owen-Smith A, et al. A Core Outcome Set for the Benefits and Adverse Events of Bariatric and Metabolic Surgery: The BARIACT Project. PLoS Med. 2016 Nov 29;13(11):e1002187.

37. Lindekilde N, Gladstone BP, Lubeck M, Nielsen J, Clausen L, Vach W, et al. The impact of bariatric surgery on quality of life: a systematic review and meta-analysis. Obes Rev. 2015 Aug;16(8):639-51.

38. Biron S, Biertho L, Marceau S, Lacasse Y. Longterm follow-up of disease-specific quality of life after bariatric surgery. Surg Obes Relat Dis. 2018 May;14(5):658-64.

39. Karlsson J, Taft C, Ryden A, Sjostrom L, Sullivan M. Ten-year trends in health-related quality of life after surgical and conventional treatment for severe obesity: the SOS intervention study. Int J Obes (Lond). 2007 Aug;31(8):1248-61.

40. Warkentin LM, Das D, Majumdar SR, Johnson JA, Padwal RS. The effect of weight loss on health-related quality of life: systematic review and meta-analysis of randomized trials. Obes Rev. 2014 Mar;15(3):169-82.

41. Kolotkin RL, Norquist JM, Crosby RD, Suryawanshi S, Teixeira PJ, Heymsfield SB, et al. One-year health-related quality of life outcomes in weight loss trial participants: comparison of three measures. Health Qual Life Outcomes. 2009 Jun 9;7:53,75257-53.

42. Schipper H, Clinch JJ, Olweny CLM. Quality of life studies: Definitions and conceptual issues. In: Spliker B e, editor. Quality of Life and Pharmacoeconomics in Clinical Trial. 2nd ed. New York: Lippincott-Raven; 1996. p. 11-23.

43. Kolotkin RL, Crosby RD, Kosloski KD, Williams GR. Development of a brief measure to assess quality of life in obesity. Obes Res. 2001 Feb;9(2):102-11.

44. de Vries CEE, Kalff MC, Prinsen CAC, Coulman KD, den Haan C, Welbourn R, et al. Recommendations on the most suitable quality-of-life measurement instruments for bariatric and body contouring surgery: a systematic review. Obes Rev. 2018 Jun 8.

45. Balague N, Combescure C, Huber O, Pittet-Cuenod $B$, Modarressi A. Plastic surgery improves long-term weight control after bariatric surgery. Plast Reconstr Surg. 2013 Oct;132(4):826-33.

46. Wiser I, Avinoah E, Ziv O, Parnass AJ, Averbuch Sagie R, Heller L, et al. Body contouring surgery decreases long-term weight regain following laparoscopic adjustable gastric banding: A matched retrospective cohort study. J Plast Reconstr Aesthet Surg. 2016 Nov;69(11):1490-6.

47. Varns JA, Fish AF, Eagon JC. Conceptualization of body image in the bariatric surgery patient. Appl Nurs Res. 2018 Jun; 41:52-8.

48. Pecori L, Serra Cervetti GG, Marinari GM, Migliori F, Adami GF. Attitudes of morbidly obese patients to weight loss and body image following bariatric surgery and body contouring. Obes Surg. 2007 Jan;17(1):68-73.

49. Adami GF, Meneghelli A, Bressani A, Scopinaro $N$. Body image in obese patients before and after stable weight reduction following bariatric surgery. $J$ Psychosom Res. 1999 Mar;46(3):275-81.

50. Dixon JB, Dixon ME, O'Brien PE. Body image: appearance orientation and evaluation in the severely obese. Changes with weight loss. Obes Surg. 2002 Feb;12(1):65-71.

51. de Zwaan M, Georgiadou E, Stroh CE, Teufel M, Kohler $\mathrm{H}$, Tengler $\mathrm{M}$, et al. Body image and quality of life in patients with and without body contouring surgery following bariatric surgery: a comparison of pre- and post-surgery groups. Front Psychol. 2014 Nov 18;5:1310.

52. Klassen AF, Cano SJ, Alderman A, Soldin M, Thoma A, Robson S, et al. The BODY-Q: A Patient-Reported Outcome Instrument for Weight Loss and Body Con- touring Treatments. Plast Reconstr Surg Glob Open. 2016 Apr 13;4(4):e679.

53. Azin A, Zhou C, Jackson T, Cassin S, Sockalingam $S$, Hawa R. Body contouring surgery after bariatric surgery: a study of cost as a barrier and impact on psychological well-being. Plast Reconstr Surg. 2014 Jun;133(6):776e-82e.

54. Staalesen T, Fagevik Olsen M, Elander A. Experience of excess skin and desire for body contouring surgery in post-bariatric patients. Obes Surg. 2013 Oct:23(10):1632-44.

55. Gusenoff JA, Messing S, O'Malley W, Langstein HN. Patterns of plastic surgical use after gastric bypass: who can afford it and who will return for more. Plast Reconstr Surg. 2008 Sep;122(3):951-8.

56. Klopper E.M., Kroese-Deutman H.C., Berends F.J. Massive weight loss after bariatric surgery and the demand (desire) for body contouring surgery. Eur $\mathrm{J}$ Plast Surg. 2014;37(2):103-8.

57. Kitzinger HB, Abayev S, Pittermann A, Karle B, Bohdjalian A, Langer FB, et al. After massive weight loss: patients' expectations of body contouring surgery. Obes Surg. 2012 Apr;22(4):544-8.

58. Giordano S, Victorzon M, Stormi T, Suominen E. Desire for body contouring surgery after bariatric surgery: do body mass index and weight loss matter? Aesthet Surg J. 2014 Jan 1;34(1):96-105.

59. Biorserud C, Olbers T, Fagevik Olsen M. Patients' experience of surplus skin after laparoscopic gastric bypass. Obes Surg. 2011 Mar;21(3):273-7.

60. Gusenoff JA, Pennino RP, Messing S, O'Malley WE, Boss TJ, Langstein HN. Post-bariatric surgery reconstruction: patient myths, perceptions, cost, and attainability strategies. Plast Reconstr Surg. 2008 Jul;122(1):1e-9e.

61. Gusenoff JA, Messing S, O'Malley W, Langstein HN Temporal and demographic factors influencing the desire for plastic surgery after gastric bypass surgery. Plast Reconstr Surg. 2008 Jun;121(6):2120-6.

62. Mukerji R, Petruc M, Fresen JL, Terry BE, Govindarajan G, Alpert MA. Effect of weight loss after bariatric surgery on left ventricular mass and ventricular repolarization in normotensive morbidly obese patients. Am J Cardiol. 2012 Aug 1;110(3):415-9.

63. Iglesias M, Butron P, Abarca L, Perez-Monzo MF, de Rienzo-Madero B. An anthropometric classification of body contour deformities after massive weight loss. Ann Plast Surg. 2010 Aug:65(2):129-34.

64. Al-Hadithy N, Mennie J, Magos T, Stewart K. Desire for post bariatric body contouring in South East Scotland. J Plast Reconstr Aesthet Surg. 2013 Jan;66(1):87-94.

65. Poelemeijer YQM, Liem RSL, Nienhuijs SW. A Dutch Nationwide Bariatric Quality Registry: DATO. Obes Surg. 2018 Jun;28(6):1602-10.

66. Angrisani L, Santonicola A, lovino P, Vitiello A, Zundel $\mathrm{N}$, Buchwald $\mathrm{H}$, et al. Bariatric Surgery and Endoluminal Procedures: IFSO Worldwide Survey 2014. Obes Surg. 2017 Apr 13.

67. Peterli R, Wolnerhanssen BK, Peters T, Vetter D, Kroll $D$, Borbely Y, et al. Effect of Laparoscopic Sleeve Gastrectomy vs Laparoscopic Roux-en-Y Gastric Bypass on Weight Loss in Patients With Morbid Obesity: The SM-BOSS Randomized Clinical Trial. JAMA. 2018 Jan 16;319(3):255-65.

68. Salminen P, Helmio M, Ovaska J, Juuti A, Leivonen M, Peromaa-Haavisto P, et al. Effect of Laparoscopic Sleeve Gastrectomy vs Laparoscopic Roux-en-Y Gastric Bypass on Weight Loss at 5 Years Among Patients With Morbid Obesity: The SLEEVEPASS Randomized Clinical Trial. JAMA. 2018 Jan 16;319(3):241-54. 


APPENDICES 



\section{SUMMARY - ENGLISH}

Obesity is a chronic disease in which abnormal or excessive fat accumulation impair health. Wether a person is obese is classified with the body mass index (BMI). The BMI can be calculated by dividing a person's weight in kilograms by the square of his height in meters: $\mathrm{kg} / \mathrm{m}^{2}$. An adult with a $\mathrm{BMI} \geq 30 \mathrm{~kg} / \mathrm{m}^{2}$ is classified as obese. When the $\mathrm{BMI} \geq 35 \mathrm{~kg} / \mathrm{m}^{2}$ with obesity-related comorbidities or the $\mathrm{BMI}$ is $\geq 40 \mathrm{~kg} / \mathrm{m}^{2}$ a person is classified as morbidly obese.

Obesity is a major public health issue in the Netherlands, $14.2 \%$ of the population older then 20 year is obese and $0.9 \%$ suffers from morbid obesity. Obesity is associated with several medical conditions, like diabetes mellitus, hypertension, sleep apnoea and cardiovascular disease. Obese persons also have higher rates of cancer, overall diseases and health related mortality. Currently the burden of healthcare expenditure on morbid obesity exceeds those of smoking.

Besides the negative effct on health, obesity is related to problems of social and psychological well-being. Obese persons generally have a lower health related quality of life (HRQoL), a more negative body image and higher rates of psychological problems.

The cause of obesity is complex, multiple factors play a role. It is assumed that cultural and environmental changes induce a higher energy intake and less physical activity leading to a positive energy balance. However, recent research is showing that other factors also play a role. Because the cause is not completely clear, treatment of obesity is difficult.

For persons with morbid obesity, a BMI $\geq 35 \mathrm{~kg} / \mathrm{m}^{2}$ with comorbid conditions or BMI $\geq 40 \mathrm{~kg} / \mathrm{m}^{2}$, bariatric surgery is the best treatment. Bariatric surgery includes a variety of surgical procedures in which the gastro-intestinal tract is altered, which results in weight loss. The weight loss is caused by lower intake and absorption of nutrients, and changes in gut hormones, bile acids and microbiota. The Roux-en-Y gastric bye pass (RYGB) is the most performed type of bariatric surgery in the Netherlands.

Whether a patient qualifies for bariatric surgery is determined after a comprehensive multidisciplinary screening by a team experienced in bariatric surgery. This team assesses if the patient meets the IFSO-criteria: the criteria for bariatric surgery developed by the International Federation for the Surgery of Obesity and Metabolic Disorders. In addition, pre-operative evaluation includes assessment of motivation, psychological disorders, willingness to life-long follow-up and acceptance of lifestyle modification. There is no guideline or consensus on how behaviour, motivation and 
psychological problems should be assessed.

Bariatric surgery generally results in significant weight loss, has positive effect on health and HRQoL. However, $20-30 \%$ of the post-bariatric patients will experience insufficient weight loss or significant weight regain. To improve weight loss results, we need to know which patients will have "unsuccesfull" weight loss. Most previous research focused on factors that can't be influenced, like age, gender and comorbid conditions. The role of patient related factors, like physical activity, eating style and psychological disorders, in weight loss remains unclear. These factors are very important because they have been linked to weight loss in the obese population and, more importantly, they can be influenced. This thesis studied the relationship between physical and psychological factors and weight loss in patients who have undergone bariatric surgery.

The clinical studies in this thesis were conducted in patients in treatment at the Nederlandse Obesitas Kliniek (NOK, Dutch Obesity Clinic). The treatment program of the NOK consists of extensive group counselling before and after bariatric surgery by a multidisciplinary team consisting of a physician, a dietician, a physiotherapist and a psychologist. This counselling is focused on long-term behavioural change.

The first part of this thesis focused on the relationship between weight loss and compliance to follow-up, physical activity, psychopathology, depressive disorders, eating disorders, HRQoL and body image. The studies in this part of the thesis were all in primary RYGB patients, to avoid bias in the results by differences in types of bariatric surgery, and secondary or tertiary procedures.

In chapter 2 we started with a systematic review and meta-analysis, to study what research was available so far. This study showed that almost no research in the bariatric population was focused on HRQoL and body image. We could conduct a mef ta-analysis for the following factors: compliance, physical activity, depressive sympn toms and binge eating. The results showed that patients with better compliance to post-operative follow-up had significantly higher weight loss, than patients with lower compliance. Higher physical activity was also related to better weight loss results. Contrary to expectations, we did not see a negative effect of depressive symptoms or binge-eating on weight loss results. The review also showed that there is great variety in psychological evaluation of bariatric patients.

Based on these results we conducted the studies in the clinical population. In chapter 3 the relationship between self-reported eating style and physical activity with weight change up to 4 years after surgery was studied in a primary RYGB population of 4,569 patients. Eating style and physical activity before bariatric surgery were not indicative 
of postoperative weight loss or weight regain in any of the follow-up moments. From this we can conclude that these factors should not be reason to deny patients for bariatric surgery.

This chapter also showed that there is a relationship between weight loss and change in self-reported physical activity and eating style. In general terms, patients who became more active and experienced less emotional and restrained eating had better weight loss results. External eating was only related to weight loss at 2-year follow-up. This demonstrates that change of eating style and physical activity after bariatric surgery is important to improve weight loss results. And therefore, treatment programs should focus on supporting patients in making these changes.

In chapter 4 the relationship between weight loss and HRQoL was studied. Previous research showed a great variation in HRQoL improvement after bariatric surgery. Based on research in the obese population we compared an obesity specific questionnaire, the Impact of Weight on Quality of Life-lite (IWQOL-lite) with a generic HRQoL questionnaire, the RAND-36. HRQoL before surgery was very low. For both questionnaires there was a significant improvement of HRQoL scores up to 2 years after surgery. Before and after surgery a higher BMI was related to lower HRQoL. The more weight the patients lost, the more HRQoL improved. The relationship between weight loss and HRQoL improvement was more apparent with the IWQOL-lite. Thus, bariatric surgery has a positive effect on HRQoL; the variety in HRQoL change is caused by the differences in weight loss and questionnaire used.

The second part of the thesis highlighted the importance of excess skin, body image and desire for body contouring surgery (BCS). In the obese population, a negative body image is very common and related to body weight. Since a large part of the post-bariatric population develops excess skin, body image after bariatric surgery might also be important. Excess skin can only be treated by BCS, a type of surgery in which the excess skin is surgically removed. We were interested in the consequences of this excess skin in relation to the desire for BCS. Especially since reimbursement of BCS is a worldwide problem, and a lot of post-bariatric patients are not able to undergo a body contouring procedure.

In chapter 5 depressive symptoms, body image and weight loss were studied in a post-bariatric population. In this cross-sectional study, we approached patients who had bariatric surgery 2-3 years before. Patients with a desire for BCS were compared with patients who already had BCS and patients without a desire for BCS. A total of 590 patients could be included, the majority of these patients had a desire for BCS (62.4\%). Patients with a desire for BCS had a more negative body image compared to patients without a desire for BCS. Surprisingly, the patients who already had BCS were quite comparable to the population who desired BCS, regarding appearance 
orientation and overweight preoccupation. This might be explained by the fact that BCS improves only certain aspects of body image.

In all patients (even the patients without a desire for BCS) a more positive body image was related to less depressive symptoms. This shows that body image is an important parameter in the bariatric population.

In the population with a desire for BCS, body image was even one of the mediators of the relationship between \% total weight loss (TWL) and depressive symptoms. Meaning that a higher \%TWL was related to less depressive symptoms, via more positive feelings of attractiveness and higher body-area satisfaction.

The research in chapter 6 was conducted in the same population as chapter 5 . However, now we focused on differences between these patient groups regarding social economic status, qualification for reimbursement of BCS, complaints of overhanging skin and satisfaction with one's body.

To qualify for reimbursement by health insurance companies in the Netherlands patients have to meet the following qualifications: (a) have to be at least 18 months past bariatric surgery, (b) should have a stable weight for at least 12 months, (c) should have a BMI below $35 \mathrm{~kg} / \mathrm{m}^{2}$. They should also have a skin excess grade 3 according to the Pittsburgh Rating Scale (PRS) or a serious impairment of bodily function. However, research has shown that rating with the PRS has great variability. Moreover, psychological complaints are not part of the current criteria, and physical complaints are not assessed objectively.

Chapter 6 showed that patients with a desire were most often unemployed and more often had an income below the Dutch median income. This might reflect the fact that patients with a bad financial status / low education are unable to stand up for themselves and try to get a reimbursement.

Patients who desired BCS had more body parts affected by overhanging skin and more often rated the overhanging skin with a the highest PRS grade (meaning more excess skin) compared to patients without a desire. There were no significant differences between the three groups regarding the percentage of patients who met the Dutch weight qualifications for reimbursement (i.e., BMI $<35 \mathrm{~kg} / \mathrm{m}^{2}$ and a stable weight).

Striking was that almost $40 \%$ of the patients who had a desire for BCS never consulted a plastic surgeon, although many of these patients did meet the weight criteria.

The results of this chapter showed that there are two issues regarding reimbursement of BCS. The first issue (what we also see in daily practice) is that with the current Dutch criteria there seems to be great variation in reimbursement. The second issue is that only a few patients consult the plastic surgeon because they assume that they will not get reimbursed. Patients should be better educated on the guidelines. 
Considered all research above we developed a new screening tool for reimbursement of BCS in chapter 7. This tool was a modification of the screening tool developed by the British Association of Plastic, Reconstructive and Aesthetic Surgeons (BAPRAS). It consists of a questionnaire from which a score is calculated using information regarding weight loss, the medical, physical and psychological problems caused by excess skin and medical history. We added the BODY-Q to the tool, so that patient reported outcome could be assessed. The BODY-Q is a validated patient reported outcome measure (PROM) specifically designed for the bariatric patient. Thereby setting the first steps to include patient well-being in decision making for reimbursement, which is lacking in the current Dutch system.

The patients who desired BCS scored significantly higher on the screening tool compared to patients who did not. The patients who qualified for reimbursement had a stable weight, higher \%TWL, lower current BMI and more medical and psychological complaints compared to patients who did not qualify for referral. Thus, the tool seems to select patients who desire BCS, have the best weight loss results and the most complaints because of the excess skin. With the BODY-Q we showed that excess skin has a significant impact on several aspects of HRQoL. With these results we slightly modified the BAPRAS screening tool and created a new version: the Dutch ReBoc tool (Referral and Reimbursement for Body Contouring tool).

In conclusion, this thesis proved that preoperative, self-reported binge eating, def pressive symptoms, eating style and physical activity are not predictive of weight loss after surgery. And that these factors should not immediately warrant denial for bariatric surgery. It also showed that postoperative physical and psychological factors are related to weight loss and thereby HRQoL after bariatric surgery. In addition, factors like body image, weight loss and depressive symptoms are also related to each other. Counselling in bariatric patients should thus include these factors, so that weight loss results can be improved.

This thesis also showed that overhanging skin has a significant impact on patient well-being. Patients with excess skin and a desire for BCS had a more negatif body iamge, more depressive symptoms and a lower HRQoL. All these factors are currently not included in the reimbursement criteria for BCS. Efforts should be made to develop en new Dutch guideline for reimbursment in which these factors are included. 



\section{SUMMARY - DUTCH}

Obesitas is een chronische ziekte, waarbij een zodanig overmatige vetstapeling in het lichaam bestaat dat dit aanleiding geeft tot gezondheidsrisico's. Of een persoon obees is wordt bepaald aan de hand van de body mass index (BMI). De BMI wordt berekend door het gewicht in kilogram te delen door de lengte in het kwadraat: kg/ $\mathrm{m}^{2}$. Bij volwassenen wordt een BMl gelijk aan of hoger dan $30 \mathrm{~kg} / \mathrm{m}^{2}$ geclassificeerd als obesitas. Er is sprake van morbide obesitas bij een BMl gelijk aan of hoger dan 40 $\mathrm{kg} / \mathrm{m}^{2}$ of bij een BMI gelijk aan of hoger is dan $35 \mathrm{~kg} / \mathrm{m}^{2}$ met een aan obesitas gerelateerde ziekte. Obesitas is een groot maatschappelijk probleem in Nederland, 14.2\% van de populatie ouder dan 20 jaar is obees en $0.9 \%$ heeft morbide obesitas.

Obesitas is gerelateerd aan verschillende medische aandoeningen, zoals diabetes mellitus, hypertensie, slaap apneu en hart- en vaatziekten. Bovendien hebben obese personen een verhoogde kans op kanker, ziekten in het algemeen en overlijden door een ziekte. Inmiddels veroorzaakt obesitas hogere zorgkosten dan roken.

Naast het negatieve effect van obesitas op gezondheid, is er ook een negatief effect op het sociaal en psychisch welbevinden. Obese personen hebben een lagere gezondheid gerelateerde kwaliteit van leven $(\mathrm{KvL})$, vaker een negatief lichaamsbeeld en vaker psychologische problemen vergeleken met personen die niet obees zijn.

De oorzaak van obesitas is complex en veel verschillende factoren spelen een rol. Over het algemeen wordt gedacht dat culturele en omgevingsfactoren hebben geleid tot een levensstijl met een hogere energie inname en een lager energie verbruik. Echter recent onderzoek toont aan dat er veel meer factoren een rol spelen. Doordat de oorzaak niet goed bekend is, is obesitas ook moeilijk te behandelen.

Voor personen met morbide obesitas, een BMI gelijk aan of hoger dan $40 \mathrm{~kg} / \mathrm{m}^{2}$ of een BMI gelijk aan of hoger dan $35 \mathrm{~kg} / \mathrm{m}^{2}$ met bijkomende ziekten, is bariatrische chirurgie de beste behandeling. Bij bariatrische chirurgie wordt het maag-darmkanaal veranderd, waardoor patiënten gewicht verliezen. Dit gewichtsverlies wordt veroorzaakt door zowel verminderde inname en opname van voedingsstoffen als ook veranderingen van hormoonspiegels, galzouten en bacteriën in het maag-darmkanaal. De Roux-en-Y gastric bypass (RYGB) is de meest uitgevoerde bariatrische operatie in Nederland.

Of een patiënt in aanmerking komt voor bariatrische chirurgie wordt bepaald na een multidisciplinaire screening door een team met expertise op het gebied van baria- 
trische chirurgie. Dit team evalueert of de patiënt aan de IFSO-criteria voldoet: de criteria voor bariatrische chirurgie die ontwikkeld zijn door de internationale vereniging voor chirurgie voor obesitas en metabole ziekten ("International Federation for the Surgery of Obesity and Metabolic Disorders"). Bovendien worden tijdens deze preoperatieve screening ook motivatie, psychologische stoornissen, bereidwilligheid tot levenslange controles en levensstijl aanpassing geëvalueerd. Er is geen richtlijn die voorschrijft hoe gedrag, motivatie en psychische problemen precies onderzocht zouden moeten worden tijdens deze screening.

Bariatrische chirurgie leidt over het algemeen tot significant gewichtsverlies, heeft een positief effect op gezondheid en op de KvL. Echter, bij 20-30\% van de bariatrische patiënten is er onvoldoende gewichtsverlies of zelfs gewichtstoename. Om het gewichtsverlies te verbeteren en de gewichtstoename te verminderen, is het van belang te weten bij welke patiënten dit zal gebeuren. Eerder onderzoek richtte zich vooral op factoren die niet beïnvloed kunnen worden, zoals leeftijd, geslacht en bijkomende ziekten. Het is niet goed duidelijk wat de rol is van patiënt gerelateerde factoren, zoals lichamelijke activiteit, eetstijl (manier van eten) en psychologische stoornissen, op het gewichtsverlies. Deze factoren zijn juist belangrijk omdat we weten dat ze gerelateerd zijn aan gewichtsverlies in de obese populatie, en belangrijker nog, ze kunnen worden beïnvloed. Dit proefschrift bestudeert de relatie tussen fysieke en psychologische factoren en gewichtsverlies in patiënten die bariatrische chirurgie ondergaan.

De klinische studies in dit proefschrift zijn uitgevoerd bij patiënten die in behandeling zijn/waren bij de Nederlandse Obesitas Kliniek (NOK). De NOK heeft een uitgebreid behandelprogramma bestaande uit groepsbehandeling zowel voor als na de bariatrische ingreep. Deze groepsbehandeling wordt uitgevoerd door een multidisciplinair team bestaande uit een arts, een diëtist, een bewegingsdeskundige en een psycholoog. De focus van de behandeling is leefstijlverandering op lange termijn.

Het eerste deel van dit proefschrift is gericht op de relatie tussen gewichtsverlies en verschillende factoren: aanwezigheid bij afspraken (compliantie), fysieke activiteit, psychopathologie, depressieve stoornissen, eetstoornissen, KvL en lichaamsbeeld. Omdat bekend is dat het type operatie de mate van gewichtsverlies kan beïnvloeden zijn de studies in dit deel van het proefschrift alleen uitgevoerd bij patiënten die een RYGB ondergingen en bij wie de RYGB de eerste bariatrische operatie was.

$\mathrm{Na}$ de inleiding (hoofdstuk 1) zijn we in hoofdstuk 2 we gestart met een systematische review en een meta-analyse, dit om te bepalen wat er al beschikbaar was aan onderzoek. We zagen dat er nauwelijks onderzoek was naar de invloed van KvL en lichaamsbeeld op gewichtsverlies na bariatrische chirurgie.

Er waren voldoende studies voor een meta-analyse naar de relatie tussen gewichtsver- 
lies en de volgende factoren: compliantie, fysieke activiteit, depressieve symptomen en eetbuien. Uit de resultaten bleek dat patiënten met een betere compliantie (zich hielden aan het behandelprogramma) tijdens postoperatieve controles een hoger gewichtsverlies hadden dan patiënten die niet compliant waren. Meer fysieke activiteit was ook gerelateerd aan meer gewichtsverlies. In tegenstelling tot onze verwachting hadden depressieve symptomen en eetbuien geen negatief effect op gewichtsverlies. Dit onderzoek liet ook zien dat er een grote variatie is in de manier waarop psychologische stoornissen worden geëvalueerd bij patiënten die voor bariatrische chirurgie gescreend worden.

Gebaseerd op deze resultaten zijn we studies gestart in de klinische populatie. In hoofdstuk 3 hebben we de relatie tussen eetstijl en fysieke activiteit en gewichtsverlies tot 4 jaar postoperatief onderzocht in 4.569 patiënten die een RYGB ondergingen. Het type eetstijl en de mate van fysieke activiteit voor operatie waren bij geen van de postoperatieve controle momenten gerelateerd aan gewichtsverlies of gewichtstoename. Hieruit hebben we geconcludeerd dat preoperatieve eetstijl en fysieke activiteit geen reden moeten zijn om patiënten de toegang tot bariatrische chirurgie te weigeren. Dit hoofdstuk toonde ook dat er een relatie is tussen gewichtsverlies en de verandering in eetstijl en fysieke activiteit. Over het algemeen hadden patiënten die actiever werden en minder emotioneel en lijngericht aten beter gewichtsverlies. De eetstijl extern eten was alleen gerelateerd aan gewichtsverlies 2 jaar na operatie. Dus, verandering in eetstijl en fysieke activiteit na operatie is belangrijk voor het verbeteren van gewichtsverlies. Daarom zouden behandelprogramma's voor bariatrische patiënten gericht moeten zijn op hulp bij verandering hiervan.

In hoofdstuk 4 hebben we de relatie tussen gewichtsverlies en KvL onderzocht. Eerder onderzoek liet een grote variatie zien in de verandering van $\mathrm{KvL}$ na bariatrische chirurgie. Gebaseerd op onderzoek in obese patiënten hebben we een vragenlijst specifiek voor de obese populatie, de Impact of Weight on Quality of Life-lite (IWQOL-lite), vergeleken met een algemene vragenlijst voor KvL, de RAND-36.

De KvL was voor de operatie erg laag. Voor beide vragenlijsten was er een significante verbetering van $\mathrm{KvL}$ tot 2 jaar na operatie. Voor en na operatie was een hoger BMI gerelateerd aan een lagere KvL. Hoe meer gewicht een patiënt verloor, hoe beter de $\mathrm{KvL}$ was. De relatie tussen gewichtsverlies en $\mathrm{KvL}$ was sterker wanneer de $\mathrm{KvL}$ werd meten met de IWQOL-lite. Dus, bariatrische chirurgie heeft een positief effect op KvL, de variatie in de verandering van $\mathrm{KvL}$ na bariatrische chirurgie wordt veroorzaakt door verschillen in gewichtsverlies van de onderzochte populatie en verschillen in de gebruikte vragenlijsten.

Het tweede deel van dit proefschrift toonde aan hoe belangrijk overhangende huid, lichaamsbeeld en wens voor contourherstellende chirurgie $(\mathrm{CHC})$ is in de bariatrische 
populatie. In obese personen is een negatief zelfbeeld veel voorkomend en is er een relatie tussen een negatief zelfbeeld en lichaamsgewicht. Aangezien een groot deel van de post-bariatrische populatie overhangende huid ontwikkelt, zou lichaamsbeeld na bariatrische chirurgie ook belangrijk kunnen zijn. $\mathrm{CHC}$ is de enige behandeling voor overhangende huid, bij $\mathrm{CHC}$ wordt deze extra huid chirurgisch verwijderd. We waren voornamelijk geïnteresseerd in de gevolgen van de overhangende huid, in relatie tot de wens voor $\mathrm{CHC}$. Vooral omdat vergoeding voor $\mathrm{CHC}$ een wereldwijd probleem is, waardoor een groot deel van de post-bariatrische patiënten nooit een contourherstellende ingreep kan ondergaan.

In hoofdstuk 5 hebben we depressieve symptomen, lichaamsbeeld en gewichtsverlies in een post-bariatrische populatie onderzocht. In dit cross-sectionele onderzoek hebben we patiënten benaderd die 2-3 jaar geleden bariatrische chirurgie hadden ondergaan. Patiënten met een wens voor $\mathrm{CHC}$ werden vergeleken met patiënten die al een contourherstellende ingreep hadden ondergaan en met patiënten die geen wens voor $\mathrm{CHC}$ hadden. Er werden 590 patiënten geïncludeerd, de meerderheid van deze patiënten had een wens voor $\mathrm{CHC}$ (62.4\%). Patiënten die deze wens hadden, hadden een meer negatief zelfbeeld in vergelijking met mensen die geen $\mathrm{CHC}$ wilden. Opvallend was dat het lichaamsbeeld van de patiënten die al $\mathrm{CHC}$ hadden gehad overeenkomsten had met die van de patiënten die $\mathrm{CHC}$ wensten. Deze patiëntengroepen waren beiden erg gefocust op uiterlijk en gepreoccupeerd met overgewicht. Dit wordt mogelijk verklaard doordat na $\mathrm{CHC}$ niet alle aspecten van lichaamsbeeld verbeteren. In alle patiënten (zelfs degene zonder wens voor $\mathrm{CHC}$ ) was een positiever lichaamsbeeld gerelateerd aan minder depressieve symptomen. Lichaamsbeeld is dus een belangrijke parameter in de gehele bariatrische populatie.

In de groep patiënten met een wens voor $\mathrm{CHC}$ was lichaamsbeeld een 'mediator' in de relatie tussen gewichtsverlies en depressieve symptomen. Dit betekent dat een hoger gewichtsverlies gerelateerd was aan minder depressieve symptomen, veroorzaakt door meer positieve gevoelens van aantrekkelijkheid en hogere tevredenheid met het lichaam.

Het onderzoek in hoofdstuk $\mathbf{6}$ is verricht in dezelfde populatie als in hoofdstuk 5. Echter nu lag de focus op de verschillen in sociale economische status, criteria voor vergoeding van $\mathrm{CHC}$, klachten van overhangende huid en lichaamstevredenheid.

Om in Nederland voor vergoeding van $\mathrm{CHC}$ in aanmerking te komen moeten patiënten aan de volgende criteria voldoen: (a) tenminste 18 maanden na bariatrische chirurgie, (b) minimaal 12 maanden een stabiel gewicht, (c) een BMI lager dan 35 $\mathrm{kg} / \mathrm{m}^{2}$. Patiënten moeten ook een bepaalde mate van overhangende huid hebben, namelijk een graad 3 op de Pittsburgh Rating Scale (PRS) of een aantoonbare lichamelijke functiestoornis. De PRS is een schaal bestaande uit foto's van mensen met 
huidoverschot: een PRS graad 1 betekent dat er geen huidoverschot is en bij een PRS graad 3 is er ernstig huidoverschot. Echter, in eerder onderzoek bleek de PRS niet betrouwbaar. Bovendien worden fysieke en psychologische factoren nu niet (objectief) meegenomen in de beslissing.

Patiënten met een wens voor $\mathrm{CHC}$ waren vaker werkloos en hadden vaker een inkomen lager dan het landelijk gemiddelde. Wat er mogelijk op duidt dat patiënten met een slechte financiële status en/of lage scholing niet de mogelijkheden hebben om voor zichzelf op te komen en vergoedingen aan te vechten bij zorgverzekeraars. Patiënten met een wens voor $\mathrm{CHC}$ hadden meer lichaamsdelen die waren aangedaan door overhangende huid en gaven hun huidoverschot vaker een PRS-graad 3 (wat betekent dat ze meer overhangende huid hadden) in vergelijking met patiënten zonder wens.

Er waren geen significante verschillen tussen de drie groepen kijkend naar het percentage, dat aan de Nederlandse "gewicht" kwalificaties voor vergoeding voldeden (BMI onder de $35 \mathrm{~kg} / \mathrm{m}^{2}$ en stabiel gewicht). Opvallend was dat bijna $40 \%$ van de patiënten met een wens voor $\mathrm{CHC}$ nooit bij een plastisch chirurg was geweest, terwijl veel van deze mensen wel aan de gewichtscriteria voldeden.

Deze twee hoofdstukken toonden aan dat er twee problemen zijn op het gebied van vergoeding van $\mathrm{CHC}$. Ten eerste het probleem wat wij in de dagelijkse praktijk zien, met de huidige criteria voor $\mathrm{CHC}$ is er een grote variatie in de toekenning van vergoeding voor $\mathrm{CHC}$. Het tweede probleem is dat slechts een klein deel van de patiënten de plastisch chirurg bezoeken, omdat ze ervan uit gaan dat ze geen vergoeding krijgen. Patiënten zouden dus beter geïnformeerd moeten worden over de richtlijnen en mogelijkheden voor vergoeding.

Gebaseerd op bovenstaande resultaten hebben we in hoofdstuk 7 een nieuwe vragenlijst ontwikkeld waarbij bepaald kan worden of patiënten in aanmerking komen voor vergoeding van $\mathrm{CHC}$. Deze vragenlijst is gebaseerd op een vragenlijst ontwikkelt door de Britse vereniging van plastische, reconstructieve en esthetische chirurgie (BAPRAS). Met de vragenlijst wordt een score berekend op basis van gewichtsverlies, medische, fysieke en psychische klachten van het huidoverschot en medische voorgeschiedenis. Patiënten die een score gelijk aan of hoger dan 8 hebben komen in aanmerking voor vergoeding van $\mathrm{CHC}$. Wij hebben aan deze vragenlijst de BODY-Q toegevoegd om ik kaart te brengen wat de impact van overhangende huid op de $\mathrm{KvL}$ is. De BODY-Q is een gevalideerde vragenlijst om patient gerelateerde uitkomsten te meten specifiek voor (post-) bariatrische patiënten. Hiermee zetten we de eerste stap richting het meewegen van patiënt welzijn in de beslissing voor vergoeding van $\mathrm{CHC}$.

De patiënten met een wens voor $\mathrm{CHC}$ hadden een significant hogere score op de vra- 
genlijst vergeleken met patiënten die geen wens hadden. En de patiënten die volgens de score in aanmerking kwamen voor vergoeding hadden een stabiel gewicht, een hoger gewichtsverlies, een lagere BMI en meer medische en psychologische klachten in vergelijking met patiënten die niet voor vergoeding in aanmerking kwamen. Kortom, de vragenlijst selecteert de patiënten die $\mathrm{CHC}$ wensen, het hoogste gewichtsverlies hebben en de meeste klachten van het huidoverschot. Met de BODY-Q toonden we aan dat verschillende aspecten van patiënt welzijn negatief beïnvloed worden door overhangende huid. Op basis van de resultaten hebben we de vragenlijst op een aantal punten aangepast. Zo is psychische problematiek niet direct reden voor een lagere score, maar dit door de psycholoog beoordeelt worden. De nieuwe versie hebben we de Dutch ReBoc tool genoemd, wat staat voor "Referral and Reimbursement for Body Contouring tool" (verwijzing en vergoeding van $\mathrm{CHC}$ ).

Concluderend heeft dit proefschrift aangetoond dat preoperatief eetbuien, depressieve symptomen, eetstijl en fysieke activiteit niet voorspellend zijn voor de mate van gewichtsverlies na bariatrische chirurgie. Dus zouden, op basis van deze factoren, morbide obese personen niet per definitie voor een bariatrische operatie geweigerd moeten worden. We toonden ook aan dat postoperatieve fysieke activiteiten en psychologische factoren wel gerelateerd zijn aan gewichtsverlies en, daardoor, KvL na bariatrische chirurgie. Bovendien waren factoren als lichaamsbeeld, gewichtsverlies en depressieve symptomen ook gerelateerd aan elkaar. Deze factoren zouden onderdeel moeten zijn van de begeleidingstrajecten van bariatrische patiënten, zodat gewichtsverlies verbeterd kan worden.

Daarnaast kunnen we uit het onderzoek concluderen dat huidoverschot een groot probleem is in de post-bariatrische populatie. Patiënten met een wens voor $\mathrm{CHC}$ hebben een negatiever lichaamsbeeld, meer depressieve symptomen en een slechtere KvL dan patiënten zonder wens. Deze factoren worden nu niet meegenomen in de toekenning van vergoeding voor $\mathrm{CHC}$. Er zal in Nederland een nieuwe richtlijn voor vergoeding van $\mathrm{CHC}$ ontwikkeld moeten worden waarin deze factoren wel worden geëvalueerd. 


\section{VALORISATION ADDENDUM}

This thesis has shown that a large majority of the post-bariatric patients will develop excess skin after bariatric surgery. This excess skin can significantly influence patient well-being by causing medical, physical and psychological problems. Body contouring surgery (BCS) is the only available treatment for excess skin. It improves body image, health-related quality of life (HRQoL) and weight loss maintenance. However, decision making regarding reimbursement of BCS in the Netherlands is based on a guideline that is not objective and does not consider all complaints caused by excess skin. This leads to unfair reimbursement: some patients with mild complaints will be reimbursed, while others with significant complaints will not. This valorization addendum will focus on improving the reimbursement pathway for post-bariatric BCS in the Netherlands.

\section{RELEVANCE}

In the Netherlands, more than 10.000 patients a year undergo bariatric surgery ${ }^{1}$. This thesis demonstrated that $63-80 \%$ of these patients will develop excess skin and desire BCS. Thus, in the Netherlands, there are around 6,000 'new' post-bariatric patients a year who desire BCS.

We showed that because of the excess skin patients experience medical issues like intertrigo (68\%); functional complaints $(78 \%)$ such as hindrance in daily activities; and psychological issues (59\%) such as depressive feelings and shame. These complaints were reflected in the lower HRQoL in patients with a desire for BCS compared to patients without a desire for BCS. Patients who desired BCS also had a more negative body image and reported more depressive symptoms. Moreover, we showed a relationship between body image, weight loss and depressive symptoms: a higher weight loss resulted in less depressive symptoms, medicated by more positive feelings of attractiveness and higher body-area satisfaction.

In addition, other studies have shown that post-bariatric patients who have undergone BCS have an improved functional status, HRQoL and body image ${ }^{2-5}$. More importantly, these patients had better long-term weight loss maintenance compared to patients who did not have BCS ${ }^{6,7}$. The latter is especially important, since weight regain is an issue that is getting more and more attention in the post-bariatric population. It is estimated that about $20-30 \%$ of the population will develop significant weight regain ${ }^{8-12}$. Although the cause of weight regain is considered to be multifactorial, a negative body image is generally not included as a cause ${ }^{8,13,14}$. However, this thesis showed that body image is an importance construct for all post-bariatric patients. Even in the population who did not want BCS, a more negative body image 
was related to depressive symptoms. This is comparable to the obese (pre-bariatric) population ${ }^{15,16}$. And in the patients who desired BCS, there was a close relationship between body weight, negative affect and body image. This might be the reason why patients who undergo BCS have better weight loss maintenance.

Weight regain has a negative effect on comorbidities and $\mathrm{HRQOL}^{10-12}$. In part of the patients who develop weight regain, a secondary or tertiary bariatric procedure will be performed ${ }^{8,17-19}$. The re-emerging of comorbidities as well as the secondary or tertiary surgeries have a significant impact on healthcare costs ${ }^{19}$.

Thus, excess skin is a serious problem in post-bariatric patients. And the only available treatment, BCS, seems to prolong and improve the results of bariatric surgery by (further) improvement of patient well-being and weight loss maintenance. This can lead to lower healthcare costs. Therefore, BCS should be considered a part of post-bariatric care and efforts should be made to reimburse BCS accordingly. With this valorization addendum, we propose the first steps to improve the reimbursement system for post-bariatric body contouring surgery in the Netherlands.

\section{CURRENT CRITERIA FOR REIMBURSEMENT}

The current criteria for reimbursement are partly based on Dutch law. This law states that plastic surgery should not be reimbursed unless there is:

- a congenital deformity: deformity which has been present since birth, or

- a grave disfigurement caused by accident, disease or medical treatment (mutilation), or

- a serious impairment of bodily function in daily life ${ }^{20}$.

For post-bariatric patients there are additional criteria to qualify for reimbursement: the patient has a) undergone the bariatric procedure more than 18 months before, b) a stable weight for more than 12 months and c) a body mass index (BMI) below 35 $\mathrm{kg} / \mathrm{m}^{2}$.

Each post-bariatric patient who desires BCS can ask her/his general practitioner or bariatric surgeon for a referral to the plastic surgeon. The plastic surgeon then decides whether the patient qualifies according to the above criteria and sends all necessary information to the insurance company (through a standardized system). The insurance company reviews the information and sometimes requests additional information such as photographs. Based on this information, the insurance company then decides whether a patient qualifies for reimbursement. This decision overrules the decision of the plastic surgeon. For example, if the plastic surgeon concludes there is a serious impairment of bodily function, but the insurance company does not agree, the patient will not get reimbursed. 


\section{Mutilation}

In the post-bariatric population, mutilation is defined as an excess skin grade 3 according to the Pittsburgh Rating Scale (PRS) ${ }^{20,21}$. The PRS consists of a grading scale for excess skin on ten anatomically defined areas, ranging from 0 (indicating normal) to 3 (indicating the most severe deformity). For each of the scores there is also an explanation available, for example excess skin grade 3 for the breasts is explained as: severe lateral roll and/or severe volume loss with loose skin. Grade 3 on the PRS scale does not always mean the most excess skin: grade 2 excess skin on the abdomen is defined as overhanging pannus and grade 3 as multiple rolls or epigastric fullness. An abdominal panniculus can be more serious than multiple rolls, however grade 3 needs more extensive surgery and is thus (in that way) a more severe deformity.

The PRS was developed by Song et al. to provide a systematic approach for selection of the appropriate body contouring procedure for post-bariatric patients ${ }^{21}$. The PRS provides a good overview of the deformities seen in the post-bariatric population and was validated by the developers. It was, however, not designed as a method to evaluate whether patients should be reimbursed for BCS. Therefore, van der Beek et al. tested the PRS in Netherlands. A total of 13 observers, plastic surgeons, nurses and students, rated photographs of 10 areas of 25 patients ${ }^{22}$. The results showed a moderate interobserver validity, meaning that the PRS is not an objective scale to rate the amount of overhanging skin. In daily practice this results in differences in rating of excess skin by plastic surgeons and insurance companies. Thus, some patients will be considered a grade 2 by the insurance company; while the plastic surgeon rates the overhanging skin as grade 3 . But, there will also be patients who will get reimbursement while the plastic surgeon does not rate the overhanging skin as grade 3. This makes the current system used to define mutilation unreliable and subjective.

\section{Impairment of bodily function}

A serious impairment of bodily function in daily life is defined as a significant restriction of movement and/or a chronic skin condition that cannot be treated with conservative measures ${ }^{20}$. Only for the abdominal overhanging skin there is an objective measurement of a significant restriction of movement: the abdominal skin surplus should cover at least $25 \%$ of the length of the femur.

However, this "objective" measurement was never tested in a post-bariatric population. It is unknown if this cut-off point correlates with complaints of the patient and if this measurement is reliable. And although we showed that overhanging skin on the abdomen is most prevalent, patients also complain of excess skin on breast, flanks, arms and legs. For these areas, there are not objective criteria to define restriction of movement. The guideline does provide examples, like when walking is restricted by 
the excess skin on the legs. How this should be measured or assessed is not clear.

Regarding chronic skin conditions, only intertrigo is included as a skin condition that can warrant reimbursement. The intertrigo has to be present for at least 6 months and hygienic measures and topical treatment as stated by the national guideline should have failed to adequately treat the intertrigo ${ }^{23}$. According to this national guideline, intertrigo is defined as redness and maceration (saturated with moisture) of skinfolds, with or without infection. However, we showed that in addition to intertrigo, patients also experienced other skin conditions like dermatitis, ulceration and hidradenitis. Moreover, some patients have multiple skin conditions because of the excess skin. This should all be part of the criteria for reimbursement.

In conclusion, the current criteria used for decision making regarding reimbursement of BCS are subjective and therefore, unreliable. In addition, physical and medical complaints are not adequately included. This leads to a daily practice in which patients who do not necessarily need BCS are reimbursed, while patients who do need BCS are not. With the plan below, we want to propose the first step to develop a guideline with complete and objective criteria for reimbursement.

\section{THE PLAN}

Healthcare in the Netherlands is organized in a way that spending more on body contouring procedures means spending less on another part of healthcare. Therefore, we need to improve the way the current budget for BCS is spent, by treating the patients that will benefit most from BCS, have the lowest complication rates and, more importantly, select these patients in an objective manner. The first step is to improve that current system with respect to the inclusion of a complete overview of complaints of excess skin and the improvement of the definition of mutilation.

The plan will involve three parties: the healthcare providers, the patients and the payers (health insurance companies and Healthinstitute of the Netherlands (Zorginstituut Nederland). The Healthinstitute of the Netherlands is a governmental organization that has been giving the task to guard quality, affordability and accessibility of healthcare in the Netherlands. This institute also advises the government on reimbursement of healthcare.

\section{Complete overview of complaints}

Several chapters in this thesis have shown that excess skin significantly impacts several aspects of patients' well-being. However, not all these aspects are captured in the current criteria for reimbursement. In the last chapter of the thesis we tested a modified version of a screening tool for reimbursement of BCS developed by the British 
Association of Plastic, Reconstructive and Aesthetic Surgeons (BAPRAS). This tool gives a complete picture of the patient and how excess skin influences the patients' well-being based on a combination of weight loss results, complaints of excess skin and smoking behavior. It assesses medical complaints (intertrigo, dermatitis, infection, ulceration, lymphedema and hidradenitis), psychological complaints (fear, depression, sleep disturbance, stress) and physical complaints (in daily routine, at work and during physical activity). Moreover, impact on patient well-being was assessed with the BODY-Q, a questionnaire specifically designed to measure HRQoL in the (post-) bariatric population ${ }^{24}$.

We showed that patients with less weight loss, higher BMI and more complaints had higher screening tool scores. And more importantly, we showed that the screening tool scores correlated with the BODY-Q scores. Patients who had higher scoring on the screening tool had lower HRQoL. Based on the results of the study, we proposed three additional modifications to the modified BAPRAS screening tool. Patients with an unstable weight, a recent pregnancy or planning to have children in the near future cannot be referred. And all patients with a recent life-event, a history of psychological issues and/or addiction, should be evaluated by the psychologist (of the bariatric team) in order to decide whether these issues can be seen as a contra-indication for BCS. With these additional modifications, we created the Dutch Reboc Tool.

\section{Definition of mutilation}

Currently, when a plastic surgeon or insurance company rates the amount of excess skin, the photograph of the patient is not systematically compared to the photograph of the PRS. This makes grading more dependent on the subjective interpretation of the plastic surgeon / insurance company and limits reliability. Currently, our study group is working on an improved version of the PRS: the PRS Rainbow Scale. This Rainbow Scale of the PRS is based on a study in patients with upper eyelid ptosis, which showed that estimation of the ptosis of the upper eyelid improved when the photograph of the patient was compared to pictures with eyelid ptosis with increasing severity ${ }^{25}$.

In the PRS Rainbow Scale the photograph of the patient is presented in the center of the PRS photographs (see figure 1). The first version of this system was recently tested and showed that validity was better when using the PRS Rainbow Scale compared to the normal PRS (results not published yet). 
Figure 1: Example of the PRS Rainbow Scale for the abdomen
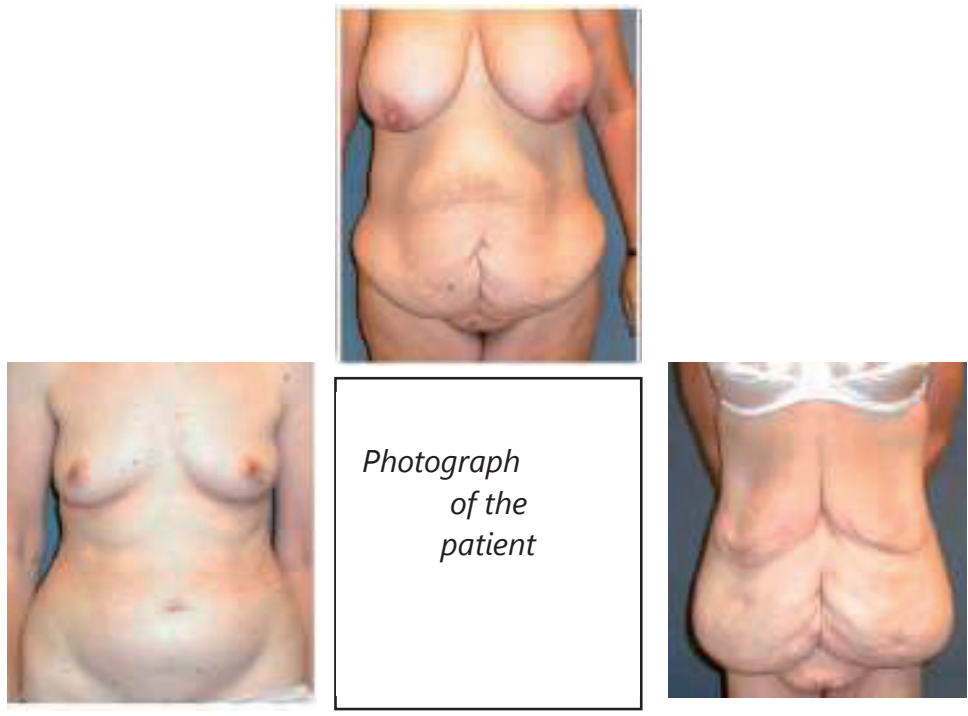

\section{PILOT STUDY}

The Dutch Reboc Tool and PRS Rainbow Scale have not been tested in a post-bariatric population that consults the plastic surgeon. Moreover, medical and physical complaints were assessed via a questionnaire and the true extent of these problems in the studied population are unknown.

The next step would be to conduct a pilot study using the Dutch ReBoc Tool (with the BODY-Q) and the PRS Rainbow Scale in patients who consult the plastic surgeon. In this study, the current criteria and the new system should both be evaluated in all patients. Thereby we can compare which patients are reimbursed with the current system and which patients would be reimbursed with the new system. Medical and physical complaints can also be objectified.

Scoring with the Dutch Reboc Tool should be parallel to assessment of the current definitions of impairment of bodily function. For example, in the Dutch Reboc Tool patients will be asked if they have physical complaints of excess skin. The amount of excess skin should also be measured. The current criteria can be used for the abdomen. Additionally, Biorserud et. al developed an objective system for measurement of excess skin that can be used for other body parts ${ }^{26}$. We have already shown that the outcome of the Dutch Reboc Tool highly correlated with BODY-Q scores. In the pilot, we can review whether the measurements of overhanging skin also correlate with the BODY-Q. 
This pilot should be conducted in 2-3 plastic surgical clinics that work closely with a bariatric team. This ensures all information regarding bariatric surgery and weight loss is available. To improve future implementation, the pilot should be developed in collaboration with the Healthinstitute of the Netherlands and insurance companies.

\section{COMMUNICATION}

An important part of improving care for the post-bariatric patients (with excess skin) is education. This thesis showed that there is a large part of the post-bariatric patients who desire BCS and never consult a plastic surgeon. These patients assume that they will not get reimbursement and/or are not aware of the current guidelines. It also seems that most healthcare providers involved in the care for bariatric patients are unaware of the current guidelines and do not routinely assess excess skin. Plastic surgeons should work together with bariatric teams to start with education of the bariatric teams and patients. In addition, general practitioners of the bariatric patients should also be educated. A good start would be a folder with general information about the current rules for reimbursement by the Dutch Society of Plastic and Reconstructive Surgery. In this folder, the general qualifications for reimbursement can be outlined, along with the current definitions for mutilation and impairment of bodily dysfunction. These folders should be readily available in bariatric clinics throughout the country.

\section{FUTURE RESEARCH}

As discussed above, it is not possible to increase spending on body contouring surgery and optimal patient selection for BCS is key. Ideally patients who will benefit most and have the lowest complications rated should be selected. Benefits in terms of healthcare costs should be included in this model. Although body contouring procedures are considered to be costly, it is unknown how many post-bariatric patients undergo BCS and what the costs of BCS in the Netherlands are. A future study should assess how many patients in the Netherlands currently undergo BCS, how often these patients will develop complications and what the costs of these procedures are. These costs can subsequently be compared to healthcare costs for post-bariatric patients who do not undergo BCS. This will allow assessment of the influence of BCS on long-term healthcare costs. More in-depth analysis will also show which patients will benefit the most.

In addition, Dutch law states the psychological complaints can never be a reason for reimbursement of plastic surgery. However, in evaluation of healthcare treatments $\mathrm{HRQ}$ oL is currently considered one of the most important outcome parameters. Future research should also focus on if and how HRQoL should be part of reimbursement criteria. 


\section{References}

1. Poelemeijer YQM, Liem RSL, Nienhuijs SW. A Dutch Nationwide Bariatric Quality Registry: DATO. Obes Surg. 2018 Jun;28(6):1602-10.

2. van der Beek ES, Geenen R, de Heer FA, van der Molen AB, van Ramshorst B. Quality of life long-term after body contouring surgery following bariatric surgery: sustained improvement after 7 years. Plast Reconstr Surg. 2012 Nov;130(5):1133-9.

3. Coriddi MR, Koltz PF, Chen R, Gusenoff JA. Changes in quality of life and functional status following abdominal contouring in the massive weight loss population. Plast Reconstr Surg. 2011 Aug;128(2):520-6.

4. Song P, Patel NB, Gunther S, Li CS, Liu Y, Lee CY, et al. Body Image \& Quality of Life: Changes With Gastric Bypass and Body Contouring. Ann Plast Surg. 2016 May;76 Suppl 3:S216-21.

5. Stuerz K, Piza H, Kinzl JF. The impact of abdominoplasty after massive weight loss: a qualitative study. Ann Plast Surg. 2013 Nov;71(5):547-9.

6. Balague $\mathrm{N}$, Combescure $\mathrm{C}$, Huber $\mathrm{O}$, Pittet-Cuenod $B$, Modarressi A. Plastic surgery improves long-term weight control after bariatric surgery. Plast Reconstr Surg. 2013 Oct;132(4):826-33.

7. Wiser I, Avinoah E, Ziv O, Parnass AJ, Averbuch Sagie R, Heller L, et al. Body contouring surgery decreases long-term weight regain following laparoscopic adjustable gastric banding: A matched retrospective cohort study. J Plast Reconstr Aesthet Surg. $2016 \mathrm{Nov}$;69(11):1490-6.

8. Karmali S, Brar B, Shi X, Sharma AM, de Gara C, Birch DW. Weight recidivism post-bariatric surgery: a systematic review. Obes Surg. 2013 Nov;23(11):1922-33.

9. Stanford FC. Controversial issues: A practical guide to the use of weight loss medications after bariatric surgery for weight regain or inadequate weight loss. Surg Obes Relat Dis. 2018 Oct 30.

10. Lauti M, Kularatna M, Hill AG, MacCormick AD. Weight Regain Following Sleeve Gastrectomy-a Systematic Review. Obes Surg. 2016 Jun;26(6):1326-34.

11. King WC, Hinerman AS, Belle SH, Wahed AS, Courcoulas AP. Comparison of the Performance of Common Measures of Weight Regain After Bariatric Surgery for Association With Clinical Outcomes. JAMA. 2018 Oct 16;320(15):1560-9.

12. Lauti M, Lemanu D, Zeng ISL, Su'a B, Hill AG, MacCormick AD. Definition determines weight regain outcomes after sleeve gastrectomy. Surg Obes Relat Dis. 2017 Jul;13(7):1123-9.

13. Livhits M, Mercado C, Yermilov I, Parikh JA, Dutson E, Mehran A, et al. Patient behaviors associated with weight regain after laparoscopic gastric bypass. Obes Res Clin Pract. 2011 Jul-Sep;5(3):e169-266.

14. Odom J, Zalesin KC, Washington TL, Miller WW, Hakmeh B, Zaremba DL, et al. Behavioral predictors of weight regain after bariatric surgery. Obes Surg. 2010 Mar;20(3):349-56.

15. Friedman KE, Reichmann SK, Costanzo PR, Musante GJ. Body image partially mediates the relationship between obesity and psychological distress. Obes Res. 2002 Jan;10(1):33-41.

16. Stunkard AJ, Wadden TA. Psychological aspects of severe obesity. Am J Clin Nutr. 1992 Feb;55(2 Suppl):524S-32S

17. Rosenthal RJ. Failure of weight loss or weight regain after baratric surgery. Bariatric Times. 2012;9(10).

18. Pinto-Bastos A, Conceicao EM, Machado PPP Reoperative Bariatric Surgery: a Systematic Review of the Reasons for Surgery, Medical and Weight Loss Outcomes, Relevant Behavioral Factors. Obes Surg. 2017 Oct;27(10):2707-15.

19. Sheppard CE, Lester EL, Chuck AW, Birch DW, Karmali S, de Gara CJ. The economic impact of weight regain. Gastroenterol Res Pract. 2013;2013:379564.

20. Association of Advising Doctors of Healthinsurence Companies (Vereniging Adviserend Geneeskundigen bij Zorgverzekeraars). Guideline for judgement of plastic surgery (Werkwijzer beoordeling behandelingen van plastisch-chirurgische aard). Vereniging Adviserend Geneeskundigen bij Zorgverzekeraars; 2018.

21. Song AY, Jean RD, Hurwitz DJ, Fernstrom $M H$, Scott JA, Rubin JP. A classification of contour deformities after bariatric weight loss: the Pittsburgh Rating Scale. Plast Reconstr Surg. 2005 Oct;116(5):1535,44; discussion 1545-6.

22. van der Beek ES, Verveld CJ, van Ramshorst B, Kon M, Mink van der Molen AB. Classification of contour deformities after massive weight loss: the applicability of the Pittsburgh Rating Scale in The Netherlands. J Plast Reconstr Aesthet Surg. 2013 Aug;66(8):1039-44.

23. Nationwide guideline for prevention and treatment of intertrigo. [Internet]. Utrecht: Ducth Society of Dermatological Nurses; 2007 [updated 07-04-2007; cited 28-12-2018]. Available from: https://www.nivel.

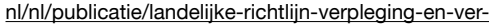
zorging-smetten-intertrigo-preventie-en.

24. Klassen AF, Cano SJ, Alderman A, Soldin M, Thoma A, Robson S, et al. The BODY-Q: A Patient-Reported Outcome Instrument for Weight Loss and Body Contouring Treatments. Plast Reconstr Surg Glob Open. 2016 Apr 13;4(4):e679.

25. van Dongen JA, Eyck BM, van der Lei B, Stevens HP. The Rainbow Scale: A Simple, Validated Online Method to Score the Outcome of Aesthetic Treatments. Aesthet Surg J. 2016 Mar;36(3):NP128-30.

26. Biorserud C, Fagevik Olsen M, Elander A, Wiklund M. Objective measurements of excess skin in post bariatric patients--inter-rater reliability. J Plast Surg Hand Surg. 2016;50(2):68-73. 


\section{CURRICULUM VITAE}

\section{Person information:}

$\begin{array}{ll}\text { Surname: } & \text { Valerie Maureen } \\ \text { Name: } & \text { Monpellier } \\ \text { Date of Birth: } & 25 \text { april } 1985 \\ \text { Place of Birth: } & \text { Nieuwegein }\end{array}$

\section{Professional experiences:}

2018 - present: Co-founder SQOT initiative

2017 - present: Researchcoordinator Nederlandse Obesitas Kliniek

2017 - present: DATO committee PROM morbide obesitas

2015 - 2016: Dutch Society for Plastic Surgery committee for postbariatric body contouring surgery

2013 - present: Medical Doctor, Nederlandse Obesitas Kliniek

\section{Education:}

2008 - 2011: $\quad$ Master of medicine (Msc), Rijksuniversiteit Groningen

2004 -2007: Bachelor of medicine (Bsc), Rijksuniversiteit Groningen

1996 - 2003: High school: Gymnasium, Oosterlicht College, Nieuwegein

\section{Other education}

2011 - present: Dressmaker course, ModeVak Amsterdam

2011:

ATLS course, Bellevue Hospital Center, New York

2007:

Study Spanish, nivel intermedio, Languageschool ICA, Xela,

Guatemala 



\section{PUBLICATIONS \& PRESENTATIONS}

\section{PUBLICATIONS}

V.M. Monpellier, I.M.C. Janssen, E.E. Antoniou, A.T.M. Jansen

Weight change after Roux-en $Y$ gastric bypass, physical activity and eating style: is there a relationship?

Obesity Surgery 2019 February; 29(2):26-533

(https://doi.org/10.1007/s11695-018-3560-x)

V.M. Monpellier, E.E. Antoniou, S. Mulkens, I.M.C. Janssen, A.B. Mink van der Molen, A.T.M. Jansen

Body image dissatisfaction and depression in post-bariatric patients is associated with less weight loss and a desire for body contouring surgery

Surgery for Obesity and Related Diseases 2018;14(10):1507-1515.

(https://doi.org/10.1016/j.soard.2018.04.016)

D. Geerards, A.B. Mink van der Molen, V.M. Monpellier, S. Klein, E.S.J. van der Beek, M.M. Hoogbergen

Patient Reported Outcome Measures of post-bariatric body contouring surgery with the BODY-Q

Dutch Journal of Plastic and Reconstructive Surgery 2017 Jan; 8(1):7-9

(https://www.nvpc.nl/nvpc_tijdschrift.php?nummer_id=37)

V.M. Monpellier, E.E. Antoniou, E.O. Aarts, I.M.C. Janssen, A.T.M. Jansen Improvement of health-related quality of life after Roux-en-Y gastric bypass related to weight loss

Obesity Surgery 2017 May;27(5):1168-1173

(https://doi.org/10.1007/s11695-016-2468-6)

E.S. van der Beek, V.M. Monpellier, I. Eland, E. Tromp, B. van Ramshorst Nutritional Deficiencies in Gastric Bypass Patients; Incidence, Time of Occurrence and Implications for Post-operative Surveillance.

Obesity Surgery 2015 May;25(5):818-23

(https://doi.org/10.1007/s11695-014-1456-y)

V.M. Monpellier, E.S.J. van der Beek, A.B. Mink van der Molen

Complications after body contouring surgery in post-bariatric patients: the role of nutritional deficiencies.

Dutch Journal of Plastic and Reconstructive Surgery 2014 Jun; 5(3):111-116

(https://www.nvpc.nl/nvpc_tijdschrift.php?nummer_id=28) 


\section{PRESENTATIONS}

\section{7}

- $\quad$ Presentation - World Congress International Federation of Surgery for Obesity (awarded with Young Investigator Award for best oral presentation) Long-term weight change after RYGB and behaviour: is there a relationship? V.M. Monpellier, I.M.C. Janssen, E.E. Antoniou, A.T.M. Jansen

- Poster - World Congress International Federation of Surgery for Obesity New screeningtool for post-bariatric body contouring surgery V.M. Monpellier, I.M.C. Janssen, E.S.J. van der Beek, A.B. Mink van der Molen, M.M. Hoogbergen, Prof. dr. B. van der Lei

- $\quad$ Poster - World Congress International Federation of Surgery for Obesity BODY-Q in post-bariatric patients who want or do not want BCS V.M. Monpellier, I.M.C. Janssen, E.S.J. van der Beek, A.B. Mink van der Molen, M.M. Hoogbergen, Prof. dr. B. van der Lei

- $\quad$ Presentation - Congres Dutch Society of Plastic Surgery New screeningtool for post-bariatric body contouring surgery V.M. Monpellier, I.M.C. Janssen, A.B. Mink van der Molen, M. Hoogbergen, E.S.J. van der Beek, B. van der Lei

- $\quad$ Presentation - Congres Dutch Society of Metabolic and Bariatric Surgery New screeningtool for post-bariatric body contouring surgery V.M. Monpellier, I.M.C. Janssen, A.B. Mink van der Molen, M. Hoogbergen, E.S.J. van der Beek, B. van der Lei

\section{6}

- Presentation - European Obesity Summit

Desire for body contouring risk factor for weight regain?

V.M. Monpellier, E.E. Antoniou, S. Mulkens, I.M.C. Janssen, A.B. Mink van der Molen, A.T.M. Jansen

\section{5}

- $\quad$ Poster - World Congress International Federation of Surgery for Obesity Desire for body contouring risk factor for weight regain? V.M. Monpellier, E.E. Antoniou, S. Mulkens, I.M.C. Janssen, A.B. Mink van der Molen, A.T.M. Jansen

- $\quad$ Poster - World Congress International Federation of Surgery for Obesity Significant improvement of QOL after RYGB.

V.M. Monpellier, O. Tettero, E.E. Antoniou, I.M.C. Janssen, A.T.M. Jansen

- $\quad$ Presentation - Congres Dutch Society of Plastic Surgery

Post-bariatric body contouring surgery in the Netherlands

V.M. Monpellier, E.E. Antoniou, S. Mulkens, K. Dijkhorst, I.M.C. Janssen, A. B. 
Mink van der Molen, A.T.M. Jansen

- $\quad$ Presentation - Congres Dutch Society of Metabolic and Bariatric Surgery

Post-bariatric body contouring surgery in the Netherlands

V.M. Monpellier, E.E. Antoniou, S. Mulkens, K. Dijkhorst, I.M.C. Janssen, A. B. Mink van der Molen, A.T.M. Jansen

- $\quad$ Presentation - Congres Dutch Society of Metabolic and Bariatric Surgery

Quality of life related to weight loss after bariatric surgery

V.M. Monpellier, O. Tettero, E.E. Antoniou, K. Dijkhorst, I.M.C. Janssen, A.T.M. Jansen

\section{4}

- Presentation - Congres Dutch Society of Plastic Surgery

Complications in body contouring surgery after gastric bypass.

V.M. Monpellier, E.S.J. van der Beek, A.B. Mink van der Molen. 



\section{ACKNOWLEDGEMENTS}

In the words of Tag Team: "whoomp there it is"! My PhD has come to an end, all the chapters are written and this is the last and final part of it: thanking the most important people in my life. I know I should be thanking everybody who helped me with the thesis, but this thesis would not be here if I hadn't had such an amazing group of friends and family who have supported me in everything I do. For all non Dutch speakers, I am sorry but you will have to use google translate for this, since it will be (mostly) in Dutch.

Anita, ik denk dat we in het begin allebei behoorlijk aan elkaar moesten wennen. Ik, net van de chirurgie vandaan waar ik vooral had geleerd door te werken en assertief zijn (wat me best goed af gaat). En nu moest ik bij de psychologie wat vaker en langer over dingen nadenken en soms zelfs even wachten.... Niet mijn sterkste kant, al ben ik er wel beter in geworden. Ik denk dat we zeker de afgelopen tijd veel meer naar elkaar toe gegroeid zijn. Ik heb van jou geleerd altijd kritisch te blijven nadenken over wat ik doe en waarom ik dat doe. Door de compleet andere invalshoek die jij had, is dit proefschrift echt een combinatie van psychologie en chirurgie geworden. Hopelijk op naar nog meer mooie samenwerkingen in de toekomst.

Ignace, zonder jou had ik hier letterlijk niet gestaan. Toen ik op een punt was waarop ik even niet meer wist hoe ik verder zou moeten, bood jij mij een promotieplek aan bij de NOK. Die plek was toen natuurlijk eigenlijk nog helemaal niet geregeld, dus het duurde even voordat ik echt kon beginnen. Maar ik denk dat we er wat moois van gemaakt hebben en ook de heren blij zijn dat het uiteindelijk door is gegaan. Je hebt me geleerd om niet bang te zijn samenwerkingen om te zetten die wat ongewoon zijn. Ik denk dat we dat voor de VENI aanvraag maar weer moeten doen!

Aebele, ondanks dat we eigenlijk maar heel kort echt samen hebben gewerkt, heb je me altijd enorme gesteund. Je was altijd eerlijk in de (on-)mogelijkheden van het onderzoek en werken bij de plastische chirurgie. En mede doordat jij meedacht ben ik aan dit promotietraject begonnen. Bedankt dat je me zo blijft steunen, ook nu ik heb besloten geen plastisch chirurg meer te worden. Ik hoop dat we voor verschillende projecten samen zullen blijven werken.

Eva (Antinou), ook voor jou een stukje in het Nederlands, ik denk dat je het ook zonder google translate wel snapt. We hebben heel wat dagen samen aan de statistiek gezeten, zeker voor de meta-analyse. Ik heb van jou geleerd dat ik niet altijd het wiel 
opnieuw uit hoef te vinden. Dank voor je hulp hierbij!

Eva (van der Beek), een van de dingen die ik echt jammer vind nu ik geen plastisch chirurg meer wordt: we gaan nooit meer samen opereren (en dan tel ik dat abces uit het UMCU niet mee). Zonder jou was ik nooit onderzoek gaan doen bij de bariatrie en had ik nooit de plastische chirurgie ontdekt. En al word ik nu geen plastisch chirurg, ik denk altijd met warme gevoelens aan die tijd terug. Bedankt hiervoor en voor de steun op de wat mindere momenten!

Edo, ik realiseerde me bij het maken van het boekje dat we maar een keer echt samen onderzoek hebben gedaan. Toch heb ik het idee gehad dat je op de achtergrond een beetje meekeek en ik voor advies altijd bij je kon komen. Bedankt dat je in Londen als enige mee ging naar het IFSO-gala om mij te steunen (en foto's te maken) toen ik daar een prijs kreeg!

Berend, bedankt voor alle hulp bij de studie naar de screening tool. Ik hoop dat hij inmiddels geaccepteerd is en we een mooie pilot met de zorgverzekeraars hebben opgezet.

Sandra, bedankt voor je hulp bij de cross-sectionele studie. Ik denk dat deze studie een van de belangrijkste studies van mijn promotie is geworden.

Maarten, bedankt voor jou altijd waardevolle adviezen en enthousiasme over onderzoek. Al is de CONTOUR niet in mijn boekje gekomen, ik ben blij dat we toen de samenwerking met jullie zijn aangegaan en ben benieuwd naar alle mooie projecten die nog volgen. In het verlengde daarvan, iedereen in de BODY-Q groep, ik kijk uit naar jullie promoties!

Claire, alleen in het laatste hoofdstuk sta je er als auteur bij, maar de afgelopen jaren hebben we samen veel mooie dingen, met als hoogtepunt SQOT. Ik hoop dat als ik promoveer we ECHT een datum hebben voor de consensus meeting.

Dennis, ik ben blij dat ik het stokje in het Antonius Ziekenhuis aan jou heb doorgegegeven. Op naar je boekje!

Zonder de vele collega's bij het NOK (vooral lokaties Velp, Nieuwegein, Den Haag, Beverwijk en Huis ter Heide) was mijn promotie niet gelukt en zeker niet zo leuk geweest! Toch zijn er een paar mensen die ik speciaal wil bedanken. De artsen van NOK West: bedankt voor de hulp bij de inclusie van de patienten in het laatste hoofdstuk en dat jullie mijn patiënten op de schaduw willen bespreken, ik weet dat dat niet altijd handig is. Onno, jij was de enige (soort van) onderzoeker toen ik begon, bedankt voor 
het sparren en hulp bij alle data. Michel, ook jij bedankt voor alle databases, zonder data geen onderzoek. Klaas, bedankt voor de opmaak van dit boekje. Sandra, ik ben altijd verbaast hoe goed jij mij door hebt. Bedankt voor jouw hulp en 'recht-door-zee' adviezen. Saskia, bedankt voor het in de gaten houden of alles wat de heren bedenken nog wel loopt en klopt. Jean Pierre en Kobus, dank dat jullie mij (toch) deze kans hebben gegeven, ik denk dat jullie er nu ook wel blij mee zijn. Mariëlla en Hyelle, wat zou ik (en de NOK) zonder jullie moeten?!

De eetgroep: al ben ik geen echt onderdeel van jullie, ik voel me altijd welkom en dat is fijn. Bedankt hiervoor!

Eva (ja de derde, Kewerkopf dit keer) en Viv, thanks voor alle mooie avonturen die we beleefd hebben. Evelien en Ellemiek studeren in Groningen was zonder jullie nooit zo leuk geweest!

Voor de boys uit Nieuwegein, thanks mannen! Wat er ook is, ik weet dat jullie er zijn en dat voelt goed. En de vrouwen van de boys, wat fijn dat we inmiddels ook vriendinnen zijn. Op naar nog heel wat weekenden weg. Sarah, bedankt voor het meelezen en corrigeren. Ilse, bedankt voor de mooie foto.

Bern, helaas wonen we ver van elkaar vandaan, maar ondanks die afstand heb ik altijd het gevoel dat we toch heel dicht bij elkaar staan.

Jytte, wat ben jij toch een fijn mens! Ik vind het fijn dat we in Amsterdam steeds closer zijn geworden.

Es, voor mij ben je echt een belangrijke vriendin! Ik ben blij dat we elkaar steeds vaker zien.

Kim, tegelijk studeren, tegelijk coschappen lopen, tegelijk ANIOS-en, tegelijk onderzoek doen en twijfelen of je eigenlijk nog wel diensten wil draaien. Het voelde goed dat allemaal met jou te kunnen delen!

Martine, de "oudste" vriendin van het lijstje. Van beugels in de brugklas tot volwassen getrouwde vrouwen. Op naar de rollator.

Chris en Sabi, voor mij zijn jullie zo veel meer dan vriendinnen, jullie zijn famiri! Bij jullie kan ik altijd terecht en alles zeggen en doen. Bedank hiervoor.

Alle famiri in Su, bedankt dat ik Rienk en ik ons altijd thuis voelen als we er zijn. Brasa! 
For the family in the States, let's make sure we meet eachother more often.

Flora dan Herman kami akan segera datang kembali untuk sunset drinks.

Alle andere familie in Nederland (Monpellier, Rijs, van de Berg, Hoven, Barto, Soe Angie) en ook de familie die officieel geen familie is (MacDonald, Wijdh, Molnar): bedankt voor alle steun en liefde!

Nigel, broer, bedankt dat je er zo vaak was toen ik eigenlijk alleen maar in de tuin kon liggen. Mocht het toch niets worden met het onderzoek, dan wordt jij sowieso CEO van kliniek Monpellier. Sam, ik ben blij dat ik nu eindelijk een zusje heb! En natuurlijk Noraine, mijn lievelingsnichtje van wie ik nu al zo veel houd. Wat een prachtig wonder ben jij, ik hoop nog heel vaak suikertante voor jou te zijn.

Papa en mama, de mensen zonder wie ik nooit geweest zou zijn waar ik nu was. Dankjulliewel voor alles! Voor het onvoorwaardelijk van mij houden en voor het altijd steunen voor mijn keuzes, al zijn ze soms wat extreem (wonen in Spanje, studeren in Groningen). Ik heb van jullie geleerd mensen nooit te veroordelen en altijd open te staan voor iedereen. En ook al ben ik er niet vaak, de tubalaan zal altijd mijn thuis zijn.

Rienk, we weten allebei dat onderzoek echt niets voor jou is, maar toch kan ik altijd bij je terecht als ik vastloop. Je weet als geen ander dat ik soms iets te veel nadenk en zorgt dan dat ik de 'bigger picture' niet vergeet. Bovendien zorg je ook dat ik niet te veel aan het werk ben. Zonder jou waren zeker de afgelopen jaren een heel stuk zwaarder geweest en ik ben blij dat we samen zo sterk staan. Ik hou van je!

Soso lobi

Valerie 
A digital version of this thesis is available through:
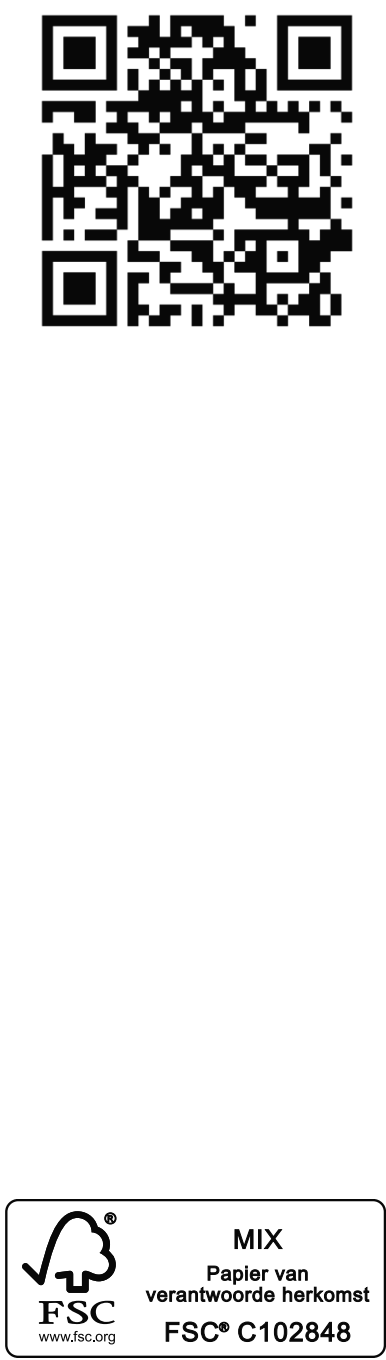